\title{
Skeletal muscle fatty acid handling in insulin resistance : the effect of dietary fatty acids
}

Citation for published version (APA):

Jans, A. (2012). Skeletal muscle fatty acid handling in insulin resistance : the effect of dietary fatty acids. [Doctoral Thesis, Maastricht University]. Universiteit Maastricht. https://doi.org/10.26481/dis.20120427aj

Document status and date:

Published: 01/01/2012

DOI:

10.26481/dis.20120427aj

Document Version:

Publisher's PDF, also known as Version of record

\section{Please check the document version of this publication:}

- A submitted manuscript is the version of the article upon submission and before peer-review. There can be important differences between the submitted version and the official published version of record.

People interested in the research are advised to contact the author for the final version of the publication, or visit the DOI to the publisher's website.

- The final author version and the galley proof are versions of the publication after peer review.

- The final published version features the final layout of the paper including the volume, issue and page numbers.

Link to publication

\footnotetext{
General rights rights.

- You may freely distribute the URL identifying the publication in the public portal. please follow below link for the End User Agreement:

www.umlib.nl/taverne-license

Take down policy

If you believe that this document breaches copyright please contact us at:

repository@maastrichtuniversity.nl

providing details and we will investigate your claim.
}

Copyright and moral rights for the publications made accessible in the public portal are retained by the authors and/or other copyright owners and it is a condition of accessing publications that users recognise and abide by the legal requirements associated with these

- Users may download and print one copy of any publication from the public portal for the purpose of private study or research.

- You may not further distribute the material or use it for any profit-making activity or commercial gain

If the publication is distributed under the terms of Article $25 \mathrm{fa}$ of the Dutch Copyright Act, indicated by the "Taverne" license above, 


\section{Skeletal muscle fatty acid handling in insulin resistance: \\ The effect of dietary fatty acids}




\section{noutrim}

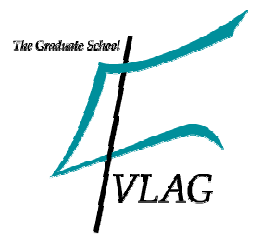

The study presented in this thesis was performed within NUTRIM School for Nutrition, Toxicology and Metabolism which participates in the Graduate School VLAG (Food Technology, Agrobiotechnology, Nutrition and Health Sciences), accredited by the Royal Netherlands Academy of Arts and Sciendes.

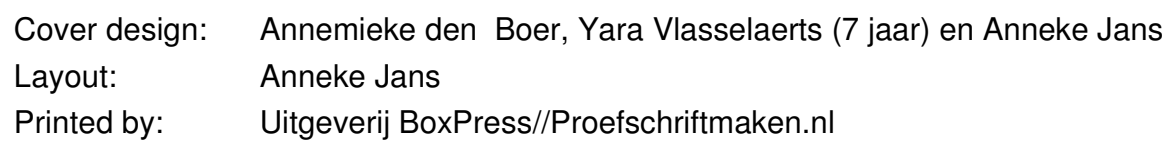

(C) Copyright Anneke Jans, Maastricht 2012

ISBN 978-90-8891-388-4 


\title{
Skeletal muscle fatty acid handling in insulin resistance: \\ The effect of dietary fatty acids
}

\author{
PROEFSCHRIFT \\ ter verkrijging van de graad van doctor \\ aan de universiteit Maastricht, \\ op gezag van de Rector Magnificus, \\ Prof. Mr. G.P.M.F Mols, \\ volgens het besluit van het College van Decanen, \\ in het openbaar te verdedigen \\ op vrijdag 27 april 2012 om 14.00uur
}

door

Anneke Jans

geboren te Hasselt op 26 januari 1984 


\section{Promotor}

Prof. dr. Ellen E. Blaak

\section{Beoordelingscommissie}

Prof. dr. Ronald P. Mensink (voorzitter)

Prof. dr. Michaela Diamant (Vrije Universiteit Medisch Centrum, Amsterdam)

Prof. dr. Jan F.C. Glatz

Prof. dr. Hans P. Sauerwein

Prof. dr. Luc J.C. van Loon

The research in this thesis was supported by a grant of the Dutch Diabetes Research Foundation (DFN 2006.00.019) and 3 chapters were performed as part of the LIPGENE project, an European Union Sixth Framework Integrated Programme funded by the European Community (FOOD-CT-2003-505944)

Financial support by the Dutch Research Foundation, the Netherlands Association of the Study of Obesity (NASO) and Bioriginal (Den Bommel, The Netherlands) for the publication of this thesis is gratefully acknowledged. 
General introduction

Chapter 2

Skeletal muscle fatty acid handling in insulin resistant men

\section{Chapter 3}

Transcriptional metabolic inflexibility in skeletal muscle among individuals with increasing insulin resistance

\section{Chapter 4}

Polyunsaturated fatty acids acutely affect triacylglycerol-derived skeletal muscle fatty acid uptake and increases postprandial insulin sensitivity

\section{Chapter 5}

Impact of dietary fat quantity and quality on skeletal muscle fatty acid metabolism in subjects with the metabolic syndrome

\section{Chapter 6}

A human dietary intervention study to improve insulin sensitivity: effects on plasma fatty acid profiles, estimated desaturase activities and stearoly-CoA desaturase 1 (SCD1) in relation to insulin sensitivity

\section{Chapter 7}

General discussion

\section{Summary}
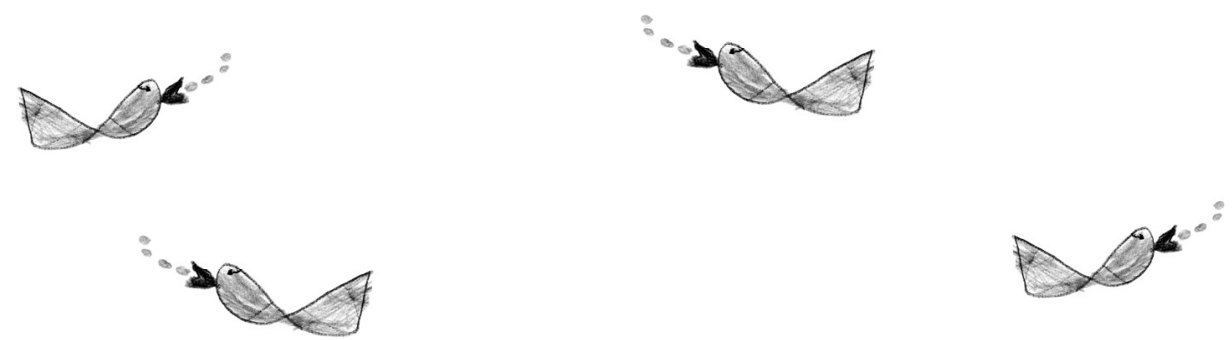



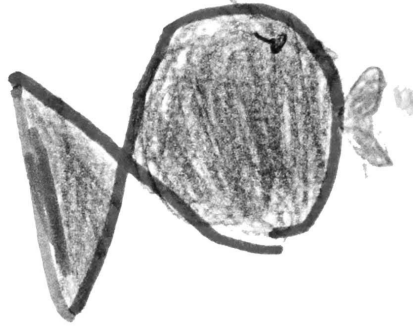

\section{CHAPTER 1}

General introduction

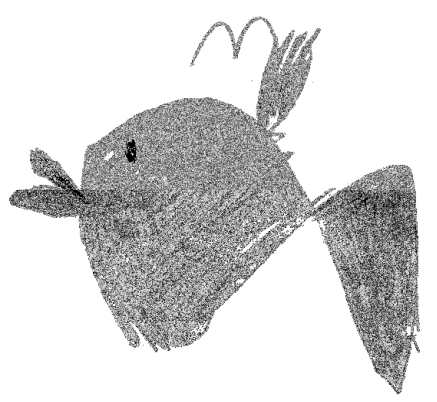




\section{ChAPTER 1}

The current social welfare has two sides. On the one hand, life has become more convenient than ever because of the advances in technology; on the other hand, the incidence of lifestyle diseases like obesity, and type 2 diabetes mellitus (T2DM) is occurring at an alarming rate. The metabolic syndrome (MetS) represents a clustering of risk factors for the development of T2DM and cardiovascular disease (CVD), like high blood pressure, dyslipedemia, insulin resistance and obesity [1]. During the last two decades the number of people with the MetS worldwide is increasing rapidly together with the global epidemic of obesity and T2DM [1, 2]. According to the latest estimates from the World Health Organization (WHO), by 2015 approximately 2.3 billion adults will have overweight and 700 million will have obesity [3], and the number of people worldwide suffering from T2DM is estimated to increase from $\sim 171$ million in 2000 to $\sim 366$ million in 2030 [4]. Moreover, CVD is the number one cause for death worldwide (representing $30 \%$ of all deaths), and it is estimated that by 2030 almost 24 million people will die from CVD [5]. The explosive increase in number of people diagnosed with MetS makes this syndrome a new health threat in the 21st century. Understanding the etiology of and finding a way to prevent the MetS, is an urgent challenge for the health care community and our society [6].

There are various definitions and descriptions of the MetS, but the condition is mainly characterized by central obesity, hyperglycaemia, insulin resistance, increased plasma triglycerides (TAG) and/or decreased plasma high-density lipoprotein (HDL)-cholesterol (i.e. dyslipidemia), and hypertension. These metabolic disturbances are all interrelated and have shown to cluster more frequently than only by chance [7]. Insulin resistance and central obesity have each been considered to be the primary factors underlying the MetS, although the underlying biological mechanisms are complex and not fully understood [8].

The introduction of this thesis is composed of three main sections. At first, a brief background on the MetS, its different definitions and its etiology will be given. Disturbances in fatty acid (FA) metabolism play an important role in the MetS. An expanded adipose tissue mass or an impaired buffering capacity of the adipose tissue may result in an increased supply of lipids (i.e. lipid overflow) to 'nonadipose' tissues such as skeletal muscle and liver, resulting in excessive fat uptake and storage $[9,10]$. Ectopic fat disposition, in particular the accumulation of lipid metabolites, can reduce insulin action in skeletal muscle by interfering with insulin signalling and inducing inflammatory pathways [11-13]. In the second part of this introduction, we will go further into detail about the role of FA handling in insulin 
resistance with emphasis on skeletal muscle FA handling. Dietary intervention aimed at reducing the intake of saturated fat may improve lipid metabolism and insulin sensitivity in the obese insulin resistant state. For this reason the effects of modulation of dietary fat quantity and quality on skeletal muscle FA handling and insulin sensitivity will be addressed at the end.

\section{The metabolic syndrome}

The MetS is a heterogeneous condition that is characterized by a clustering of risk factors for CVD and T2DM, including central (abdominal) obesity, hyperglycaemia, hyperinsulinaemia, insulin resistance, dyslipidemia, and hypertension [1, 14] (Figure 1). In addition, several other manifestations may be present that are not included in the definitions of the MetS, such as chronic low-grade inflammation, a pro-thrombotic state, hyperuricemia, endothelial dysfunction, and disturbances in the pituitary-adrenal axis [14]. There is no doubt that lifestyle factors such as cigarette smoking, physical inactivity, and an atherogenic diet are related to several components of the MetS [1].

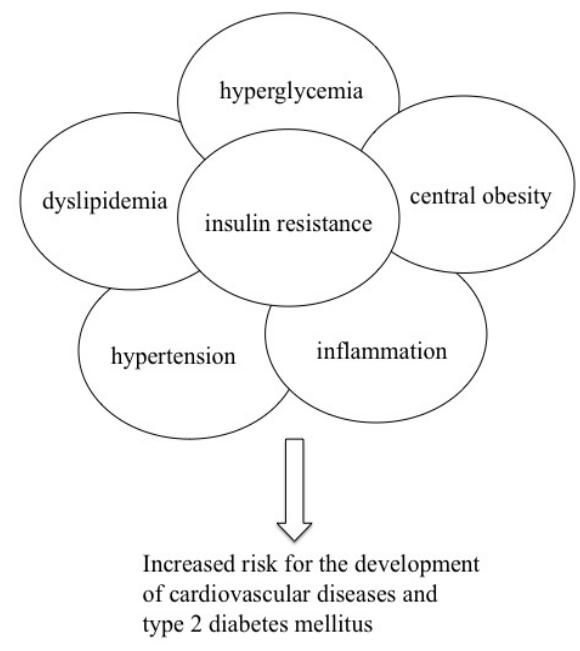

Figure 1. The metabolic syndrome is characterized by obesity, hyperglycemia, dyslipidemia, hypertension, inflammation and insulin resistance and gives an increased risk for the development of T2DM and CVD.

\subsection{Definitions of the metabolic syndrome}

During the past decades numerous definitions have been proposed for the MetS (Table 1). The WHO was the first (1999) to formulate a definition. The European group for the Study on Insulin Resistance (EGIR) formulated a modified version of 


\section{Chapter 1}

the WHO definition. Because the EGIR definition relied on fasting insulin levels, it was easier to use than the WHO definition. In 2011, the Adult Treatment Panel III (ATPIII) of the National Cholesterol Education Program (NCEP) proposed a definition that facilitated the diagnosis. The NCEP states a person can be diagnosed with the MetS if three out of five risk factors are present, including abdominal obesity, increased fasting glucose levels, hypertension, increased plasma TAG and decreased HDL cholesterol. Later, in 2005, the International Diabetes Federation (IDF) published a definition that intended to facilitate the comparison of research across different countries and populations. This definition avoided the need for measurements usually only available in research settings. There are substantial differences between the four definitions. Both WHO and EGIR consider insulin resistance as an essential risk factor for the MetS, whereas NCEP treats all risk factors equally. The IDF definition, on the other hand, indicates abdominal obesity as the crucial risk factor. The NCEP and IDF definition do not even include insulin resistance. Furthermore, WHO and EGIR take the decreased HDL cholesterol and/or increased TAG as one risk factor, whereas NCEP and IDF consider these two disturbances as independent risk factors. Finally, only WHO includes microalbuminuria. Although the four definitions have substantial differences, all recognize the MetS as a multiplex risk factor for the development of cardiovascular diseases and T2DM [14, 15].

\subsection{Etiology}

The etiology of the MetS is complex and not fully understood, as reflected by the difficulties in reaching consensus about one general definition for the MetS. Several metabolic disturbances characterize the MetS and they are all related [7]. Currently, central obesity and/or insulin resistance are considered to be the primary factors underlying the MetS. The role of both obesity, a disturbed fatty acid metabolism and insulin resistance in the etiology of the MetS will be described in more detail in the next chapters. 
General INTRODUCtION

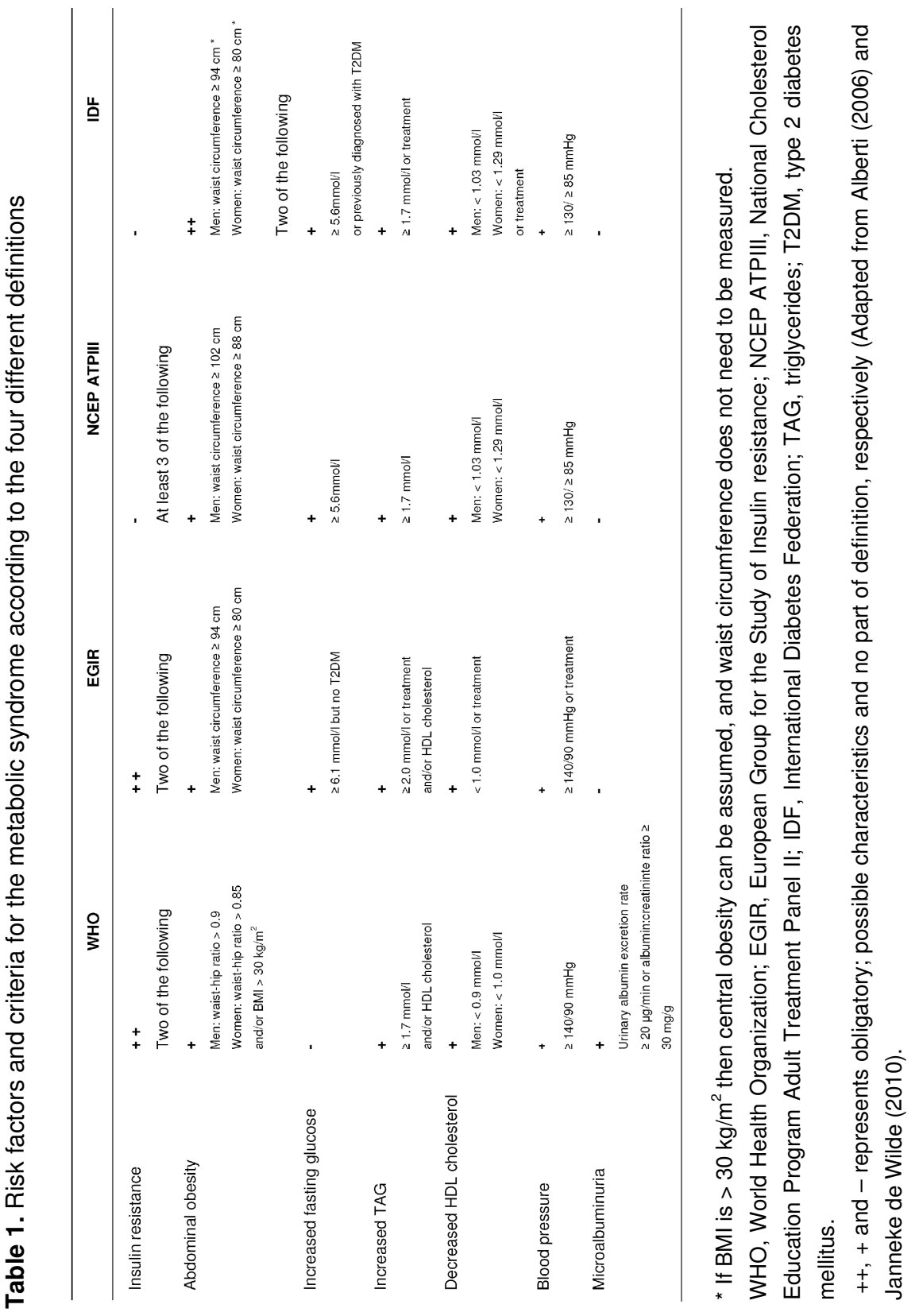




\section{CHAPTER 1}

\section{Fat metabolism in insulin resistance and the metabolic syndrome}

Obesity and insulin resistance are central characteristics of the MetS. The consumption of energy-rich food in combination with a sedentary lifestyle is a major risk factor for the development of obesity. Obesity is strongly related to insulin resistance. An impaired lipid metabolism in adipose tissue and skeletal muscle may play an important role in the development of insulin resistance and dyslipidemia, as seen in the MetS. Disturbances in adipose tissue function (leading to lipid overflow) and intrinsic disturbances in skeletal muscle FA handling, may contribute to an increase storage of lipids in non-adipose tissue like skeletal muscle, liver and pancreas, where it may be related to insulin resistance and an impaired insulin secretion [10,16]. Beside lipid overflow, also intrinsic disturbances in the capacity of skeletal muscle to adjust fat oxidation to supply may increase the accumulation of lipids in skeletal muscle [17]. It has been shown that not skeletal muscle TAG per se, but rather the accumulation of lipid metabolites like DAG, ceramides or fatty acyl-CoA may reduced insulin action through interference with insulin signalling $[11-13,18,19]$. The accumulation and dysfunction of adipose tissue mass during the development of obesity is also associated with increased secretion of adipokines and pro-inflammatory cytokines like TNF $\alpha$, IL6, MCP1 and leptin. The dysregulation of the production of pro-inflammatory and anti-inflammatory adipokines in obese individuals leads to a state of chronic low-grade inflammation and may promote obesity-linked metabolic disorders [20, 21].

\subsection{Lipid overflow}

Healthy people respond to a positive energy balance by storing excess energy as triglycerides (TAG) in the adipose tissue. The insulin resistant state is often accompanied by adipose tissue dysfunction characterized by an impaired capacity to take up and store lipids [10,21]. This loss of buffering capacity of the adipose tissue against the daily flux of dietary fat into the circulation, leads to increased concentration of FFA and TAG in the circulation, also called lipid overflow (Figure 2). The buffering capacity of adipose tissue also refers to its ability to suppress the release of $F A$ into the circulation and to increase the clearance of circulating chylomicron-TAG and VLDL-TAG [10]. Insulin resistance of the adipose tissue, which is frequently observed in obese people, further elevates FFA levels. Under normal conditions, FFA concentrations increase during fasting, while in the fed 
state, adipose tissue lipolysis is suppressed by insulin. However, in obesity, insulin action is impaired and even in the fed state FFA is released into the circulation [22, 23]. This oversupply of lipids causes a redistribution of fats from adipose to nonadipose tissues like liver, pancreas and skeletal muscle (ectopic fat accumulation) [24].

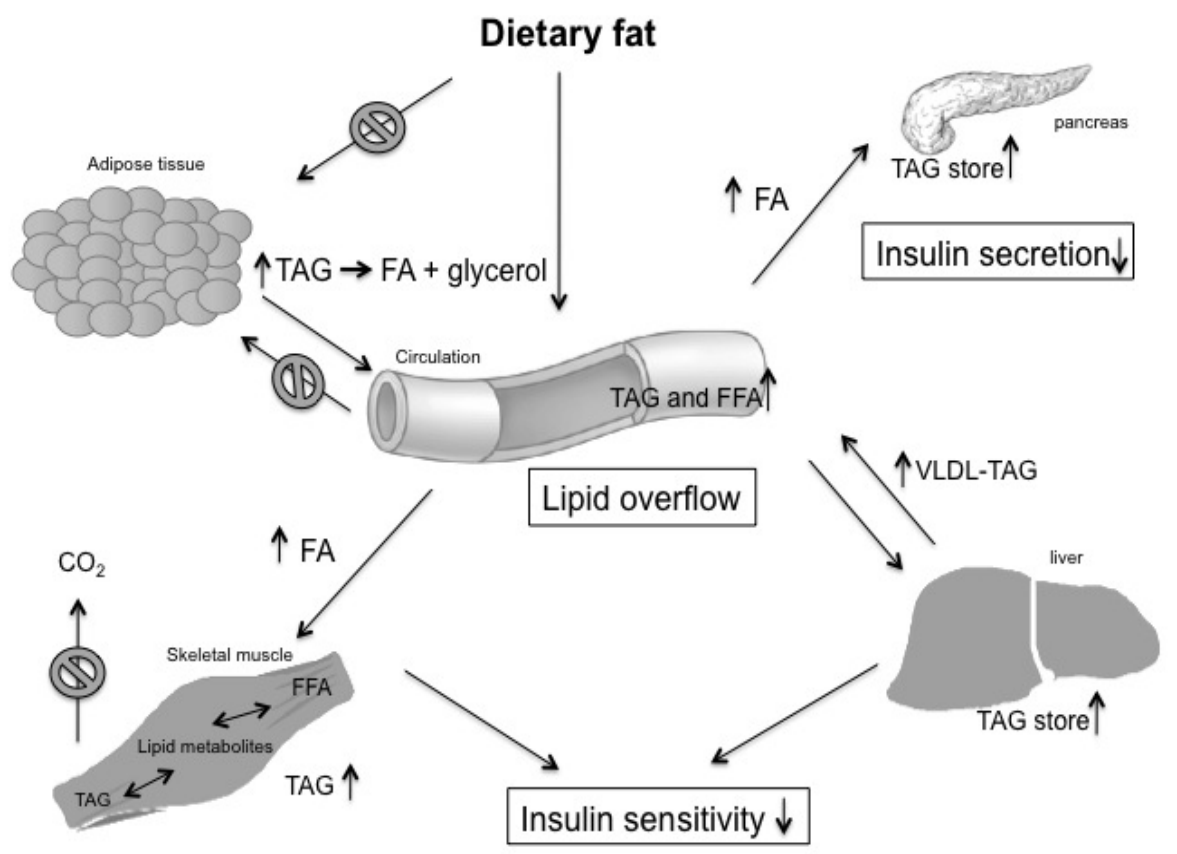

Figure 2. Lipid overflow: Loss of the normal buffering capacity of the adipose tissue against the daily influx of dietary fat into the circulation leads to an excessive flux of fatty acids and triglycerides into the circulation. The excess is deposited as TAG and lipid metabolites in other tissues where the lipotoxic lipid metabolites interfere with the insulin signalling cascade in liver and skeletal muscle or with glucose-stimulated insulin secretion (pancreas). TAG, triacylglycerol; FFA, free fatty acids; VLDL, very low-density lipoprotein.

The contribution of dietary fat (chylomicron-TAG) and endogenous fat (FFA and VLDL-TAG) to the lipid overflow is relatively unknown. In the fasted state, plasma FFA concentrations largely reflect lipolytic activity in the adipose tissue. After meal ingestion, FA will be absorbed in the intestine and enter the blood as chylomicrons. There are indications that insulin resistance is associated with a blunted clearance of dietary TAG by adipose tissue and an impaired insulin mediated suppression of VLDL production in the liver [25]. There is also evidence that insulin-mediated suppression of lipolysis in adipose tissue is decreased after meal ingestion in the 


\section{Chapter 1}

insulin resistant state. This might contribute to an increase of FFA concentrations in the circulation, although postprandial FFA release per unit fat mass has been reported to be reduced in insulin resistant conditions [26]. At the same time, it has been shown that the spillover of FFA derived from lipoprotein lipase (LPL)mediated TAG hydrolysis across adipose tissue is less suppressed during hyperinsulinaemia in obese people with T2DM compared to non-obese healthy controls [27]. The increased supply of endogenous FFA to the liver increases the VLDL-TAG output, and this may contribute to the rise in plasma TAG concentrations in insulin resistance. Also, dietary FA can make a substantial contribution to VLDL-TAG, already in the early postprandial phase [28, 29].

\subsection{Disturbed fatty acid metabolism in skeletal muscle in insulin resistance and the MetS}

Lipid overload in the muscle results from mismatch between FFA uptake and oxidation. Recent literature provides abundant evidence that beside the lipid overflow in the circulation, intrinsic disturbances in skeletal muscle FA handling may also play a role in this tissue lipotoxicity.

\subsubsection{Fatty acid uptake}

FA uptake is dependent on diffusion and thus on the concentration gradient over the muscle membrane. The uptake of FA by skeletal muscle not only occurs by passive diffusion but also by protein-mediated transport [30-32]. A number of proteins have been identified to facilitate the uptake of FA into muscle cells like membrane-bound FA translocase (FAT)/CD36 [33], plasma membrane associated FABPm [34] and a family of FA transporters (FATP1-6) [35], but their role in the regulation of fat metabolism remains unclear. Of these FA transporters CD36 has been best characterized. FAT/CD36 deficiency has been associated with functionally important impairment of FA transport in muscle and adipose tissue [36, 37]. In humans, it was shown that CD36 protein expression may be acutely upregulated by insulin [38] and that this upregulation may be more pronounced in insulin resistant conditions [39]. Furthermore, it has been shown that FAT/CD36 translocation to the plasma membrane may be increased in muscle strips of obese subjects and people with T2DM, which was FA uptake, as measured within the giant vesicle model, was increased 4-fold compared to overweight and lean controls [40]. On the other hand, studies by Blaak et al. [41] and others [42-44] have shown a lowered muscle FFA uptake in subjects with T2DM as compared 
with that of lean control. At first sight these data seem in contrast to the increased FA transport capacity, as measured during in vitro conditions. This may be explained by the fact that FA uptake, as measured during 'in vivo' conditions, is also determined by the plasma and intracellular FFA concentrations and by blood flow. Very little is known about the precise function or regulation of CD36 under different physiological conditions in human skeletal muscle in vivo.

In skeletal muscle, the relative importance of FA uptake from the action of LPL on circulating TAG and of direct FFA uptake is not well understood. Some studies suggest a major contribution of TAG-derived FFA [45], whereas others suggested that this contribution is immeasurably small. Many studies have suggested that chylomicron-TAG is the preferred substrate for LPL and competes with VLDL-TAG for lipolysis [46], while VLDL-TAG make a large contribution to circulating TAG, even in the postprandial phase [47]. It is has been thought that the uptake of TAGderived FA after hydrolysis is highly efficient in skeletal muscle when compared to adipose tissue [45]. Nevertheless, others have suggested that there is substantial spillover of TAG-derived FA into the plasma FFA pool across skeletal muscle [46, 48], and these TAG-derived FA merge with the plasma FFA pool to compete for cellular uptake [49]. It is still not completely clear if the latter process is disturbed in insulin resistance.

\subsubsection{Fatty acid partitioning within the skeletal muscle}

Once FFA have entered the muscle cells, they are activated by acyl-CoA synthetase to form fatty acyl-CoA (FA-CoA) complex. This complex can then be partitioned toward the synthesis of intramyocelluar lipids or goes into the mitochondria for oxidation [50]. In the mitochondrial matrix FA-CoA is degraded to acetyl-CoA during $\beta$-oxidation. The formed acetyl-CoA (can also be formed during glycolysis) then enters the Kreb cycle, here the acetyl-CoA are completely oxidized. During the process of $\beta$-oxidation and the Kreb cycle large amounts of energy are released that are transferred to the electron transport chain located in within the mitochondria to form ATP [50-52].

\section{Fat oxidation}

The impairments in the regulation of substrate oxidation in the muscle in insulin resistant conditions are referred to as metabolic inflexibility, more precisely defined as the impaired capacity to increase fat oxidation upon increased FA availability and to switch between fat and glucose during insulin-mediated conditions [17]. The 


\section{ChAPTER 1}

use of metabolic inflexibility rather than impaired fat oxidation does more justice to the complexity of changes in fat oxidation during the day [53]. As mentioned above, the skeletal muscle of people with insulin resistance and the MetS shows a great reduction in metabolic flexibility, defined as metabolic inflexibility [54]. FA oxidation measured across the muscle is reduced in obese people with T2DM in fasting conditions $[41,43,55,56]$ and stimulation of glucose oxidation and suppression of fat oxidation are blunted in response to insulin in people with T2DM [43, 56]. Our research group extended this concept also to other metabolic conditions showing that in obese people with impaired glucose tolerance and T2DM, skeletal muscle FA oxidation was reduced during exercise [57] and during B-adrenergic stimulation [41]. In the NUGENOB study, it was demonstrated that insulin resistance in obese subjects was independently associated with an impaired capacity to increase fasting fat oxidation and an impaired ability to suppress postprandial fat oxidation [58]. Consistent with this, Corpeleijn et al. also showed an impaired switch between substrates in vivo across forearm muscle in the transition from the fasting to the postprandial state in obese impaired glucose tolerant subjects (IGT) versus NGT people. This suggests that this impairment may be an early factor towards the development of T2DM [59]. Kelley et al. [60] reported that obese individuals had a greater leg $R Q$ and lower rate of fat oxidation in the fasting state as compared with lean people. Fasting leg $R Q$ values were negatively correlated with insulin sensitivity, providing further evidence that a connection exists between obesity, reduced skeletal muscle FA oxidation, and insulin resistance. The underlying mechanisms responsible for the impaired fat oxidation are discussed below and may include a reduced transport across the mitochondrial membrane, a reduced mitochondrial content and function or may be related to muscle fibre type.

\section{Transport across the mitochondrial membrane}

FAT/CD36 has also been found on rat and human muscle mitochondria [61-63], possibly contributing, together with carnitine, to the regulation of mitochondrial FA transport and oxidation in skeletal muscle. Carnitine transports LCFA-CoA into the mitochondrial matrix. Carnitine palmitoyltransferase 1 (CPT1) conjugates carnitine to the LCFA-CoA and is transported across the outer mitochondrial membrane by a carnitine-acylcarnitine translocase. The complex is subsequently converted back to LCFA-CoA and carnitine by CPT2, located in the inner mitochondrial membrane. The liberated carnitine returns to the cytosol to transport other LCFA-COA across the mitochondrial membrane. The transport of LCFA into the mitochondria by CPT1 is the rate limiting step for FA oxidation. CPT1 is under control of malonyl-CoA [64]. Malonyl-CoA is formed out of acetyl-CoA by the action of acetyl-CoA carboxylase 
(ACC). The lipogenic gene sterol regulatory element-binding protein (SREBP1C), which is under control of insulin, stimulates ACC and FA syntase (FAS) to promote malonyl-CoA formation and lipogenesis. The increased malonyl-CoA may, in turn, leads to inhibition of CPT1 and a lower transport of FA into the mitochondria and a FA oxidation (Figure 4) [23, 65].
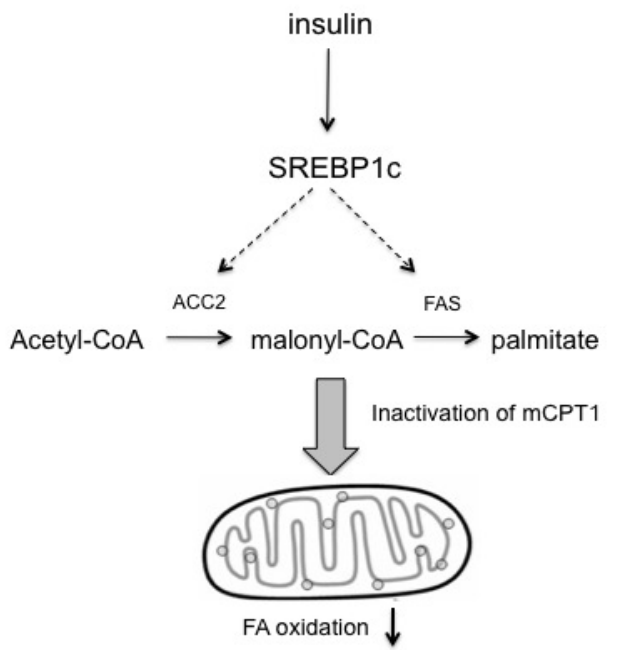

Figure 4. Regulation of the mitochondrial fatty acid oxidation via FA transport in the mitochondria by means of CPT1. Adapted from Lelliot et al. [23]. SREBP1c; sterol regulatory elementbinding protein, ACC2; acetyl-CoA carboxylase, FA; fatty acid, FAS; fatty acid synthase, mCPT1; muscle carnitine palmitoyltransferase 1.

In rodent models of obesity and insulin resistance an increased content of malonylCoA has been shown in skeletal muscle in combination with hyperglycaemia and hyperinsulinaemia and a reduced lipid oxidation [34]. Also, in human skeletal muscle it has been shown that a combination of hyperglycaemia and hyperinsulinaemia increases malonyl-CoA, inhibits functional CPT1 activity and shunts LCFA away from oxidation and towards storage in human muscle [66]. Furthermore, two studies have shown that an improvement in fat oxidation by exercise [67] or by lifestyle intervention [68] was accompanied by decreased acetyl-CoA carboxylase mRNA expression, suggesting that a reduced inhibition of mitochondrial FA transport through malonyl-CoA may have contributed to the improved fat oxidative capacity. Therefore, there are strong indications that a lowered mitochondrial transport through CPT1 may contribute to the reduced fat oxidation in the muscle of subjects who are obese and/or have T2DM [9].

\subsubsection{Fat storage}

The TAG synthesizing enzyme DAG acyltransferase 1 (DGAT1) catalyzes the last step in the glycerol phosphate pathway of TAG synthesis and produces TAG from 


\section{ChAPTER 1}

DAG and FA-CoA [69]. This enzyme has dual significance in that it promotes TAG storage but also decreases FA substrates. Overexpression of DGAT1 in the skeletal muscle of mice has been reported to increase both TAG and insulin sensitivity [70]. Timmers et al. [69] concluded that unilateral DGAT1 overexpression can rescue from insulin resistance, possibly by increasing DAG and TAG turnover in skeletal muscle and thus in case of a proper balance between the supply and oxidation of FA in skeletal muscle, the lipid intermediate DAG may not exert harmful effects on insulin signalling. It has also been proposed that the saturation of FA in DAG could play a role in insulin signalling [71]. The activity of $\triangle 9$-desaturase or steroyl-CoA desaturase 1 (SCD1) in muscle could play an important role in the partitioning of FA and acts by conversion of palmitic and stearic acid into palmitoleic and oleic acid, respectively. The activity also can be indirectly estimated by the ratio of C18:1n-9 to C18:0. Overexpression of SCD1 has been reported to protect $L 6$ myotubes from FA-induced insulin resistance despite increased TAG esterification [72]. Recently, it was found that SCD1 mRNA expression was upregulated in the muscle of obese subjects [73] and that its activity in myocytes is associated with low rates of FA oxidation and increased TAG synthesis [73]. It has been suggested by Pinnamaneni et al. [72] that the accumulation of TAG provides a protective effect against lipotoxicity by limiting the accumulation of other lipid metabolites such as DAG and ceramide, which are known to have an inhibitory effect on insulin signalling.

Disturbances in the regulation of skeletal muscle lipolysis may also contribute to the accumulation of lipids and lipid intermediates in skeletal muscle of obese subjects. Hormone-sensitive lipase (HSL) hydrolyzes TAG to glycerol and FFA via DAG and monoacylglycerol. Adipose triglyceride lipase (ATGL) is also capable to hydrolyse TAG to DAG. HSL deficient mice show an increased DAG storage and signs of impaired skeletal muscle insulin sensitivity [74, 75], while ATGL deficient mice have increased TAG accumulation in skeletal muscle and show improved insulin sensitivity [76]. Obese people show a blunted catecholamine-induced lipolysis in their skeletal muscle [77] and a reduced HSL expression, phosphorylation and activity are likely to be involved [78-80]. Furthermore, Jocken et al. [53] recently showed that the skeletal muscle of obese insulin resistant men have lower HSL and higher ATGL protein content. This marked difference in muscle lipase content in obese insulin-resistant men was accompanied by a lower DAGH activity, resulting in a $60 \%$ lower ratio of DAGH to TAGH activity, suggesting incomplete TAG hydrolysis [53]. Nevertheless this dysbalance in lipase activity was 
not associated with DAG accumulation in skeletal muscle of the obese insulin resistant men [53].

\subsection{Paradigms relating disturbed fat metabolism to insulin resistance}

It has become clear that impairments in lipid metabolism play an important role in the development of insulin resistance and the MetS. It remains the question what the underlying mechanisms are that could explain the relation between an impaired glucose and FA utilization in the skeletal muscle and insulin resistance. There are two paradigms that may explain this.

\subsubsection{Glucose-fatty acid cycle}

Randle and colleagues were the first to introduce the glucose-FA cycle, which was based on substrate competition between FFA and glucose [54]. The Randle cycle coupled an increase in FFA availability to an increase in FFA oxidation, which in turn reduced glucose oxidation and glucose uptake. An increase in FFA availability would lead to an increased FFA oxidation, inhibiting pyruvate dehydrogenase and phosphofructokinase. A subsequent accumulation of glucose-6-phosphate inhibits hexokinase activity, and the rise in intracellular glucose concentrations would then result in a reduction in glucose uptake. There are studies that disagree with the post-receptor mechanisms of the Randle cycle, they point to an inhibition of the insulin signalling cascade by FFA or lipid intermediates [16, 20, 81]. Studies with FFA infusion demonstrate a delay in the effect of FA on muscle insulin resistance. This delayed inhibition of insulin-stimulated glucose uptake may be caused by an accumulation of intramuscular TAG and lipid intermediates that interfere with the insulin signalling [16], rather than by acute post-receptor mechanisms. In addition, there is increasing evidence that in skeletal muscle of obese and/or subjects with T2DM, FA uptake and oxidation are reduced rather than increased [43, 44, 78].

\subsubsection{Ectopic fat accumulation}

The increased entry of FFA into myocytes without a corresponding increase in lipid oxidation contributes to the accumulation of intramuscular lipids (IMCL). The content of IMCL has been proposed to be related to insulin resistance, there is a negative relationship between IMCL and insulin sensitivity in high fat feeding models [82], and the lean offspring of people with T2DM [83]. Recently, studies reported that low-calorie diets in people with T2DM decreased IMCL along with improved insulin sensitivity [84]. However, endurance athletes have elevated IMCL 


\section{ChAPTER 1}

levels and are very insulin sensitive [85]. From this paradox, it became evident that not IMCL per se but rather the content of other lipid intermediate metabolites like DAG, ceramide and LCFA-CoA are associated with skeletal muscle insulin resistance by interference with the insulin signalling pathway [86, 87].

The insulin signalling pathway is responsible for the translocation of the GLUT4 receptor to the plasma membrane. In skeletal muscle, insulin binds to its receptor, activating the receptor tyrosine kinase activity, with subsequent phosphorylation and activation of insulin-receptor substrate 1 (IRS1) whereby the phosphorylated IRS1 subsequently activates 1-phosphatidylinositol 3-kinase (PI3K) [88]. PI3K activates 3-phosphoinositide-dependent protein kinase 1 (PDK1), which activates Akt (PKB), a serine kinase [89]. Akt in turn deactivates glycogen synthase kinase 3 (GSK-3), leading to activation of glycogen synthase and thus glycogen synthesis [89]. Activation of Akt also results in the translocation of GLUT4 vesicles from their intracellular pool to the plasma membrane, where they allow uptake of glucose into the cell [89] (Figure 3).

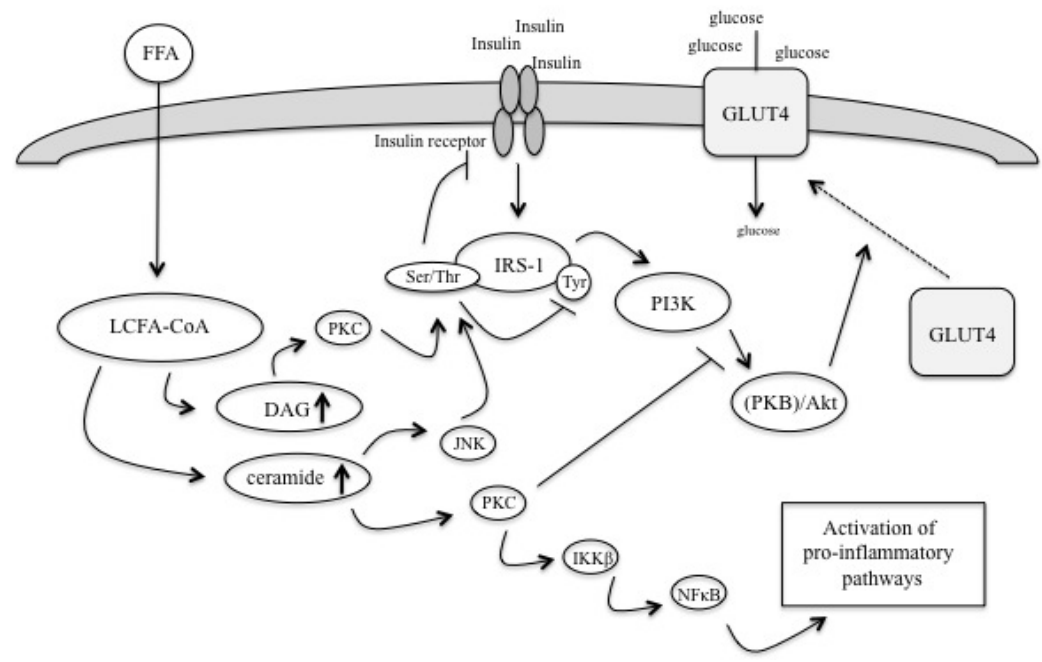

Figure 3. Simplified overview of intracellular signalling cascades involved in skeletal muscle insulin resistance by lipid metabolites. In obesity lipid overflow lead to accumulation of lipids in the muscle. This provides a source for lipid metabolites like DAG and ceramide. Increased levels of these mediators are involved in the activation of PKC, JNK and IKK $\beta$, which in turn impair insulin-stimulated signalling cascades leading to e.g. disturbed glucose uptake. In addition, pro-inflammatory pathways involving NFKB are activated. (Adapted from Eckardt et al. and Consitt et al.) 
Protein kinase C (PKC) as well as IKB kinase (IKK 3 ) and c-JUN N-terminal kinases (JNK) are able to phosphorylate serine/threonine sites of the insulin receptor and of IRS-1 and are able to decrease phosphorylation of (PKB)/Akt [12, 90]. Consequently, there is an attenuation of the activation of the insulin receptor, IRS-1 (tyrosine phosphorylation), and (PKB)/Akt, hereby impairing insulin signalling and impeding GLUT4 translocation to the plasma membrane. Therefore, insulinmediated glucose uptake may be reduced or even abrogated [22]. Furthermore, IKK $\beta$ can activate nuclear factor (NF)-KB, which in turn regulates the production of pro-inflammatory cytokines like interleukin (IL)-6 [91]. Abnormal accumulation of metabolites like LCFA-CoAs, DAG and ceramides are thought to be involved in the activation of PKC, IKK $\beta$ and JNK [92].

\section{Long-chain acyl-CoAs}

LCFA-CoAs are the metabolically activated form of intracellular FA and they are transported into the mitochondria for $\beta$-oxidation or used as an intermediate in the production of other lipid species [51, 69, 86]. Several data support a link between LCFA-CoAs and insulin resistance. Increased muscular LCA-CoAs levels have been associated with insulin resistance based on several animal and human studies in which the LFCA-CoAs levels are modulated by different dietary interventions or acutely via lipid infusion [15, 86, 93, 94] Impaired insulin-mediated glucose disposal and elevated LCFA-CoAs have been reported in both moderately and morbidly obese individuals [95, 96]. Studies utilizing lipid infusion [94] and high-fat diets [86] have demonstrated increased skeletal muscle LCFA-CoAs in conjunction with insulin resistance. Several mechanisms have been postulated that link LCFA-CoAs with decreased insulin signalling.

\section{Ceramides}

Ceramides can be generated from two FA and serine via 4 enzymatic steps. They have a function as signalling molecule in several important physiological events including inhibition of cell division and stimulation of apoptosis [69]. Ceramides are also proposed to play a role in the development of insulin resistance since elevated ceramide levels have been shown in the skeletal muscle of insulin-resistant animals [97], in skeletal muscle of subjects during lipid infusion [98], and in skeletal muscle of obese insulin-resistant subjects [99] and lean offspring of subjects with T2DM [100]. It has been speculated that ceramides may inhibit insulin signalling via inhibition at the level of Akt $[92,99,101]$. 


\section{ChAPTER 1}

$\underline{D A G}$

DAG acts as a key intermediate in both TAG and phospholipid (PL) metabolism and acts as an important second messenger in the regulation of intracellular signalling and thought to have detrimental effects on insulin signalling through its ability to activate PKC [51]. Increased skeletal muscle DAG content has been reported with fasting [102] and lipid infusion [87, 103]. The majority of research supports the notion that DAG promotes insulin resistance through the activation of PKC isoforms. In animals, it was demonstrated that lipid infusion resulted in a threefold increase in intracellular DAG mass, which was associated with PKC activation [103]. In humans, Itani et al. [87] reported that PKC content and activity were elevated in the skeletal muscle of obese, subjects with T2DM compared with obese subjects without T2DM [51].

Shifting the FA into the mitochondria for oxidation would decrease the accumulation of lipid, and thus protect the cell from insulin resistance. It has been demonstrated in L6 cells that the overexpression of CPT1 protected the cells against FA-induced insulin resistance by inhibiting the accumulation of lipid intermediates such as DAG and ceramide, and also decreasing the activation of PKC [104]. Furthermore, exercise intervention studies that produce increased skeletal muscle FAO have been reported to increase insulin sensitivity and decrease the levels of DAG and ceramide $[105,106]$. These findings support the importance of skeletal muscle FA oxidation in protecting the muscle from the accumulation of harmful lipid intermediates [51].

\section{Dietary fatty acids and insulin sensitivity}

Studies in our laboratory and others (DPS [107] and DPP [14]) showed that lifestyle intervention (reduction in total and saturated dietary fat content, increased physical activity) improves glucose tolerance in prediabetic subjects $[68,108]$, which is proposed to be mediated by changes in dietary fat quality [109] and an improved muscle metabolic flexibility [110]. The role of dietary fat in relation to T2DM has been of interest for decades. It is important to understand how specific dietary FA differentially can alter insulin sensitivity in skeletal muscle and adipose tissue function and how the risk or severity of insulin resistance can be modulated by dietary fat quantity and quality. The principal SFA in the diet and adipose tissue stores is palmitic acid (16:0). Another major dietary FA is the MUFA oleic acid 1(8:1). A healthy diet must also provide two "essential" PUFA; linoleic acid (18:2n-6 
or $n-6)$ and $\alpha$-linolenic acid (18:3n-3 or n-3, which are found in vegetable oils but cannot be synthesized by humans [111]. In the next paragraph evidence of dietary intervention studies of the effect of dietary FA on insulin sensitivity will be discussed.

\subsection{Evidence from dietary intervention studies}

There is good evidence to suggest that metabolic stressors including energydense, high-fat diets promote obesity and insulin resistance [112-114]. Epidemiologic studies suggest that high SFA intake increases the risk for the development of T2DM. In a 20-year follow-up study in the Netherlands and Finland, Feskens et al. [115] found that men with T2DM have a higher intake of total fat, SFA and MUFA than men that are NGT. Furthermore, men with T2DM also had a higher intake of PUFA than non-diabetic men with IGT. There is general consensus that total fat, particularly SFA may promote insulin resistance $[116,117]$. In overweight subjects, substitution of SFA for MUFA or carbohydrates increased insulin sensitivity $[118,119]$. In the KANWU study, one of the largest well-controlled dietary intervention studies, 162 subjects received isocaloric diets that differed only in fat quality; both the SFA diet (17E\% from SFA, 14E\% from MUFA, $6 \mathrm{E} \%$ from PUFA) and the MUFA diet (23E\% from MUFA, 8E\% from SFA, 6E\% from PUFA) had a total fat intake of $37 \mathrm{E} \%$. The main finding was that substituting SFA for MUFA improved insulin sensitivity [118] in subjects with a habitual fat intake below 37E\%. Consistent with this, Corpeleijn et al. [109] reported that the lifestyle intervention-induced changes in serum lipid profile were associated with changes in insulin sensitivity. Furthermore, Perez-Jimenez et al. [119, 120] performed two smaller studies and concluded a more positive effect on insulin sensitivity of a MUFA versus a SFA diet. In contrast with these above described studies, the RISCK trial, a 5-center, randomized controlled trial did not support the hypothesis that isoenergetic replacement of SFA with MUFA or carbohydrates improves insulin sensitivity in 548 people after a 24 week intervention with high-SFA, high-MUFA and low-fat diets [121]. The relationship between long chain $n-3$ PUFA (LCn-3) and insulin resistance is not entirely clear. Earlier short-term, high-dose LCn-3 PUFA supplementation trials (3-6 g per day for 2-8 weeks) in subjects with IGT improved insulin sensitivity $[122,123]$. However, subsequent long-term, lower-dose LC $n-3$ PUFA trials (1.8-3.6 g/day for 2-6 months) failed to improve insulin sensitivity [124-126]. 


\section{Chapter 1}

\subsection{Potential mechanisms for effects of dietary fatty acids}

Dietary FA may influence insulin sensitivity via different mechanisms, which are described below.

\subsubsection{Effect on skeletal muscle membrane}

The original observation on a relation between dietary fat quality and skeletal muscle TAG concentration and insulin resistance was gained in rats fed isocalorically on high fat diets differing only in FA profile of the fat component [127]. The effects of diet on insulin resistance were particularly pronounced in skeletal muscle and were related to a relative reduction of $n-3 F A$ in the muscle membrane and to a reduction in the number and diameter of fat droplets. Dietary FA might alter the risk of insulin resistance and T2DM by increasing the concentration of unsaturated FA in the cell membrane; this contributes to certain physical properties, such as "plasticity", which facilitates the movement of the GLUT4 receptor to the cell's surface $[128,129]$. In humans, insulin sensitivity is correlated with the amount of $n-3$ FA in skeletal muscle phospholipids [130]. Borkman et al. [131] showed that a decreased insulin sensitivity is associated with decreased concentrations of PUFA in skeletal muscle PL in man raising the possibility that changes in the FA composition of muscle PL modulate the action of insulin.

\subsubsection{Effect on lipid accumulation and oxidation}

Interestingly, there are indications from human muscle cell lines that dietary FA may differentially affect the accumulation of lipids. It has been found that SFA accumulate preferentially as DAG, whilst unsaturated $F A$ were readily converted to TAG [19]. Furthermore, oleic acid accumulates to a lesser extent as DAG or TAG than palmitic acid. In cultured myocytes, palmitic acid seems to accumulate as DAG and TAG, whereas oleic acid accumulates as intracellular FFA [132] Also, rats fed a high SFA diet manifest higher muscle concentration of DAG compared with those fed a fat source primarily containing linoleic acid [133]. Consistent with this, literature suggests that oleic acid and other unsaturated FAs may be more readily oxidized than SFA (122]. Furthermore, Jones et al. [134] showed that an increased PUFA intake for 7 days caused a $40 \%$ increase in fat oxidation in the fed state and a decreased (25\%) basal fat oxidation. Kien et al. [135] reported that a diet high in palmitic acid caused a decrease in the rate of fat oxidation as compared to a diet low in palmitic acid and high in oleic acid. Finally, myotubes of people with T2DM expressed a reduced palmitic acid oxidation whereas oleic acid 
oxidation was not different as compared to a healthy control group [132]. Effects on skeletal muscle gene expression probably mediate these effects.

\subsubsection{Effect on skeletal muscle gene expression}

There are now clearly defined intracellular pathways that are differently altered by FA subtypes. Experimental data point toward direct regulatory effects on gene expression and enzyme activity [136]. SFA and MUFA have little effect on lipogenic gene expression, while PUFA suppresses lipogenic expression [137]. It has been shown that PUFA may downregulate SREBP1c expression [138]. PUFA may regulate gene transcription within minutes, acting as agonists of nuclear hormone receptor family peroxisome proliferator activated receptors (PPARs) [139]. PPARs are transcription factors that regulate FA oxidation, adipogenesis, and inflammation, among other cellular processes [140]. Activation of PPAR increases FA oxidation and alters skeletal muscle gene expression in favour of increased FA oxidation [140]. By inducing their own oxidation, PUFA may be used to a lesser extent for fat storage within the muscle cell than SFA [141]. PGC-1a plays a major role in the regulating mitochondrial FA oxidation and energy generation. In skeletal muscle, PGC-1 $\alpha$ also stimulates mitochondrial biogenesis by coactivating the nuclear respiratory factor [142]. It has been shown that diets high in SFA or palmitic acid downregulate mRNA expression of PGC-1 $\alpha$ [140, 143, 144]. Furthermore, it has been proposed that the lipid infusion and nutrient excess result in a reduced expression of genes encoding key enzymes in oxidative metabolism and mitochondrial function (regulated by PGC-1 $\alpha$ ), and that these pathways are impaired in subjects with an impaired glucose metabolism and in people with T2DM [145].

\section{Outline of the thesis}

There is evidence that dietary fat quality may modulate muscle FA partitioning and lipid accumulation, resulting in a subsequent change in insulin sensitivity. The focus of this thesis is on skeletal muscle FA handling in relation to insulin sensitivity and the effect of dietary fat quantity and quality on skeletal muscle FA handling. The contribution of dietary fat (chylomicron-TAG) and endogenous fat (FFA and VLDL-TAG) to lipid overflow and intramuscular lipid accumulation is unknown. For this reason, we studied the contribution of different fat sources to skeletal muscle FA uptake and storage in insulin resistant men and a control group in chapter 2. FA partitioning was studied using an unique recently developed dual stable isotope 


\section{Chapter 1}

tracer technique in combination with arterio-venous concentration measurements across the forearm muscle. The second step in this thesis was to further characterize the insulin resistant phenotype at the transcriptional level. Results of previous studies on skeletal muscle gene expression are not consistent which may be partly explained by relatively small samples sizes and heterogeneity in metabolic phenotypes. Therefore, we studied, in chapter 3 the gene expression profiles of a relatively large group of subjects with a wide range of insulin sensitivity. Dietary fat quality may affect skeletal muscle FA handling thereby possibly improving insulin sensitivity. In chapter 4 , we firstly studied the acute effect of meals different in fat quality on skeletal muscle FA handling and postprandial insulin sensitivity in obese insulin resistant men. Furthermore, in skeletal muscle biopsies we studied intracellular fatty acid partitioning by determining the incorporation of dietary fatty acids in the different lipid pools and by studying the transcriptional regulation of FA metabolism. Subsequently, we studied the chronic effects of isocaloric manipulation of dietary fat quantity and quality on muscle FA partitioning within the framework of the European multi-centre dietary intervention study, LIPGENE (chapter 5), eight European countries. Previously, relationships between plasma fatty acid profiles and insulin sensitivity have been reported. The plasma fatty acid profiles may be influenced by lifestyle factors and endogenous fatty acid metabolism. In chapter $\mathbf{6}$, we investigated the relationship between dietary fat quality and quantity-induced changes in plasma FA profiles (and estimated desaturase activities) and insulin sensitivity within the framework of the LIPGENE study. Subsequently, we explored the activity of $\Delta^{9}$ desaturase (SCD1) in more detail at adipose tissue level due to the strong link with insulin sensitivity. Finally, in chapter $\mathbf{7}$ the major findings of all studies are discussed and implications for further research are presented. 


\section{References}

1. Eckel RH, Grundy SM, Zimmet PZ: The metabolic syndrome. Lancet 2005, 365(9468):1415-1428.

2. Zimmet P, Alberti KG, Shaw J: Global and societal implications of the diabetes epidemic. Nature 2001, 414(6865):782-787.

3. Fact sheet $\mathbf{N} \mathbf{3} 11$ [http://www.who.int/mediacentre/factsheets/fs311/en/index.html]

4. Wild S, Roglic G, Green A, Sicree R, King H: Global prevalence of diabetes: estimates for the year 2000 and projections for 2030. Diabetes Care 2004, 27(5):1047-1053.

5. Fact Sheet $\mathbf{N}^{\circ} \mathbf{3 1 7}$ [http://www.who.int/mediacentre/factsheets/fs317/en/index.html]

6. Cheng D: Prevalence, predisposition and prevention of type II diabetes. Nutr Metab (Lond) 2005, 2:29.

7. Ferrannini E, Haffner SM, Mitchell BD, Stern MP: Hyperinsulinaemia: the key feature of a cardiovascular and metabolic syndrome. Diabetologia 1991, 34(6):416-422.

8. Petersen KF, Dufour S, Savage DB, Bilz S, Solomon G, Yonemitsu S, Cline GW, Befroy D, Zemany L, Kahn BB et al: The role of skeletal muscle insulin resistance in the pathogenesis of the metabolic syndrome. Proc Natl Acad Sci U S A 2007, 104(31):12587-12594.

9. Blaak EE: Basic disturbances in skeletal muscle fatty acid metabolism in obesity and type 2 diabetes mellitus. Proc Nutr Soc 2004, 63(2):323-330.

10. Frayn KN: Adipose tissue as a buffer for daily lipid flux. Diabetologia 2002, 45(9):1201-1210.

11. Corcoran MP, Lamon-Fava S, Fielding RA: Skeletal muscle lipid deposition and insulin resistance: effect of dietary fatty acids and exercise. Am J Clin Nutr 2007, 85(3):662-677.

12. Schmitz-Peiffer C: Signalling aspects of insulin resistance in skeletal muscle: mechanisms induced by lipid oversupply. Cell Signal 2000, 12(9-10):583-594.

13. Schrauwen $P$, Hesselink MK: Oxidative capacity, lipotoxicity, and mitochondrial damage in type 2 diabetes. Diabetes 2004, 53(6):1412-1417.

14. Alberti KG, Zimmet P, Shaw J: Metabolic syndrome--a new world-wide definition. A Consensus Statement from the International Diabetes Federation. Diabet Med 2006, 23(5):469-480.

15. Zimmet P, Magliano D, Matsuzawa Y, Alberti G, Shaw J: The metabolic syndrome: a global public health problem and a new definition. J Atheroscler Thromb 2005, 12(6):295-300.

16. Boden G, Lebed B, Schatz M, Homko C, Lemieux S: Effects of acute changes of plasma free fatty acids on intramyocellular fat content and insulin resistance in healthy subjects. Diabetes 2001, 50(7):1612-1617.

17. Corpeleijn E, Saris WH, Blaak EE: Metabolic flexibility in the development of insulin resistance and type 2 diabetes: effects of lifestyle. Obes Rev 2009, 10(2):178-193.

18. Roden M: How free fatty acids inhibit glucose utilization in human skeletal muscle. News Physiol Sci 2004, 19:92-96.

19. Montell E, Turini M, Marotta M, Roberts M, Noe V, Ciudad CJ, Mace K, GomezFoix AM: DAG accumulation from saturated fatty acids desensitizes insulin stimulation of glucose uptake in muscle cells. Am J Physiol Endocrinol Metab 2001, 280(2):E229-237.

20. Roden M, Krssak M, Stingl H, Gruber S, Hofer A, Furnsinn C, Moser E, WaldhausI W: Rapid impairment of skeletal muscle glucose transport/phosphorylation by free fatty acids in humans. Diabetes 1999, 48(2):358-364. 
21. Goossens $\mathrm{GH}$ : The role of adipose tissue dysfunction in the pathogenesis of obesity-related insulin resistance. Physiol Behav 2008, 94(2):206-218.

22. Eckardt $\mathrm{K}$, Taube A, Eckel J: Obesity-associated insulin resistance in skeletal muscle: Role of lipid accumulation and physical inactivity. Rev Endocr Metab Disord 2011.

23. Lelliott C, Vidal-Puig AJ: Lipotoxicity, an imbalance between lipogenesis de novo and fatty acid oxidation. Int $J$ Obes Relat Metab Disord 2004, 28 Suppl 4:S22-28.

24. Unger $\mathrm{RH}$, Orci L: Lipotoxic diseases of nonadipose tissues in obesity. Int $J$ Obes Relat Metab Disord 2000, 24 Suppl 4:S28-32.

25. Frayn KN, Fielding BA, Karpe F: Adipose tissue fatty acid metabolism and cardiovascular disease. Curr Opin Lipidol 2005, 16(4):409-415.

26. Bickerton AS, Roberts R, Fielding BA, Tornqvist H, Blaak EE, Wagenmakers AJ, Gilbert M, Humphreys SM, Karpe F, Frayn KN: Adipose tissue fatty acid metabolism in insulin-resistant men. Diabetologia 2008, 51(8):1466-1474.

27. Riemens SC, Sluiter WJ, Dullaart RP: Enhanced escape of non-esterified fatty acids from tissue uptake: its role in impaired insulin-induced lowering of total rate of appearance in obesity and Type II diabetes mellitus. Diabetologia 2000, 43(4):416-426.

28. Heath RB, Karpe F, Milne RW, Burdge GC, Wootton SA, Frayn KN: Selective partitioning of dietary fatty acids into the VLDL TG pool in the early postprandial period. J Lipid Res 2003, 44(11):2065-2072.

29. Heath RB, Karpe F, Milne RW, Burdge GC, Wootton SA, Frayn KN: Dietary fatty acids make a rapid and substantial contribution to VLDL-triacylglycerol in the fed state. Am J Physiol Endocrinol Metab 2007, 292(3):E732-739.

30. Glatz JF, Luiken JJ, Bonen A: Involvement of membrane-associated proteins in the acute regulation of cellular fatty acid uptake. $J$ Mol Neurosci 2001,16 (23):123-132; discussion 151-127.

31. Bonen A, Chabowski A, Luiken JJ, Glatz JF: Is membrane transport of FFA mediated by lipid, protein, or both? Mechanisms and regulation of proteinmediated cellular fatty acid uptake: molecular, biochemical, and physiological evidence. Physiology (Bethesda) 2007, 22:15-29.

32. Glatz JF, Bonen A, Luiken JJ: Exercise and insulin increase muscle fatty acid uptake by recruiting putative fatty acid transporters to the sarcolemma. Curr Opin Clin Nutr Metab Care 2002, 5(4):365-370.

33. Abumrad NA, el-Maghrabi MR, Amri EZ, Lopez E, Grimaldi PA: Cloning of a rat adipocyte membrane protein implicated in binding or transport of long-chain fatty acids that is induced during preadipocyte differentiation. Homology with human CD36. J Biol Chem 1993, 268(24):17665-17668.

34. Stremmel W, Lotz G, Strohmeyer G, Berk PD: Identification, isolation, and partial characterization of a fatty acid binding protein from rat jejunal microvillous membranes. J Clin Invest 1985, 75(3):1068-1076.

35. Schaffer JE, Lodish HF: Expression cloning and characterization of a novel adipocyte long chain fatty acid transport protein. Cell 1994, 79(3):427-436.

36. Coburn CT, Knapp FF, Jr., Febbraio M, Beets AL, Silverstein RL, Abumrad NA: Defective uptake and utilization of long chain fatty acids in muscle and adipose tissues of CD36 knockout mice. J Biol Chem 2000, 275(42):3252332529.

37. Hajri T, Ibrahimi A, Coburn CT, Knapp FF, Jr., Kurtz T, Pravenec M, Abumrad NA: Defective fatty acid uptake in the spontaneously hypertensive rat is a primary determinant of altered glucose metabolism, hyperinsulinemia, and myocardial hypertrophy. J Biol Chem 2001, 276(26):23661-23666. 
38. Bonen A, Benton CR, Campbell SE, Chabowski A, Clarke DC, Han XX, Glatz JF, Luiken JJ: Plasmalemmal fatty acid transport is regulated in heart and skeletal muscle by contraction, insulin and leptin, and in obesity and diabetes. Acta Physiol Scand 2003, 178(4):347-356.

39. Corpeleijn E, Pelsers MM, Soenen S, Mensink M, Bouwman FG, Kooi ME, Saris $\mathrm{WH}$, Glatz JF, Blaak EE: Insulin acutely upregulates protein expression of the fatty acid transporter CD36 in human skeletal muscle in vivo. $J$ Physiol Pharmacol 2008, 59(1):77-83.

40. Bonen A, Parolin ML, Steinberg GR, Calles-Escandon J, Tandon NN, Glatz JF Luiken JJ, Heigenhauser GJ, Dyck DJ: Triacylglycerol accumulation in human obesity and type 2 diabetes is associated with increased rates of skeletal muscle fatty acid transport and increased sarcolemmal FAT/CD36. FASEB J 2004, 18(10):1144-1146.

41. Blaak EE, Wagenmakers AJ, Glatz JF, Wolffenbuttel BH, Kemerink GJ, Langenberg CJ, Heidendal GA, Saris WH: Plasma FFA utilization and fatty acidbinding protein content are diminished in type 2 diabetic muscle. Am J Physiol Endocrinol Metab 2000, 279(1):E146-154.

42. Colberg SR, Simoneau JA, Thaete FL, Kelley DE: Skeletal muscle utilization of free fatty acids in women with visceral obesity. J Clin Invest 1995, 95(4):18461853.

43. Kelley DE, Simoneau JA: Impaired free fatty acid utilization by skeletal muscle in non-insulin-dependent diabetes mellitus. J Clin Invest 1994, 94(6):23492356.

44. Turpeinen AK, Takala TO, Nuutila P, Axelin T, Luotolahti M, Haaparanta M, Bergman $\mathrm{J}$, Hamalainen $\mathrm{H}$, lida $\mathrm{H}$, Maki $\mathrm{M}$ et al: Impaired free fatty acid uptake in skeletal muscle but not in myocardium in patients with impaired glucose tolerance: studies with PET and 14(R,S)-[18F]fluoro-6-thia-heptadecanoic acid. Diabetes 1999, 48(6):1245-1250.

45. Evans K, Burdge GC, Wootton SA, Clark ML, Frayn KN: Regulation of dietary fatty acid entrapment in subcutaneous adipose tissue and skeletal muscle. Diabetes 2002, 51(9):2684-2690.

46. Bickerton AS, Roberts R, Fielding BA, Hodson L, Blaak EE, Wagenmakers AJ, Gilbert M, Karpe F, Frayn KN: Preferential uptake of dietary Fatty acids in adipose tissue and muscle in the postprandial period. Diabetes 2007, 56(1):168-176.

47. Cohn JS, Johnson EJ, Millar JS, Cohn SD, Milne RW, Marcel YL, Russell RM, Schaefer EJ: Contribution of apoB-48 and apoB-100 triglyceride-rich lipoproteins (TRL) to postprandial increases in the plasma concentration of TRL triglycerides and retinyl esters. J Lipid Res 1993, 34(12):2033-2040.

48. Miles JM, Park YS, Walewicz D, Russell-Lopez C, Windsor S, Isley WL, Coppack SW, Harris WS: Systemic and forearm triglyceride metabolism: fate of lipoprotein lipase-generated glycerol and free fatty acids. Diabetes 2004, 53(3):521-527.

49. Teusink B, Voshol PJ, Dahlmans VE, Rensen PC, Pijl H, Romijn JA, Havekes LM: Contribution of fatty acids released from lipolysis of plasma triglycerides to total plasma fatty acid flux and tissue-specific fatty acid uptake. Diabetes 2003, 52(3):614-620.

50. Jeukendrup AE: Regulation of fat metabolism in skeletal muscle. Ann N Y Acad Sci 2002, 967:217-235.

51. Consitt LA, Bell JA, Houmard JA: Intramuscular lipid metabolism, insulin action, and obesity. IUBMB Life 2009, 61(1):47-55.

52. Kiens B: Skeletal muscle lipid metabolism in exercise and insulin resistance. Physiol Rev 2006, 86(1):205-243. 
53. Jocken JW, Moro C, Goossens GH, Hansen D, Mairal A, Hesselink MK, Langin D, van Loon LJ, Blaak EE: Skeletal muscle lipase content and activity in obesity and type 2 diabetes. J Clin Endocrinol Metab 2010, 95(12):5449-5453.

54. Randle PJ, Garland PB, Hales CN, Newsholme EA: The glucose fatty-acid cycle. Its role in insulin sensitivity and the metabolic disturbances of diabetes mellitus. Lancet 1963, 1(7285):785-789.

55. Blaak EE, Wagenmakers AJ: The fate of [U-(13)C]palmitate extracted by skeletal muscle in subjects with type 2 diabetes and control subjects. Diabetes 2002, 51(3):784-789.

56. Kelley DE: Skeletal muscle fat oxidation: timing and flexibility are everything. $J$ Clin Invest 2005, 115(7):1699-1702.

57. Mensink M, Blaak EE, van Baak MA, Wagenmakers AJ, Saris WH: Plasma free Fatty Acid uptake and oxidation are already diminished in subjects at high risk for developing type 2 diabetes. Diabetes 2001, 50(11):2548-2554.

58. Blaak EE, Hul G, Verdich C, Stich V, Martinez A, Petersen M, Feskens EF, Patel K, Oppert JM, Barbe $\mathrm{P}$ et al: Fat oxidation before and after a high fat load in the obese insulin-resistant state. J Clin Endocrinol Metab 2006, 91(4):1462-1469.

59. Corpeleijn E, Mensink M, Kooi ME, Roekaerts PM, Saris WH, Blaak EE: Impaired skeletal muscle substrate oxidation in glucose-intolerant men improves after weight loss. Obesity (Silver Spring) 2008, 16(5):1025-1032.

60. Kelley DE, Goodpaster B, Wing RR, Simoneau JA: Skeletal muscle fatty acid metabolism in association with insulin resistance, obesity, and weight loss. Am J Physiol 1999, 277(6 Pt 1):E1130-1141.

61. Campbell SE, Tandon NN, Woldegiorgis G, Luiken JJ, Glatz JF, Bonen A: A novel function for fatty acid translocase (FAT)/CD36: involvement in long chain fatty acid transfer into the mitochondria. J Biol Chem 2004, 279(35):36235-36241.

62. Bezaire V, Bruce CR, Heigenhauser GJ, Tandon NN, Glatz JF, Luiken JJ, Bonen A, Spriet LL: Identification of fatty acid translocase on human skeletal muscle mitochondrial membranes: essential role in fatty acid oxidation. Am J Physiol Endocrinol Metab 2006, 290(3):E509-515.

63. Holloway GP, Bezaire V, Heigenhauser GJ, Tandon NN, Glatz JF, Luiken JJ, Bonen A, Spriet LL: Mitochondrial long chain fatty acid oxidation, fatty acid translocase/CD36 content and carnitine palmitoyltransferase I activity in human skeletal muscle during aerobic exercise. J Physiol 2006, 571(Pt 1):201210.

64. McGarry JD: Banting lecture 2001: dysregulation of fatty acid metabolism in the etiology of $t$ ype 2 diabetes. Diabetes 2002, 51(1):7-18.

65. Pender C, Trentadue AR, Pories WJ, Dohm GL, Houmard JA, Youngren JF: Expression of genes regulating malonyl-CoA in human skeletal muscle. $J$ Cell Biochem 2006, 99(3):860-867.

66. Rasmussen BB, Holmback UC, Volpi E, Morio-Liondore B, Paddon-Jones D, Wolfe $\mathrm{RR}$ : Malonyl coenzyme $A$ and the regulation of functional carnitine palmitoyltransferase-1 activity and fat oxidation in human skeletal muscle. $J$ Clin Invest 2002, 110(11):1687-1693.

67. Schrauwen $P$, van Aggel-Leijssen DP, Hul G, Wagenmakers AJ, Vidal H, Saris WH, van Baak MA: The effect of a 3-month low-intensity endurance training program on fat oxidation and acetyl-CoA carboxylase-2 expression. Diabetes 2002, 51(7):2220-2226.

68. Mensink M, Blaak EE, Vidal H, De Bruin TW, Glatz JF, Saris WH: Lifestyle changes and lipid metabolism gene expression and protein content in skeletal muscle of subjects with impaired glucose tolerance. Diabetologia 2003, 46(8):1082-1089.

69. Timmers S, Schrauwen $\mathrm{P}$, de Vogel J: Muscular diacylglycerol metabolism and insulin resistance. Physiol Behav 2008, 94(2):242-251. 
70. Liu L, Zhang Y, Chen N, Shi X, Tsang B, Yu YH: Upregulation of myocellular DGAT1 augments triglyceride synthesis in skeletal muscle and protects against fat-induced insulin resistance. J Clin Invest 2007, 117(6):1679-1689.

71. Bergman BC, Perreault L, Hunerdosse DM, Koehler MC, Samek AM, Eckel RH: Intramuscular lipid metabolism in the insulin resistance of smoking. Diabetes 2009, 58(10):2220-2227.

72. Pinnamaneni SK, Southgate RJ, Febbraio MA, Watt MJ: Stearoyl CoA desaturase 1 is elevated in obesity but protects against fatty acid-induced skeletal muscle insulin resistance in vitro. Diabetologia 2006, 49(12):3027-3037.

73. Goodpaster BH, Theriault R, Watkins SC, Kelley DE: Intramuscular lipid content is increased in obesity and decreased by weight loss. Metabolism 2000, 49(4):467-472.

74. Mulder $\mathrm{H}$, Sorhede-Winzell M, Contreras JA, Fex M, Strom K, Ploug T, Galbo H, Arner $\mathrm{P}$, Lundberg $\mathrm{C}$, Sundler $\mathrm{F}$ et al: Hormone-sensitive lipase null mice exhibit signs of impaired insulin sensitivity whereas insulin secretion is intact. $J$ Biol Chem 2003, 278(38):36380-36388.

75. Osuga J, Ishibashi S, Oka T, Yagyu H, Tozawa R, Fujimoto A, Shionoiri F, Yahagi $\mathrm{N}$, Kraemer FB, Tsutsumi $\mathrm{O}$ et al: Targeted disruption of hormone-sensitive lipase results in male sterility and adipocyte hypertrophy, but not in obesity. Proc Natl Acad Sci U S A 2000, 97(2):787-792.

76. Haemmerle G, Lass A, Zimmermann R, Gorkiewicz G, Meyer C, Rozman J, Heldmaier G, Maier R, Theussl C, Eder S et al: Defective lipolysis and altered energy metabolism in mice lacking adipose triglyceride lipase. Science 2006, 312(5774):734-737.

77. Blaak EE, Schiffelers SL, Saris WH, Mensink M, Kooi ME: Impaired betaadrenergically mediated lipolysis in skeletal muscle of obese subjects. Diabetologia 2004, 47(8):1462-1468.

78. Blaak EE, Van Baak MA, Kemerink GJ, Pakbiers MT, Heidendal GA, Saris WH: Beta-adrenergic stimulation of energy expenditure and forearm skeletal muscle metabolism in lean and obese men. Am J Physiol 1994, 267(2 Pt 1):E306-315.

79. Large V, Reynisdottir S, Langin D, Fredby K, Klannemark M, Holm C, Arner P: Decreased expression and function of adipocyte hormone-sensitive lipase in subcutaneous fat cells of obese subjects. J Lipid Res 1999, 40(11):2059-2066.

80. Reynisdottir S, Wahrenberg H, Carlstrom K, Rossner S, Arner P: Catecholamine resistance in fat cells of women with upper-body obesity due to decreased expression of beta 2-adrenoceptors. Diabetologia 1994, 37(4):428-435.

81. Dresner A, Laurent D, Marcucci M, Griffin ME, Dufour S, Cline GW, Slezak LA, Andersen DK, Hundal RS, Rothman DL et al: Effects of free fatty acids on glucose transport and IRS-1-associated phosphatidylinositol 3-kinase activity. J Clin Invest 1999, 103(2):253-259.

82. Dobbins RL, Szczepaniak LS, Bentley B, Esser V, Myhill J, McGarry JD: Prolonged inhibition of muscle carnitine palmitoyltransferase-1 promotes intramyocellular lipid accumulation and insulin resistance in rats. Diabetes 2001, 50(1):123-130.

83. Jacob S, Machann J, Rett K, Brechtel K, Volk A, Renn W, Maerker E, Matthaei S, Schick F, Claussen CD et al: Association of increased intramyocellular lipid content with insulin resistance in lean nondiabetic offspring of type 2 diabetic subjects. Diabetes 1999, 48(5):1113-1119. 
84. Jazet IM, Schaart G, Gastaldelli A, Ferrannini E, Hesselink MK, Schrauwen $P$, Romijn JA, Maassen JA, Pijl H, Ouwens DM et al: Loss of $50 \%$ of excess weight using a very low energy diet improves insulin-stimulated glucose disposal and skeletal muscle insulin signalling in obese insulin-treated type 2 diabetic patients. Diabetologia 2008, 51(2):309-319.

85. Goodpaster BH, He J, Watkins S, Kelley DE: Skeletal muscle lipid content and insulin resistance: evidence for a paradox in endurance-trained athletes. $J$ Clin Endocrinol Metab 2001, 86(12):5755-5761.

86. Ellis BA, Poynten A, Lowy AJ, Furler SM, Chisholm DJ, Kraegen EW, Cooney GJ: Long-chain acyl-CoA esters as indicators of lipid metabolism and insulin sensitivity in rat and human muscle. Am J Physiol Endocrinol Metab 2000, 279(3):E554-560.

87. Itani SI, Ruderman NB, Schmieder F, Boden G: Lipid-induced insulin resistance in human muscle is associated with changes in diacylglycerol, protein kinase C, and IkappaB-alpha. Diabetes 2002, 51(7):2005-2011.

88. Folli F, Saad MJ, Backer JM, Kahn CR: Insulin stimulation of phosphatidylinositol 3-kinase activity and association with insulin receptor substrate 1 in liver and muscle of the intact rat. J Biol Chem 1992, 267(31):22171-22177.

89. Chang L, Chiang SH, Saltiel AR: Insulin signaling and the regulation of glucose transport. Mol Med 2004, 10(7-12):65-71.

90. Shulman GI: Cellular mechanisms of insulin resistance. J Clin Invest 2000, 106(2):171-176.

91. Shoelson SE, Lee J, Yuan M: Inflammation and the IKK beta/I kappa B/NFkappa $B$ axis in obesity- and diet-induced insulin resistance. Int $J$ Obes Relat Metab Disord 2003, 27 Suppl 3:S49-52.

92. Schmitz-Peiffer $C$ : Protein kinase $\mathbf{C}$ and lipid-induced insulin resistance in skeletal muscle. Ann N Y Acad Sci 2002, 967:146-157.

93. Chen MT, Kaufman LN, Spennetta T, Shrago E: Effects of high fat-feeding to rats on the interrelationship of body weight, plasma insulin, and fatty acylcoenzyme A esters in liver and skeletal muscle. Metabolism 1992, 41(5):564569.

94. Chalkley SM, Hettiarachchi M, Chisholm DJ, Kraegen EW: Five-hour fatty acid elevation increases muscle lipids and impairs glycogen synthesis in the rat. Metabolism 1998, 47(9):1121-1126.

95. Hulver MW, Berggren JR, Cortright RN, Dudek RW, Thompson RP, Pories WJ, MacDonald KG, Cline GW, Shulman GI, Dohm GL et al: Skeletal muscle lipid metabolism with obesity. Am J Physiol Endocrinol Metab 2003, 284(4):E741-747.

96. Dohm GL, Tapscott EB, Pories WJ, Dabbs DJ, Flickinger EG, Meelheim D, Fushiki $\mathrm{T}$, Atkinson SM, Elton CW, Caro JF: An in vitro human muscle preparation suitable for metabolic studies. Decreased insulin stimulation of glucose transport in muscle from morbidly obese and diabetic subjects. $J$ Clin Invest 1988, 82(2):486-494.

97. Turinsky J, O'Sullivan DM, Bayly BP: 1,2-Diacylglycerol and ceramide levels in insulin-resistant tissues of the rat in vivo. J Biol Chem 1990, 265(28):1688016885.

98. Straczkowski M, Kowalska I, Nikolajuk A, Dzienis-Straczkowska S, Kinalska I, Baranowski M, Zendzian-Piotrowska M, Brzezinska Z, Gorski J: Relationship between insulin sensitivity and sphingomyelin signaling pathway in human skeletal muscle. Diabetes 2004, 53(5):1215-1221.

99. Adams JM, 2nd, Pratipanawatr T, Berria R, Wang E, DeFronzo RA, Sullards MC, Mandarino LJ: Ceramide content is increased in skeletal muscle from obese insulin-resistant humans. Diabetes 2004, 53(1):25-31. 
100. Straczkowski M, Kowalska I, Baranowski M, Nikolajuk A, Otziomek E, Zabielski P, Adamska A, Blachnio A, Gorski J, Gorska M: Increased skeletal muscle ceramide level in men at risk of developing type 2 diabetes. Diabetologia 2007, 50(11):2366-2373.

101. Hajduch E, Balendran A, Batty IH, Litherland GJ, Blair AS, Downes CP, Hundal HS: Ceramide impairs the insulin-dependent membrane recruitment of protein kinase B leading to a loss in downstream signalling in L6 skeletal muscle cells. Diabetologia 2001, 44(2):173-183.

102. Turinsky J, Bayly BP, O'Sullivan DM: 1,2-Diacylglycerol and ceramide levels in rat liver and skeletal muscle in vivo. Am J Physiol 1991, 261(5 Pt 1):E620-627.

103. Yu C, Chen Y, Cline GW, Zhang D, Zong H, Wang Y, Bergeron R, Kim JK, Cushman SW, Cooney GJ et al: Mechanism by which fatty acids inhibit insulin activation of insulin receptor substrate-1 (IRS-1)-associated phosphatidylinositol 3-kinase activity in muscle. J Biol Chem 2002, 277(52):50230-50236.

104. Sebastian D, Herrero L, Serra D, Asins G, Hegardt FG: CPT I overexpression protects L6E9 muscle cells from fatty acid-induced insulin resistance. Am J Physiol Endocrinol Metab 2007, 292(3):E677-686.

105. Bruce CR, Thrush AB, Mertz VA, Bezaire V, Chabowski A, Heigenhauser GJ, Dyck DJ: Endurance training in obese humans improves glucose tolerance and mitochondrial fatty acid oxidation and alters muscle lipid content. $A m \mathrm{~J}$ Physiol Endocrinol Metab 2006, 291(1):E99-E107.

106. Dube JJ, Amati F, Stefanovic-Racic M, Toledo FG, Sauers SE, Goodpaster BH: Exercise-induced alterations in intramyocellular lipids and insulin resistance: the athlete's paradox revisited. Am J Physiol Endocrinol Metab 2008, 294(5):E882-888.

107. Knowler WC, Barrett-Connor E, Fowler SE, Hamman RF, Lachin JM, Walker EA, Nathan DM: Reduction in the incidence of type 2 diabetes with lifestyle intervention or metformin. N Engl J Med 2002, 346(6):393-403.

108. Mensink M, Blaak EE, Wagenmakers AJ, Saris WH: Lifestyle intervention and fatty acid metabolism in glucose-intolerant subjects. Obes Res 2005, 13(8):1354-1362.

109. Corpeleijn E, Feskens EJ, Jansen EH, Mensink M, Saris WH, de Bruin TW, Blaak $\mathrm{EE}$ : Improvements in glucose tolerance and insulin sensitivity after lifestyle intervention are related to changes in serum fatty acid profile and desaturase activities: the SLIM study. Diabetologia 2006, 49(10):2392-2401.

110. Corpeleijn E MM, M E Kooi, PMHJ Roeckaerts, WHM Saris, and EE Blaak: 2006.

111. Kien CL: Dietary interventions for metabolic syndrome: role of modifying dietary fats. Curr Diab Rep 2009, 9(1):43-50.

112. Roche HM: Fatty acids and the metabolic syndrome. Proc Nutr Soc 2005, 64(1):23-29.

113. Storlien LH, Baur LA, Kriketos AD, Pan DA, Cooney GJ, Jenkins AB, Calvert GD, Campbell LV: Dietary fats and insulin action. Diabetologia 1996, 39(6):621-631.

114. Marshall JA, Hoag S, Shetterly S, Hamman RF: Dietary fat predicts conversion from impaired glucose tolerance to NIDDM. The San Luis Valley Diabetes Study. Diabetes Care 1994, 17(1):50-56.

115. Feskens EJ, Virtanen SM, Rasanen L, Tuomilehto J, Stengard J, Pekkanen J, Nissinen A, Kromhout D: Dietary factors determining diabetes and impaired glucose tolerance. A 20-year follow-up of the Finnish and Dutch cohorts of the Seven Countries Study. Diabetes Care 1995, 18(8):1104-1112.

116. Melanson EL, Astrup A, Donahoo WT: The relationship between dietary fat and fatty acid intake and body weight, diabetes, and the metabolic syndrome. Ann Nutr Metab 2009, 55(1-3):229-243. 
117. Warensjo E, Riserus U, Vessby B: Fatty acid composition of serum lipids predicts the development of the metabolic syndrome in men. Diabetologia 2005, 48(10):1999-2005.

118. Vessby B, Uusitupa M, Hermansen K, Riccardi G, Rivellese AA, Tapsell LC, Nalsen C, Berglund L, Louheranta A, Rasmussen BM et al: Substituting dietary saturated for monounsaturated fat impairs insulin sensitivity in healthy men and women: The KANWU Study. Diabetologia 2001, 44(3):312-319.

119. Perez-Jimenez F, Lopez-Miranda J, Pinillos MD, Gomez P, Paz-Rojas E, Montilla P, Marin C, Velasco MJ, Blanco-Molina A, Jimenez Pereperez JA et al: A Mediterranean and a high-carbohydrate diet improve glucose metabolism in healthy young persons. Diabetologia 2001, 44(11):2038-2043.

120. Paniagua JA, Gallego de la Sacristana A, Romero I, Vidal-Puig A, Latre JM, Sanchez E, Perez-Martinez P, Lopez-Miranda J, Perez-Jimenez F:

Monounsaturated fat-rich diet prevents central body fat distribution and decreases postprandial adiponectin expression induced by a carbohydraterich diet in insulin-resistant subjects. Diabetes Care 2007, 30(7):1717-1723.

121. Jebb SA, Lovegrove JA, Griffin BA, Frost GS, Moore CS, Chatfield MD, Bluck LJ, Williams CM, Sanders TA: Effect of changing the amount and type of fat and carbohydrate on insulin sensitivity and cardiovascular risk: the RISCK (Reading, Imperial, Surrey, Cambridge, and Kings) trial. Am J Clin Nutr 2010, 92(4):748-758.

122. Popp-Snijders C, Schouten JA, Heine RJ, van der Meer J, van der Veen EA: Dietary supplementation of omega-3 polyunsaturated fatty acids improves insulin sensitivity in non-insulin-dependent diabetes. Diabetes Res 1987, 4(3):141-147.

123. Fasching $\mathrm{P}$, Ratheiser K, Waldhausl W, Rohac M, Osterrode W, Nowotny P, Vierhapper $\mathrm{H}$ : Metabolic effects of fish-oil supplementation in patients with impaired glucose tolerance. Diabetes 1991, 40(5):583-589.

124. Vessby B: Effects of omega 3 fatty acids on glucose and lipid metabolism in non-insulin-dependent diabetes mellitus. World Rev Nutr Diet 1991, 66:407-416.

125. Griffin MD, Sanders TA, Davies IG, Morgan LM, Millward DJ, Lewis F, Slaughter S, Cooper JA, Miller GJ, Griffin BA: Effects of altering the ratio of dietary n-6 to n-3 fatty acids on insulin sensitivity, lipoprotein size, and postprandial lipemia in men and postmenopausal women aged 45-70 y: the OPTILIP Study. Am J Clin Nutr 2006, 84(6):1290-1298.

126. Kabir M, Skurnik G, Naour N, Pechtner V, Meugnier E, Rome S, QuignardBoulange A, Vidal H, Slama G, Clement $K$ et al: Treatment for 2 mo with $\mathbf{n} 3$ polyunsaturated fatty acids reduces adiposity and some atherogenic factors but does not improve insulin sensitivity in women with type 2 diabetes: a randomized controlled study. Am J Clin Nutr 2007, 86(6):1670-1679.

127. Storlien LH, Jenkins AB, Chisholm DJ, Pascoe WS, Khouri S, Kraegen EW: Influence of dietary fat composition on development of insulin resistance in rats. Relationship to muscle triglyceride and omega- 3 fatty acids in muscle phospholipid. Diabetes 1991, 40(2):280-289.

128. Salmeron J, Hu FB, Manson JE, Stampfer MJ, Colditz GA, Rimm EB, Willett WC: Dietary fat intake and risk of type 2 diabetes in women. Am J Clin Nutr 2001, 73(6):1019-1026.

129. Storlien LH, Pan DA, Kriketos AD, O'Connor J, Caterson ID, Cooney GJ, Jenkins AB, Baur LA: Skeletal muscle membrane lipids and insulin resistance. Lipids 1996, 31 Suppl:S261-265.

130. Baur LA, O'Connor J, Pan DA, Kriketos AD, Storlien LH: The fatty acid composition of skeletal muscle membrane phospholipid: its relationship with the type of feeding and plasma glucose levels in young children. Metabolism 1998, 47(1):106-112. 
131. Borkman M, Storlien LH, Pan DA, Jenkins AB, Chisholm DJ, Campbell LV: The relation between insulin sensitivity and the fatty-acid composition of skeletalmuscle phospholipids. N Engl J Med 1993, 328(4):238-244.

132. Gaster M, Rustan AC, Beck-Nielsen H: Differential utilization of saturated palmitate and unsaturated oleate: evidence from cultured myotubes. Diabetes 2005, 54(3):648-656.

133. Lee JS, Pinnamaneni SK, Eo SJ, Cho IH, Pyo JH, Kim CK, Sinclair AJ, Febbraio MA, Watt MJ: Saturated, but not $\mathbf{n}-6$ polyunsaturated, fatty acids induce insulin resistance: role of intramuscular accumulation of lipid metabolites. $J$ Appl Physiol 2006, 100(5):1467-1474.

134. Jones PJ, Schoeller DA: Polyunsaturated:saturated ratio of diet fat influences energy substrate utilization in the human. Metabolism 1988, 37(2):145-151.

135. Kien CL, Bunn JY, Ugrasbul F: Increasing dietary palmitic acid decreases fat oxidation and daily energy expenditure. Am J Clin Nutr 2005, 82(2):320-326.

136. Ginsberg BH, Brown TJ, Simon I, Spector AA: Effect of the membrane lipid environment on the properties of insulin receptors. Diabetes 1981, 30(9):773780.

137. Yoshikawa T, Shimano H, Yahagi N, Ide T, Amemiya-Kudo M, Matsuzaka T, Nakakuki M, Tomita S, Okazaki H, Tamura $Y$ et al: Polyunsaturated fatty acids suppress sterol regulatory element-binding protein 1c promoter activity by inhibition of liver X receptor (LXR) binding to LXR response elements. J Biol Chem 2002, 277(3):1705-1711.

138. Hannah VC, Ou J, Luong A, Goldstein JL, Brown MS: Unsaturated fatty acids down-regulate srebp isoforms $1 \mathrm{a}$ and 1c by two mechanisms in HEK-293 cells. J Biol Chem 2001, 276(6):4365-4372.

139. Evans RM, Barish GD, Wang YX: PPARs and the complex journey to obesity. Nat Med 2004, 10(4):355-361.

140. Muoio DM, Newgard CB: Obesity-related derangements in metabolic regulation. Annu Rev Biochem 2006, 75:367-401.

141. Manco $M$, Calvani M, Mingrone G: Effects of dietary fatty acids on insulin sensitivity and secretion. Diabetes Obes Metab 2004, 6(6):402-413.

142. Mensink M, Hesselink MK, Russell AP, Schaart G, Sels JP, Schrauwen P: Improved skeletal muscle oxidative enzyme activity and restoration of PGC-1 alpha and PPAR beta/delta gene expression upon rosiglitazone treatment in obese patients with type 2 diabetes mellitus. Int J Obes (Lond) 2007, 31(8):1302-1310.

143. Koves TR, Li P, An J, Akimoto T, Slentz D, Ilkayeva O, Dohm GL, Yan Z, Newgard $\mathrm{CB}$, Muoio DM: Peroxisome proliferator-activated receptor-gamma coactivator 1alpha-mediated metabolic remodeling of skeletal myocytes mimics exercise training and reverses lipid-induced mitochondrial inefficiency. $J$ Biol Chem 2005, 280(39):33588-33598.

144. Coll T, Jove M, Rodriguez-Calvo R, Eyre E, Palomer X, Sanchez RM, Merlos M, Laguna JC, Vazquez-Carrera M: Palmitate-mediated downregulation of peroxisome proliferator-activated receptor-gamma coactivator 1alpha in skeletal muscle cells involves MEK1/2 and nuclear factor-kappaB activation. Diabetes 2006, 55(10):2779-2787.

145. Patti ME, Kahn BB: Nutrient sensor links obesity with diabetes risk. Nat Med 2004, 10(10):1049-1050. 



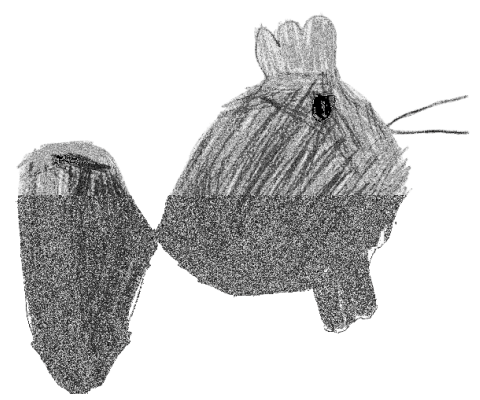

\section{CHAPTER 2}

\section{Skeletal muscle fatty acid handling in insulin resistant men}

Anneke M.J. van Hees, Anneke Jans, Gabby B. Hul, Helen M. Roche, Wim H.M. Saris and Ellen E. Blaak

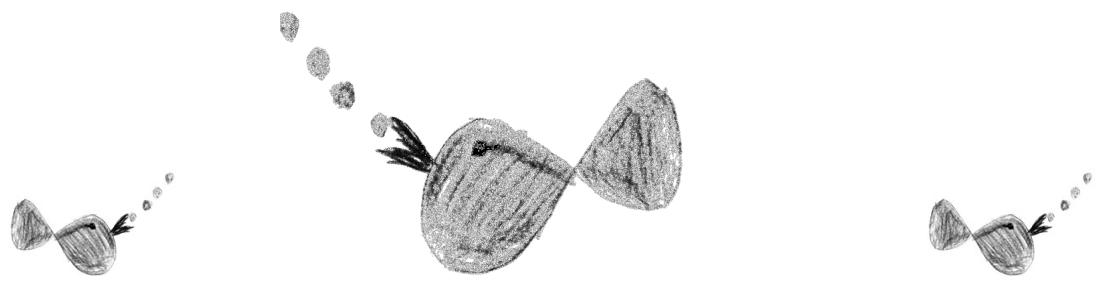




\section{Chapter 2}

\section{ABSTRACT}

Background: Disturbances in skeletal muscle lipid metabolism may precede or contribute to the development of whole body insulin resistance.

Aim: In this study, we examined fasting and postprandial skeletal muscle fatty acid (FA) handling in insulin resistant men.

Methods: Thirty men with the metabolic syndrome (NCEP ATPIII) were included in this sub-study to the LIPGENE study, and divided in two groups (insulin resistant and control) based on the median of insulin sensitivity $\left(2.06\left(\mathrm{mU} / /^{-1}\right)^{*} \mathrm{~min}^{-1 *} 10^{-4}\right)$. Fasting and postprandial skeletal muscle FA handling were examined by combining the forearm balance technique with stable isotopes of palmitate. $\left[{ }^{2} \mathrm{H}_{2}\right]-$ palmitate was infused intravenously to label endogenous triacylglycerol (TAG) and free fatty acids (FFA) in the circulation and $\left[\mathrm{U}-{ }^{13} \mathrm{C}\right]$-palmitate was incorporated in a high-fat mixed-meal (2.6MJ, $61 \mathrm{E} \%$ fat) to label chylomicron-TAG. Muscle biopsies were taken to determine muscle TAG, diacylglycerol, FFA and phospholipid content, their fractional synthetic rates (FSR) and degree of saturation, as well as mRNA expression of genes involved in lipid metabolism.

Results: In the first hour after meal consumption, forearm muscle $\left[{ }^{2} \mathrm{H}_{2}\right]$-labeled TAG extraction was higher in insulin resistant versus control $(p=0.05)$. Fasting percentage saturation of muscle diacylglycerol was higher in insulin resistant versus control $(p=0.016)$. No differences were observed for intramuscular TAG, diacylglycerol, FFA and phospholipid content, FSR and muscle mRNA expression.

Conclusion: In conclusion, increased muscle (hepatically-derived) TAG extraction during postprandial conditions and increased saturation of intramuscular diacylglycerol are associated with insulin resistance, suggesting that disturbances in skeletal muscle FA handling could play a role in the development of whole body insulin resistance and type 2 diabetes mellitus. 


\section{INTRODUCTION}

Disturbances in skeletal muscle lipid metabolism may play a central role in the development of insulin resistance, the metabolic syndrome (MetS) and type 2 diabetes mellitus (T2DM) [1-3]. Conditions of chronic excessive energy intake and/or a sedentary lifestyle may lead to an increased supply of triacylglycerol (TAG) and free fatty acids (FFA) to non-adipose tissues such as skeletal muscle and liver (lipid overflow hypothesis) [4]. Together with an impaired capacity of skeletal muscle to oxidize fat [5-7], lipid overflow is hypothesised to create excess fat storage in skeletal muscle and liver. In particular the intramuscular accumulation of lipid metabolites like diacylglycerol, long-chain fatty acyl-CoA and ceramide, as well as the saturation of these lipid fractions, may reduce insulin action in skeletal muscle by interfering with insulin signalling and/or inducing inflammatory pathways [8-12]. The contribution of dietary fat (chylomicron-TAG) and endogenous fat (FFA and very low-density lipoprotein (VLDL)-TAG) to lipid overflow and intramuscular lipid accumulation is unknown. Elevated FFA concentrations may originate from an expanded fat mass or decreased peripheral clearance $[5,6,13]$, although findings are inconsistent [14]. Insulin-mediated suppression of adipose tissue FFA output after meal ingestion has been considered to be impaired in the insulin resistant state, thereby contributing to increased systemic FFA concentrations, although postprandial FFA release per unit fat mass has been reported to be reduced in insulin resistant conditions [14]. At the same time, it has been shown that the spillover of fatty acids (FA) derived from lipoprotein lipase (LPL)-mediated TAGhydrolysis across adipose tissue is less suppressed during hyperinsulinaemia in obese patients with T2DM compared with non-obese healthy controls [15]. Plasma TAG concentrations may rise in the insulin resistant state due to increased supply of endogenous FFA to the liver and subsequent increased VLDL-TAG output. Also, dietary FA can make a substantial contribution to VLDL-TAG, already in the early postprandial phase $[16,17]$. The contribution of plasma TAG to the FA delivery to skeletal muscle is not entirely clear. It has been demonstrated in healthy subjects that LPL prefers chylomicron-TAG above VLDL-TAG for hydrolysis [18], although VLDL-TAG make a large contribution to circulating TAG, even in the postprandial phase [19]. The uptake of TAG-derived FA after hydrolysis is thought to be highly efficient in skeletal muscle when compared to adipose tissue [20]. However, others suggested that there is substantial release of TAG-derived FA into the plasma FFA pool (i.e. spillover) across skeletal muscle [18, 21], and that TAG-derived FA mix with the plasma FFA pool to compete for cellular uptake [22]. Most studies on 


\section{Chapter 2}

VLDL- and chylomicron-TAG metabolism have been performed in healthy subjects and little is known about their metabolism in skeletal muscle during different conditions such as insulin resistance, the MetS and type T2DM [23]. A previous study showed that postprandial plasma VLDL- and chylomicron-TAG concentrations are elevated in the insulin resistant state [14]. The aim of this study was to examine fasting and postprandial skeletal muscle FA handling in insulin resistant men compared to a control group, using a recently developed dual stable isotope tracer technique in combination with arterio-venous measurements across the forearm muscle which enables us to differentiate between the metabolic fate of dietary versus endogenous FA. Additionally, muscle biopsies were taken to investigate skeletal muscle lipid metabolites, their fractional synthetic rates and the transcriptional regulation of FA metabolism.

\section{METHODS}

The present study was performed in a sub-cohort of men in the Netherlands within the LIPGENE human dietary intervention study. In total, 30 men with the MetS at the age of 35-70y and body mass index (BMI) between 27 and $38 \mathrm{~kg} / \mathrm{m}^{2}$ were included in this study. Definition of the MetS was based on the NCEP ATP III report [24], with subjects meeting at least three of the following criteria: 1) fasting plasma glucose concentration between 5.5 and $7.0 \mathrm{mmol} / \mathrm{l}$; 2) fasting plasma TAG concentration $\geq 1.5 \mathrm{mmol} / \mathrm{l}$; 3) fasting plasma high-density lipoprotein (HDL)cholesterol concentration $<1.0 \mathrm{mmol} / \mathrm{l}$; 4) systolic blood pressure $\geq 130 \mathrm{mmHg}$ and/or diastolic blood pressure $\geq 85 \mathrm{mmHg}$ and/or treatment of previously diagnosed hypertension; 5) waist circumference $>102 \mathrm{~cm}$. Exclusion criteria included weight change $>3 \mathrm{~kg}$ within the 3 months prior to the study; diabetes or other endocrine disorders; chronic inflammatory conditions; kidney or liver dysfunction; use of hypolipidaemic or anti-inflammatory medication; use of antihypertensive medication in the class of $\beta$-blockers; use of aspirin $>1$ per week; highly trained or endurance athletes; and alcohol abuse.

Subjects were split in two groups based on the median of insulin sensitivity (2.06 $\left.\left(\mathrm{mU} / /^{-1}\right) * \mathrm{~min}^{-1} * 10^{-4}\right)$ as measured during a frequently sampled insulin modified intravenous glucose tolerance test (IVGTT). Men below the median of insulin sensitivity were considered as the insulin resistant group ( $n=15)$, and men above the median as the control group $(n=15)$. All subjects were informed about the nature of the study and written informed consent was attained prior to study participation. The study protocol was approved by the local Medical Ethical Committee of the Maastricht University. 


\section{Experimental design}

Subjects came to the university after an overnight fast on two different occasions. On one day, subjects completed anthropometric measurements, donated a fasting blood sample and completed an IVGTT to measure insulin sensitivity as described previously $[25,26]$. Insulin sensitivity was the primary endpoint of the LIPGENE human dietary intervention study. On a separate day, a tracer infusion study was performed to evaluate the contribution of dietary TAG (labeled with $\left[\mathrm{U}-{ }^{13} \mathrm{C}\right]-$ palmitate) and endogenous TAG, i.e. VLDL, and circulating FFA (both labeled with $\left[{ }^{2} \mathrm{H}_{2}\right]$-palmitate) to lipid overflow and skeletal muscle $F A$ handling during fasting and after the consumption of a high-fat mixed-meal, as validated previously [18].

\section{Tracer infusion study}

Subjects came to the university after an overnight fast and were asked to refrain from drinking alcohol and to perform no strenuous exercise $24 \mathrm{~h}$ prior to the study day. In addition, they were asked to avoid food products naturally enriched with $\left[{ }^{13} \mathrm{C}\right]$ for 7 days before the study day. Skeletal muscle metabolism was studied in the forearm muscle, using arteriovenous concentration differences corrected for blood flow. Three catheters were inserted before the start of the experiment. One catheter was placed in the radial artery of the forearm to sample arterial blood, and in the same arm another catheter was placed in an antecubital vein for the infusion of the $\left[{ }^{2} \mathrm{H}_{2}\right]$-palmitate tracer. $A$ third catheter was placed retrogradely in a deep antecubital vein of the contralateral forearm to sample venous blood draining the forearm muscle. After taking an arterial and deep venous background sample at $\mathrm{t}$ 95 (i.e. 95min before meal ingestion (t0)), a continuous intravenous infusion of the stable isotope tracer $\left[{ }^{2} \mathrm{H}_{2}\right]$-palmitate $(97 \%$ enrichment, Cambridge Isotope Laboratories, Andover, MA, USA) complexed to albumin was started $(0.035 \mu \mathrm{mol}$ * $\mathrm{kg}$ body weight $\left.{ }^{-1} * \mathrm{~min}^{-1}\right)$. Baseline blood sampling was started after one hour of tracer infusion to allow for isotopic equilibration to occur. Blood samples were taken simultaneously from the radial artery and the deep muscle vein at three time points during fasting (t-35, t-20, t-5) and six time points postprandially (t30, t60, t90, t120, $\mathrm{t} 180, \mathrm{t} 240$ ) after consumption of a high-fat mixed meal (t0) containing $200 \mathrm{mg}$ [U${ }^{13} \mathrm{C}$-palmitate (98\% enrichment, Cambridge Isotope Laboratories). Forearm blood flow was measured before each blood sampling as described previously [27].

The liquid test meal provided 2.6MJ, consisting of 61 energy\% (E\%) fat $(35.5 \mathrm{E} \%$ saturated fat, $18.8 \mathrm{E} \%$ monounsaturated fat and $1.7 \mathrm{E} \%$ polyunsaturated fat), $33 \mathrm{E} \%$ carbohydrates and $6.3 \mathrm{E} \%$ protein. Subjects were asked to drink the test meal within $5 \mathrm{~min}$. 


\section{CHAPTER 2}

Skeletal muscle biopsies were taken before the start of the experiment during fasting and at the end of the postprandial measurement period (t240) to determine intramuscular TAG, diacylglycerol (DAG), FFA and phospholipid (PL) content, their degree of saturation, as well as the fractional synthetic rate (FSR) of TAG, DAG and PL (see skeletal muscle lipids). Furthermore, mRNA expression of genes involved in lipid metabolism was determined (see skeletal muscle mRNA expression). Biopsies were taken from the vastus lateralis muscle under local anaesthesia of the skin and fascia using the Bergström method with suction [28], cleaned from any visible fat and blood, immediately frozen in isopentane at its melting point and stored at $-80^{\circ} \mathrm{C}$ until analysis.

\section{Biochemical analyses}

Blood was collected in tubes containing ethylenediaminetetraacetic acid, centrifuged $\left(1000 \mathrm{~g}, 10 \mathrm{~min}, 4^{\circ} \mathrm{C}\right)$ and plasma was immediately frozen in liquid nitrogen and stored at $-80^{\circ} \mathrm{C}$ until analysis. Plasma FFA and 3-hydroxybutyrate were analysed using standard enzymatic techniques automated on a Cobas Fara centrifugal spectrophotometer (Roche Diagnostica, Basel, Switzerland). Plasma TAG, glycerol, glucose and lactate were analysed enzymatically on a Cobas Mira automated spectrophotometer. Plasma insulin was measured with a double antibody radioimmunoassay (Linco Research Inc., St. Charles, MO, USA). Plasma total cholesterol, HDL-cholesterol and low-density lipoprotein (LDL)-cholesterol were determined with an ILab 600 clinical chemical analyser (Instrumentation Laboratory, Warrington, UK), using enzymatic colourimetric kits. Haematocrit was determined in heparinised blood using a microcapillary system.

To determine isotope enrichment of plasma FFA and TAG, total lipids were extracted from the plasma using chloroform-methanol 2:1 (vol/vol). The FFA and TAG fractions were separated by thin-layer chromatography and derivatised to their methyl esters for the analysis of plasma palmitate. Plasma fractions were analysed for the ${ }^{13} \mathrm{C}$-to- ${ }^{12} \mathrm{C}$ ratio on a gas chromatography continuous-flow isotope ratio-mass spectrometer (Finnigan MAT-252 GC-IRMS, Bremen, Germany) and for enrichment of $\left[^{2} \mathrm{H}_{2}\right]$ (Finnigan Incos-XL GC-MS). The methyl ester of palmitate contains 17 carbon atoms and therefore, the tracer/tracee ratio (TTR) of palmitate was corrected for the extra methyl group. Plasma palmitate concentrations $(\mu \mathrm{mol} / \mathrm{l})$ were analysed on an analytical GC with ion flame detection using heptadecanoic acid as internal standard. 


\section{Skeletal muscle lipids}

Skeletal muscle biopsies were lyophilised and dissected free of extramyocellular lipid, blood and connective tissue. Total lipids were extracted from 10-20mg muscle sample using chloroform-methanol $(2: 1 \mathrm{vol} / \mathrm{vol})$ and internal standards, and thereafter evaporated under nitrogen at $37^{\circ} \mathrm{C}$. The extracted lipids were separated into FFA, DAG, TAG and PL by thin-layer chromatography and transferred into tubes for methylation. The TAG and DAG fractions were methylated by adding $1 \mathrm{ml}$ of toluene-methanol-(BF3-methanol 14\%) (20\%-55\%-25\% vol/vol) and incubated in capped tubes for $30 \mathrm{~min}$ at $100^{\circ} \mathrm{C}$. The PL fraction was methylated by adding $1 \mathrm{ml}$ of (BF3-methanol 14\%) and incubation in capped tubes for $90 \mathrm{~min}$ at $100^{\circ} \mathrm{C}$. The FFA fraction was methylated by adding $1 \mathrm{ml}$ of methanol-(BF3-methanol 14\%) (50\%$50 \% \mathrm{vol} / \mathrm{vol}$ ) and incubation in capped tubes at room temperature for $15 \mathrm{~min}$. After incubation, $2 \mathrm{ml}$ pentane was added to the samples, vortexed and centrifuged $\left(1000 \mathrm{~g}, 5 \mathrm{~min}, 20^{\circ} \mathrm{C}\right)$, followed by isolation of pentane extracts (upper phase) and evaporation under nitrogen at $30^{\circ} \mathrm{C}$. Finally, the residues were dissolved in isooctane and concentrations of fatty acids in the fractions were determined using an analytical GC. Stable isotope enrichment of the lipid fractions was determined by measuring the ${ }^{13} \mathrm{C}$-to- ${ }^{12} \mathrm{C}$ ratio on a GC-IRMS (Finnigan MAT-252).

\section{Skeletal muscle mRNA expression}

RNA was isolated from approximately $25 \mathrm{mg}$ of snap frozen muscle tissue. The tissues were homogenised in $1 \mathrm{ml}$ Trizol for RNA stabilisation and RNA was isolated according to a standardised protocol as described by the manufacturer. Next, RNA was purified using the RNeasy mini kit (Qiagen Benelux B.V., Venlo, The Netherlands) and dissolved in RNase/DNase free water. RNA was quantified and checked for purity on the NanoDrop 1000 (NanoDrop Technologies, Wilmington, DE, USA), and considered suitable for further processing at ratios between $260 / 280$ and $260 / 230$ of $>1.7$. Integrity was evaluated using the BioAnalyzer (Agilent, Palo Alto CA, USA) and considered to be intact with an RNA integrity number $>7.0$. Isolated RNA was reverse transcribed using the iScript cDNA synthesis Kit. The qPCR reactions were performed in a volume of $25 \mu \mathrm{l}$ containing $12.5 \mathrm{ng}$ cDNA, $1 \times$ IQ SYBR Green Supermix and 400nM of genespecific forward and reverse primers (Supplemental table). cDNA was amplified using a two-step program ( 40 cycles of $10 \mathrm{sec}$ at $95^{\circ} \mathrm{C}$ and $45 \mathrm{sec}$ at $60^{\circ} \mathrm{C}$ ) with a MyiQ system (Bio-Rad, Laboratiories, Veenendaal, The Netherlands). Gene expression levels of LPL, peroxisome proliferator-activated receptor a (PPAR $\alpha$ ), PPARy coactivator 1a (PGC1 $\alpha$ ), acetyl-CoA carboxylase 2 (ACC2), muscle 


\section{CHAPTER 2}

carnitine palmitoyltransferase $1 \mathrm{~b}$ (mCPT1b), sterol regulatory element binding protein 1c (SREBP1c), SREBP2 and carbohydrate responsive element-binding protein (ChREBP) were expressed relative to the geometric mean of two internal reference genes, i.e. ribosomal protein L13a (RPL13a) and $\beta$-2-microglobulin.

\section{Calculations}

Insulin sensitivity was determined using the MINMOD Millennium program [26]. Net fluxes of metabolites (labeled and unlabeled) across the forearm were calculated by multiplying arterio-venous concentration differences by forearm plasma flow. Plasma flow was calculated by multiplying forearm blood flow with (1haematocrit/100). A positive flux indicates net uptake across forearm muscle, whereas a negative flux indicates net release. Fractional extraction of metabolites (\%) was calculated as the arterio-venous concentration difference divided by the arterial concentration. As a measure of efficiency of substrate removal from the circulation, substrate clearance across forearm muscle was calculated by multiplying fractional extraction with forearm plasma flow.

Fasting rate of appearance of FFA $\left(\mathrm{Ra}_{\mathrm{FFA}}\right)\left(\mu \mathrm{mol}{ }^{*} \mathrm{~kg}^{-1}{ }^{*} \mathrm{~min}^{-1}\right)$ was calculated using Steele's equation for steady state, and Steele's single-pool non-steady state equations adapted for use with stable isotopes in the postprandial state [29]. Labeled FFA and TAG concentrations were calculated as the product of TTR of [U$\left.{ }^{13} \mathrm{C}\right]$ - and $\left[{ }^{2} \mathrm{H}_{2}\right]$-palmitate and the concentration of palmitate in FFA and TAG. Fractional extraction of $\left[\mathrm{U}-{ }^{13} \mathrm{C}\right]$-palmitate derived from the hydrolysis of $\left[\mathrm{U}-{ }^{13} \mathrm{C}\right]-$ labeled TAG (i.e. percentage 'entrapment') across forearm muscle was calculated as described previously, with the assumption that a proportion of FA derived from TAG hydrolysis may not be taken up by skeletal muscle [18].

Fractional synthetic rates (FSR) of skeletal muscle TAG, DAG and PL were calculated by using skeletal muscle FFA as the precursor pool for lipid synthesis [30]. The increase in TTR of $\left[\mathrm{U}-{ }^{13} \mathrm{C}\right]$ from fasting to $4 \mathrm{~h}$ postprandially was divided by the enrichment of skeletal muscle FFA and expressed as percentage per hour $(\% / \mathrm{h})$. The degree of saturation of skeletal muscle TAG, DAG, PL and FFA (\%) was calculated by dividing the sum of saturated FA by the total amount of FA in a fraction. $\Delta^{9}$-desaturase activity was estimated as the proportion palmitoleic acid (C16:1n-7) to palmitic acid (C16:0), and as the proportion oleic acid (C18:1n-9) to stearic acid (C18:0). Total skeletal muscle TAG, DAG, FFA and PL contents were estimated as the sum of the particular FA content of the assessed fraction.

Postprandial area under the curve (AUC) and incremental AUC (iAUC) of metabolites and substrate fluxes were calculated using the trapezium rule. Besides 
the total ${ }_{(\mathrm{i})} \mathrm{AUC}$ (0-4h after meal ingestion), also the 'early' (0-2h) and 'mid' (2-4h) (i) $A \cup C$ were calculated to obtain more detailed information about the time course of postprandial responses.

\section{Statistical methods}

All statistical analyses were performed using SPSS 15.0 for Windows (SPSS Inc.) and were defined a priori. Data are presented as means \pm standard error of mean (SEM). Independent samples t-tests were used to test for differences between the insulin resistant and control group during fasting and the postprandial period ('total', 'early' and 'mid'). Repeated-measures ANOVA was used to test for changes in time between groups (group by time effect) during the postprandial period. Statistical significance was set at $p<0.05$.

\section{RESULTS}

By definition, insulin sensitivity was different between insulin resistant men and controls (1.28 \pm 0.12 versus $3.22 \pm 0.27 \mathrm{mU} / l^{-1 *} \mathrm{~min}^{-1} * 10^{-4}$ ) (Table 1). Groups were otherwise matched for age, BMI, fat mass, blood pressure and fasting total cholesterol, HDL-cholesterol and LDL-cholesterol concentrations.

Arterial metabolites, forearm blood flow and forearm muscle metabolism

Fasting arterial plasma glucose concentrations tended to be higher in the insulin resistant group compared with the control group $(p=0.09)$, whereas postprandial concentrations were similar between groups (Figure 1A). Arterial plasma insulin concentrations were comparable between groups in the fasting state, but the postprandial insulin response was higher in the insulin resistant group compared with control (iAUC/min: $33.4 \pm 4.1$ versus $23.9 \pm 2.2 \mathrm{mU} / \mathrm{l}, \mathrm{p}=0.05$ ) (Figure 1B). Fasting arterial plasma lactate concentrations were higher in insulin resistant men compared to control $(0.88 \pm 0.11$ versus $0.57 \pm 0.04 \mathrm{mmol} / \mathrm{l}, \mathrm{p}=0.01)$ and remained significantly higher throughout the entire postprandial period (AUC/min: $1.19 \pm 0.08$ versus $0.88 \pm 0.07 \mathrm{mmol} / \mathrm{l}, \quad \mathrm{p}=0.005$ ). Arterial plasma 3-hydroxybutyrate concentrations did not differ between groups at any time (data not shown).

Forearm blood flow and net glucose uptake and glycerol release across forearm muscle were similar between groups, both during fasting and after meal ingestion (Table 2). Also, no significant differences were observed in fasting and postprandial net release of lactate and net uptake 3-hydroxybutyrate across forearm muscle between groups (data not shown). 
Table 1. Subject characteristics

\begin{tabular}{lccc}
\hline & Insulin resistant & Control & p-value \\
\hline $\mathrm{n}$ & 15 & 15 & \\
Age $(\mathrm{y})$ & $58 \pm 2$ & $58 \pm 2$ & 0.983 \\
Body weight $(\mathrm{kg})$ & $99.5 \pm 1.9$ & $96.3 \pm 2.4$ & 0.304 \\
BMI $\left(\mathrm{kg} / \mathrm{m}^{2}\right)$ & $31.8 \pm 0.6$ & $30.6 \pm 0.7$ & 0.206 \\
Waist $(\mathrm{cm})$ & $110 \pm 2$ & $109 \pm 1$ & 0.650 \\
Waist-hip ratio & $1.05 \pm 0.01$ & $1.04 \pm 0.01$ & 0.794 \\
Fat mass $(\mathrm{kg})$ & $27.6 \pm 2.0$ & $25.2 \pm 1.0$ & 0.231 \\
Systolic blood pressure $(\mathrm{mmHg})$ & $135 \pm 4$ & $137 \pm 4$ & 0.687 \\
Diastolic blood pressure $(\mathrm{mmHg})$ & $85 \pm 3$ & $86 \pm 3$ & 0.795 \\
Insulin sensitivity $\left.\left(\mathrm{mU} / \mathrm{I}^{-1}\right)^{*} \mathrm{~min}^{-1 *} 10^{-4}\right)$ & $1.28 \pm 0.12$ & $3.22 \pm 0.27$ & $<0.001$ \\
Glucose $(\mathrm{mmol} / \mathrm{l})$ & $5.57 \pm 0.11$ & $5.33 \pm 0.09$ & 0.088 \\
Insulin $(\mathrm{mU} / \mathrm{l})$ & $15.6 \pm 1.7$ & $12.3 \pm 0.8$ & 0.111 \\
Free fatty acids $(\mu \mathrm{mol} / \mathrm{l})$ & $593 \pm 45$ & $504 \pm 26$ & 0.099 \\
Triacylglycerol $(\mathrm{mmol} / \mathrm{l})$ & $1.49 \pm 0.15$ & $1.32 \pm 0.18$ & 0.497 \\
Total cholesterol $(\mathrm{mmol} / \mathrm{l})$ & $5.17 \pm 0.19$ & $5.00 \pm 0.20$ & 0.550 \\
HDL-cholesterol $(\mathrm{mmol} / \mathrm{l})$ & $0.89 \pm 0.05$ & $0.97 \pm 0.06$ & 0.279 \\
LDL-cholesterol $(\mathrm{mmol} / \mathrm{l})$ & $3.32 \pm 0.24$ & $2.92 \pm 0.21$ & 0.213 \\
\hline
\end{tabular}

Values are mean \pm SEM. $p$-value for difference between groups, Student's t-test for unpaired samples.

Fat mass: $n=9$ (insulin resistant) and $n=14$ (control)

\section{Whole body and forearm muscle FFA metabolism}

Whole body FFA metabolism. Arterial FFA concentrations were slightly higher in the insulin resistant group than the control group during fasting and tended to remain higher after the high-fat mixed-meal (AUC/min: $410 \pm 22$ versus $356 \pm 19 \mu \mathrm{mol} / \mathrm{l}, \quad \mathrm{p}=0.07$ ) (Figure 2A). $\left[{ }^{2} \mathrm{H}_{2}\right]$-labeled palmitate was infused intravenously, mixed with the plasma FFA pool, and reached steady state concentrations during fasting measurements. After meal ingestion, $\left[{ }^{2} \mathrm{H}_{2}\right]$-palmitate concentrations in plasma FFA were suppressed in both groups. Also the $\mathrm{Ra}_{\mathrm{FFA}}$ decreased after meal ingestion in both groups, indicating suppression of whole body lipolysis, with no differences between groups (Figure 2B). $\left[{ }^{13} \mathrm{C}\right]$-labeled palmitate (resulting from spillover of FA derived from chylomicron-TAG hydrolysis) appeared in the plasma FFA pool from 60min after meal ingestion and concentrations increased throughout the postprandial period. There were no differences in arterial concentrations of $\left[{ }^{2} \mathrm{H}_{2}\right]-$ or $\left[{ }^{13} \mathrm{C}\right]$-labeled palmitate in FFA between groups at any time (data not shown). 

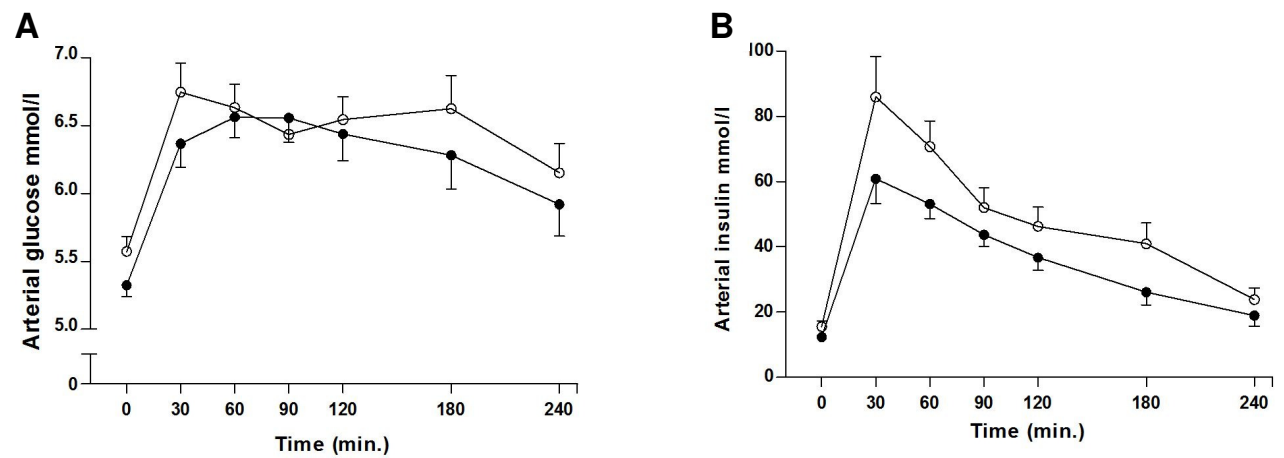

Figure 1. Arterial plasma glucose $(\mathbf{A})$ and insulin

(B) concentrations during fasting (t 0 ) and after consumption of a high-fat mixed-meal. Black circles; control group, white circles; insulin resistant group. Values are mean \pm SEM.

The TTR of $\left[{ }^{2} \mathrm{H}_{2}\right]$-palmitate in FFA was significantly higher in arterial vs. deep venous plasma at all time-points during the study day in both the insulin resistant and control group (respectively $p=0.01$ and $p<0.001$, source by time effect), indicating dilution of the $\left[{ }^{2} \mathrm{H}_{2}\right]$-tracer in the plasma FFA pool across forearm muscle (Figure 2C). On the other hand, the TTR of $\left[{ }^{13} \mathrm{C}\right]$-palmitate in FFA was not different in arterial vs. deep venous plasma at all time-points in both groups (respectively $p=0.98$ and $p=0.90$, source by time effect) (Figure 2D).

Forearm muscle FFA metabolism. Fasting and postprandial net FFA extraction across forearm muscle (arteriovenous difference multiplied by forearm plasma flow) were not different between groups. Furthermore, there was consistent net uptake of $\left[{ }^{2} \mathrm{H}_{2}\right]$-labeled palmitate across forearm muscle during the entire study period, without significant differences between groups (Table 2).

\section{Whole body and forearm muscle TAG metabolism}

Whole body TAG metabolism. Arterial plasma TAG concentrations were similar between groups during fasting and increased after meal ingestion, without significant differences between groups (Figure 3A). The $\left[{ }^{2} \mathrm{H}_{2}\right]$-palmitate tracer could be measured in plasma TAG from the first baseline sample onward, reflecting incorporation of the intravenously infused tracer into VLDL-TAG (Figure 3B). The $\left[{ }^{13} \mathrm{C}\right]$-palmitate tracer, given with the meal, appeared in plasma TAG from $60 \mathrm{~min}$ after meal ingestion, representing chylomicron-TAG in the circulation 


\section{ChAPTER 2}

(Figure 3B). Both labeled TAG fractions rose up to 4h postprandially, without significant differences between groups at any time.

A

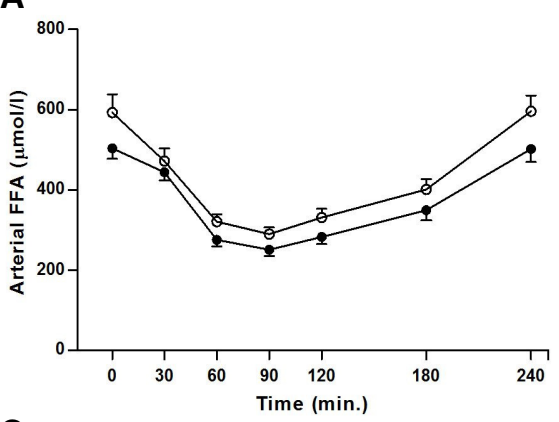

C

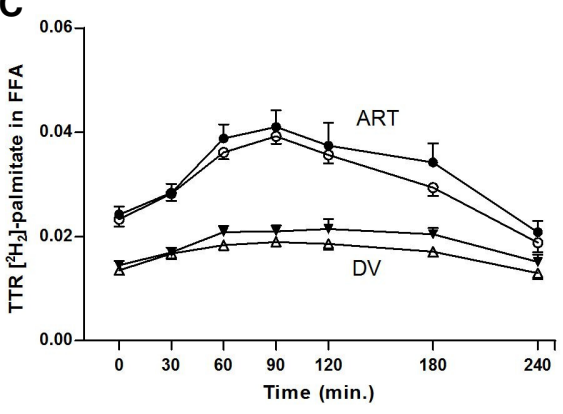

B

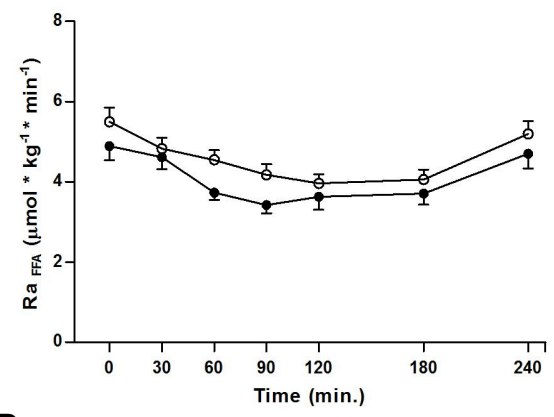

D

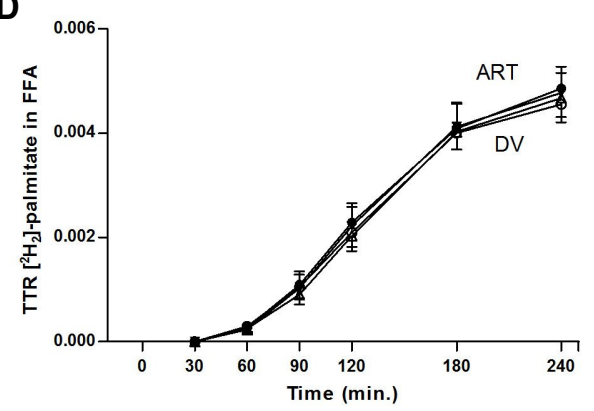

Figure 2. Arterial plasma free fatty acid (FFA) concentrations (A), rate of appearance of FFA (RaFFA) (B) and tracer/tracee ratio (TTR) of $\left[{ }^{2} \mathrm{H}_{2}\right]$-palmitate $(\mathbf{C})$ and $\left[{ }^{13} \mathrm{C}\right]$-palmitate in the plasma FFA fraction (D) during fasting (t 0 ) and after consumption of a high-fat mixed-meal. Black symbols; control group, white symbols; insulin resistant group. Panel C and D: circles; arterial plasma concentrations, triangles; forearm venous plasma concentrations. Values are mean $\pm \mathrm{SEM}$.

Forearm muscle TAG metabolism. Extraction of $\left[{ }^{2} \mathrm{H}_{2}\right]$-palmitate in TAG across forearm muscle was higher in the insulin resistant group than the control group in the early phase after meal ingestion $\left(A \cup C_{0-2 h}: p=0.05\right)$, indicating increased LPLmediated hydrolysis of VLDL-TAG at the capillary bed of forearm muscle in insulin resistant men (Table 2, Figure $\mathbf{3 C}$ ). Extraction of $\left[{ }^{13} \mathrm{C}\right]$-palmitate in TAG across forearm muscle could be measured from $60 \mathrm{~min}$ onward and was not different between groups, although values for extraction were higher in the mid-postprandial period (2-4h postprandially) in insulin resistant subjects (not significant) (Table 2, Figure 3D). Fractional extraction of $\left[{ }^{13} \mathrm{C}\right]$-palmitate in TAG across forearm muscle was consistently greater than the fractional extraction of $\left[{ }^{2} \mathrm{H}_{2}\right]$-palmitate in TAG throughout the whole postprandial period, without differences between groups 
Table 2. Fasting and postprandial lipid metabolism

\begin{tabular}{|c|c|c|c|}
\hline & & $\begin{array}{l}\text { Insulin resistant } \\
\qquad(\mathrm{n}=15)\end{array}$ & $\begin{array}{l}\text { Control } \\
(n=14)\end{array}$ \\
\hline \multirow[t]{2}{*}{ Forearm blood flow } & fasting $\left(\mathrm{ml} \cdot 100 \mathrm{ml}^{-1} \cdot \mathrm{min}^{-1}\right)$ & $2.12 \pm 0.15$ & $2.51 \pm 0.34$ \\
\hline & postprandial $(0-4 \mathrm{~h})$ & $2.24 \pm 0.15$ & $2.73 \pm 0.33$ \\
\hline \multicolumn{4}{|c|}{ Net flux across forearm muscle } \\
\hline \multirow[t]{3}{*}{ Glucose } & fasting $\left(\mu \mathrm{mol} * 100 \mathrm{ml}^{-1 *} \mathrm{~min}^{-1}\right)$ & $0.23 \pm 0.06$ & $0.21 \pm 0.10$ \\
\hline & early postprandial (0-2 h) & $0.77 \pm 0.09$ & $0.88 \pm 0.11$ \\
\hline & mid postprandial (2-4 h) & $0.62 \pm 0.11$ & $0.70 \pm 0.13$ \\
\hline \multirow[t]{3}{*}{ Glycerol } & fasting $\left(\mathrm{nmol} * 100 \mathrm{ml}^{-1} * \mathrm{~min}^{-1}\right)$ & $-27.8 \pm 10.1$ & $-23.1 \pm 8.3$ \\
\hline & early postprandial $(0-2 \mathrm{~h})$ & $-26.8 \pm 4.7$ & $-17.7 \pm 13.0$ \\
\hline & mid postprandial (2-4 h) & $-17.5 \pm 4.8$ & $-27.0 \pm 9.5$ \\
\hline \multirow[t]{3}{*}{$\begin{array}{l}\text { Free fatty acids } \\
\text { (FFA) }\end{array}$} & fasting $\left(\mathrm{nmol} * 100 \mathrm{ml}^{-1} * \mathrm{~min}^{-1}\right)$ & $-17.3 \pm 34.0$ & $-21.3 \pm 21.7$ \\
\hline & early postprandial $(0-2 \mathrm{~h})$ & $-48.5 \pm 21.0$ & $-42.2 \pm 10.5$ \\
\hline & mid postprandial $(2-4 \mathrm{~h})$ & $3.5 \pm 14.1$ & $19.0 \pm 10.7$ \\
\hline \multirow[t]{3}{*}[{}^{2}\mathrm{H}_{2}]{-palmitate FFA } & fasting $\left(\mathrm{nmol}^{*} 100 \mathrm{ml}^{-1 *} \mathrm{~min}^{-1}\right)$ & $1.60 \pm 0.18$ & $1.54 \pm 0.16$ \\
\hline & early postprandial (0-2 h) & $1.39 \pm 0.14$ & $1.34 \pm 0.11$ \\
\hline & mid postprandial (2-4 h) & $1.62 \pm 0.14$ & $1.77 \pm 0.20$ \\
\hline \multirow[t]{3}{*}{$\begin{array}{l}\text { Triacylglycerol } \\
\text { (TAG) }\end{array}$} & fasting $\left(\mathrm{nmol}^{*} 100 \mathrm{ml}^{-1}{ }^{*} \mathrm{~min}^{-1}\right)$ & $30.5 \pm 7.7$ & $-10.3 \pm 31.1$ \\
\hline & early postprandial $(0-2 \mathrm{~h})$ & $88.1 \pm 32.0$ & $35.1 \pm 13.3$ \\
\hline & mid postprandial (2-4 h) & $30.1 \pm 71.3$ & $-7.2 \pm 32.6$ \\
\hline \multirow[t]{3}{*}[{}^{2}\mathrm{H}_{2}]{-palmitate TAG } & fasting $\left(\mathrm{nmol} * 100 \mathrm{ml}^{-1} * \mathrm{~min}^{-1}\right)$ & $1.07 \pm 0.99$ & $0.08 \pm 0.22$ \\
\hline & early postprandial $(0-2 \mathrm{~h})$ & $1.08 \pm 0.72$ & $-0.64 \pm 0.36$ * \\
\hline & mid postprandial (2-4 h) & $1.42 \pm 1.38$ & $-0.30 \pm 2.08$ \\
\hline \multirow[t]{3}{*}{$\begin{array}{l}{\left[\mathrm{U}-{ }^{13} \mathrm{C}\right] \text {-palmitate }} \\
\text { TAG }\end{array}$} & fasting $\left(\mathrm{nmol}^{*} 100 \mathrm{ml}^{-1 *} \mathrm{~min}^{-1}\right)$ & NA & NA \\
\hline & early postprandial (0-2 h) & $0.45 \pm 0.07$ & $0.39 \pm 0.12$ \\
\hline & mid postprandial (2-4 h) & $1.05 \pm 0.24$ & $0.58 \pm 0.37$ \\
\hline
\end{tabular}

Values are mean \pm SEM. Postprandial data are expressed as AUC/min. A positive flux indicates net uptake across forearm muscle, whereas a negative flux indicates net release. $\mathrm{NA}$, not applicable. $\left[{ }^{2} \mathrm{H}_{2}\right]$-palmitate FFA: Insulin resistant $\mathrm{n}=14$, control $\mathrm{n}=12$. $\left[{ }^{2} \mathrm{H}_{2}\right]$-palmitate TAG: Insulin resistant $\mathrm{n}=15$, control $\mathrm{n}=13$.

${ }^{*} P=0.05$ for difference between groups, Student's t-test for unpaired samples.

(data not shown). The fractional extraction of $\left[{ }^{13} \mathrm{C}\right]$-palmitate derived from chylomicron-TAG hydrolysis ('entrapment') was $\sim 100 \%$ during the entire 


\section{CHAPTER 2}

postprandial period in both groups, indicating a highly efficient forearm muscle uptake of FA derived from LPL-mediated TAG hydrolysis. Specific entrapment of FA derived from VLDL-TAG hydrolysis could not be calculated because both circulating FFA and VLDL-TAG are labeled with $\left[{ }^{2} \mathrm{H}_{2}\right]$-palmitate.

A
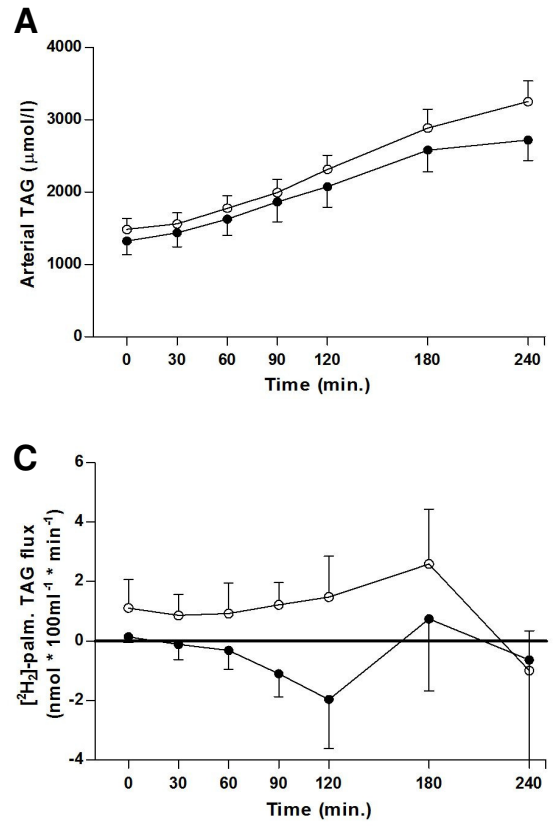
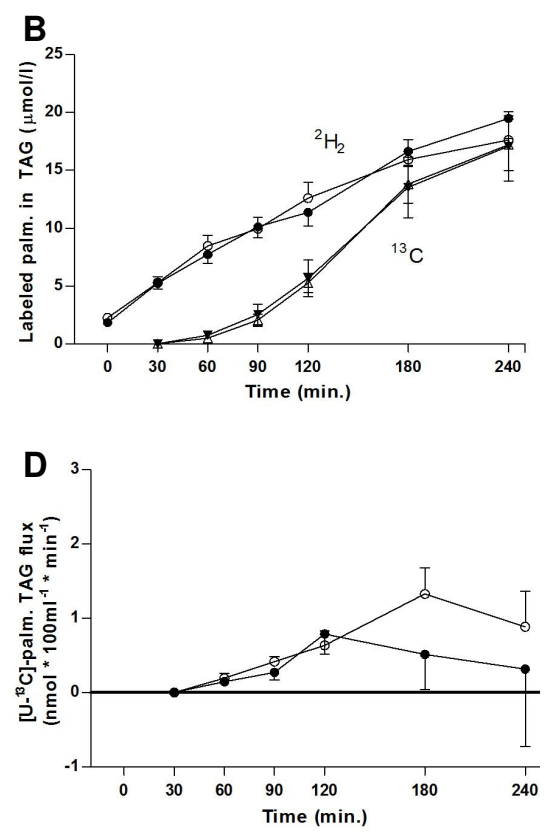

Figure 3. Arterial plasma triacylglycerol (TAG) concentrations (A), $\left[{ }^{2} \mathrm{H}_{2}\right]$ - and $\left[{ }^{13} \mathrm{C}\right]$-palmitate concentrations in the plasma TAG fraction (B) and the net flux of $\left[{ }^{2} \mathrm{H}_{2}\right]$-palmitate TAG (C) and $\left[{ }^{13} \mathrm{C}\right]$-palmitate TAG (D) across forearm muscle during fasting (to) and after consumption of a high-fat mixed-meal. A positive flux indicates net uptake across forearm muscle, whereas a negative flux indicates net release. Black symbols; control group, white symbols; insulin resistant group. Panel B: circles; $\left[{ }^{2} \mathrm{H}_{2}\right]$-palmitate TAG, triangles; $\left[{ }^{13} \mathrm{C}\right]$-palmitate TAG. Values are mean \pm SEM.

\section{$\underline{\text { Intramuscular lipid metabolism }}$}

Lipid content. Skeletal muscle TAG, DAG, FFA and PL content were comparable between groups at baseline, although muscle TAG tended to be slightly higher in insulin resistant men versus control $(213.0 \pm 40.7$ versus $136.6 \pm 20 \mu \mathrm{mol} / \mathrm{g}$ dry weight, $p=0.11$ ) (Table 3). Muscle PL content increased after the high-fat mixed meal in insulin resistant men compared the control group (change from fasting: $28.29 \pm 11.22$ versus $-4.30 \pm 9.8 \mu \mathrm{mol} / \mathrm{g}$ dry weight, $p=0.038)$. No differences 
between groups were observed for changes in muscle TAG, DAG and FFA content (data not shown).

Table 3. Skeletal muscle lipid content and saturation during fasting, and their fractional synthetic rates

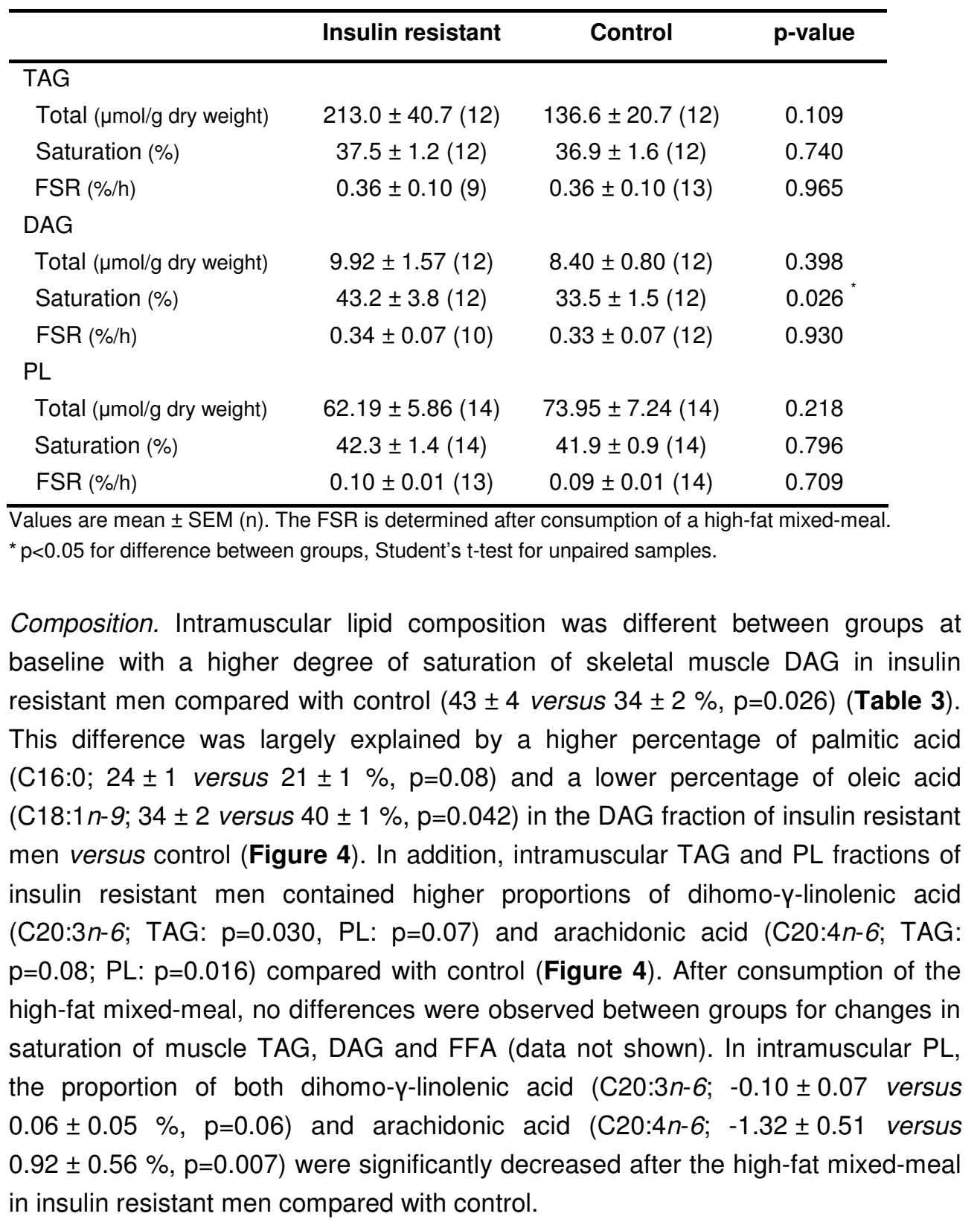




\section{ChAPTER 2}

Estimated $\Delta^{9}$-desaturase activity was not different between groups at baseline and did not significantly change after consumption of the high-fat mixed-meal.

Fractional synthetic rate. The FSR of skeletal muscle TAG, DAG and PL was comparable between groups (Table 3 ), indicating that a similar proportion of palmitate from the intramuscular FFA pool was directed towards storage in insulin resistant men and control after the high-fat mixed-meal.

\section{Skeletal muscle mRNA expression}

Postabsorptive skeletal muscle mRNA expression of LPL and genes involved in lipid oxidation and lipid synthesis were comparable between groups (Table 4). Postprandially, there was a significant down-regulation of mCPT1b $(p=0.048)$ as well as a tendency for up-regulation of LPL $(p=0.09)$ in the total group of subjects $(n=14$, data not shown). Between groups, however, there were no significant differences in postprandial gene expression (Table 4). Subject characteristics of the insulin resistant men $(n=6)$ and control $(n=8)$ in this sub-analysis were comparable to those presented in Table 1.

Table 4. Skeletal muscle mRNA normalised expression during fasting and after consumption of a high-fat mixed meal

\begin{tabular}{lcccc}
\hline & \multicolumn{2}{c}{ Insulin resistant $(\boldsymbol{n}=6)$} & \multicolumn{2}{c}{ Control $(\boldsymbol{n}=\mathbf{8})$} \\
& fasting & fold change & fasting & fold change \\
\hline LPL & $0.37 \pm 0.05$ & $2.2 \pm 1.2$ & $0.46 \pm 0.10$ & $3.3 \pm 1.1$ \\
PPARa & $1.49 \pm 0.18$ & $0.9 \pm 0.2$ & $1.46 \pm 0.24$ & $1.0 \pm 0.3$ \\
PGC1a & $0.38 \pm 0.07$ & $2.7 \pm 0.9$ & $0.48 \pm 0.09$ & $2.3 \pm 1.0$ \\
ACC2 & $2.01 \pm 0.43$ & $0.7 \pm 0.2$ & $1.71 \pm 0.32$ & $1.3 \pm 0.5$ \\
mCPT1b & $1.31 \pm 0.39$ & $0.6 \pm 0.1$ & $1.74 \pm 0.29$ & $1.0 \pm 0.4$ \\
SREBP1c & $0.90 \pm 0.22$ & $0.9 \pm 0.2$ & $0.82 \pm 0.15$ & $1.1 \pm 0.2$ \\
SREBP2 & $1.68 \pm 0.22$ & $0.8 \pm 0.2$ & $1.88 \pm 0.32$ & $1.0 \pm 0.3$ \\
ChREBP & $1.13 \pm 0.15$ & $0.7 \pm 0.2$ & $1.30 \pm 0.40$ & $1.1 \pm 0.4$ \\
\hline
\end{tabular}

Values are mean \pm SEM, expressed in arbitrary units. Fold change is calculated as (4h / $\mathrm{h}$ ). No significant differences between groups, Student's t-test for unpaired samples. 


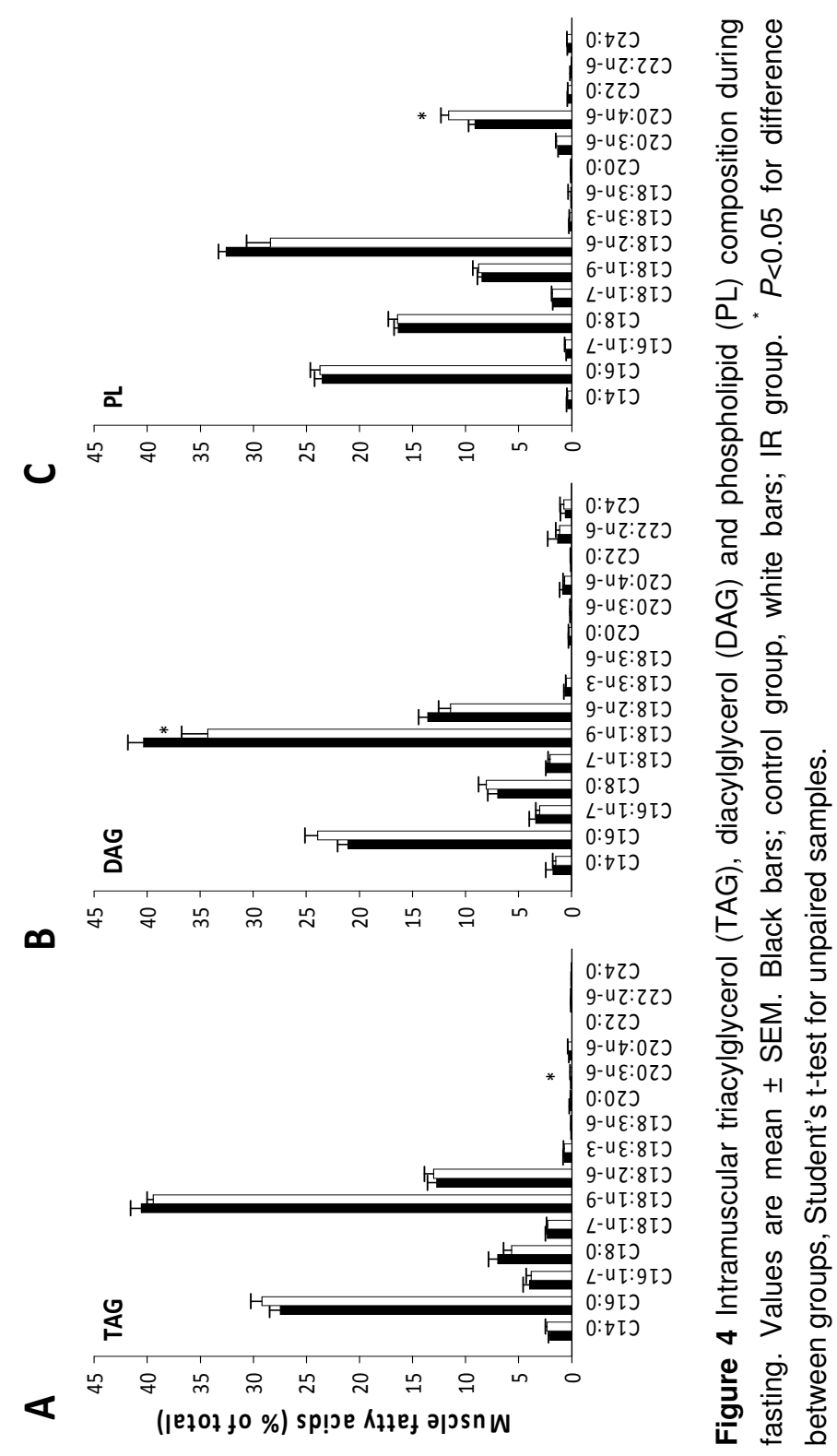




\section{Chapter 2}

\section{DISCUSSION}

In this study we examined fasting and postprandial skeletal muscle FA handling in insulin resistant men. By using a dual stable isotope technique we were able to differentiate between the contribution of circulating FFA, endogenous (VLDL)-TAG and dietary (chylomicron)-TAG to skeletal muscle FA metabolism, and observed a significant difference in the handling of VLDL-TAG between insulin resistant men and control. In insulin resistant men, a higher net extraction of VLDL-TAG across forearm muscle was observed during the first $2 \mathrm{~h}$ after meal ingestion, despite a similar supply of plasma TAG. Furthermore, intramuscular lipid composition was different between groups with a higher fasting percentage saturation of muscle DAG in insulin resistant men.

To our knowledge this is the first study showing differential quantitative handling of hepatically derived TAG by forearm muscle in insulin resistant men and the underlying mechanisms for this observation remain to be elucidated. Findings may extent to chylomicron-TAG as also the uptake of this particle tended to increase more in the insulin resistant group at the end of the postprandial period, although not statistically significant. However, measurements were not performed in the late postprandial phase (i.e. 4-6h postprandially), as it has been shown that dietary FA appear in the VLDL-TAG fraction from 2-3h after meal ingestion, making it difficult to completely separate chylomicron-TAG and VLDL-TAG in the late postprandial phase using the current dual stable isotope technique [16-18]. The importance of TAG metabolism in insulin resistance extends results from a previous study investigating FA metabolism using the same dual stable isotope methodology [14], although Bickerton et al. showed no differences in postprandial chylomicron-TAG extraction and VLDL-TAG extraction. In that study, insulin resistant men and controls were selected from a healthy population with overweight, whereas we studied the isolated effects of insulin sensitivity in subjects with the MetS. Further in vivo research in subjects with varying phenotypes is needed to obtain more insight in the importance of skeletal muscle FA metabolism in insulin resistance.

Inhibitory effects of insulin on skeletal muscle LPL activity may be impaired in the insulin resistant state, resulting in increased postprandial skeletal muscle TAG extraction. In this study skeletal muscle LPL mRNA was not differentially expressed after meal ingestion, but a role of LPL cannot be excluded since it has been shown that LPL activity is mainly regulated at posttranscriptional and posttranslational levels [31-33]. 
Apart from the observed differences in lipid uptake, also the partitioning of FA within skeletal muscle has previously been shown to be more directed towards storage than oxidation in the insulin resistant state [1]. An increased TAG fractional synthetic rate may protect the muscle from excess FFA concentrations and subsequent accumulation of lipid metabolites that may interfere with insulin signalling. In this study the FSR of intramuscular lipid fractions was not different between insulin resistant men and control, which is in line with findings from a recent study of intramuscular lipid synthesis in smokers and non-smokers with clear differences in insulin sensitivity [34]. Also, mRNA normalised expression levels of several key genes important in skeletal muscle FA uptake, mitochondrial FA transport, oxidation and synthesis were not significantly different between insulin resistant men and control. Our results indicate that a similar proportion of FA from the intramuscular FFA pool was directed towards storage in the different lipid fractions in insulin resistant men and control. Increased extraction of (VLDL)TAG across skeletal muscle combined with a similar intramuscular FSR may be a trigger for intramuscular lipid accumulation in the insulin resistant state.

Saturation of muscle DAG was significantly higher in insulin resistant men compared to control at baseline, mainly reflected by a higher proportion of palmitic acid (C16:0) and a lower proportion of oleic acid (C18:1n-9). This finding is in line with results from studies in human muscle cell lines and rodents showing that longchain SFA accumulate preferentially as DAG and are associated with insulin resistance, whereas unsaturated FA are more readily converted into TAG [12, 35, 36]. In another study, incubation of $\mathrm{C} 2 \mathrm{C} 12$ myotubes with palmitate was associated with increased DAG accumulation and reduced insulin action, whereas incubation with oleic acid had no effects [37]. The activity of $\Delta^{9}$-desaturase in muscle could play an important role in the partitioning of fatty acids and can be estimated by the ratio of $\mathrm{C} 18: 1 n-9$ to $\mathrm{C} 18: 0$. It has been suggested that increased $\Delta^{9}$-desaturase expression in human skeletal muscle is associated with obesity by stimulating FA storage in intramuscular TAG rather than FA oxidation [38]. On the other hand, increased $\Delta^{9}$-desaturase activity in the obese insulin resistant state may be protective for further insulin resistance by stimulating intramuscular TAG accumulation and subsequently reducing the accumulation of saturated FA in muscle DAG and ceramide [39,40]. In this study there were no differences in estimated $\Delta^{9}$-desaturase activity between insulin resistant men and control during fasting and after the high-fat mixed meal. It is important to mention that total DAG content as measured by others and us might not reflect the DAG component that 


\section{ChAPTER 2}

may interfere with insulin signalling and contribute to the development of insulin resistance [34, 37]. Therefore, future research should elucidate which specific DAG form may be related to skeletal muscle insulin resistance. Nevertheless, the present findings implicate a relationship between a higher saturation of intramuscular DAG and the presence of insulin resistance.

All subjects in our study were selected from a population of subjects with the MetS. However, insulin resistance was not a requirement for the definition of the MetS in this study and because of the range in insulin sensitivity it was possible to create two groups with a pronounced difference in insulin sensitivity. Mean values of insulin sensitivity in the insulin resistant group were slightly higher than values described in literature for patients with T2DM [41, 42], whereas mean values of insulin sensitivity in the control group were comparable with values reported for healthy subjects with normal glucose tolerance [41, 43]. Moreover, postprandial arterial insulin concentrations were higher in insulin resistant men versus control, whereas postprandial arterial glucose concentrations and glucose uptake across the forearm muscle were comparable between groups. These data indicate that men in the insulin resistant group were indeed more insulin resistant as compared with men in the control group, both at whole body and forearm muscle level. Since insulin resistance is normally related to increased body weight, an abdominal fat distribution and increased lipids, our subject selection may be artificial due to the fact that all subjects had the metabolic syndrome. On the other hand, from a mechanistic point of view this may represent a strength of the study showing the metabolic disturbances related to insulin sensitivity per se, independent of the other characteristics of the metabolic syndrome. We observed only small differences in skeletal muscle FA handling between groups which may be related to how subjects were selected. Nevertheless, these small differences in TAG extraction may be of relevance for skeletal muscle fat storage in the longer term. Therefore, we believe that the current results provide new and relevant insights in the relationship between skeletal muscle FA metabolism and insulin resistance, which have to be confirmed and investigated further in a larger number of subjects selected from an insulin resistant population and a healthy control population.

In conclusion, by combining this dual stable isotope technique with skeletal muscle lipid analyses, we were able to demonstrate that insulin resistance is associated with increased postprandial forearm muscle (hepatically-derived) TAG uptake and increased saturation of muscle DAG. Although there were only small differences between groups in skeletal muscle TAG extraction, in the longer term this may be 
one of the mechanisms contributing to intramuscular lipid accumulation, insulin resistance and the development of T2DM.

\section{ACKNOWLEDGEMENTS}

We gratefully thank all volunteers for their time and motivation, and J. Stegen, W. Sluijsmans, H. Aydeniz, R. Jacobs and A. Gijsen for their excellent analytical support.

Supplemental table Gene-specific forward and reverse primers for qPCR

\begin{tabular}{lll}
\hline Gene & Forward primer sequence (5'-3') & Reverse primer sequence (3'-5') \\
\hline B2M & GGACTTCGAGCAAGAGATGG & AGCACTGTGTTGGCGTACAG \\
RPL13a & CCTGGAGGAGAAGAGGAAGAGA & TTGAGGACCTCTGTGTATTTGTCAA \\
LPL & CATCTCTTGGGATACAGCCTTG & GGGCTTCTGCATACTCAAAGT \\
PPARa & AAAAGCCTAAGGAAACCGTTCTG & TATCGTCCGGGTGGTTGCT \\
PGC1a & CCAGGTCAAGATCAAGGTCTCCAG & TTCGGTGCGTGCGGTGTC \\
ACC2 & GCAAGAACGTGTGGGGTTACT & TCGTAGTGGGCTTGCTGAAAA \\
mCPT1b & CGGGACAGGGGTAAGTTCTG & TCTCGCAGGTCTGCTTTTGTG \\
SREBP1C & ACACAGCAACCAGAAACTCAAGC & GCCGACACCAGATCCTTCAGAG \\
SREBP2 & GCACCACTCCGCAGACGAG & TGGACTTGAGGCTCAAGGACTTG \\
ChREBP & GCCTCAAGGTGAGCAAAGCTA & GCTGGCACAGGTTAATGGC \\
\hline
\end{tabular}

RPL13a, ribosomal protein L13a; B2M, $\beta$-2-microglobulin; LPL, lipoprotein lipase; PPARa, peroxisome proliferator-activated receptor $\alpha$; PGC1 $\alpha$, PPARy coactivator 1 $\alpha$; ACC2, acetyl-CoA carboxylase; mCPT1, muscle carnitine palmitoyltransferase 1b; SREBP, sterol regulatory element binding protein; ChREBP, carbohydrate responsive element-binding protein. 


\section{REFERENCES}

1. Blaak EE: Basic disturbances in skeletal muscle fatty acid metabolism in obesity and type 2 diabetes mellitus. Proc Nutr Soc 2004, 63(2):323-330.

2. Savage DB, Petersen KF, Shulman GI: Disordered lipid metabolism and the pathogenesis of insulin resistance. Physiol Rev 2007, 87(2):507-520.

3. Petersen KF, Dufour S, Savage DB, Bilz S, Solomon G, Yonemitsu S, Cline GW, Befroy D, Zemany L, Kahn BB et al: The role of skeletal muscle insulin resistance in the pathogenesis of the metabolic syndrome. Proc Natl Acad Sci U S A 2007, 104(31):12587-12594.

4. Frayn KN: Adipose tissue as a buffer for daily lipid flux. Diabetologia 2002, 45(9):1201-1210.

5. Blaak EE, Wagenmakers AJ, Glatz JF, Wolffenbuttel BH, Kemerink GJ, Langenberg CJ, Heidendal GA, Saris WH: Plasma FFA utilization and fatty acidbinding protein content are diminished in type 2 diabetic muscle. Am J Physiol Endocrinol Metab 2000, 279(1):E146-154.

6. Mensink M, Blaak EE, van Baak MA, Wagenmakers AJ, Saris WH: Plasma free Fatty Acid uptake and oxidation are already diminished in subjects at high risk for developing type 2 diabetes. Diabetes 2001, 50(11):2548-2554.

7. Kelley DE, Goodpaster B, Wing RR, Simoneau JA: Skeletal muscle fatty acid metabolism in association with insulin resistance, obesity, and weight loss. Am J Physiol 1999, 277(6 Pt 1):E1130-1141.

8. Corcoran MP, Lamon-Fava S, Fielding RA: Skeletal muscle lipid deposition and insulin resistance: effect of dietary fatty acids and exercise. Am J Clin Nutr 2007, 85(3):662-677.

9. Schmitz-Peiffer C: Signalling aspects of insulin resistance in skeletal muscle: mechanisms induced by lipid oversupply. Cell Signal 2000, 12(9-10):583-594.

10. Schrauwen $P$, Hesselink MK: Oxidative capacity, lipotoxicity, and mitochondrial damage in type 2 diabetes. Diabetes 2004, 53(6):1412-1417.

11. Roden $\mathrm{M}$ : How free fatty acids inhibit glucose utilization in human skeletal muscle. News Physiol Sci 2004, 19:92-96.

12. Montell E, Turini M, Marotta M, Roberts M, Noe V, Ciudad CJ, Mace K, GomezFoix AM: DAG accumulation from saturated fatty acids desensitizes insulin stimulation of glucose uptake in muscle cells. Am J Physiol Endocrinol Metab 2001, 280(2):E229-237.

13. Coppack SW, Evans RD, Fisher RM, Frayn KN, Gibbons GF, Humphreys SM, Kirk ML, Potts JL, Hockaday TD: Adipose tissue metabolism in obesity: lipase action in vivo before and after a mixed meal. Metabolism 1992, 41(3):264-272.

14. Bickerton AS, Roberts R, Fielding BA, Tornqvist H, Blaak EE, Wagenmakers AJ, Gilbert M, Humphreys SM, Karpe F, Frayn KN: Adipose tissue fatty acid metabolism in insulin-resistant men. Diabetologia 2008, 51(8):1466-1474.

15. Riemens SC, Sluiter WJ, Dullaart RP: Enhanced escape of non-esterified fatty acids from tissue uptake: its role in impaired insulin-induced lowering of total rate of appearance in obesity and Type II diabetes mellitus. Diabetologia 2000, 43(4):416-426.

16. Heath RB, Karpe F, Milne RW, Burdge GC, Wootton SA, Frayn KN: Selective partitioning of dietary fatty acids into the VLDL TG pool in the early postprandial period. J Lipid Res 2003, 44(11):2065-2072.

17. Heath RB, Karpe F, Milne RW, Burdge GC, Wootton S, Frayn KN: Dietary fatty acids make a rapid and substantial contribution to VLDL-triacylglycerol in the fed state. Am J Physiol Endocrinol Metab 2007, 292(3):E732-739. 

Gilbert M, Karpe F, Frayn KN: Preferential uptake of dietary fatty acids in adipose tissue and muscle in the postprandial period. Diabetes 2007, 56(1):168-176.

19. Cohn JS, Johnson EJ, Millar JS, Cohn SD, Milne RW, Marcel YL, Russell RM, Schaefer EJ: Contribution of apoB-48 and apoB-100 triglyceride-rich lipoproteins (TRL) to postprandial increases in the plasma concentration of TRL triglycerides and retinyl esters. J Lipid Res 1993, 34(12):2033-2040.

20. Evans K, Burdge GC, Wootton SA, Clark ML, Frayn KN: Regulation of dietary fatty acid entrapment in subcutaneous adipose tissue and skeletal muscle. Diabetes 2002, 51(9):2684-2690.

21. Miles JM, Park YS, Walewicz D, Russell-Lopez C, Windsor S, Isley WL, Coppack SW, Harris WS: Systemic and forearm triglyceride metabolism: fate of lipoprotein lipase-generated glycerol and free fatty acids. Diabetes 2004, 53(3):521-527.

22. Teusink B, Voshol PJ, Dahlmans VE, Rensen PC, Pijl H, Romijn JA, Havekes LM: Contribution of fatty acids released from lipolysis of plasma triglycerides to total plasma fatty acid flux and tissue-specific fatty acid uptake. Diabetes 2003, 52(3):614-620.

23. Karpe F, Bickerton AS, Hodson L, Fielding BA, Tan GD, Frayn KN: Removal of triacylglycerols from chylomicrons and VLDL by capillary beds: the basis of lipoprotein remnant formation. Biochem Soc Trans 2007, 35(Pt 3):472-476.

24. Third Report of the National Cholesterol Education Program (NCEP) Expert Panel on Detection, Evaluation, and Treatment of High Blood Cholesterol in Adults (Adult Treatment Panel III) final report. Circulation 2002, 106(25):31433421.

25. Finegood DT, Hramiak IM, Dupre J: A modified protocol for estimation of insulin sensitivity with the minimal model of glucose kinetics in patients with insulin-dependent diabetes. J Clin Endocrinol Metab 1990, 70(6):1538-1549.

26. Boston RC, Stefanovski D, Moate PJ, Sumner AE, Watanabe RM, Bergman RN: MINMOD Millennium: a computer program to calculate glucose effectiveness and insulin sensitivity from the frequently sampled intravenous glucose tolerance test. Diabetes Technol Ther 2003, 5(6):1003-1015.

27. Goossens GH, Blaak EE, Schiffers PM, Saris WH, van Baak MA: Effect of shortterm ACE inhibitor treatment on peripheral insulin sensitivity in obese insulin-resistant subjects. Diabetologia 2006, 49(12):3009-3016.

28. Bergstrom J, Hermansen L, Hultman E, Saltin B: Diet, muscle glycogen and physical performance. Acta Physiol Scand 1967, 71(2):140-150.

29. Wolfe RR: Radioactive and stable isotope tracers in biomedicine: principles and practice of kinetic analysis. New York, USA: Wiley-Liss; 1992.

30. Guo Z, Jensen MD: Intramuscular fatty acid metabolism evaluated with stable isotopic tracers. J Appl Physiol 1998, 84(5):1674-1679.

31. Semenkovich CF, Wims M, Noe L, Etienne J, Chan L: Insulin regulation of lipoprotein lipase activity in 3T3-L1 adipocytes is mediated at posttranscriptional and posttranslational levels. J Biol Chem 1989, 264(15):9030-9038.

32. Doolittle MH, Ben-Zeev O, Elovson J, Martin D, Kirchgessner TG: The response of lipoprotein lipase to feeding and fasting. Evidence for posttranslational regulation. J Biol Chem 1990, 265(8):4570-4577.

33. Wang $\mathrm{H}$, Eckel $\mathrm{RH}$ : Lipoprotein lipase: from gene to obesity. Am J Physiol Endocrinol Metab 2009, 297(2):E271-288. 
34. Bergman BC, Perreault L, Hunerdosse DM, Koehler MC, Samek AM, Eckel RH: Intramuscular lipid metabolism in the insulin resistance of smoking. Diabetes 2009, 58(10):2220-2227.

35. Lee JS, Pinnamaneni SK, Eo SJ, Cho IH, Pyo JH, Kim CK, Sinclair AJ, Febbraio MA, Watt MJ: Saturated, but not $n-6$ polyunsaturated, fatty acids induce insulin resistance: role of intramuscular accumulation of lipid metabolites. $J$ Appl Physiol 2006, 100(5):1467-1474.

36. Gaster $M$, Rustan AC, Beck-Nielsen $H$ : Differential utilization of saturated palmitate and unsaturated oleate: evidence from cultured myotubes. Diabetes 2005, 54(3):648-656.

37. Chavez JA, Summers SA: Characterizing the effects of saturated fatty acids on insulin signaling and ceramide and diacylglycerol accumulation in 3T3-L1 adipocytes and C2C12 myotubes. Arch Biochem Biophys 2003, 419(2):101-109.

38. Hulver MW, Berggren JR, Carper MJ, Miyazaki M, Ntambi JM, Hoffman EP, Thyfault JP, Stevens R, Dohm GL, Houmard JA et al: Elevated stearoyl-CoA desaturase-1 expression in skeletal muscle contributes to abnormal fatty acid partitioning in obese humans. Cell Metab 2005, 2(4):251-261.

39. Pinnamaneni SK, Southgate RJ, Febbraio MA, Watt MJ: Stearoyl CoA desaturase 1 is elevated in obesity but protects against fatty acid-induced skeletal muscle insulin resistance in vitro. Diabetologia 2006, 49(12):3027-3037.

40. Peter A, Weigert C, Staiger H, Machicao F, Schick F, Machann J, Stefan N, Thamer C, Haring HU, Schleicher E: Individual stearoyl-coa desaturase 1 expression modulates endoplasmic reticulum stress and inflammation in human myotubes and is associated with skeletal muscle lipid storage and insulin sensitivity in vivo. Diabetes 2009, 58(8):1757-1765.

41. Avignon A, Boegner C, Mariano-Goulart D, Colette C, Monnier L: Assessment of insulin sensitivity from plasma insulin and glucose in the fasting or post oral glucose-load state. Int J Obes Relat Metab Disord 1999, 23(5):512-517.

42. Saad MF, Anderson RL, Laws A, Watanabe RM, Kades WW, Chen YD, Sands RE Pei D, Savage PJ, Bergman RN: A comparison between the minimal model and the glucose clamp in the assessment of insulin sensitivity across the spectrum of glucose tolerance. Insulin Resistance Atherosclerosis Study. Diabetes 1994, 43(9):1114-1121.

43. Erichsen L, Agbaje OF, Luzio SD, Owens DR, Hovorka R: Population and individual minimal modeling of the frequently sampled insulin-modified intravenous glucose tolerance test. Metabolism 2004, 53(10):1349-1354. 


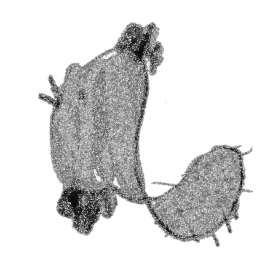

CHAPTER 3

Transcriptional metabolic inflexibility

in skeletal muscle among individuals

with increasing insulin resistance

Anneke Jans, Lauren M. Sparks, Anneke M.J. van Hees, Ingrid M.F. Gjelstad, Audrey C. Tierney, Ulf Risérus, Christian A. Drevon, Helen M. Roche, Patrick Schrauwen and Ellen E. Blaak

Obesity (Silver Spring). 2011 [Accepted-in press] 


\section{ChAPTER 3}

\section{ABStRACT}

Background: Disturbances in skeletal muscle lipid metabolism may play an important role in development of insulin resistance.

Aim: The aim was to investigate transcriptional control of skeletal muscle fatty acid (FA) metabolism in individuals with the metabolic syndrome (MetS) with varying degrees of insulin sensitivity.

Methods: 122 individuals with MetS (NCEP-ATP III criteria) at age 35-70y, BMI 27$38 \mathrm{~kg} / \mathrm{m}^{2}$ were studied (subgroup EU-LIPGENE study). Individuals were divided into quartiles of insulin sensitivity measured during a frequently sampled insulin modified intravenous glucose tolerance test. Skeletal muscle normalized mRNA expression levels of genes important in skeletal muscle FA handling were analyzed with qRT-PCR.

Results: The expression of SREBP1c, ACC2, DGAT and NRF was higher in the lowest 2 quartiles of insulin sensitivity $\left(<50^{\text {th }}\right)$ compared with the highest 2 quartiles of insulin sensitivity $\left(>50^{\text {th }}\right)$. Interestingly, PGC1 $\alpha$, PPAR $\alpha$ and $\mathrm{mCPT} 1$, important for oxidative metabolism, showed a complex mRNA expression profile; levels were lower in both the most 'insulin sensitive' as well as the most 'insulin resistant' individuals. LPL mRNA was reduced in the lowest quartile of insulin sensitivity. Enhanced gene expression of SREBP1C and ACC2 in the insulin resistant state suggests a tendency towards FA storage rather than oxidation.

Conclusion: From the lower expression of PGC1a, PPAR $\alpha$ and mCPT1 in both the most 'insulin sensitive' as well as the most insulin resistant individuals, it may be speculated that 'insulin sensitive' subjects do not need to upregulate these genes to have a normal FA oxidation, whereas the most 'insulin resistant' individuals are inflexible in upregulating these genes. 


\section{INTRODUCTION}

Disturbances in skeletal muscle lipid metabolism may play an important role in the development of insulin resistance and type 2 diabetes (T2DM) [1]. Insulin resistance is often accompanied by increased fat mass and disturbed adipose tissue function promoting increased supply of triacylglycerol (TAG) and fatty acids (FA) to non-adipose tissues such as skeletal muscle and liver (lipid overflow) [2]. The uptake of FA in skeletal muscle may be reduced in subjects with impaired glucose tolerance (IGT) [3] and in T2DM individuals as compared with normal glucose tolerant individuals, during fasting and $\beta$-adrenergic stimulation [4-6]. Moreover, skeletal muscles of insulin resistant individuals are characterized by a reduced FA oxidation during fasting conditions, $\beta$-adrenergic stimulation [5] and exercise [7] and by an 'inflexibility' to switch between oxidation of FA and glucose in the transition from the post-absorptive to postprandial state [8]. Recently, it was also suggested that skeletal muscle lipolysis is reduced in obese insulin resistant individuals in the fasted state [9]. Thus, lipid overflow, together with intrinsic disturbances in skeletal muscle FA metabolism, may promote enhanced lipid storage in skeletal muscle. Lipid accumulation, and in particular accumulation of lipid intermediates, may lead to insulin resistance [10]. The underlying mechanisms for the impaired skeletal muscle FA metabolism in insulin resistance are unclear. Firstly, altered expression levels of genes involved in FA transport across the skeletal muscle cell membrane have been reported in insulin resistant muscle [11]. The transport of FA-CoA across the mitochondrial membranes is controlled by the carnitine shuttle [12]. It had been suggested that a decreased expression of muscle carnitine palmitoyl transferase $1 \mathrm{~b}$ (mCPT1), or a more pronounced inhibition of its activity by malonyl-CoA, could lead to decreased mitochondrial uptake and oxidation of FA [13]. Secondly, mitochondrial dysfunction has been proposed as one of the underlying causes of insulin resistance. Peroxisome proliferatoractivated receptor (PPAR)y coactivator $1 \alpha(P G C 1 \alpha)$ is involved in mitochondrial biogenesis by supporting the transcriptional activity of nuclear respiration factor 1 (NRF1), thereby regulating transcription of genes involved in oxidative metabolism [14]. Reduced expression of PGC1 $\alpha$ has been implicated in the development of muscular insulin resistance and T2DM [15-17]. The expression of genes responsible for oxidative phosphorylation (OXPHOS) is coordinately downregulated in skeletal muscle of T2DM individuals [16-18]. Moreover a marked reduction in mitochondrial oxidative and phosphorylation activities, together with intramyocellular fat accumulation, were found in skeletal muscle of insulin resistant 


\section{CHAPTER 3}

subjects $[16,17]$. PGC1 $\alpha$ co-activates PPAR $\alpha$; which then induces transcription of genes associated with lipid transport, $\beta$-oxidation, glucose sparing and uncoupling proteins $[18,19]$. Finally, disturbances in TAG turnover could contribute to insulin resistance by the accumulation of diacylglycerol (DAG). TAG is formed by the action of DAG acyltransferase (DGAT) and overexpression of DGAT protects against fat-induced insulin resistance [20]. Hydrolysis of TAG and DAG occurs by the activity of adipose tissue triglyceride (ATGL) and hormone sensitive lipase (HSL) [9] and reduced expression and phosphorylation of muscle HSL has been reported in obese subjects [21]. The aim of the current study was to investigate the transcriptional regulation of genes involved in FA metabolism among subjects with the metabolic syndrome. Several relatively small previous studies addressed similar issues but the results are inconsistent. The size of our study in combination with a detailed phenotype and a wide range of insulin sensitivity provide a unique possibility to study the impact of degree of insulin resistance, independent of body weight and BMI. This will certainly provide novel insights in the transcriptional regulation of FA uptake, mitochondrial transport, mitochondrial oxidation, lipolysis and lipogenesis in relation to insulin sensitivity.

\section{METHODS}

\section{Ethics Statement}

All subjects were informed about the nature of the study and written informed consent was attained before study participation. The study protocol was approved by the local research ethics committees at Maastricht University, at University college of Dublin, at University of Oslo and at Uppsala University.

The current work was conducted as part of an EU Framework 6 Integrated Project LIPGENE. The LIPGENE human dietary intervention study was a randomized, controlled trial in individuals with the MetS, approved by local ethics committees at each of the 8 intervention centres, conforming to the Helsinki Declaration of 1975 as revised in 1983. In this sub-study, 122 individuals were included from 4 centres (Uppsala, Dublin, Oslo and Maastricht) at the age $35-70 \mathrm{y}$ and BMl $27-38 \mathrm{~kg} / \mathrm{m}^{2}$. The definition of the MetS was based on the NCEP ATP III report [22]. Exclusion criteria were weight change $>3 \mathrm{~kg}$ within 3 months prior to the study, T2DM or other endocrine disorders, chronic inflammatory conditions, kidney or liver dysfunction, use of hypolipidemic or anti-inflammatory medication, use of aspirin $>1$ per week, use of FA supplements or high doses of antioxidant vitamins, consumption of $>2$ portions of oily fish per week, highly trained or endurance athletes, and alcohol 
abuse. The group of 122 individuals was divided into quartiles based on insulin sensitivity as measured during a frequently sampled insulin modified intravenous glucose tolerance test (IVGTT).

\section{Experimental design}

Individuals completed anthropometric measurements, donated fasting blood samples and completed an IVGTT. On a separate day, after overnight fast, a skeletal muscle biopsy was taken from $m$. vastus lateralis under local anesthesia applying the Bergström method with suction [23]. Biopsies were cleaned from visible fat and blood, immediately frozen in liquid nitrogen or RNAlater, and stored at $-80^{\circ} \mathrm{C}$ until analysis.

\section{Skeletal muscle mRNA and DNA isolation}

RNA was isolated from approximately $25 \mathrm{mg}$ of snap frozen muscle tissue. The tissues were homogenized in $1 \mathrm{ml}$ Trizol for RNA stabilization and subsequent RNA isolation according to a standardized protocol described by manufacturer. RNA was then purified using the RNeasy mini kit (Qiagen Benelux B.V., Venlo, the Netherlands) followed by dissolving RNA in RNase and DNase free water. RNA was quantified and checked for purity on the NanoDrop 1000 (NanoDrop Technologies, Wilmington, DE, USA), and considered suitable for further processing at ratios between $260 / 280$ and $260 / 230$ of $>1.7$. RNA integrity was evaluated using the BioAnalyzer (Agilent, Palo Alto CA, USA) and considered to be intact with a RNA integrity number $>7.0$. Total DNA was isolated from $5 \mathrm{mg}$ of each muscle section using QIAamp DNA Micro Kit (Qiagen).

\section{Real-time $q R T$-PCR for RNA}

Both SYBR Green and Taqman were used for quantification of mRNA expression levels. All samples were analyzed in duplicates. For the expression of the genes in the upper half of Table 1, isolated RNA was reversely transcribed using the iScript cDNA synthesis Kit. The qPCR reactions were performed in a volume of $25 \mu \mathrm{l}$ containing $12.5 \mathrm{ng}$ cDNA, $1 \times$ IQ SYBR Green Supermix and 400nM of gene-specific forward and reverse primers (Table 1). cDNA was amplified using a two-step program ( 40 cycles of $10 \mathrm{sec}$ at $95^{\circ} \mathrm{C}$ and $45 \mathrm{sec}$ at $60^{\circ} \mathrm{C}$ ) with a MyiQ system (BioRad Laboratories, Veenendaal, the Netherlands). Gene expression levels were expressed relative to geometric mean of two internal reference genes, i.e. ribosomal protein L13a (RPL13a) and $\beta$-2-microglobulin. RPL13a and $\beta$-2microglobulin genes were used as references genes because they were identified 


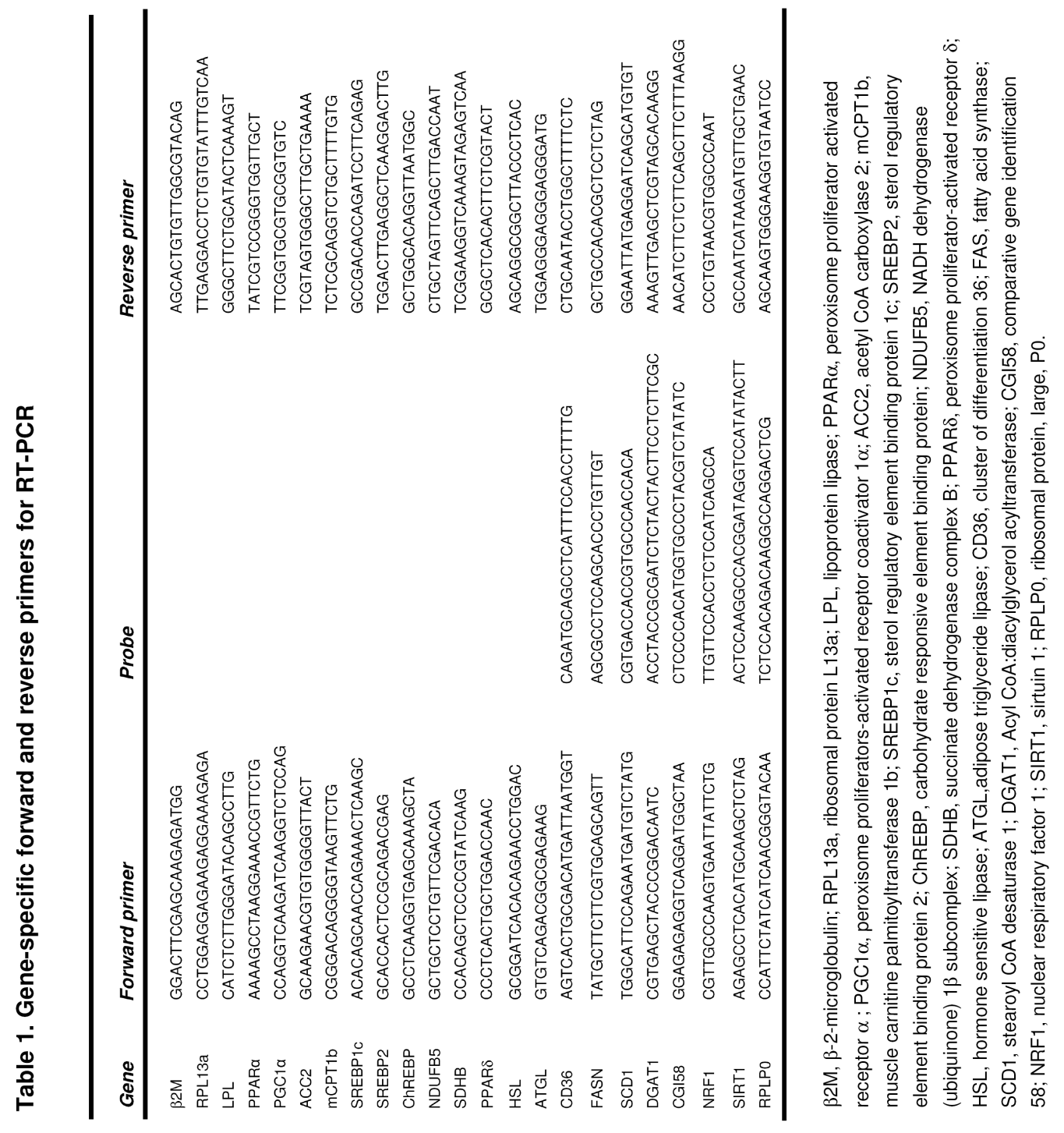


as most stably expressed reference genes as established by Genorm [24]. For expression of genes in the lower half of Table 1, all primers and probes were designed using Primer Express version 2.1 (Applied Biosystems, Roche, Branchburg, NJ). qRT-PCR reactions [25] were performed as one-step reactions in ABI PRISM 7900 (Applied Biosystems, Branchburg, NJ) using the following conditions: one cycle of $48^{\circ} \mathrm{C}$ for $3 \mathrm{~min}$, then $95^{\circ} \mathrm{C}$ for $10 \mathrm{~min}$, followed by 40 cycles at $95^{\circ} \mathrm{C}$ for $15 \mathrm{sec}$ and $60^{\circ} \mathrm{C}$ for $1 \mathrm{~min}$. For all assays performed using Taqman primers and probe, the ribosomal phosphoprotein large P0 gene (RPLP0) was used as internal control. All data on mRNA were normalized by dividing the target gene by the internal control. The internal control gene was tested for interindividual variability with a coefficient of variance to ensure precision in the measurements.

\section{Mitochondrial DNA content}

Quantification of mitochondrial content was performed as previously described using mtDNA copy number [26]. The sequences for the primer/probe sets used in Taqman analysis of mtDNA content for NADH dehydrogenase subunit 1 (mitochondrial genome (ND1) and of nuclear DNA for lipoprotein lipase (LPL) were designed using Primer express version 2.1 (Applied Biosystems-Roche, Branchburg, $\mathrm{NJ}$ ) and can be e-mailed on request.

\section{Biochemical analyses}

Blood for lipid analyses was collected in potassium EDTA vacutainer tubes. Glucose samples were collected in fluoride oxalate vacutainers, and insulin samples in serum tubes. All plasma samples were centrifuged immediately (10min, $4^{\circ} \mathrm{C}, 1500 \mathrm{~g}$ ), whereas serum samples were allowed to clot for $30 \mathrm{~min}$ at room temperature before centrifugation. Samples were then aliquoted and stored $\left(-80^{\circ} \mathrm{C}\right)$ until further analysis. Serum insulin concentrations were determined by solid phase, two-side fluoroimmunometric assays (AutoDELFIA Insulin kit, Wallac Oy, Turku, Finland) using a 1235 AutoDELFIA automatic immunoassay system. Plasma TAG, glucose, and HDL-cholesterol were determined with an ILab 600 clinical chemical analyzer (Instrumentation Laboratory, Warrington, UK) using enzymatic colorimetric kits. HDL-cholesterol was isolated using a HDL-cholesterol kit (Instrument Laboratory, Warrington, UK). 


\section{ChAPTER 3}

Calculations

Insulin sensitivity was determined using MINMOD Millennium program (version 6.02, Richard Bergman) [27]. The homeostasis model assessment of IR (HOMA $\left.\mathrm{IR}_{\mathrm{R}}\right)$ was calculated from fasting glucose $(\mathrm{mmol} / \mathrm{l})$ multiplied by fasting insulin $(\mathrm{mU} / \mathrm{l})$ concentration, divided by 22.5 [28].

\section{Statistical analyses}

Statistical analyses were performed using SPSS 18.0 for Mac (SPSS Inc.). All data are presented as means \pm standard error of the mean (SEM). Furthermore, all variables were checked for normal distribution and non-normally distributed data were log-transformed to satisfy conditions of normality. At first, normalized gene expression levels were compared between quartiles of insulin sensitivity by oneway ANOVA. Significant major effects were investigated using LSD post-hoc tests. In case of significance adjustments were made for gender (full-factorial), body weight and waist girth (continuous variables) in an univariate analysis. To address correlations between the genes, Pearson correlation analyses were performed. Statistical significance was set at $p<0.05$.

\section{RESULTS}

\section{Subject characteristics}

All the individuals had the MetS and by definition, insulin sensitivity was different between quartiles (Table 2). Groups were similar in age, BMI, blood pressure and fasting plasma glucose concentrations. Body weight, waist girth and plasma HDLcholesterol concentrations were significantly different between the lowest quartile and the other quartiles (Table 2). There was an unequal distribution of women and men in the quartiles, therefore all presented data are corrected for gender.

FA transport, mitochondrial function, oxidative phosphorylation and mtDNA copy number

We monitored several genes involved in FA transport, mitochondrial biogenesis and oxidative metabolism. LPL mRNA expression was significantly different among insulin sensitivity groups $(p=0.002)$ (Figure 1A), with lowest expression in the most insulin resistant group. There were no differences in CD36 and SIRT1 mRNA expression across the quartiles (Figure 1B and C). NRF1 mRNA levels were slightly higher in the IR state $(p=0.012$, Figure 1D) with the two lower insulin sensitivity groups $\left(<25^{\text {th }}\right.$ and $<50^{\text {th }}$ quartile) having higher levels than the highest groups ( $>50^{\text {th }}$ and $>75^{\text {th }}$ quartile). One of the most important transcription factors for 
A
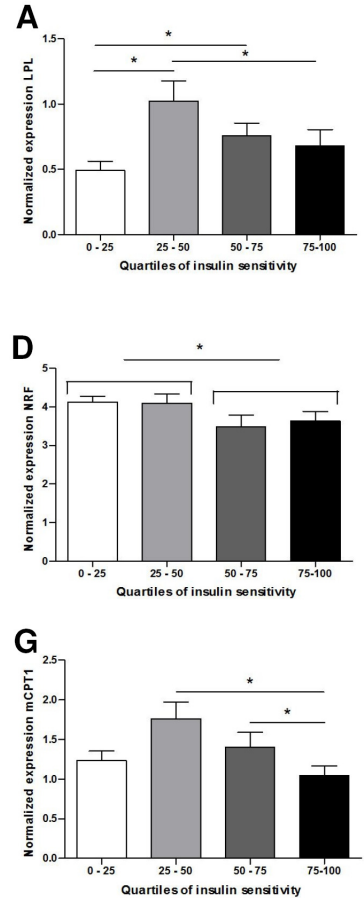

$\mathbf{J}$

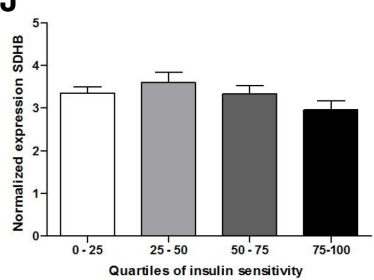

B

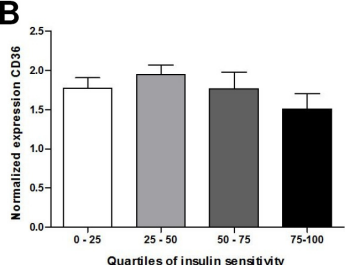

E

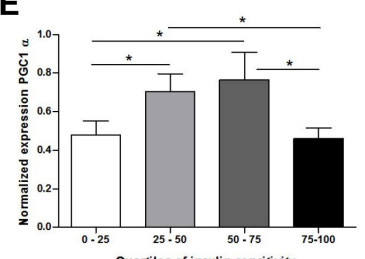

H

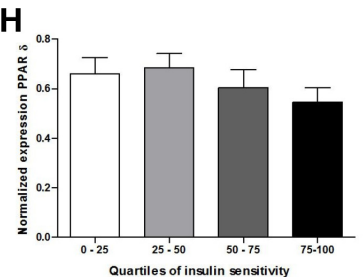

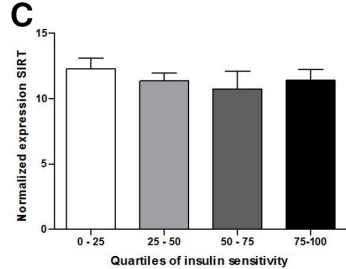
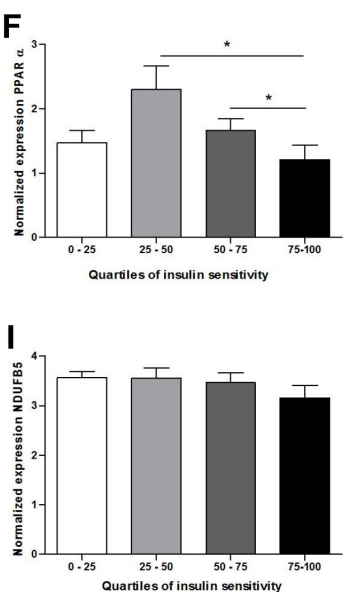

Figure 1. Basal normalized mRNA expression levels of genes important in transcriptional regulation of mitochondrial function, oxidative phosphorylation, and fatty acid transport in the four quartiles of insulin sensitivity. (A) LPL, (B) CD36, (C) SIRT, (D) NRF, (E) PGC1a, (F) PPARa, (G) mCPT1b, (H) PPARס, (I) NDUFB5, and (J) SDHB. The overall difference between the quartiles for $L P L$ was $p=0.002$, for NRF $p=0.012$ (median), for PGC1 $\alpha p=0.05$, for PPAR $a=0.002$, for $m C P T 1 b p=0.005$. Significant post hoc differences between the quartiles separately are indicated with asterisk. ${ }^{*} p<0.05$.

ACC2, acetyl-CoA carboxylase 2; CD36, cluster of differentiation 36; LPL, lipoprotein lipase; mCPT1b, muscle carnitine palmitoyltransferase 1b; NDUFB5, NADH dehydrogenase (ubiquinone) $1 \beta$ subcomplex; NRF1, nuclear respiratory factor 1; PGC1 $\alpha$, peroxisome proliferators-activated receptor coactivator 1a; PPARa, peroxisome proliferator-activated receptor $\alpha$; PPARō, peroxisome proliferatoractivated receptor $\overline{0}$; RPLP0, ribosomal protein, large, P0; SIRT1, sirtuin 1; SDHB, succinate dehydrogenase complex $B$. 


\section{ChAPTER 3}

the regulation of the FA oxidation, PGC1 1 , showed an interesting expression pattern (Figure 1E). The overall gene expression was different for the quartiles $(p=0.05)$. PGC1 $\alpha$ mRNA expression was similar in the two extreme groups $\left(<25^{\text {th }}\right.$

Table 2. Individual characteristics according to insulin sensitivity

\begin{tabular}{|c|c|c|c|c|c|}
\hline $\begin{array}{l}\text { Insulin sensitivity } \\
\left(\mathrm{mU} / /^{-1}\right)^{*} \mathrm{~min}^{-1 *} 10^{-4}\end{array}$ & $\begin{array}{c}0-25 \\
1.09 \pm 0.07^{2}\end{array}$ & $\begin{array}{r}25-50 \\
2.08 \pm 0.04 \\
\end{array}$ & $\begin{array}{r}50-75 \\
2.84 \pm 0.03 \\
\end{array}$ & $\begin{array}{c}75-100 \\
5.24 \pm 0.47 \\
\end{array}$ & p-value \\
\hline $\begin{array}{l}N \\
M / F\end{array}$ & $\begin{array}{c}30 \\
24 / 6\end{array}$ & $\begin{array}{c}31 \\
19 / 12\end{array}$ & $\begin{array}{c}31 \\
15 / 16\end{array}$ & $\begin{array}{c}30 \\
18 / 12\end{array}$ & \\
\hline Age (y) & $56.4 \pm 1.54$ & $54.9 \pm 1.81$ & $57.6 \pm 1.50$ & $57.5 \pm 1.35$ & NS \\
\hline Weight (kg) & $100.2 \pm 0.20^{1}$ & $92.3 \pm 2.50$ & $90.1 \pm 2.35$ & $89.4 \pm 2.77$ & 0.009 \\
\hline BMI $\left(\mathrm{kg} / \mathrm{m}^{2}\right)$ & $32.8 \pm 0.77$ & $30.7 \pm 0.55$ & $30.6 \pm 0.62$ & $31.1 \pm 0.90$ & NS \\
\hline Waist girth $(\mathrm{cm})$ & $110.9 \pm 1.61^{1}$ & $104.1 \pm 1.73$ & $105.0 \pm 1.67$ & $103.0 \pm 1.82$ & 0.007 \\
\hline $\begin{array}{l}\text { Systolic blood } \\
\text { pressure (mmHg) }\end{array}$ & $137.9 \pm 3.09$ & $142.5 \pm 2.73$ & $139.1 \pm 2.76$ & $134.5 \pm 2.85$ & NS \\
\hline $\begin{array}{l}\text { Diastolic blood } \\
\text { pressure }(\mathrm{mmHg})\end{array}$ & $87.9 \pm 1.87$ & $87.7 \pm 1.22$ & $86.1 \pm 1.91$ & $84.9 \pm 1.68$ & NS \\
\hline $\begin{array}{l}\text { Serum TAG } \\
(\mathrm{mmol} / \mathrm{l})\end{array}$ & $2.13 \pm 0.18$ & $1.72 \pm 0.12$ & $1.82 \pm 0.24$ & $1.67 \pm 0.09$ & NS \\
\hline $\begin{array}{l}\text { Plasma HDL-C } \\
(\mathrm{mmol} / \mathrm{l})\end{array}$ & $0.94 \pm 0.04^{1}$ & $1.08 \pm 0.05$ & $1.09 \pm 0.05$ & $1.15 \pm 0.06$ & 0.026 \\
\hline $\begin{array}{l}\text { Plasma glucose } \\
(\mathrm{mmol} / \mathrm{l})\end{array}$ & $6.33 \pm 0.16$ & $5.99 \pm 0.13$ & $5.87 \pm 0.11$ & $5.96 \pm 0.16$ & NS \\
\hline $\begin{array}{l}\text { Serum insulin } \\
(\mathrm{mU} / \mathrm{l})\end{array}$ & $13.0 \pm 1.17^{2}$ & $8.6 \pm 0.71$ & $7.5 \pm 0.64$ & $6.8 \pm 0.48$ & $<0.001$ \\
\hline $\mathrm{HOMA}_{\mathrm{IR}}$ & $3.62 \pm 0.32^{2}$ & $2.32 \pm 0.23$ & $1.96 \pm 0.18$ & $1.80 \pm 0.14$ & $<0.001$ \\
\hline
\end{tabular}

Statistical analyses comparing the quartiles of insulin sensitivity were performed by an one-way ANOVA, with $p$-values reported in the last column on the right. NS: non-significant.

Values are significant at $p<0.05$, Data represent means \pm SEM

${ }^{1}$ Weight, waist girth and plasma HDL-cholesterol are significantly different between the lowest quartile and the other quartiles (post-hoc LSD) ${ }^{2}$ Serum insulin, $\mathrm{HOMA}_{\mathrm{IR}}$ and insulin sensitivity are significantly different between the quartile groups (post-hoc LSD)

quartile and $>75^{\text {th }}$ quartile) and lower than in the middle groups. Moreover, PPARa (co-activated by PGC1 $\alpha$ ) showed a similar expression pattern (Figure 1F, $p=0.002$ ) also mCTP1b mRNA levels were comparable with PGC1a (Figure 1G, $p=0.005$ ). PPAR $\delta$, NDUFB5 and SDHB mRNA were similar is all groups (Figure $\mathbf{1 H}, \mathbf{1 l}$ and J). In a sub-group ( $n=37$ ), we also measured mtDNA copy number in skeletal muscle and did not observe any differences across the quartiles of insulin 
sensitivity (Figure 2A). There was a correlation between mtDNA copy number and the basal mRNA expression of PGC1 $\alpha(r=0.353, p=0.037)$ (Figure 2B), the correlation was strongest in the most insulin sensitive group (data not shown). A negative correlation was observed between mtDNA copy number and waist-to-hip ratio (WHR) ( $r=-0.353, p=0.022)$ (Figure $2 \mathrm{C}$ ).

A
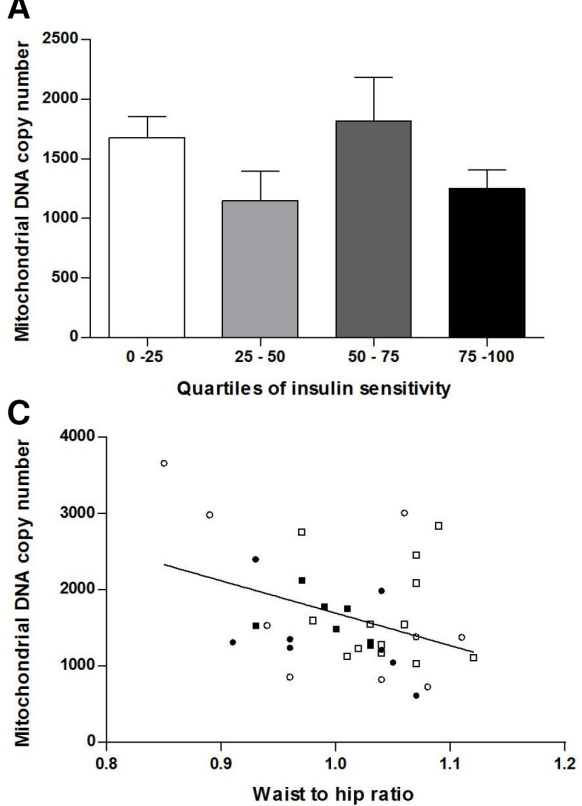

B

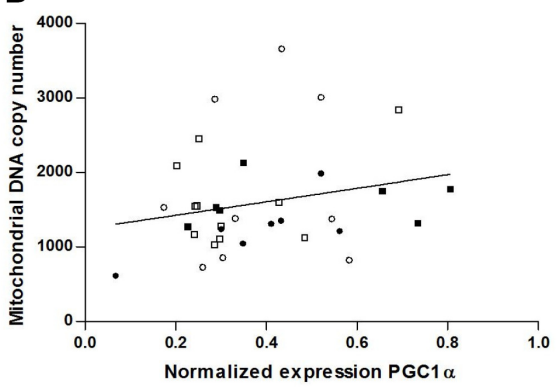

Figure 2. Mitochondrial DNA (mtDNA) copy number $(n=37)$. mtDNA copy number was calculated as the ratio between ND1 to LPL. (A) mtDNA copy number among quartiles of insulin sensitivity. (B) Correlation between mtDNA copy number and the basal mRNA expression of $P G C 1 \alpha(r=0.353, p=0.037)$ and $(\mathbf{C})$ waist-to-hip ratio $(r=-0.353, p=0.022)$.

$\square$ 0-25 a 25-50 50-75 • 75-100 LPL, lipoprotein lipase; PGC1a, peroxisome proliferators-activated receptor coactivator $1 \alpha$.

\section{Lipogenesis}

Figure 3 illustrates mRNA expression levels of genes involved in lipogenesis. The normalized mRNA level of SREBP1c and ACC2 was significantly increased in the insulin resistant state ( $p=0.001$ and $p=0.022$, respectively) (Figure $3 \mathbf{A}$ and $C$ ) with the two lower groups $\left(<25^{\text {th }}\right.$ and $<50^{\text {th }}$ quartile) having higher levels than the two highest groups $\left(>50^{\text {th }}\right.$ and $>75^{\text {th }}$ quartile). A significant gender*insulin sensitivity interaction was observed for SREBP1c (gender*insulin sensitivity, $p=0.001$ ), with only women having a higher SREBP1c expression in the insulin resistant groups. 


\section{CHAPTER 3}

For FAS (Figure 3D), SREBP2 (Figure 3E) and ChREBP (Figure 3F) there were no differences in mRNA levels among the four groups.

A

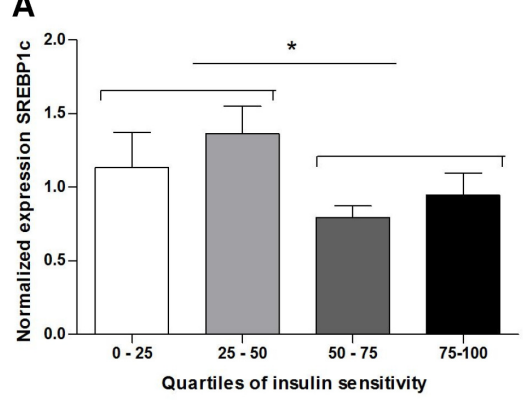

C

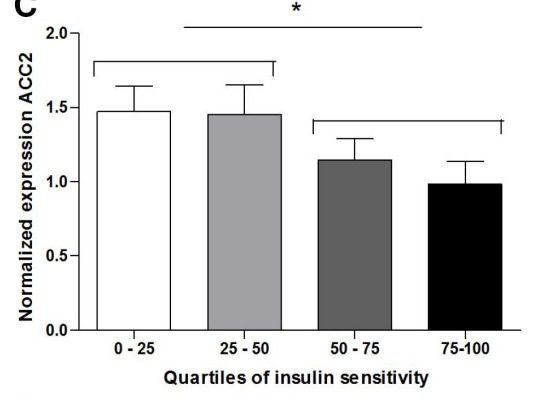

$\mathbf{E}$

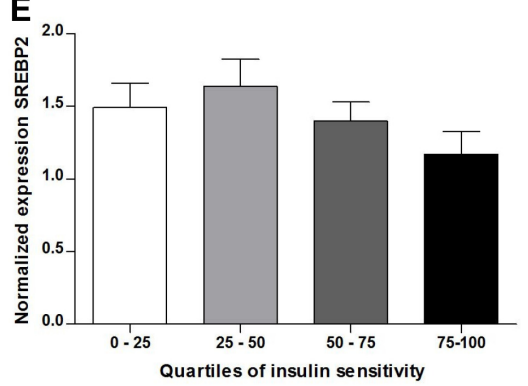

B
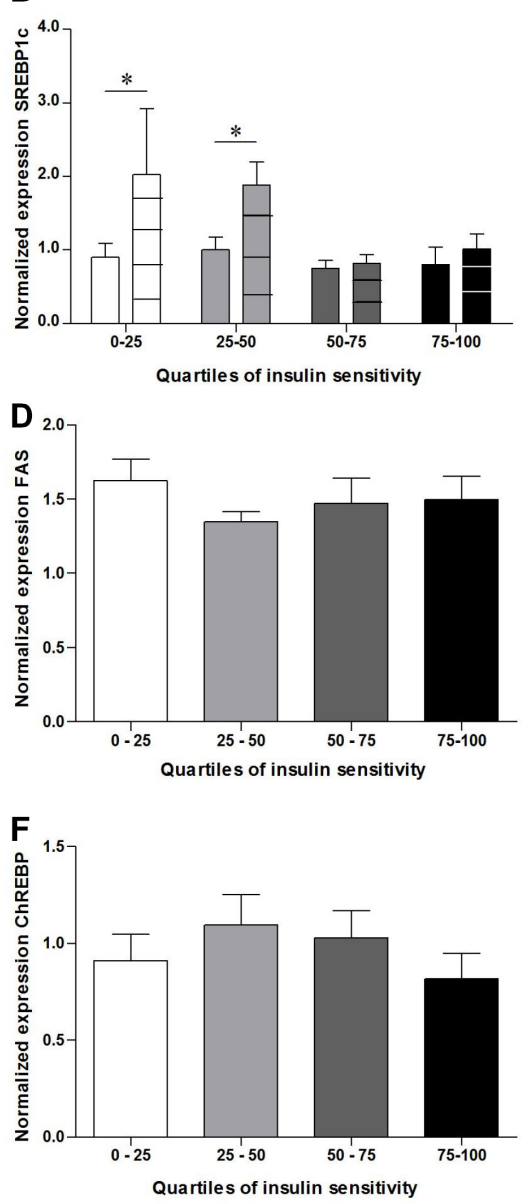

Figure 3. Basal normalized mRNA expression levels of genes important in lipogenesis in the four quartiles of insulin sensitivity. (A) SREBP1C, (B) Normalized expression levels in the four groups divided by gender for SREBP1c, (C) ACC2, (D) FAS, (E) SREBP2, and $(\mathbf{F})$ ChREBP. Women are represented by the bares with horizontal lines. The overall difference between the quartiles for SREBP1c was $p=0.001$, for $A C C 2 p=0.022$. The gender*insulin sensitivity interaction for SREBP1c was $p=0.022$. Significant post hoc differences among the quartiles separately are indicated with asterisk. ${ }^{*} p<0.05$. ACC2, acetyl-CoA carboxylase 2; ChREBP, carbohydrate responsive element binding protein; FAS, fatty acid synthase; SREBP1c, sterol regulatory element binding protein 1c; SREBP2, sterol regulatory element binding protein 2. 


\section{Intramuscular TAG turnover}

The normalized mRNA level of DGAT1 was slightly but significantly increased in the insulin resistant state $(p=0.048$ Figure $4 \mathrm{~A})$ with the two lower groups $\left(<25^{\text {th }}\right.$ and $<50^{\text {th }}$ quartile) having higher levels than the two highest groups $\left(>50^{\text {th }}\right.$ and $>75^{\text {th }}$ quartile). No differences between quartiles were present for HSL, ATGL, CGI58 and SCD1 mRNA expression (Figure 4 B, C, D and E).

A

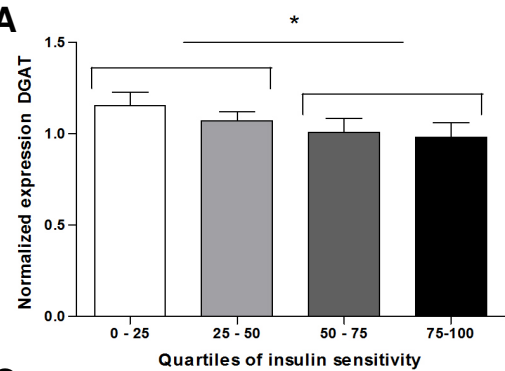

C
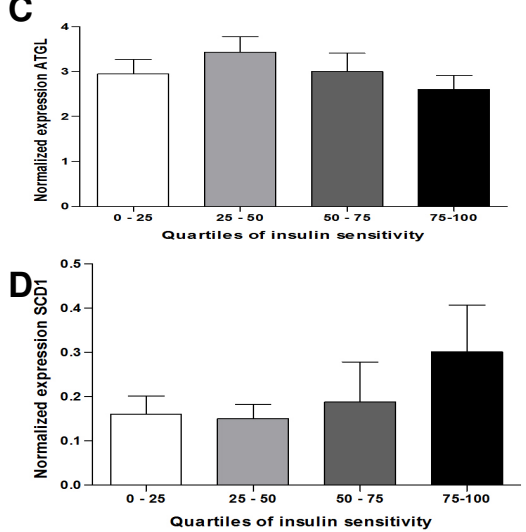

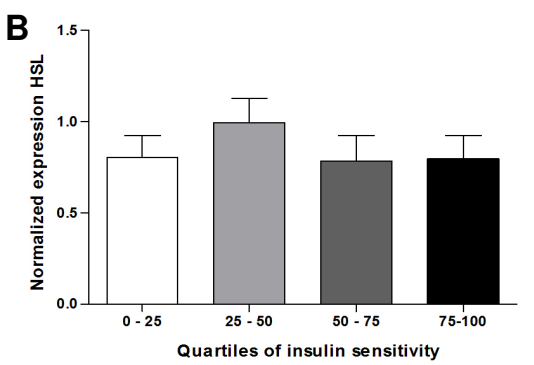

D

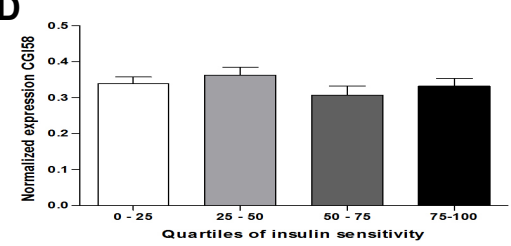

Figure 4. Basal normalized mRNA expression levels of genes important in intramuscular hydrolysis in the four quartiles of insulin sensitivity. (A) DGAT, (B) HSL, (C) ATGL, (D) CGI58, and (E) SCD1. Significant post hoc differences among the quartiles are indicated with asterisk. ${ }^{*} \mathrm{p}<0.05$. ATGL, adipose triglyceride lipase; CGI58, comparative gene identification 58; DGAT1, diacylglycerol acyltransferase; HSL, hormone sensitive lipase; SCD1, stearoyl-CoA desaturase 1. 


\section{ChAPter 3}

Gender differences in basal skeletal muscle mRNA expression

A number of genes were differentially expressed among men and women. As mentioned above the expression of SREBP1c mRNA was higher in insulin resistant women (Figure 3B) than men. The expression of PPAR $\alpha(p=0.037)$, PPAR $\delta$ $(p=0.077)$, LPL $(p<0.001)$, ATGL $(p=0.001)$, CGI58 $(p=0.031)$, CD36 $(p=0.013)$ and SCD1 $(p<0.001)$ was significantly higher in women than men (Figure 5$)$. Women had a lower body weight $(85.64 \pm 1.68 \mathrm{~kg}$ versus $98.38 \pm 1.55 \mathrm{~kg}, \mathrm{p}<0.001)$, but BMI (31.44 \pm 0.62 versus $31.15 \pm 0.44)$ was similar, whereas WHR was also significantly lower in women $(0.90 \pm 0.01$ versus $1.02 \pm 0.01, p<0.001)$. Women were more insulin sensitive than men $\left(3.45 \pm 0.34(\mathrm{mU} /)^{*} \mathrm{~min}^{-1 *} 10^{-4}\right.$ versus $2.33 \pm 0.17(\mathrm{mU} /)^{*} \mathrm{~min}^{-1 *} 10^{-4}$, $\mathrm{p}=0.002)$ but the gender-related differences in gene expression were independent of insulin sensitivity and body weight (no significant gender*insulin sensitivity interactions).

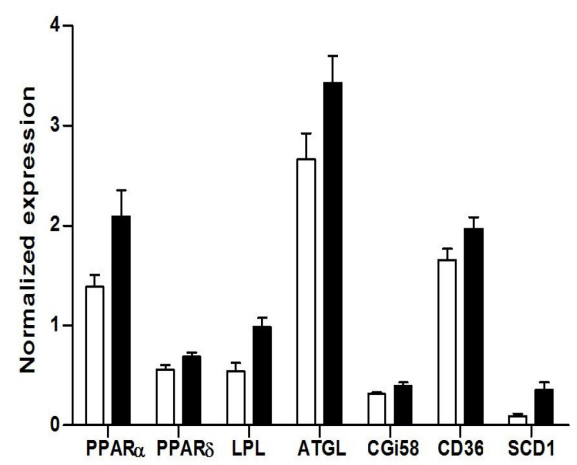

Figure 5. Gender differences in basal normalized mRNA expression levels. The expression of PPARa $(p=0.037)$, PPARס ( $P=0.077)$, LPL $(p<0.001)$, ATGL $(p=0.001)$, CGI58 $(p=0.031), \operatorname{CD} 36(p=0.013)$, and SCD1 $(p<0.001)$ in women and men. ATGL, adipose triglyceride lipase; CGI58, comparative gene identification 58; CD36, cluster of differentiation 36; LPL, lipoprotein lipase; PPARa, peroxisome proliferator-activated receptor a; PPARס̄, peroxisome proliferator activated receptor $\overline{0}$; SCD1, stearoyl-CoA desaturase 1.

\section{DISCUSSION}

The individuals with MetS in this study demonstrated a wide range of insulin sensitivity, thus facilitating examination of the transcriptional regulation of skeletal muscle FA metabolism in relation to different degrees of insulin resistance. The average insulin sensitivity of the most 'insulin sensitive' group is similar to that of healthy obese individuals [21], indicating that insulin sensitivity ranges from insulin sensitive to insulin resistant. Our data show enhanced mRNA of SREBP1c and 
ACC2 in the insulin resistant individuals, suggesting a metabolic profile directed towards storage rather than oxidation. Interestingly, three genes involved in mitochondrial biogenesis, fat oxidation and mitochondrial FA transport, PGC1 $\alpha$, PPAR $\alpha$ and mCPT1b, had a lower mRNA level in both the upper and lower quartiles of insulin sensitivity, from which it can be speculated that the most insulin resistant subjects are metabolically inflexible to regulate the expression of these genes and that the most insulin sensitive subjects do not need to increase these genes.

PGC1 $\alpha$, downstream pathways and transport of fatty acids

$P G C 1 \alpha$ is a coregulator of the mitochondrial biogenesis and stimulates FA oxidation [14]. Two studies reported a coordinated reduction of PGC1 $\alpha$ in T2DM $[16,17]$, whereas two other studies [29-31] did not observe this reduction. The importance of studying subjects with a wide range of insulin sensitivity is illustrated in our present study suggesting that a reduced mRNA expression of PGC1 $\alpha$ is present in the most insulin resistant individuals as well as in the most insulin sensitive group. PPAR a and mCTP1b (under control of PGC1 $\alpha$ ), display a similar expression pattern in our study. Both genes play an important role in FA oxidation and mitochondrial FA transport, respectively $[11,12]$. It is tempting to speculate that very insulin resistant individuals may be metabolically inflexible to upregulate PCG1a. This may ultimately lead to reduced mitochondrial FA transport and oxidation, accumulation of lipid metabolites and insulin resistance. On the other hand, the expression of this coregulator in relatively insulin sensitive individuals is sufficient for normal FA oxidation to maintain insulin sensitivity. The middle groups may increase their basal FA oxidation, via upregulation of PGC1a, PPARa and mCPT1b and be able to maintain a certain degree of insulin sensitivity. This would fit with the concept postulated by Perseghin et al. [32] showing that higher lipid oxidation rates might counteract lipid accumulation in skeletal muscle and thereby avoid FA-induced insulin resistance in overweight individuals. No differences were observed between quartiles for SIRT1 and PPAR $\delta$ mRNA and downstream genes regulating mitochondrial oxidative phosphorylation, like OXPHOS genes: NDUFB5 (complex I) and SDHB (complex II). The results of our current study may support the theory proposed by Muoio and Koves [18]. This implies that lipid-induced insulin resistance is characterized by disturbances in upstream genes that do not correspond with changes in more downstream metabolic pathways, such as the mitochondrial respiratory chain. Like Morino et al. [30], we did not observe any differences in the mtDNA content among the quartiles of insulin sensitivity. The 


\section{ChAPTER 3}

mtDNA copy number negatively correlates with the WHR which may suggest that obesity per se is a stronger predictor of low mtDNA copy number than low insulin sensitivity. It is important to indicate that in our study, all quartiles were matched for BMI, allowing separating the effect of obesity from that of insulin sensitivity. The expression of LPL mRNA was reduced in the lowest quartile of insulin sensitivity compared with the other three groups, with concomitant lower HDL-cholesterol concentrations in this group. Lower expression of LPL mRNA may reduce clearance of VLDL-TAG and chylomicron-TAG, which might explain lower HDL levels.

\section{Lipogenic genes}

The transcription factor SREBP1c interacts with insulin on transcription of several genes encoding enzymes in glucose and lipid metabolism [29, 33, 34], and insulin has been shown to upregulate SREBP1c. In this study, SREBP1c mRNA was significantly upregulated in the most insulin resistant groups, which is consistent with previous reports $[29,35]$. This upregulation of SREBP1c was only present in women, possibly reflecting a higher lipogenic potential in women compared to men. ACC2 mRNA, under control of SREBP1c, is upregulated in all insulin resistant men and women $\left(<50^{\text {th }}\right.$ quartile). ACC2 converts acetyl CoA to malonyl-CoA thereby prioritizing lipogenesis instead of FA oxidation by inhibiting $\mathrm{mCPT1}$ via malonylCoA $[1,36]$. Thus, if these higher mRNA levels of SREBP1C and ACC2 translate into activity, this may cause increased malonyl-CoA formation, reduced mitochondrial FA transport and a reduced FA oxidation. This conclusion fits with that of insulin resistant individuals having a metabolic profile favouring FA synthesis above oxidation [37].

\section{Gender differences}

Several researchers have shown that women have higher lipid oxidation than men [38] and women show higher in vivo lipolysis and uptake of plasma FFA in skeletal muscle [38, 39]. This is in accordance with our present results. ATGL, CGI58 and LPL mRNA are all higher at the basal level in women. Also PPAR $\alpha$ and PPAR $\delta$ were elevated, suggesting a higher FA oxidation. The increased expression of CD36 mRNA may implicate that there is a higher transport of LCFA into the cytosol. The enhanced expression of SREBP1c could imply that women also have a higher rate of lipogenesis. The gender-related differences in gene expression could not be explained by differences in body weight, body fat distribution or insulin sensitivity. Thus, our data may indicate that women have higher fat oxidative capacity and possibly higher FA turnover than men. 
In conclusion, SREBP1c and ACC2 mRNA levels were higher in 'insulin resistant' $\left(<50^{\text {th }}\right.$ quartile) as compared with 'insulin sensitive' $\left(>50^{\text {th }}\right.$ quartile) individuals, probably reflecting a propensity for lipogenesis and a lower FA transport if $\mathrm{mCPT1b}$ activity is also reduced. Several other genes involved in FA partitioning and oxidative metabolism such as PGC1 $\alpha$, PPAR $\alpha$ and mCPT1b exhibited reduced expression in both the most 'insulin sensitive' (above $75^{\text {th }}$ quartile), as well as the most 'insulin resistant' individuals (below $25^{\text {th }}$ quartile), although mtDNA copy number was similar. It is possible that the most 'insulin sensitive' individuals with a relatively higher propensity for FA oxidation, do not need to upregulate the genes important in FA oxidation, whereas the most 'insulin resistant' individuals have a reduced ability to upregulate these genes. Women seem to have a higher expression of genes involved in lipolysis, lipogenesis, FA uptake and oxidation, which possibly reflects a higher FA turnover.

\section{ACKNOWLEDGEMENTS}

We thank the participants for so enthusiastically taking part in the present study. We are grateful to all the staff at different centres whose help ensured the smooth running of this study. 


\section{REFERENCES}

1. Blaak EE: Basic disturbances in skeletal muscle fatty acid metabolism in obesity and type 2 diabetes mellitus. Proc Nutr Soc 2004, 63(2):323-330.

2. Corpeleijn E, Saris WH, Blaak EE: Metabolic flexibility in the development of insulin resistance and type 2 diabetes: effects of lifestyle. Obes Rev 2009, 10(2):178-193.

3. Turpeinen AK, Takala TO, Nuutila P, Axelin T, Luotolahti M, Haaparanta M, Bergman J, Hamalainen $\mathrm{H}$, lida $\mathrm{H}$, Maki $\mathrm{M}$ et al: Impaired free fatty acid uptake in skeletal muscle but not in myocardium in patients with impaired glucose tolerance: studies with PET and 14(R,S)-[18F]fluoro-6-thia-heptadecanoic acid. Diabetes 1999, 48(6):1245-1250.

4. Kelley DE, Goodpaster B, Wing RR, Simoneau JA: Skeletal muscle fatty acid metabolism in association with insulin resistance, obesity, and weight loss. Am J Physiol 1999, 277(6 Pt 1):E1130-1141.

5. Blaak EE, Wagenmakers AJ, Glatz JF, Wolffenbuttel BH, Kemerink GJ, Langenberg CJ, Heidendal GA, Saris WH: Plasma FFA utilization and fatty acidbinding protein content are diminished in type 2 diabetic muscle. Am J Physiol Endocrinol Metab 2000, 279(1):E146-154.

6. Bonen A, Parolin ML, Steinberg GR, Calles-Escandon J, Tandon NN, Glatz JF, Luiken JJ, Heigenhauser GJ, Dyck DJ: Triacylglycerol accumulation in human obesity and type 2 diabetes is associated with increased rates of skeletal muscle fatty acid transport and increased sarcolemmal FAT/CD36. Faseb $J$ 2004, 18(10):1144-1146.

7. Blaak EE, van Aggel-Leijssen DP, Wagenmakers AJ, Saris WH, van Baak MA: Impaired oxidation of plasma-derived fatty acids in type 2 diabetic subjects during moderate-intensity exercise. Diabetes 2000, 49(12):2102-2107.

8. Corpeleijn E, Mensink M, Kooi ME, Roekaerts PM, Saris WH, Blaak EE: Impaired skeletal muscle substrate oxidation in glucose-intolerant men improves after weight loss. Obesity (Silver Spring) 2008, 16(5):1025-1032.

9. Jocken JW, Roepstorff C, Goossens GH, van der Baan P, van Baak M, Saris WH, Kiens $B$, Blaak EE: Hormone-sensitive lipase serine phosphorylation and glycerol exchange across skeletal muscle in lean and obese subjects: effect of beta-adrenergic stimulation. Diabetes 2008, 57(7):1834-1841.

10. Itani SI, Ruderman NB, Schmieder F, Boden G: Lipid-induced insulin resistance in human muscle is associated with changes in diacylglycerol, protein kinase C, and IkappaB-alpha. Diabetes 2002, 51(7):2005-2011.

11. Corpeleijn E, Pelsers MM, Soenen S, Mensink M, Bouwman FG, Kooi ME, Saris $\mathrm{WH}$, Glatz JF, Blaak EE: Insulin acutely upregulates protein expression of the fatty acid transporter CD36 in human skeletal muscle in vivo. $J$ Physiol Pharmacol 2008, 59(1):77-83.

12. Turcotte LP, Fisher JS: Skeletal muscle insulin resistance: roles of fatty acid metabolism and exercise. Phys Ther 2008, 88(11):1279-1296.

13. McGarry JD: Banting lecture 2001: dysregulation of fatty acid metabolism in the etiology of type 2 diabetes. Diabetes 2002, 51(1):7-18.

14. Mensink M, Hesselink MK, Russell AP, Schaart G, Sels JP, Schrauwen P: Improved skeletal muscle oxidative enzyme activity and restoration of PGC-1 alpha and PPAR beta/delta gene expression upon rosiglitazone treatment in obese patients with type 2 diabetes mellitus. International journal of obesity (2005) 2007, 31(8):1302-1310.

15. Sparks LM, Xie H, Koza RA, Mynatt R, Hulver MW, Bray GA, Smith SR: A high-fat diet coordinately downregulates genes required for mitochondrial oxidative phosphorylation in skeletal muscle. Diabetes 2005, 54(7):1926-1933. 
16. Patti ME, Butte AJ, Crunkhorn S, Cusi K, Berria R, Kashyap S, Miyazaki Y, Kohane I, Costello M, Saccone $\mathrm{R}$ et al: Coordinated reduction of genes of oxidative metabolism in humans with insulin resistance and diabetes: Potential role of PGC1 and NRF1. Proc Natl Acad Sci U S A 2003, 100(14):8466-8471.

17. Mootha VK, Lindgren CM, Eriksson KF, Subramanian A, Sihag S, Lehar J, Puigserver P, Carlsson E, Ridderstrale M, Laurila E et al: PGC-1alpha-responsive genes involved in oxidative phosphorylation are coordinately downregulated in human diabetes. Nat Genet 2003, 34(3):267-273.

18. Muoio DM, Koves TR: Skeletal muscle adaptation to fatty acid depends on coordinated actions of the PPARs and PGC1 alpha: implications for metabolic disease. Applied physiology, nutrition, and metabolism = Physiologie appliquee, nutrition et metabolisme 2007, 32(5):874-883.

19. Kliewer SA, Xu HE, Lambert MH, Willson TM: Peroxisome proliferator-activated receptors: from genes to physiology. Recent progress in hormone research 2001, 56:239-263.

20. Carrasco S, Merida I: Diacylglycerol, when simplicity becomes complex. Trends Biochem Sci 2007, 32(1):27-36.

21. Jocken JW, Langin D, Smit E, Saris WH, Valle C, Hul GB, Holm C, Arner P, Blaak EE: Adipose triglyceride lipase and hormone-sensitive lipase protein expression is decreased in the obese insulin-resistant state. $J$ Clin Endocrinol Metab 2007, 92(6):2292-2299.

22. Third Report of the National Cholesterol Education Program (NCEP) Expert Panel on Detection, Evaluation, and Treatment of High Blood Cholesterol in Adults (Adult Treatment Panel III) final report. Circulation 2002, 106(25):31433421.

23. Bergstrom J, Hermansen L, Hultman E, Saltin B: Diet, muscle glycogen and physical performance. Acta Physiol Scand 1967, 71(2):140-150.

24. Vandesompele J, De Preter K, Pattyn F, Poppe B, Van Roy N, De Paepe A, Speleman F: Accurate normalization of real-time quantitative RT-PCR data by geometric averaging of multiple internal control genes. Genome Biol 2002 3(7):RESEARCH0034.

25. Bustin SA: Absolute quantification of mRNA using real-time reverse transcription polymerase chain reaction assays. $J$ Mol Endocrinol 2000, 25(2):169-193.

26. Bogacka I, Xie H, Bray GA, Smith SR: Pioglitazone induces mitochondrial biogenesis in human subcutaneous adipose tissue in vivo. Diabetes 2005, 54(5):1392-1399.

27. Boston RC, Stefanovski D, Moate PJ, Sumner AE, Watanabe RM, Bergman RN: MINMOD Millennium: a computer program to calculate glucose effectiveness and insulin sensitivity from the frequently sampled intravenous glucose tolerance test. Diabetes Technol Ther 2003, 5(6):1003-1015.

28. Matthews DR, Hosker JP, Rudenski AS, Naylor BA, Treacher DF, Turner RC: Homeostasis model assessment: insulin resistance and beta-cell function from fasting plasma glucose and insulin concentrations in man. Diabetologia 1985, 28(7):412-419.

29. Palsgaard J, Brons $C$, Friedrichsen $M$, Dominguez $H$, Jensen $M$, Storgaard $H$, Spohr C, Torp-Pedersen C, Borup R, De Meyts $P$ et al: Gene expression in skeletal muscle biopsies from people with type 2 diabetes and relatives: differential regulation of insulin signaling pathways. PloS one 2009, 4(8):e6575. 
30. Morino K, Petersen KF, Dufour S, Befroy D, Frattini J, Shatzkes N, Neschen S, White MF, Bilz S, Sono $S$ et al: Reduced mitochondrial density and increased IRS-1 serine phosphorylation in muscle of insulin-resistant offspring of type 2 diabetic parents. The Journal of clinical investigation 2005, 115(12):3587-3593.

31. Karlsson HK, Ahlsen M, Zierath JR, Wallberg-Henriksson H, Koistinen HA: Insulin signaling and glucose transport in skeletal muscle from first-degree relatives of type 2 diabetic patients. Diabetes 2006, 55(5):1283-1288.

32. Perseghin G, Scifo P, Danna M, Battezzati A, Benedini S, Meneghini E, Del Maschio A, Luzi L: Normal insulin sensitivity and IMCL content in overweight humans are associated with higher fasting lipid oxidation. American journal of physiology 2002, 283(3):E556-564.

33. Kim JB, Sarraf P, Wright M, Yao KM, Mueller E, Solanes G, Lowell BB, Spiegelman $B M$ : Nutritional and insulin regulation of fatty acid synthetase and leptin gene expression through ADD1/SREBP1. The Journal of clinical investigation 1998, 101(1):1-9.

34. Foretz M, Pacot C, Dugail I, Lemarchand P, Guichard C, Le Liepvre X, BerthelierLubrano C, Spiegelman B, Kim JB, Ferre $P$ et al: ADD1/SREBP-1c is required in the activation of hepatic lipogenic gene expression by glucose. Molecular and cellular biology 1999, 19(5):3760-3768.

35. Guillet-Deniau I, Mieulet V, Le Lay S, Achouri Y, Carre D, Girard J, Foufelle F Ferre $P$ : Sterol regulatory element binding protein-1c expression and action in rat muscles: insulin-like effects on the control of glycolytic and lipogenic enzymes and UCP3 gene expression. Diabetes 2002, 51(6):1722-1728.

36. Pender C, Trentadue AR, Pories WJ, Dohm GL, Houmard JA, Youngren JF: Expression of genes regulating malonyl-CoA in human skeletal muscle. Journal of cellular biochemistry 2006, 99(3):860-867.

37. Debard C, Laville M, Berbe V, Loizon E, Guillet C, Morio-Liondore B, Boirie Y, Vidal $\mathrm{H}$ : Expression of key genes of fatty acid oxidation, including adiponectin receptors, in skeletal muscle of Type 2 diabetic patients. Diabetologia 2004, 47(5):917-925.

38. Maher AC, Fu MH, Isfort RJ, Varbanov AR, Qu XA, Tarnopolsky MA: Sex differences in global mRNA content of human skeletal muscle. PloS one 2009, 4(7):e6335.

39. Kiens B, Roepstorff C, Glatz JF, Bonen A, Schjerling P, Knudsen J, Nielsen JN: Lipid-binding proteins and lipoprotein lipase activity in human skeletal muscle: influence of physical activity and gender. J Appl Physiol 2004, 97(4):1209-1218. 


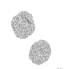

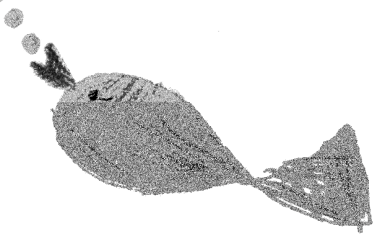

CHAPTER 4

Polyunsaturated fatty acids acutely affect triacylglycerol-derived skeletal muscle fatty acid uptake and increases postprandial insulin sensitivity

Anneke Jans*, Ellen Konings*, Gijs H. Goossens, Freek G. Bouwman, Chantalle C. Moors, Mark V. Boekschoten, Lydia A. Afman, Michael Müller, Edwin C. Mariman and Ellen E. Blaak

${ }^{*}$ Authors contributed equally

American Journal of Clinical nutrition. 2012 [Accepted-in press]

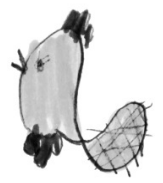




\section{ChAPTER 4}

\section{ABSTRACT}

Background: Dietary fat quality may influence skeletal muscle lipid handling and fat accumulation, thereby modulating insulin sensitivity.

Objective: To examine acute effects of meals with various fatty acid (FA) compositions on skeletal muscle FA handling and postprandial insulin sensitivity in obese insulin resistant men.

Design: In a single-blind randomized crossover study, 10 insulin resistant men consumed three high-fat mixed-meals $(2.6 \mathrm{MJ})$, which were high in saturated FA (SFA), monounsaturated FA (MUFA) or polyunsaturated FA (PUFA). Fasting and postprandial skeletal muscle FA handling were examined by measuring arteriovenous concentration differences across the forearm muscle. $\left.{ }_{2} \mathrm{H}^{2}\right]$-palmitate was infused intravenously to label endogenous triacylglycerol (TAG) and FFA in the circulation and $\left[\mathrm{U}-{ }^{13} \mathrm{C}\right]$-palmitate was added to the meal to label chylomicron-TAG. Skeletal muscle biopsies were taken to assess intramuscular lipid metabolism and gene expression.

Results: Insulin and glucose responses (AUC) after SFA meal were significantly higher compared with the PUFA meal ( $p=0.006$ and 0.033 , respectively). Uptake of TAG-derived FA was lower in the postprandial phase after the PUFA meal as compared with the other meals $\left(\mathrm{AUC}_{60-240}, \mathrm{p}=0.02\right)$. Fractional synthetic rate of the TAG, DAG and PL pool was higher after the MUFA meal as compared with the SFA meal. PUFA induced less transcriptional downregulation of oxidative pathways compared with other meals.

Conclusion: PUFA reduced TAG-derived skeletal muscle FA uptake, which was accompanied by higher postprandial insulin sensitivity, a more transcriptional oxidative phenotype and altered intramyocellular lipid partitioning and may therefore be protective against the development of insulin resistance. 


\section{INTRODUCTION}

Increased fat storage in non-adipose tissues like skeletal muscle (ectopic fat accumulation) is a strong indicator of insulin resistance [1]. Conditions characterized by insulin resistance are often accompanied by adipose tissue dysfunction and a reduced lipid buffering capacity, which may lead to an increased supply of triacylglycerol (TAG) and free fatty acids (FFA) to non-adipose tissues (lipid overflow hypothesis) [1, 2]. Together with an impaired capacity of skeletal muscle to oxidize fat [3-6], lipid overflow may cause excess fat storage in skeletal muscle. Increased lipid accumulation in skeletal muscle, in particular the accumulation of lipid metabolites like diacylglycerol (DAG), long-chain fatty acyl$\mathrm{CoA}$ and ceramides, may reduce insulin action by interference with insulin signaling [7-10]. Dietary intervention, in particular a reduction of saturated fat (SFA), may improve insulin sensitivity [11-13], possibly through effects on lipid overflow and skeletal muscle FA handling. Polyunsaturated FA (PUFA) may reduce lipid overflow in the circulation by increasing lipid uptake and storage in adipose tissue by inducing adipocyte differentiation [14]. Furthermore, it has been found in human muscle cell lines that SFA accumulate preferentially as DAG, thereby activating protein kinase $C$ and inhibiting insulin signaling, whilst unsaturated $F A$ are readily converted to TAG [15]. Furthermore, oleic acid accumulates to a lesser extent as DAG or TAG than palmitic acid and is more directed towards oxidation [16]. The underlying mechanisms for the differential effect of FA on metabolism may relate to intracellular pathways that are differently tuned by FA subtypes. It has been shown that PUFA may regulate gene transcription within minutes, acting as agonists of peroxisome proliferator-activated receptors (PPARs) and sterol regulatory element-binding protein 1c (SREBP1C) [17]. However, human in vivo studies investigating the effects of meals with different FA composition on skeletal muscle FA handling are lacking. Recently, a unique dual stable isotope tracer approach was validated to study skeletal muscle FA metabolism in detail. This offers, in combination with measurements of arterio-venous concentration differences across the forearm muscle [6, 18], the possibility of differentiation between the metabolic fate of dietary versus endogenous FA. The hypothesis of the present study was that a meal high in unsaturated FA may acutely improve insulin sensitivity by reducing lipid overflow and shifting FA partitioning within muscle towards oxidation as compared with a meal high in SFA in obese insulin resistant subjects. The objective of the present study was to examine the acute effects of meals with various FA compositions on forearm muscle FA handling and postprandial insulin sensitivity in obese insulin resistant men using the dual stable 


\section{ChAPTER 4}

isotope technique. Furthermore, baseline and postprandial skeletal muscle biopsies were collected for assessment of intramuscular FA handling and the transcriptional regulation of FA metabolism.

\section{METHODS}

10 insulin resistant men (age 50-70 years; BMI $29-39 \mathrm{~kg} / \mathrm{m}^{2} ; \mathrm{HOMA}_{\mathrm{IR}}>2.5$ ) participated in a single-blind randomized cross-over study (Table 1). Exclusion criteria were weight change of $>3 \mathrm{~kg}$ within the last 3 months before the study; diabetes; chronic inflammatory conditions; kidney or liver dysfunction; use of hypolipidemic or anti-inflammatory medication; use of $\beta$-blockers; use of aspirin $>1$ per week; highly-trained athletes; and alcohol abuse. All subjects were informed about the nature of the study and written informed consent was obtained before study participation. The local Medical Ethical Committee of Maastricht University Medical Centre approved the study protocol.

Table 1. Subject characteristics.

\begin{tabular}{|c|c|}
\hline & NGT $(n=10)$ \\
\hline Age (yrs) & $61.5 \pm 1.6$ \\
\hline Body weight (kg) & $98.1 \pm 2.8$ \\
\hline $\mathrm{BMI}\left(\mathrm{kg} / \mathrm{m}^{2}\right)$ & $33.8 \pm 3.8$ \\
\hline Body fat (\%) & $31.6 \pm 0.9$ \\
\hline Fat free mass $(\mathrm{kg})$ & $70.3 \pm 1.8$ \\
\hline Fat mass (kg) & $28.1 \pm 1.6$ \\
\hline Waist-hip ratio & $1.04 \pm 0.01$ \\
\hline $\mathrm{FPG}(\mathrm{mmol} / \mathrm{l})$ & $5.6 \pm 0.1$ \\
\hline 2h PG (mmol/l) & $6.2 \pm 0.4$ \\
\hline Fasting insulin $(\mu \mathrm{U} / \mathrm{l})$ & $13.7 \pm 1.3$ \\
\hline $\mathrm{HOMA}_{\mathrm{IR}}$ & $3.5 \pm 0.4$ \\
\hline M-value $\left(\mu \mathrm{mol}^{*} \mathrm{kgBW}^{-1 *} \min ^{-1}\right)$ & $3.4 \pm 0.8$ \\
\hline $\mathrm{HbA} 1 \mathrm{c}(\%)$ & $5.7 \pm 0.2$ \\
\hline \multicolumn{2}{|c|}{$\begin{array}{l}\text { Values are mean } \pm \text { SEM. NGT, normal glucose tolerant; FPG, fasting plasma } \\
\text { glucose; PG, plasma glucose }\end{array}$} \\
\hline \multicolumn{2}{|l|}{ Experimental design } \\
\hline \multicolumn{2}{|c|}{$\begin{array}{l}\text { The design of the study was a randomized cross-over design with three different } \\
\text { treatments. On four occasions, subjects arrived at the university after an overnight } \\
\text { fast. On the first day, subjects completed anthropometric measurements, a fasting } \\
\text { blood sample was collected, and a hyperinsulinaemic-euglycaemic clamp was } \\
\text { performed to measure insulin sensitivity, using a modification of the method }\end{array}$} \\
\hline 84 & \\
\hline
\end{tabular}


described by DeFronzo et al. [19]. On the other three days (2-3 weeks between measurements, in randomized order), subjects were studied under baseline conditions and for 4 hours after the ingestion of a liquid high-fat mixed-meal, which was high either in SFA, MUFA or PUFA. A dual stable isotope technique was used, to study the contribution of dietary TAG (labeled with $\left[\mathrm{U}-{ }^{13} \mathrm{C}\right]$-palmitate), and endogenous TAG, i.e. VLDL, and circulating FFA (both labeled with $\left[{ }^{2} \mathrm{H}_{2}\right]$-palmitate) to lipid overflow and skeletal muscle FA handling, as reported previously $[6,18$, 20].

\section{Test meal composition}

The liquid test meal provided $2.6 \mathrm{MJ}$, consisting of $61 \mathrm{E} \%$ fat, 33E\% carbohydrates and $6.3 \mathrm{E} \%$ protein. Subjects were asked to drink the test meal within $5 \mathrm{~min}$. The FA composition of the test meals is presented in table 2. The MUFA meal consisted out of $40 \mathrm{~g}$ olive oil and the PUFA meal contained $20 \mathrm{~g}$ safflower oil and $20 \mathrm{~g}$ fish oil (18\% EPA $/ 12 \%$ DHA) (sponsored by Bioriginal, Den Bommel, The Netherlands).

Table 2. Fatty acid composition of test meals.

\begin{tabular}{rccc}
\hline & SFA & MUFA & PUFA \\
\hline Protein (E\%) & 6.3 & 6.5 & 6.5 \\
CH (E\%) & 32.6 & 32.3 & 32.3 \\
Fat (E\%) & 61.2 & 61.2 & 61.2 \\
SFA (E\%) & $\mathbf{3 5 . 5}$ & 11.6 & 14.4 \\
MUFA (E\%) & 18.8 & $\mathbf{4 2 . 2}$ & 11.9 \\
PUFA (E\%) & 1.7 & 4.6 & $\mathbf{3 4 . 8}$ \\
\hline
\end{tabular}

$\mathrm{CH}$, carbohydrate; SFA, saturated fatty acid; MUFA, monounsaturated; PUFA,

polyunsaturated fatty acid; FFA, free fatty acids.

\section{Tracer infusion study}

Subjects arrived at the university after an overnight fast and were asked to refrain from drinking alcohol and to perform no strenuous exercise $24 \mathrm{~h}$ before the study day. In addition, they were asked to avoid food products naturally enriched with $\left[{ }^{13} \mathrm{C}\right]$ (i.e corn or pineapple) during the whole study period. Skeletal muscle metabolism was studied in the forearm muscle, using arterio-venous concentration differences corrected for blood flow. Three catheters were inserted before the start of the experiment. One catheter was placed retrogradely into a superficial dorsal hand vein, which was heated in a hot-box $\left(60^{\circ} \mathrm{C}\right)$ to obtain arterialized blood. In the same arm another catheter was placed in an antecubital vein for the infusion of the $\left[{ }^{2} \mathrm{H}_{2}\right]$-palmitate tracer. A third catheter was placed retrogradely in a deep 


\section{ChAPTER 4}

antecubital vein of the contralateral forearm to sample venous blood draining the forearm muscle. After taking an arterialized and deep venous background sample at t-90 (i.e., $90 \mathrm{~min}$ before meal ingestion), a continuous intravenous infusion of the stable isotope tracer $\left[{ }^{2} \mathrm{H}_{2}\right]$-palmitate $(97 \%$ enrichment, Cambridge Isotope Laboratories, Andover, MA) complexed to albumin was started $\left(0.035 \mu \mathrm{mol}{ }^{*} \mathrm{~kg}\right.$ body weight $\left.{ }^{-1 *} \min ^{-1}\right)$. Baseline blood sampling was started after $1 \mathrm{~h}$ of tracer infusion to allow for isotopic equilibration to occur. Blood samples were taken simultaneously from the radial artery and the deep muscle vein at three time points during fasting (t-30, t-15, t0), and six time points postprandial (t30, t60, t90, t120, $\mathrm{t} 180, \mathrm{t} 240$ ) after consumption of a high-fat mixed-meal (t0) containing $200 \mathrm{mg}$ [U${ }^{13} \mathrm{C}$-palmitate (98\% enrichment, Cambridge Isotope Laboratories). Forearm blood flow was measured before each blood sampling as described previously [21]. Skeletal muscle biopsies were taken during fasting conditions (after placing the three catheters and before the background blood sampling) and at the end of the postprandial measurement period (t240).

\section{Indirect calorimetry}

Energy expenditure and whole-body substrate utilization were measured using an open-circuit ventilated hood system (Omnical, Maastricht University, The Netherlands) under fasting conditions and after meal ingestion (t30, t60, t90, t120, t180 and t240) [22]. Gas analyses, which occurred every 15seconds, were performed by dual paramagnetic $\mathrm{O}_{2}$ analyzers and dual infrared $\mathrm{CO}_{2}$ analyzers (type 1156, 1507, 1520; Servomex, Cowborough, Sussex, UK), similar to the analysis system described by Schoffelen et al. [23]. Nitrogen excretion was calculated based on the assumption that protein oxidation represents $\sim 15 \%$ of total energy expenditure. Energy expenditure was calculated using the formula of Weir [24].

\section{Biochemical analyses}

Blood was collected in EDTA tubes, centrifuged (1000g, $10 \mathrm{~min}, 4^{\circ} \mathrm{C}$ ) and plasma was immediately frozen in liquid nitrogen and stored at $-80^{\circ} \mathrm{C}$ until analysis. Plasma FFA was analyzed using standard enzymatic techniques automated on a Cobas Fara centrifugal spectrophotometer (Roche Diagnostics, Basel, Switzerland). Plasma TAG, glycerol, glucose, and lactate were analyzed enzymatically on a Cobas Mira automated spectrophotometer. Plasma insulin was measured with a double antibody radioimmunoassay (Linco Research, St Charles, $\mathrm{MO}$ ). Hematocrit was determined in heparinized blood using a microcapillary system. 
To determine isotope enrichment of plasma FFA and TAG, total lipids were extracted from the plasma using chloroform-methanol 2:1 (vol/vol). The FFA and TAG fractions were separated by thin-layer chromatography and derivatized to their methyl esters for the analysis of plasma palmitate. Plasma fractions were analyzed for the ${ }^{13} \mathrm{C}$-to- ${ }^{12} \mathrm{C}$ ratio on a gas chromatography continuous-flow isotope ratio-mass spectrometer (Finnigan MAT-252 GC-IRMS, Bremen, Germany) and for enrichment of $\left[{ }^{2} \mathrm{H}_{2}\right.$ ] (Finnigan Incos-XL GC-MS). The methyl ester of palmitate contains 17 carbon atoms and therefore, the tracer/tracee ratio (TTR) of palmitate was corrected for the extra methyl group. Plasma palmitate concentrations $(\mu \mathrm{mol} / \mathrm{l})$ were analyzed on an analytical GC with ion flame detection using heptadecanoic acid as internal standard.

\section{Skeletal muscle biopsy}

Skeletal muscle biopsies were taken at baseline (after placing the three catheters and before the background blood sampling) and at the end of the postprandial measurement period (t240). Biopsies were obtained from the vastus lateralis muscle under local anesthesia of the skin and fascia using the Bergström method with suction [25], cleaned from any visible fat and blood, immediately frozen in isopentane at its melting point, and stored at $-80^{\circ} \mathrm{C}$ until analysis. The biopsies were taken to determine intramuscular TAG, DAG, FFA, and phospholipid (PL) content, their degree of saturation, as well as the fractional synthetic rate (FSR) of TAG, DAG, and PL (see skeletal muscle lipids). We investigated gene expression profiles using microarray.

\section{Skeletal muscle lipids}

Skeletal muscle biopsies were lyophilized and dissected free of extramyocellular lipid, blood, and connective tissue. Total lipids were extracted from 10 to $20 \mathrm{mg}$ muscle sample using chloroform-methanol (2:1 vol/vol) and internal standards, and thereafter evaporated under nitrogen at $37^{\circ} \mathrm{C}$. The extracted lipids were separated into TAG, DAG, FFA, and PL by thin-layer chromatography and transferred into tubes for methylation. The TAG and DAG fractions were methylated by adding $1 \mathrm{ml}$ of toluene-methanol-(BF3-methanol 14\%) (20\%-55\%-25\% vol/vol) and incubated in capped tubes for $30 \mathrm{~min}$ at $100^{\circ} \mathrm{C}$. The PL fraction was methylated by adding $1 \mathrm{ml}$ of (BF3-methanol 14\%) and incubation in capped tubes for $90 \mathrm{~min}$ at $100^{\circ} \mathrm{C}$. The FFA fraction was methylated by adding $1 \mathrm{ml}$ of methanol-(BF3-methanol 14\%) (50\%$50 \% \mathrm{vol} / \mathrm{vol}$ ) and incubation in capped tubes at room temperature for $15 \mathrm{~min}$. After incubation, $2 \mathrm{ml}$ pentane was added to the samples, vortexed, and centrifuged $\left(1000 \mathrm{~g}, 5 \mathrm{~min}, 20^{\circ} \mathrm{C}\right.$ ), followed by isolation of pentane extracts (upper phase) and 


\section{Chapter 4}

evaporation under nitrogen at $30^{\circ} \mathrm{C}$. Finally, the residues were dissolved in isooctane and concentrations of FA in the fractions were determined using an analytical GC. Stable isotope enrichment of the lipid fractions was determined by measuring the ${ }^{13} \mathrm{C}$-to- $-{ }^{12} \mathrm{C}$ ratio on a gas chromatography continuous-flow isotope ratio-mass spectrometer (Finnigan MAT-252).

\section{Skeletal muscle gene expression}

RNA extraction

Total RNA was extracted from frozen skeletal muscle specimens using TRIzol reagent (Invitrogen, Breda, the Netherlands). RNA quantity was measured with the ND-100 spectrophotometer (Isogen Life Science, ljsselstein, the Netherlands), and RNA integrity was analyzed on an Agilent 2100 BioAnalyzer (Agilent Technologies, Amsterdam, The Netherlands) using nanochips according to manufacturer's instructions.

\section{Microarray processing}

Total RNA (100ng/sample) was labeled by using Whole Transcript Sense Target Assay and hybridized to human whole-genome Affymetrix Gene 1.0 ST arrays targeting 19793 unique genes (Affymetrix, Santa Clara, CA). Sample labeling, hybridization to chips, and image scanning were performed according to the manufacturers' instructions.

\section{Microarray data analysis}

Quality control was performed and fulfilled the criteria for array hybridization suggested by the Tumor Analysis Best Practices Working Group [26]. Microarrays were analyzed by using the reorganized oligonucleotide probes as described by Dai et al [27]. All individual probes for a gene were combined, which allowed the possibility of detecting overall transcription activity on the basis of the latest genome and transcriptome information instead of on the basis of the Affymetrix probe set annotation. Expression values were calculated with the Robust Multichip Average (RMA) method and normalized by using quantile normalization [28, 29]. Only probe sets with normalized signals $>20$ on $>4$ arrays were defined as expressed and selected for analysis. Individual genes were defined as changed when comparison of the normalized signal intensities showed a false discovery rate (FDR) [30] $Q$ value $<0.05$ in a 2-tailed paired t-test with Bayesian correction (Limma) [31]. Data were analyzed with the use of Ingenuity Pathway Analysis version 6.0 (Ingenuity Systems, Redwood City, CA). Our analysis identified 
canonical pathways that were most significant to the data set. The analysis was performed for up- and down-regulated gene sets together. Array data have been submitted to the Gene Expression Omnibus GSE31901.

cDNA synthesis and quantitative real-time polymerase chain reaction

Real-time quantitative Polymerase Chain Reaction (PCR) was used to analyze RNA samples. Total RNA was reverse-transcribed in a $20 \mu$ l reaction using the iScript cDNA synthesis Kit (Bio-Rad,Veenendaal, the Netherlands) according to the manufacturer's instructions. Primers (available upon request) were designed using Beacon designer or were obtained by using Primer Bank. Real-time PCR was carried out in an icycler thermal cycler upgraded with a MylQ ${ }^{\mathrm{TM}}$ Single Color RealTime PCR detection system (Bio-Rad, Veenendaal, the Netherlands). Gene expression levels were normalized using housekeeping genes $\beta$-actin and $\beta$-2 microglobulin ( $\beta 2 \mathrm{M})$. GeNorm was used to test the stability of the housekeeping genes [32].

\section{Calculations}

The homeostasis model assessment for insulin resistance $\left(\mathrm{HOMA}_{\mathrm{IR}}\right)$ was calculated according to Matthews et al. [33]. The M-value from the hyperinsulinaemic-euglycaemic clamp was calculated as described by DeFronzo [19]. Glucose and insulin AUC in response to the meal and $A \cup C_{\text {glucose }}{ }^{*} A U C_{\text {insulin }}{ }^{*}$ $10^{-6}$ (Plasma Glucose Index, PGI) were used as indices of postprandial insulin sensitivity [34, 35]. Lower values of PGI are indicative of better insulin sensitivity. The net flux of metabolites (labeled and unlabeled) across the forearm muscle was calculated by multiplying the arterio-venous concentration difference by forearm plasma flow. Plasma flow was calculated by multiplying forearm blood flow with (1hematocrite)/100. A positive flux indicates net uptake across forearm muscle, whereas a negative flux indicates net release. Fractional extraction of metabolites (\%) was calculated as the arterio-venous concentration difference divided by the arterialized concentration. As a measure of efficiency of substrate removal from the circulation, clearance across forearm muscle was calculated by multiplying the fractional extraction with forearm plasma flow. Fasting rate of appearance of FFA $\left(R_{\mathrm{FFA}}\right)\left(\mu \mathrm{mol}^{*} \mathrm{~kg}^{-1 *} \mathrm{~min}^{-1}\right)$ was calculated with Steele's equation for steady-state, whereas Steele's single-pool non-steady-state equations adapted for use with stable isotopes was used to calculate $\mathrm{Ra}_{\mathrm{FFA}}$ in the postprandial state [36]. Labeled FFA and TAG concentrations were calculated as the product of TTR of $\left[{ }^{2} \mathrm{H}_{2}\right]$ - and $\left[\mathrm{U}-{ }^{13} \mathrm{C}\right]$-palmitate and the concentration of palmitate in FFA and TAG. Fractional 


\section{ChAPTER 4}

extraction of $\left[\mathrm{U}-{ }^{13} \mathrm{C}\right]$-palmitate derived from the hydrolysis of $\left[\mathrm{U}-{ }^{13} \mathrm{C}\right]$-palmitate in TAG (i.e., percentage "entrapment") across forearm muscle was calculated as described previously, with the assumption that a proportion of FA derived from TAG hydrolysis may not be taken up by skeletal muscle $[6,18]$.

The FSR of skeletal muscle TAG, DAG, and PL were calculated using skeletal muscle FFA as the precursor pool for lipid synthesis [37]. The increase in TTR of $\left[\mathrm{U}-{ }^{13} \mathrm{C}\right]$ from fasting to $4 \mathrm{~h}$ postprandial was divided by the enrichment of skeletal muscle FFA and expressed as percentage per hour $(\% / h)$. The degree of saturation of skeletal muscle TAG, DAG, PL, and FFA (\%) was calculated by dividing the sum of SFA by the total amount of FA in a fraction. $\Delta^{9}$-desaturase activity was estimated as the proportion palmitoleic acid $(\mathrm{C} 16: 1 n-7)$ to palmitic acid (C16:0), and as the proportion oleic acid (C18:1n-9) to stearic acid (C18:0). Total skeletal muscle TAG, DAG, FFA, and PL contents were estimated as the sum of the particular FA content of the assessed fraction. Postprandial AUC of metabolites and substrate fluxes were calculated using the trapezoidal rule. Besides the total AUC (0-4h after meal ingestion), also the "early" (0-2h), and "mid" (2-4h) AUC was calculated to obtain more detailed information about the time course of postprandial responses.

\section{Statistics}

Differences between the diets were examined using repeated-measures ANOVA (using AUC). When a significant diet by time interaction was observed, Bonferroni post-hoc testing was performed. Statistical analyses were performed using SPSS 19.0 for Mac (SPSS Inc., Chicago, IL, USA). All data are presented as mean \pm standard error of the mean (SEM). Statistical significance was set at $p<0.05$.

\section{RESULTS}

Arterialized metabolites, forearm blood flow and forearm muscle metabolism Fasting arterialized plasma glucose (Figure 1A) and insulin (Figure 1B) concentrations were comparable between the different meal test days. The postprandial arterialized plasma glucose and insulin concentrations were higher after the SFA meal then after the PUFA meal (glucose: $p=0.006$ and insulin: $\mathrm{p}=0.033$, Table 3) with intermediate values after the MUFA meal. AUC for glucose and insulin, and the product of $A \cup C_{\text {glucose }}{ }^{*} A U C_{\text {insulin }}{ }^{*} 10^{-6}$ (PGI) were used as indices of insulin sensitivity. The PGI after the SFA meal $(12.8 \pm 1.5 \mathrm{PGI})$ was significantly higher as compared with the PUFA meal $(8.5 \pm 0.8 \mathrm{PGl}, p=0.02)$. Net 
glucose flux (Figure 1C), arterialized lactate concentrations (Figure 1D) and net lactate flux (data not shown) were not different after intake of the different meals (Table 3).
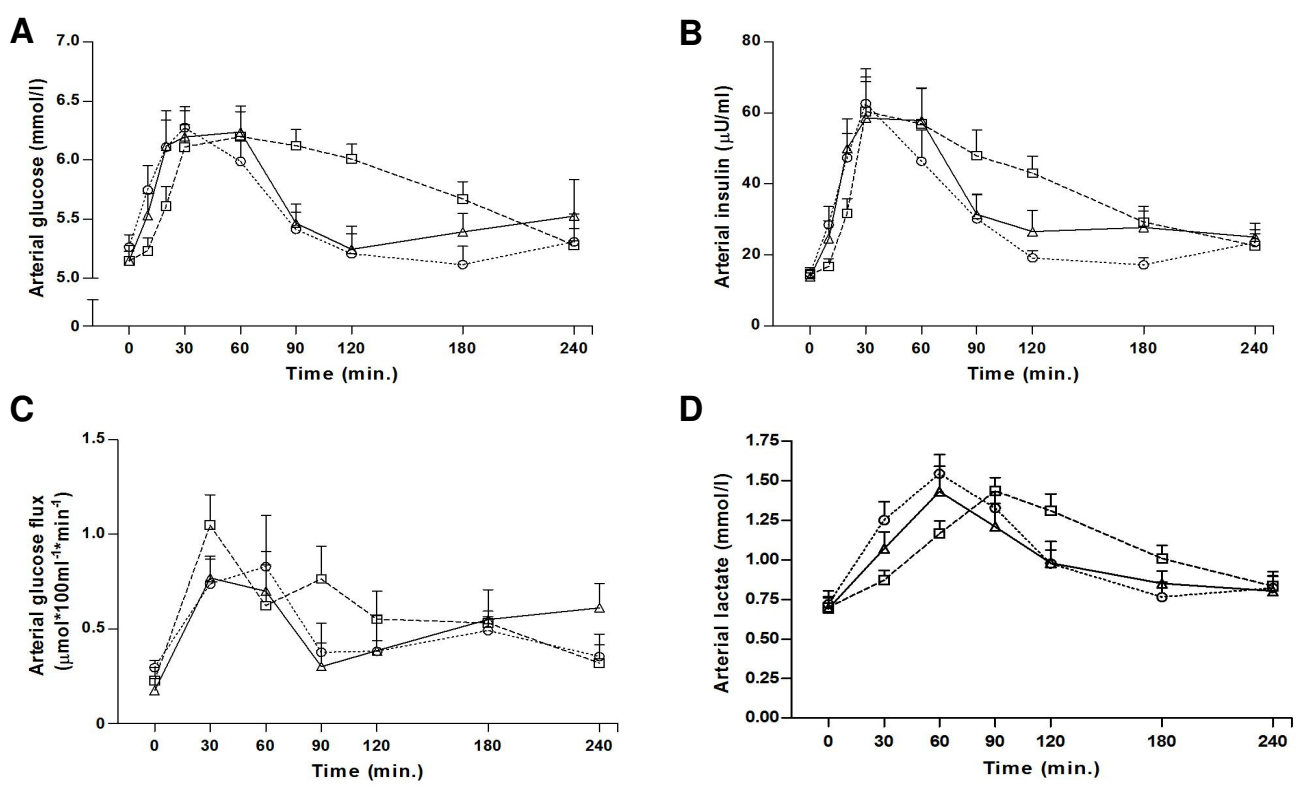

Figure 1. Postprandial arterialized glucose, insulin and lactate response.

(A) Arterialized glucose, (B) arterialized insulin, (C) the net flux of glucose and (D) arterialized lactate concentrations under fasting conditions $(\mathrm{t}=0)$ and after consumption of a high-fat mixed-meal. Values are mean \pm SEM. $n=10$. Repeated measures ANOVA were performed with Bonferroni post-hoc testing using the integrated responses (AUC) (Table 3). Square; SFA, triangle; MUFA, circles; PUFA.

\section{Whole-body and forearm muscle FFA metabolism}

\section{Whole-body FFA metabolism}

Postprandially, arterialized FFA concentrations decreased during the first $2 \mathrm{~h}$ and returned to fasting values after $4 \mathrm{~h}$ in all conditions (Figure 2A). FFA concentrations tended to be lower after the SFA meal in the mid phase (2-4h) compared with the PUFA meal ( $p=0.086$, Table 3$)$. $\left[{ }^{2} \mathrm{H}_{2}\right]$-labeled palmitate was infused intravenously and mixed with the plasma FFA pool. The tracer/tracee ratio (TTR) reached a steady state during fasting measurements (Figure 2B). Consistent with these 


\section{Chapter 4}

Table 3. Integrated responses (AUC) of plasma metabolites after the intake of high-fat mixed meals.

\begin{tabular}{|c|c|c|c|c|c|c|c|}
\hline & \multirow[b]{2}{*}{ SFA } & \multirow[b]{2}{*}{ MUFA } & \multirow[b]{2}{*}{ PUFA } & \multirow[b]{2}{*}{$\begin{array}{l}\text { ANOVA } \\
p \text {-value }\end{array}$} & \multicolumn{3}{|c|}{ Post-hoc } \\
\hline & & & & & $\begin{array}{l}\text { SFA vs } \\
\text { MUFA }\end{array}$ & $\begin{array}{l}\text { SFA vs } \\
\text { PUFA }\end{array}$ & $\begin{array}{l}\text { MUFA VS } \\
\text { PUFA }\end{array}$ \\
\hline \multicolumn{8}{|c|}{ Arterialized Glucose (mmol/l per min) } \\
\hline Postprandial (0-4h) & $5.77 \pm 0.13$ & $5.59 \pm 0.14$ & $5.48 \pm 0.12$ & 0.003 & 0.139 & 0.006 & 0.301 \\
\hline Early & $5.94 \pm 0.15$ & $5.79 \pm 0.15$ & $5.74 \pm 0.13$ & 0.040 & 0.474 & 0.013 & 1.000 \\
\hline Mid & $5.61 \pm 0.14$ & $5.39 \pm 0.15$ & $5.22 \pm 0.15$ & 0.002 & 0.179 & 0.011 & 0.174 \\
\hline \multicolumn{8}{|c|}{ Arterialized Insulin ( $\mu \mathrm{U} / \mathrm{ml}$ per min) } \\
\hline Postprandial (0-4h) & $38.7 \pm 4.5$ & $34.5 \pm 4.1$ & $27.0 \pm 2.5$ & 0.028 & 0.681 & 0.033 & 0.387 \\
\hline Early & $46.3 \pm 6.2$ & $42.2 \pm 5.3$ & $34.7 \pm 4.3$ & 0.182 & NA & NA & NA \\
\hline Mid & $31.0 \pm 3.9$ & $26.8 \pm 3.6$ & $19.3 \pm 2.0$ & 0.006 & 0.243 & 0.021 & 0.305 \\
\hline \multicolumn{8}{|c|}{ Net Glucose Flux across forearm muscle $\left(\mu \mathrm{mol}^{\star} 100 \mathrm{ml}^{-1 *} \min ^{-1}\right.$ per $\left.\mathrm{min}\right)$} \\
\hline Postprandial (0-4h) & $0.59 \pm 0.09$ & $0.52 \pm 0.06$ & $0.51 \pm 0.11$ & 0.228 & NA & NA & NA \\
\hline Early & $0.70 \pm 0.14$ & $0.51 \pm 0.06$ & $0.58 \pm 0.14$ & 0.075 & 0.107 & 0.254 & 1.000 \\
\hline Mid & $0.48 \pm 0.05$ & $0.52 \pm 0.09$ & $0.43 \pm 0.09$ & 0.289 & NA & NA & NA \\
\hline \multicolumn{8}{|c|}{ Arterialized Lactate (mmol// per min) } \\
\hline Postprandial (0-4h) & $1.08 \pm 0.06$ & $1.00 \pm 0.09$ & $1.02 \pm 0.08$ & 0.366 & NA & NA & NA \\
\hline Early & $1.12 \pm 0.06$ & $1.14 \pm 0.11$ & $1.20 \pm 0.09$ & 0.244 & NA & NA & NA \\
\hline Mid & $1.04 \pm 0.08$ & $0.87 \pm 0.07$ & $0.83 \pm 0.09$ & 0.048 & 0.068 & 0.145 & 1.000 \\
\hline \multicolumn{8}{|c|}{ Arterialized FFA (mmol/l per min) } \\
\hline Postprandial (0-4h) & $336 \pm 17$ & $377 \pm 33$ & $377 \pm 26$ & 0.193 & NA & NA & NA \\
\hline Early & $374 \pm 28$ & $360 \pm 33$ & $350 \pm 29$ & 0.704 & NA & NA & NA \\
\hline Mid & $297 \pm 16$ & $393 \pm 36$ & $403 \pm 29$ & 0.019 & 0.142 & 0.086 & 1.000 \\
\hline \multicolumn{8}{|c|}{ Rate of appearance FFA $\left(\mu \mathrm{mol}^{*} \mathrm{~kg}^{-1 *} \mathrm{~min}^{-1}\right.$ per min) } \\
\hline Postprandial (0-4h) & $4.60 \pm 0.40$ & $5.29 \pm 0.42$ & $5.62 \pm 0.28$ & 0.019 & 0.202 & 0.044 & 1.000 \\
\hline Early & $5.09 \pm 0.43$ & $5.71 \pm 0.47$ & $5.86 \pm 0.36$ & 0.174 & NA & NA & NA \\
\hline Mid & $4.11 \pm 0.42$ & $4.88 \pm 0.46$ & $5.37 \pm 0.25$ & 0.021 & 0.357 & 0.029 & 0.717 \\
\hline \multicolumn{8}{|c|}{ Arterialized TAG ( $\mu \mathrm{mol} / /$ per $\mathrm{min})$} \\
\hline Postprandial (0-4h) & $1716 \pm 192$ & $1727 \pm 183$ & $1424 \pm 180$ & 0.377 & NA & NA & NA \\
\hline Early & $1359 \pm 179$ & $1274 \pm 162$ & $1125 \pm 148$ & 0.656 & NA & NA & NA \\
\hline Mid & $2073 \pm 209$ & $2181 \pm 208$ & $1724 \pm 218$ & 0.141 & NA & NA & NA \\
\hline \multicolumn{8}{|c|}{$\left.{ }^{2} \mathrm{H}_{2}\right]$-labeled palmitate in TAG ( $\mu \mathrm{mol} / \mathrm{l}$ per $\left.\mathrm{min}\right)$} \\
\hline Postprandial (0-4h) & $9.8 \pm 0.9$ & $8.8 \pm 0.8$ & $8.0 \pm 0.8$ & 0.036 & 0.208 & 0.176 & 0.496 \\
\hline Early & $6.0 \pm 0.6$ & $5.5 \pm 0.5$ & $5.3 \pm 0.6$ & 0.224 & NA & NA & NA \\
\hline Mid & $13.6 \pm 1.3$ & $12.0 \pm 1.2$ & $10.6 \pm 1.1$ & 0.025 & 0.185 & 0.125 & 0.445 \\
\hline
\end{tabular}




\section{$\left[U-{ }^{13} \mathrm{C}\right]$-labeled palmitate in TAG ( $\mu \mathrm{mol} / \mathrm{l}$ per $\left.\mathrm{min}\right)$}

\begin{tabular}{lcccccccc} 
Postprandial $(0-4 h)$ & $4.0 \pm 0.4$ & $7.0 \pm 1.0$ & $3.8 \pm 0.5$ & $\mathbf{0 . 0 2 4}$ & 0.149 & 1.000 & 0.079 \\
Early (1-2h) & $13.3 \pm 3.2$ & $22.2 \pm 10.2$ & $7.5 \pm 2.5$ & 0.249 & NA & NA & NA \\
Mid & $5.6 \pm 0.8$ & $9.9 \pm 1.7$ & $5.4 \pm 1.0$ & $\mathbf{0 . 0 1 9}$ & 0.107 & 1.000 & 0.069 \\
\hline
\end{tabular}

Postprandial data are expressed as AUC/min and based on postprandial period (0-4h after meal ingestion) unless otherwise stated. Early is $0-2 \mathrm{~h}$ after meal ingestion and mid is $2-4 \mathrm{~h}$ after meal ingestion. SFA, saturated fatty acid; MUFA, monounsaturated; PUFA, polyunsaturated fatty acid; FFA, free fatty acids; TAG, triacylglycerol; NA, not applicable. Values are mean \pm SEM. $n=10$. $p$-value represents overall $p$-value of the repeated measures ANOVA. Post-hoc testing was performed using the Bonferroni correction.

findings, the $\mathrm{Ra}_{\mathrm{FFA}}$ in the circulation decreased after the meals, which is indicative of suppression of whole-body lipolysis (Figure 2C). The $\mathrm{Ra}_{\mathrm{FFA}}$ was more reduced after the SFA meal in the postprandial phase as compared with the PUFA meal $\left(\mathrm{p}=0.044\right.$, Table 3). $\left[\mathrm{U}-{ }^{13} \mathrm{C}\right]$-labeled palmitate (resulting from spillover of FA derived from chylomicron-TAG hydrolysis) appeared in the plasma FFA pool from 60min after meal ingestion and concentrations increased throughout the postprandial period. There were no differences in arterialized concentrations of $\left[{ }^{2} \mathrm{H}_{2}\right]-$ or $\left[\mathrm{U}-{ }^{13} \mathrm{C}\right]-$ labeled palmitate in FFA after the three high-fat mixed-meals at any time (data not shown). The TTR of $\left[{ }^{2} \mathrm{H}_{2}\right]$-labeled palmitate in FFA was higher in arterialized versus deep venous plasma after all high-fat mixed-meals (SFA: $p=0.004$, MUFA: $p=0.002$, PUFA: $p=0.001$ ), indicating dilution of the $\left[{ }^{2} \mathrm{H}_{2}\right]$-tracer in the plasma FFA pool across forearm muscle (Figure 2B). The TTR of $\left[\mathrm{U}-{ }^{13} \mathrm{C}\right]$-palmitate in FFA was not different in arterialized versus deep venous plasma after the three high-fat mixed-meals (Figure 2D).

\section{Forearm muscle FFA metabolism}

The net flux of plasma FFA across forearm muscle (arterio-venous concentration difference multiplied by forearm plasma flow) was not different after the high-fat mixed-meals (Table 4). At the same time, a consistent uptake of $\left[{ }^{2} \mathrm{H}_{2}\right]$-labeled palmitate FFA was observed after all high-fat mixed-meals (Table 4), with no differences between meals. 


\section{Chapter 4}

A

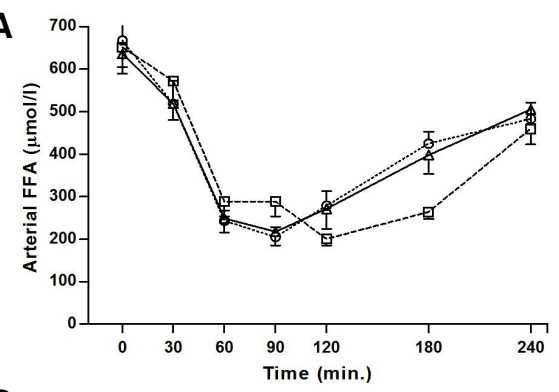

C

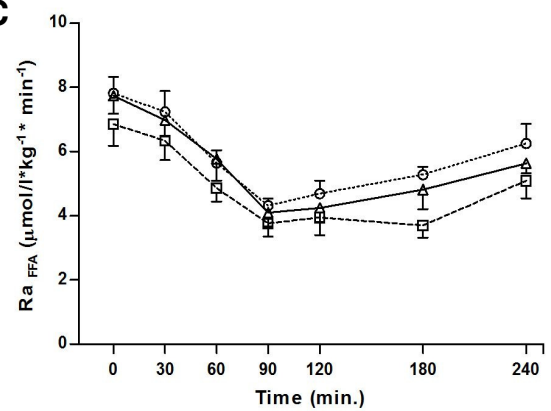

B
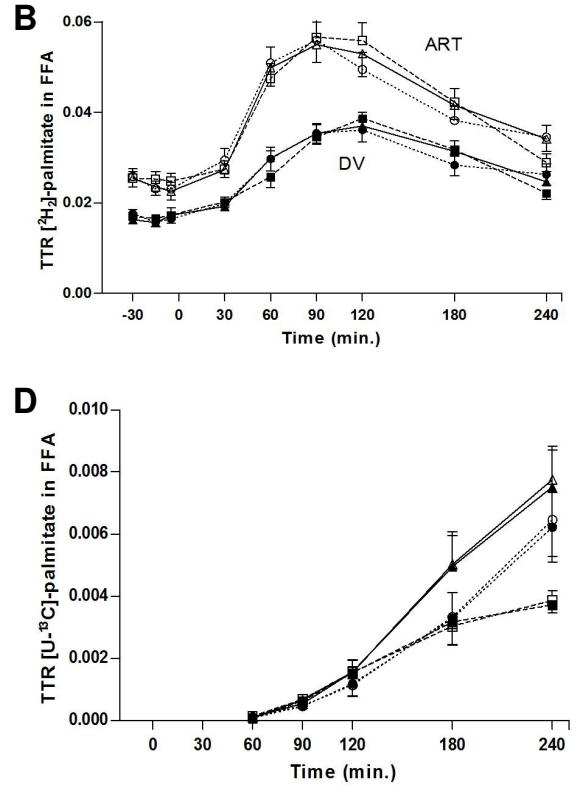

Figure 2. Postprandial whole body free fatty acid (FFA) metabolism.

(A) Arterialized plasma free fatty acid (FFA) concentrations, (B) the tracer-tracee ratio (TTR) of $\left[^{2} \mathrm{H}_{2}\right]$-palmitate, (C) the rate of appearance of FFA (RaFFA) and (D) TTR of $\left[\mathrm{U}-{ }^{13} \mathrm{C}\right]-$ palmitate. Values are mean \pm SEM. $n=10$. Repeated measures ANOVA were performed with Bonferroni post-hoc testing using the integrated responses (AUC) (Table 3). For figure $B$ and $D$ also paired student's t-test were performed to analyze the difference in TTR between arterialized and deep venous plasma. (B) The TTR of $\left[{ }^{2} \mathrm{H}_{2}\right]$-labeled palmitate in FFA was higher in arterialized versus deep venous plasma after all high-fat mixed-meals (iUC: SFA: $p=0.004$, MUFA: $p=0.002$, PUFA: $p=0.001$ ). (D) The TTR of $\mathrm{U}-{ }^{13} \mathrm{C}$-labeled palmitate was not different in arterialized versus deep venous plasma after the three high-fat mixed meals. (B and D) There were no differences between the three high fat mixed meals. Square; SFA, triangle; MUFA, circles; PUFA. White symbols: arterialized plasma concentration (ART); Black symbols: deep venous plasma concentration (DV).

\section{Whole-body and forearm muscle TAG metabolism}

\section{Whole-body TAG metabolism}

Arterialized plasma TAG concentrations were similar between groups under fasting conditions and after ingestion of a high-fat mixed-meal (Figure 3A and Table $\mathbf{3}$ ). The $\left[{ }^{2} \mathrm{H}_{2}\right]$-palmitate tracer could be measured in plasma TAG from the first baseline sample onward, reflecting incorporation of the intravenously infused tracer into VLDL-TAG (Figure 3B). The $\left[\mathrm{U}-{ }^{13} \mathrm{C}\right]$-palmitate tracer, given with the meal, appeared in plasma TAG from 60min after meal ingestion, representing chylomicron-TAG in the circulation (Figure 3B). Both labeled TAG fractions increased up to $4 \mathrm{~h}$ postprandial, whilst the $\left[\mathrm{U}-{ }^{13} \mathrm{C}\right]$-labeled palmitate in TAG tended 
to increase more pronounced after the MUFA meal as compared with the PUFA meal $\left(p=0.079\right.$, Figure 3B and Table 3). The increase in $\left[{ }^{2} \mathrm{H}_{2}\right]$-labeled palmitate in TAG was most pronounced after the SFA meal $(p=0.036$, Figure 3B and Table 3 ).

\section{A}

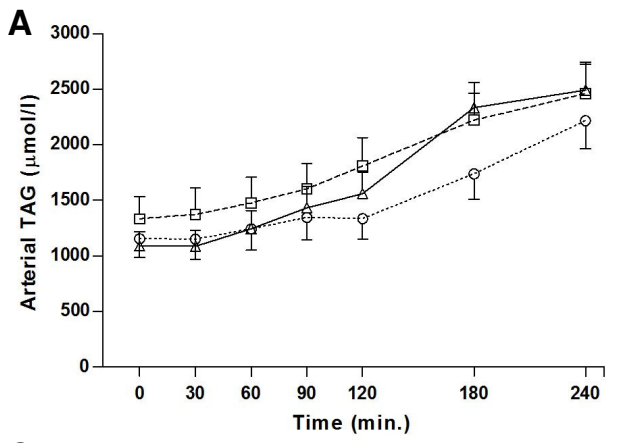

C

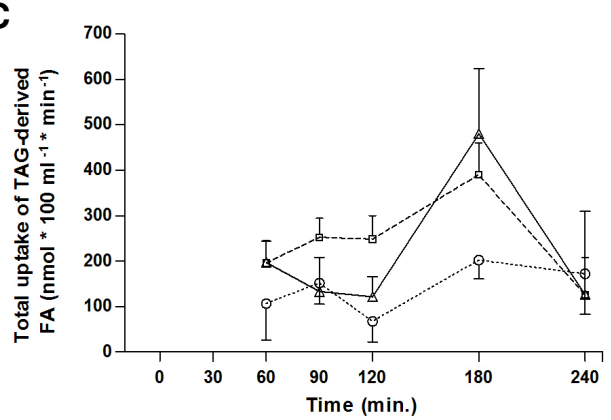

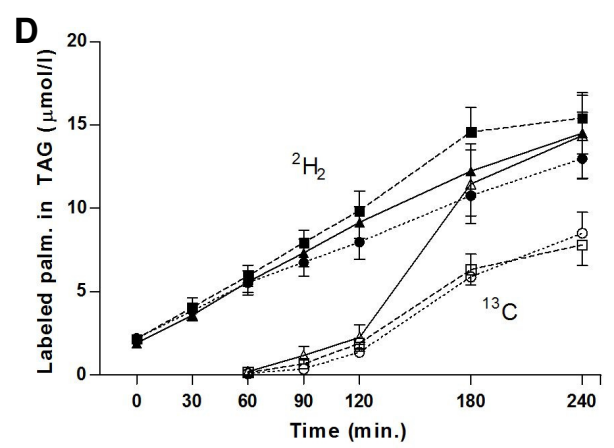

Figure 3. Postprandial whole triacylglycerol (TAG) metabolism.

(A) Arterialized plasma triacylglycerol (TAG) concentrations, (B) $\left[{ }^{2} \mathrm{H}_{2}\right]$-palmitate in TAG and $\left[\mathrm{U}-{ }^{13} \mathrm{C}\right.$-palmitate in TAG, and $(\mathrm{C})$ total uptake of TAG-derived FA during fasting $(\mathrm{t}=0)$ and after consumption of a high-fat mixed-meal. Values are mean \pm SEM. $n=10$. Repeated measures ANOVA were performed with Bonferroni post-hoc testing using the integrated responses (AUC) (Table 3 and 4). Square; SFA, triangle; MUFA, circles; PUFA. Black symbols are $\left[{ }^{2} \mathrm{H}_{2}\right]$-palmitate and white symbols are $\left[{ }^{13} \mathrm{C}\right]$-palmitate in panel $\mathrm{C}$.

\section{Forearm muscle TAG metabolism}

Fractional extraction of $\left[\mathrm{U}-{ }^{13} \mathrm{C}\right]$-labeled palmitate in TAG across forearm muscle was consistently greater than the fractional extraction of $\left[{ }^{2} \mathrm{H}_{2}\right]$-labeled palmitate in TAG throughout the whole postprandial period (data not shown). There were no significant differences in extraction of $\left[{ }^{2} \mathrm{H}_{2}\right]$-labeled palmitate in TAG after the three high-fat mixed-meals (Table 4). Extraction of $\left[\mathrm{U}-{ }^{13} \mathrm{C}\right]$-labeled palmitate in TAG tended to be reduced after the PUFA meal compared with the MUFA meal in the early phase ( $p=0.06$, Table 4$)$. The (unidirectional) uptake of FA derived from TAG hydrolysis across forearm muscle was reduced after the PUFA meal as compared with the SFA meal $(p=0.02$, Figure $3 C$ and Table 4$)$. 


\section{Chapter 4}

Table 4. Fasting and postprandial FFA and TAG metabolism and forearm blood flow

\begin{tabular}{|c|c|c|c|c|}
\hline & SFA & MUFA & PUFA & $p$-value \\
\hline \multicolumn{5}{|c|}{ Forearm blood flow $\left(\mathrm{ml}^{\star} 100 \mathrm{ml}^{-1 *} \mathrm{~min}^{-1}\right)$} \\
\hline Fasting & $3.28 \pm 0.53$ & $2.74 \pm 0.29$ & $2.65 \pm 0.21$ & 0.189 \\
\hline Postprandial (0-4h) & $3.25 \pm 0.41$ & $2.95 \pm 0.26$ & $2.59 \pm 0.26$ & 0.859 \\
\hline Early & $3.28 \pm 0.48$ & $2.90 \pm 0.27$ & $2.77 \pm 0.26$ & 0.725 \\
\hline Mid & $3.10 \pm 0.26$ & $2.87 \pm 0.23$ & $3.01 \pm 0.23$ & 0.628 \\
\hline
\end{tabular}

Net FFA flux across forearm muscle $\left(\mathrm{nmol}^{*} 100 \mathrm{ml}^{-1 *} \mathrm{~min}^{-1}\right)$

$\begin{array}{lcccc}\text { Fasting } & 14.3 \pm 80.9 & 20.4 \pm 61.2 & 11.5 \pm 60.1 & 0.937 \\ \text { Postprandial (0-4h) } & 26.7 \pm 37.2 & 47.2 \pm 29.6 & 20.0 \pm 32.7 & 0.375 \\ \text { Early } & -14.0 \pm 52.2 & 6.7 \pm 39.1 & -20.2 \pm 35.0 & 0.195 \\ \text { Mid } & 67.3 \pm 24.0 & 87.6 \pm 22.0 & 64.5 \pm 37.5 & 0.601\end{array}$

$\left.{ }^{2} \mathrm{H}_{2}\right]$-palmitate FFA net flux across forearm muscle $\left(\mathrm{nmol}^{*} 100 \mathrm{ml}^{-1 *} \mathrm{~min}^{-1}\right.$ )

$\begin{array}{lllll}\text { Fasting } & 2.19 \pm 0.47 & 1.78 \pm 0.40 & 1.80 \pm 0.34 & 0.504 \\ \text { Postprandial (0-4h) } & 1.80 \pm 0.37 & 1.58 \pm 0.23 & 1.68 \pm 0.29 & 0.703 \\ \text { Early } & 1.78 \pm 0.40 & 1.49 \pm 0.32 & 1.48 \pm 0.32 & 0.271 \\ \text { Mid } & 1.83 \pm 0.38 & 1.66 \pm 0.32 & 1.89 \pm 0.33 & 0.826\end{array}$

$\left[{ }^{13} \mathrm{C}\right]$-palmitate FFA net flux across forearm muscle $\left(\mathrm{nmol}^{\star} 100 \mathrm{ml}^{-1 *} \mathrm{~min}^{-1}\right)$

$\begin{array}{lcccc}\text { Fasting } & \text { NA } & \text { NA } & \text { NA } & \\ \text { Postprandial (0-4h) } & 7.53 \pm 3.64 & 9.87 \pm 3.97 & 3.69 \pm 4.56 & 0.448 \\ \text { Early } & 0.07 \pm 0.10 & -0.07 \pm 0.12 & 0.02 \pm 0.03 & 0.505 \\ \text { Mid } & 0.06 \pm 0.03 & 0.08 \pm 0.03 & 0.03 \pm 0.04 & 0.408\end{array}$

Net TAG flux across forearm muscle $\left(\mathrm{nmol}^{\star} 100 \mathrm{ml}^{-1 *} \mathrm{~min}^{-1}\right)$

$\begin{array}{lcccc}\text { Fasting } & 58.0 \pm 35.5 & 21.6 \pm 9.7 & 44.8 \pm 21.5 & 0.365 \\ \text { Postprandial (0-4h) } & 81.4 \pm 9.9 & 70.3 \pm 55.0 & 48.7 \pm 16.3 & 0.526 \\ \text { Early } & 85.6 \pm 33.8 & 47.6 \pm 10.8 & 44.6 \pm 16.3 & 0.904 \\ \text { Mid } & 74.4 \pm 25.2 & 87.2 \pm 24.1 & 68.9 \pm 15.3 & 0.647\end{array}$

$\left.{ }^{2} \mathrm{H}_{2}\right]$-palmitate TAG net flux across forearm muscle $\left(\mathrm{nmol}^{*} 100 \mathrm{ml}^{-1}{ }^{-1} \mathrm{~min}^{-1}\right)$

$\begin{array}{lcccc}\text { Fasting } & 0.05 \pm 0.27 & 0.12 \pm 0.21 & 0.38 \pm 0.14 & 0.479 \\ \text { Postprandial (0-4h) } & -0.08 \pm 0.30 & -0.35 \pm 0.20 & 0.18 \pm 0.18 & 0.277 \\ \text { Early } & 0.13 \pm 0.24 & 0.31 \pm 0.19 & 0.34 \pm 0.23 & 0.678 \\ \text { Mid } & -0.28 \pm 0.53 & -1.02 \pm 0.31 & 0.02 \pm 0.36 & 0.255\end{array}$

$\left.I^{13} \mathrm{C}\right]$-palmitate TAG net flux across forearm muscle $\left(\mathrm{nmol}^{*} 100 \mathrm{ml}^{-1 *} \mathrm{~min}^{-1}\right)$

$\begin{array}{lcccc}\text { Fasting } & \text { NA } & \text { NA } & \text { NA } & \text { NA } \\ \text { Postprandial (0-4h) } & 0.35 \pm 0.18 & -0.18 \pm 0.18 & 0.12 \pm 0.30 & 0.256 \\ \text { Early } & 0.19 \pm 0.07 & 0.30 \pm 0.10 & 0.04 \pm 0.02^{\#} & 0.103 \\ \text { Mid } & 0.43 \pm 0.26 & -0.43 \pm 0.31 & 0.16 \pm 0.45 & 0.214\end{array}$


Unidirectional uptake FA derived from TAG hydrolysis (nmol*100 $\mathrm{ml}^{-1 *} \mathrm{~min}^{-1}$ )

$\begin{array}{lllll}\text { Fasting } & 271.5 \pm 41.9 & 250.3 \pm 61.4 & 147.3 \pm 41.8^{*} & 0.082 \\ \text { Postprandial (0-4h) } & 237.3 \pm 28.2 & 146.5 \pm 46.9 & 119.8 \pm 40.4^{*} & 0.069 \\ \text { Early } & 288.6 \pm 51.5 & 302.3 \pm 76.0 & 161.1 \pm 46.1^{*} & 0.094\end{array}$

Postprandial data are expressed as AUC/min and based on postprandial period (0-4h after meal ingestion) unless otherwise stated. Early is $0-2 \mathrm{~h}$ after meal ingestion and mid is $2-4 \mathrm{~h}$ after meal ingestion. SFA, saturated fatty acid; MUFA, monounsaturated; PUFA, polyunsaturated fatty acid; FFA, free fatty acids; TAG, triacylglycerol; NA, not applicable. Values are mean \pm SEM. $n=10$. $p$-value represents overall $p$-value of the repeated measures ANOVA. Post-hoc testing was performed using the bonferroni correction. * SFA versus PUFA $p<0.05$. \# MUFA versus PUFA $p<0.1$.

\section{Energy expenditure and whole-body substrate metabolism}

Whole-body energy expenditure, respiratory quotient, carbohydrate oxidation and fat oxidation during fasting and after meal ingestion were comparable between the different meals (data not shown).

\section{A}

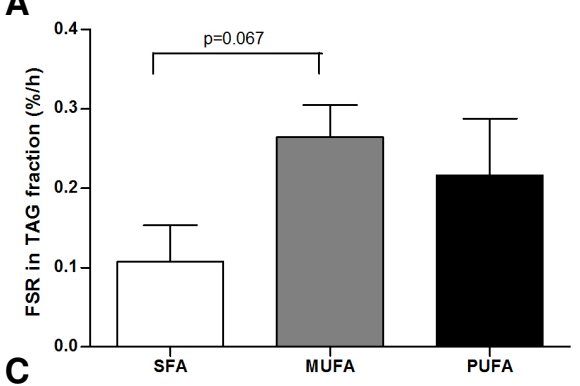

B

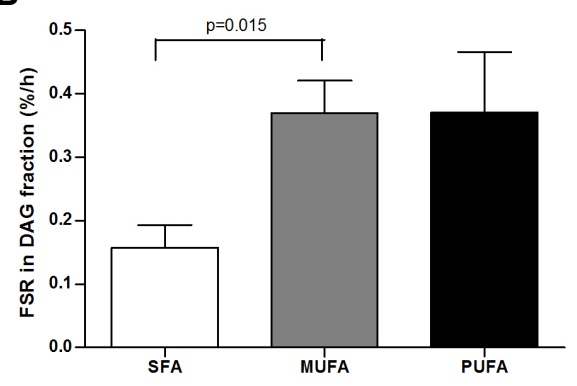

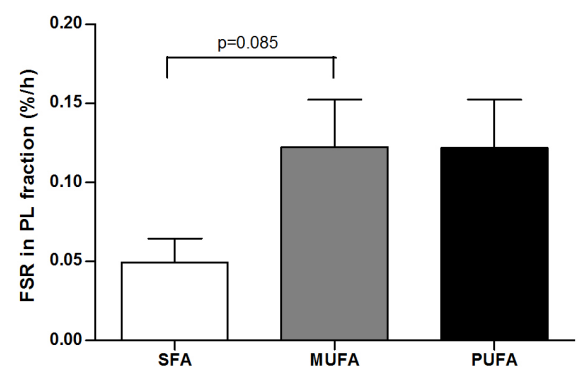

Figure 4. Fractional synthetic rate after the high-fat mixed-meals.

The FSR in (A) TAG, (B) DAG and (C) PL after consumption of a high-fat mixed-meal. $D A G$, Diacylglycerol; $F S R$, fractional synthetic rate; $T A G$, triacylglycerol. Values are mean $\pm S E M$. $n=8$. Paired student's t-tests were performed. 


\section{Chapter 4}

\section{Intramuscular lipid metabolism}

\section{Muscle lipid content and composition}

The content of skeletal muscle TAG, DAG, FFA, and PL did not change after the three high-fat mixed-meals (data not shown). The saturation of muscle TAG, DAG, $P L$ and FFA was not different after the ingestion of the different meals (data not shown). Also the individual FA in the different muscle lipid pools did not change after the three meals (data not shown).

Incorporation of [U- $\left.{ }^{13} \mathrm{C}\right]$-labeled palmitate in muscle lipids (FSR).

The fractional synthetic rate (FSR) of skeletal muscle DAG $(p=0.015)$ was higher after the MUFA meal and tended to be higher in the TAG ( $p=0.067)$ and PL fraction $(p=0.08)$ as compared with the SFA meal (Figure 4). After the PUFA meal, FSR values were of similar magnitude as after the MUFA meal but were not statistically different as compared with the SFA meal. This may indicate that a higher proportion of palmitate from the intramuscular FFA pool was directed toward the muscle lipid pools after the unsaturated FA meals.

A

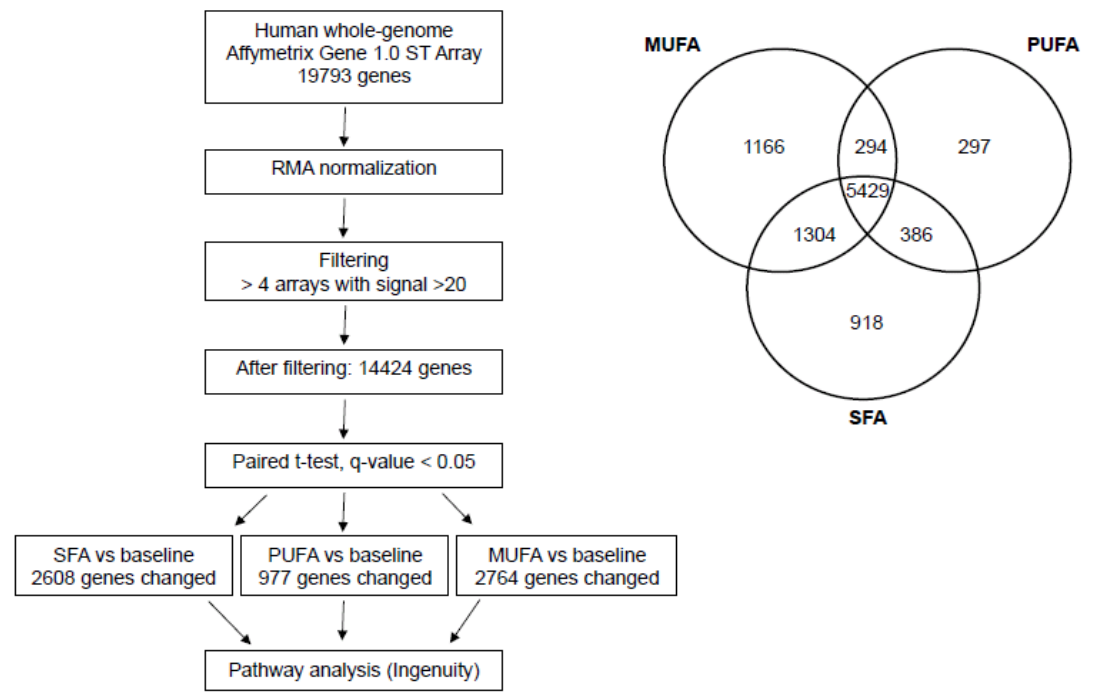

Figure 5. Gene selection procedures and criteria.

(A) Flow chart of gene selection and number of genes changed in the microarray analysis.

(B) Venn diagram of selected genes with a q-value $<0.05$. Overlapping genes were regulated in the same manner after the three meals and were not taken into account for 
further analysis. MUFA, monounsaturated fatty acid; PUFA, polyunsaturated fatty acid; RMA, robust multichip average; SFA, saturated fatty acid.

\section{Microarry analysis}

Microarray analysis was performed on skeletal muscle tissue before and 4 hours after consumption of a high-fat mixed-meal consisting of SFA, MUFA or PUFA. During 2 skeletal muscle biopsy procedures, we could not obtain enough biopsy material for further analysis From the 19793 genes present on the array, 14,424 genes were defined as expressed in skeletal muscle (Figure 5A). Genes that showed comparable regulation after the three meals $(5,429$ genes) were not taken into account for further analysis (Figure 5B). About $66 \%$ of the genes that were changed after the SFA and MUFA meal were down-regulated, whereas $60 \%$ of the genes were down-regulated after the PUFA meal. To obtain further insight into the physiological relevance of these genes, pathway analysis was performed. The top 10 most significantly regulated pathways after each meal are listed in Figure 6 . The pathways that were affected the most after consumption of the SFA and MUFA meal were those involved in ubiquinone biosynthesis, mitochondrial dysfunction and oxidative phosphorylation, which consisted of genes involved in complex I-V of the respiratory chain. Consumption of the SFA meal resulted in significantly decreased expression of 33 out of 96 OXPHOS genes, while 28 genes were downregulated after the MUFA meal and 7 after the PUFA meal. Thus, there were less genes significantly down-regulated after the PUFA meal, indicating less downregulation of mitochondrial function (data not shown). To confirm gene expression changes revealed by microarray analysis, GPCR was used. We selected genes involved in complex I-V of the respiratory chain. All genes were significantly downregulated after the SFA meal, which confirmed the microarray analysis. NDUFA1, NDUFB3, COX17 and ATP5J were less down-regulated after the PUFA meal, so the change in expression of genes showed the same direction of change as the microarray, but the relatively small differences in expression of individual genes did not reach statistical significance between meals (data not shown). 


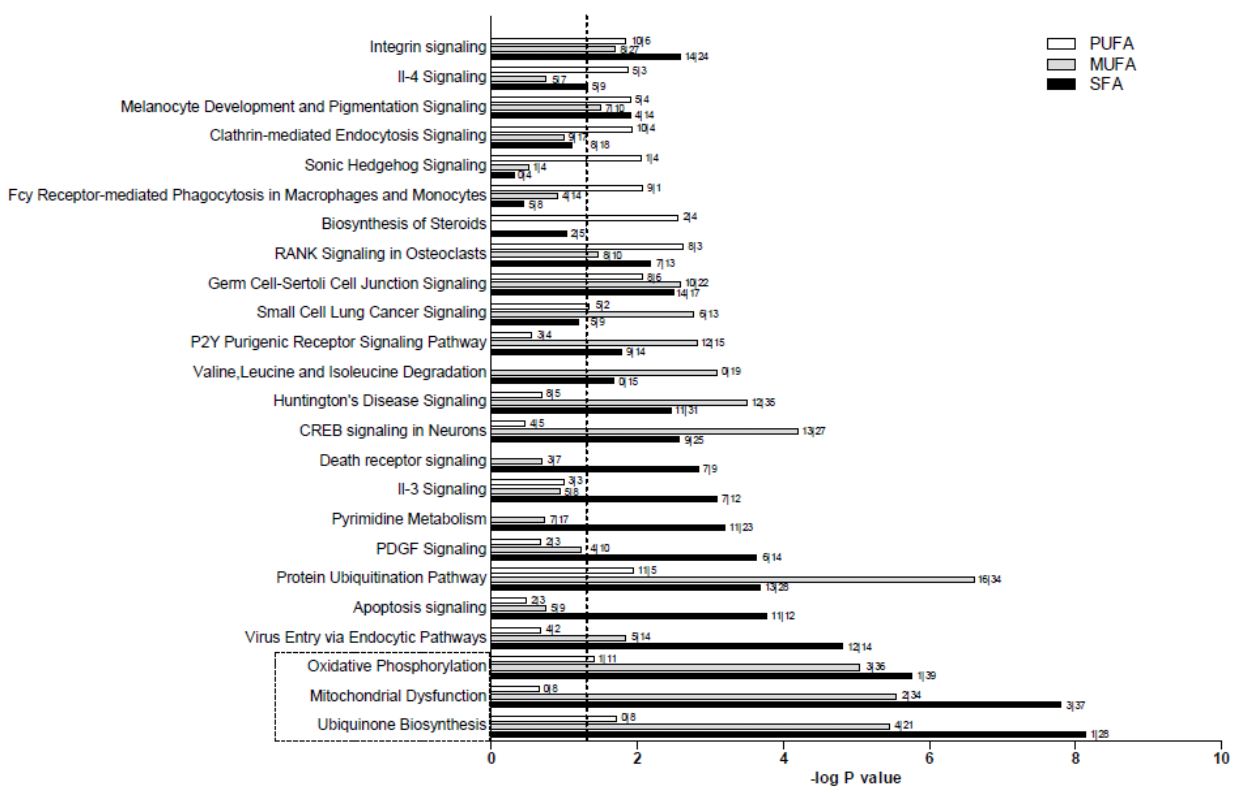

Figure 6. Top 10 significantly regulated canonical pathways after each high-fat mixedmeal according to Ingenuity Pathway Analysis (Ingenuity Systems, Redwood City, CA). Black bars indicate the saturated fatty acid (SFA) meal, the grey bars indicate the monounsaturated fatty acid (MUFA) meal and the white bars indicate the polyunsaturated fatty acid (PUFA) meal. The first number next to the bar indicates the number of significantly up-regulated genes involved in each pathway and the second number indicates the number of significantly down-regulated genes. The significance of each pathway is indicated by $\log (P$ value $)>1.3$, which corresponds to $P<0.05$. The dashed vertical line crosses the $x$ axis at $-\log (P$ value $)=1.3$. The dashed box indicates the three pathways that were most significant after a SFA meal.

\section{DISCUSSION}

The present study examined postprandial skeletal muscle FA handling in obese insulin resistant men consuming three high-fat mixed-meals with different FA composition. Ingestion of the PUFA meal resulted in an improved postprandial insulin sensitivity compared with SFA, which was accompanied by a reduced muscle TAG-derived FA uptake, and a tendency towards increased intramuscular lipid turnover. 
Arterialized plasma insulin and glucose concentrations were higher after the SFA meal as compared with the PUFA meal, with intermediate values for the MUFA meal. Since there were no differences in net glucose flux between meals, this implies higher postprandial insulin sensitivity after the PUFA meal (as evidenced by data of the PGI). Our data are in line with previous studies, showing that a PUFA meal improved insulin sensitivity as compared with a SFA meal [38, 39]. We found that the effect of MUFA was intermediate between the SFA meal and the PUFA meal, which is in agreement with studies that have shown beneficial effects of MUFA on insulin sensitivity as compared with SFA [39-42].

This differential effect on insulin sensitivity of PUFA versus SFA was accompanied by differences in skeletal muscle FA metabolism. The uptake of TAG-derived FA by forearm muscle decreased after the PUFA meal in the postprandial period as compared with the SFA and MUFA meal. Circulating TAG concentrations were not significantly lower after the PUFA meal compared to the other meals, suggesting that a reduced TAG supply is not responsible for the reduced PUFA-induced TAG extraction. The reduced TAG extraction may be related to the decreased postprandial insulin concentrations, which may have resulted in reduced muscle lipoprotein lipase (LPL) activity [35]. Furthermore, the FA transporter CD36 is acutely upregulated during insulin stimulation [34]. Thus, reduced CD36 content in skeletal muscle may also have contributed to the lower TAG extraction after the PUFA meal.

Beside the reduced uptake of TAG-derived FA with PUFA, it seemed that there was a higher FSR of the TAG, DAG and PL pool after the MUFA meal compared with the SFA meal. The FSR of the lipid pools was comparable after the PUFA and MUFA meal but values after the PUFA meal were not significantly different from the SFA meal. These data should be interpreted with caution, since skeletal muscle biopsies were taken $4 \mathrm{~h}$ hours after ingestion of the high-fat mixed-meal, when a steady-state has not yet been reached. Nevertheless, these data hint towards a higher incorporation of dietary $\left[\mathrm{U}-{ }^{13} \mathrm{C}\right]$-labeled palmitate from the muscle FFA pool in the different lipid fractions in skeletal muscle with unsaturated FA compared with SFA. Additionally, there was a lesser down-regulation of the mitochondrial oxidative genes after the PUFA compared with the SFA or MUFA meal, suggesting that overall lipid turnover is higher after the PUFA compared with the SFA meal. The finding that a PUFA-induced improvement in postprandial insulin sensitivity is accompanied by a higher intramuscular lipid turnover is consistent with a recent study, demonstrating that obese prediabetic insulin resistant subjects have a 


\section{ChAPTER 4}

reduced fractional synthetic rate of intramuscular TAG compared with controls [43]. Overall, our data support the concept that not the TAG concentration per se but rather lipid turnover may determine insulin sensitivity.

Human studies examining the short-term effect of dietary FA on postprandial lipid profile suggest that the FA composition of the meal may influence the absorption, synthesis, and secretion of dietary TAG as well as the size of the chylomicron particles [44-46]. This study showed that postprandial circulating chylomicron concentrations were highest after the MUFA meal. Other studies also found increased TAG concentration after a MUFA meal [44, 47-49]. De Bruin et al. [48] found that the removal rate of olive oil chylomicron remnants was lower, which may be explained by a reduced endothelial LPL action due to their TAG content or greater particle number. This may imply that MUFA-chylomicrons have to rely on an alternative route for their removal from the circulation. Indeed, it has been suggested that hepatic lipase plays a significant role in the removal of MUFAenriched particles $[48,50]$.

It should be noted that we measured responses in the acute postprandial period. It remains to be established if improvement in insulin sensitivity after the PUFA meal due to lower lipid uptake (and possible less accumulation of fat in the muscle) is relevant in the acute postprandial period. In fact, the increase in insulin sensitivity after the PUFA meal may also be explained by other mechanisms beside lower lipid uptake. For example, differences in the secretion of gut hormones (glucagonlike peptide 1 and cholecystokinin) could potentiate differential insulin secretion and insulin sensitivity according to FA composition of the meals [41, 46]. Thus, the exact mechanisms responsible for the differential postprandial insulin sensitivity should be elucidated in future studies. Furthermore, it remains to be established whether these acute effects may contribute to findings after long-term dietary intervention. It has become clear from dietary intervention studies that long-term isocaloric replacement of SFA has no major effects on insulin sensitivity [51].

In conclusion, the present study demonstrated that dietary FA have an acute effect on postprandial insulin sensitivity. Replacing SFA with PUFA may induce a reduced TAG-derived FA uptake, and a tendency toward a higher lipid turnover as reflected by a more transcriptional oxidative phenotype and altered intracellular lipid partitioning. These data suggest that the effects of replacement of SFA by PUFA may contribute to lower uptake of lipids in skeletal muscle and may be therefore protective against the development of insulin resistance in humans. 


\section{ACKNOWLEDGEMENTS}

We thank all subjects for participation in the present study. We gratefully thank Jos Stegen, Wendy Sluijsmans, Hasibe Aydeniz, Yvonne Essers and Annemie Gijssen for their excellent analytical support.

\section{REFERENCES}

1. Goossens $\mathrm{GH}$ : The role of adipose tissue dysfunction in the pathogenesis of obesity-related insulin resistance. Physiol Behav 2008, 94(2):206-218.

2. Frayn KN: Adipose tissue as a buffer for daily lipid flux. Diabetologia 2002, 45(9):1201-1210.

3. Blaak EE, Wagenmakers AJ, Glatz JF, Wolffenbuttel BH, Kemerink GJ, Langenberg CJ, Heidendal GA, Saris WH: Plasma FFA utilization and fatty acidbinding protein content are diminished in type 2 diabetic muscle. $A m \mathrm{~J}$ Physiol Endocrinol Metab 2000, 279(1):E146-154.

4. Mensink M, Blaak EE, van Baak MA, Wagenmakers AJ, Saris WH: Plasma free Fatty Acid uptake and oxidation are already diminished in subjects at high risk for developing type 2 diabetes. Diabetes 2001, 50(11):2548-2554.

5. Kelley DE, Goodpaster B, Wing RR, Simoneau JA: Skeletal muscle fatty acid metabolism in association with insulin resistance, obesity, and weight loss. Am J Physiol 1999, 277(6 Pt 1):E1130-1141.

6. van Hees AM, Jans A, Hul GB, Roche HM, Saris WH, Blaak EE: Skeletal Muscle Fatty Acid Handling in Insulin Resistant Men. Obesity (Silver Spring) 2011.

7. Corcoran MP, Lamon-Fava S, Fielding RA: Skeletal muscle lipid deposition and insulin resistance: effect of dietary fatty acids and exercise. Am J Clin Nutr 2007, 85(3):662-677.

8. Schmitz-Peiffer C: Signalling aspects of insulin resistance in skeletal muscle: mechanisms induced by lipid oversupply. Cell Signal 2000, 12(9-10):583-594.

9. Schrauwen $P$, Hesselink MK: Oxidative capacity, lipotoxicity, and mitochondrial damage in type 2 diabetes. Diabetes 2004, 53(6):1412-1417.

10. Roden M: How free fatty acids inhibit glucose utilization in human skeletal muscle. News Physiol Sci 2004, 19:92-96.

11. Mensink M, Blaak EE, Vidal H, De Bruin TW, Glatz JF, Saris WH: Lifestyle changes and lipid metabolism gene expression and protein content in skeletal muscle of subjects with impaired glucose tolerance. Diabetologia 2003, 46(8):1082-1089.

12. Mensink M, Hesselink MK, Russell AP, Schaart G, Sels JP, Schrauwen P. Improved skeletal muscle oxidative enzyme activity and restoration of PGC-1 alpha and PPAR beta/delta gene expression upon rosiglitazone treatment in obese patients with type 2 diabetes mellitus. Int $J$ Obes (Lond) 2007, 31(8):1302-1310.

13. Corpeleijn E, Feskens EJ, Jansen EH, Mensink M, Saris WH, de Bruin TW, Blaak $\mathrm{EE}$ : Improvements in glucose tolerance and insulin sensitivity after lifestyle intervention are related to changes in serum fatty acid profile and desaturase activities: the SLIM study. Diabetologia 2006, 49(10):2392-2401.

14. Hanada H, Morikawa K, Hirota K, Nonaka M, Umehara Y: Induction of apoptosis and lipogenesis in human preadipocyte cell line by n-3 PUFAs. Cell Biol Int 2011, 35(1):51-59. 
15. Montell E, Turini M, Marotta M, Roberts M, Noe V, Ciudad CJ, Mace K, GomezFoix AM: DAG accumulation from saturated fatty acids desensitizes insulin stimulation of glucose uptake in muscle cells. Am $J$ Physiol Endocrinol Metab 2001, 280(2):E229-237.

16. Gaster $M$, Rustan AC, Beck-Nielsen $H$ : Differential utilization of saturated palmitate and unsaturated oleate: evidence from cultured myotubes. Diabetes 2005, 54(3):648-656.

17. Roche HM: Fatty acids and the metabolic syndrome. Proc Nutr Soc 2005, 64(1):23-29.

18. Bickerton AS, Roberts R, Fielding BA, Hodson L, Blaak EE, Wagenmakers AJ, Gilbert M, Karpe F, Frayn KN: Preferential uptake of dietary Fatty acids in adipose tissue and muscle in the postprandial period. Diabetes 2007, 56(1):168-176.

19. DeFronzo RA, Tobin JD, Andres R: Glucose clamp technique: a method for quantifying insulin secretion and resistance. Am J Physiol 1979, 237(3):E214223.

20. van Hees AM, Saris WH, Hul GB, Schaper NC, Timmerman BE, Lovegrove JA, Roche HM, Blaak EE: Effects of dietary fat modification on skeletal muscle fatty acid handling in the metabolic syndrome. Int $J$ Obes (Lond) 2010, 34(5):859-870.

21. Goossens GH, Blaak EE, Schiffers PM, Saris WH, van Baak MA: Effect of shortterm ACE inhibitor treatment on peripheral insulin sensitivity in obese insulin-resistant subjects. Diabetologia 2006, 49(12):3009-3016.

22. Adriaens MP, Schoffelen PF, Westerterp KR: Intra-individual variation of basal metabolic rate and the influence of daily habitual physical activity before testing. Br J Nutr 2003, 90(2):419-423.

23. Schoffelen PF, Westerterp KR, Saris WH, Ten Hoor F: A dual-respiration chamber system with automated calibration. J Appl Physiol 1997, 83(6):20642072.

24. Weir JB: New methods for calculating metabolic rate with special reference to protein metabolism. J Physiol 1949, 109(1-2):1-9.

25. Bergstrom J, Hermansen L, Hultman E, Saltin B: Diet, muscle glycogen and physical performance. Acta Physiol Scand 1967, 71(2):140-150.

26. Hoffman E: Expression profiling--best practices for data generation and interpretation in clinical trials. Nature reviews 2004, 5(3):229-237.

27. Dai M, Wang P, Boyd AD, Kostov G, Athey B, Jones EG, Bunney WE, Myers RM, Speed TP, Akil $\mathrm{H}$ et al: Evolving gene/transcript definitions significantly alter the interpretation of GeneChip data. Nucleic acids research 2005, 33(20):e175.

28. Irizarry RA, Bolstad BM, Collin F, Cope LM, Hobbs B, Speed TP: Summaries of Affymetrix GeneChip probe level data. Nucleic acids research 2003, 31(4):e15.

29. Bolstad BM, Irizarry RA, Astrand M, Speed TP: A comparison of normalization methods for high density oligonucleotide array data based on variance and bias. Bioinformatics (Oxford, England) 2003, 19(2):185-193.

30. Storey JD, Tibshirani R: Statistical significance for genomewide studies. Proceedings of the National Academy of Sciences of the United States of America 2003, 100(16):9440-9445.

31. Smyth GK: Linear models and empirical bayes methods for assessing differential expression in microarray experiments. Statistical applications in genetics and molecular biology 2004, 3:Article3.

32. Vandesompele J, De Preter K, Pattyn F, Poppe B, Van Roy N, De Paepe A, Speleman F: Accurate normalization of real-time quantitative RT-PCR data by geometric averaging of multiple internal control genes. Genome biology 2002, 3(7):RESEARCH0034. 
33. Matthews DR, Hosker JP, Rudenski AS, Naylor BA, Treacher DF, Turner RC: Homeostasis model assessment: insulin resistance and beta-cell function from fasting plasma glucose and insulin concentrations in man. Diabetologia 1985, 28(7):412-419.

34. Bonen A, Benton CR, Campbell SE, Chabowski A, Clarke DC, Han XX, Glatz JF, Luiken JJ: Plasmalemmal fatty acid transport is regulated in heart and skeletal muscle by contraction, insulin and leptin, and in obesity and diabetes. Acta Physiol Scand 2003, 178(4):347-356.

35. Wang $\mathrm{H}$, Eckel $\mathrm{RH}$ : Lipoprotein lipase: from gene to obesity. Am J Physiol Endocrinol Metab 2009, 297(2):E271-288.

36. RR W: Radioactive and Stable Isotope Tracers in Biomedicine: Principles and Practice of Kinetics Analysis.: Wiley-Liss: New York, USA; 1992.

37. Guo Z, Jensen MD: Intramuscular fatty acid metabolism evaluated with stable isotopic tracers. J Appl Physiol 1998, 84(5):1674-1679.

38. Xiao C, Giacca A, Carpentier A, Lewis GF: Differential effects of monounsaturated, polyunsaturated and saturated fat ingestion on glucosestimulated insulin secretion, sensitivity and clearance in overweight and obese, non-diabetic humans. Diabetologia 2006, 49(6):1371-1379.

39. Lopez S, Bermudez B, Pacheco YM, Villar J, Abia R, Muriana FJ: Distinctive postprandial modulation of beta cell function and insulin sensitivity by dietary fats: monounsaturated compared with saturated fatty acids. Am J Clin Nutr 2008, 88(3):638-644.

40. Lopez S, Bermudez B, Ortega A, Varela LM, Pacheco YM, Villar J, Abia R, Muriana FJ: Effects of meals rich in either monounsaturated or saturated fat on lipid concentrations and on insulin secretion and action in subjects with high fasting triglyceride concentrations. Am J Clin Nutr 2011, 93(3):494-499.

41. Robertson MD, Jackson KG, Fielding BA, Williams CM, Frayn KN: Acute effects of meal fatty acid composition on insulin sensitivity in healthy postmenopausal women. Br J Nutr 2002, 88(6):635-640.

42. Paniagua JA, de la Sacristana AG, Sanchez E, Romero I, Vidal-Puig A, Berral FJ, Escribano A, Moyano MJ, Perez-Martinez P, Lopez-Miranda J et al: A MUFA-rich diet improves posprandial glucose, lipid and GLP-1 responses in insulinresistant subjects. J Am Coll Nutr 2007, 26(5):434-444.

43. Perreault L, Bergman BC, Hunerdosse DM, Playdon MC, Eckel RH: Inflexibility in intramuscular triglyceride fractional synthesis distinguishes prediabetes from obesity in humans. Obesity (Silver Spring) 2010, 18(8):1524-1531.

44. Jackson KG, Wolstencroft EJ, Bateman PA, Yaqoob P, Williams CM: Acute effects of meal fatty acids on postprandial NEFA, glucose and apo $E$ response: implications for insulin sensitivity and lipoprotein regulation? $\mathrm{Br} J$ Nutr 2005, 93(5):693-700.

45. Weintraub MS, Zechner R, Brown A, Eisenberg S, Breslow JL: Dietary polyunsaturated fats of the W-6 and W-3 series reduce postprandial lipoprotein levels. Chronic and acute effects of fat saturation on postprandial lipoprotein metabolism. J Clin Invest 1988, 82(6):1884-1893.

46. Zampelas A, Peel AS, Gould BJ, Wright J, Williams CM: Polyunsaturated fatty acids of the $n-6$ and $n-3$ series: effects on postprandial lipid and apolipoprotein levels in healthy men. Eur J Clin Nutr 1994, 48(12):842-848.

47. Mekki N, Charbonnier M, Borel P, Leonardi J, Juhel C, Portugal H, Lairon D: Butter differs from olive oil and sunflower oil in its effects on postprandial lipemia and triacylglycerol-rich lipoproteins after single mixed meals in healthy young men. J Nutr 2002, 132(12):3642-3649. 
48. de Bruin TW, Brouwer CB, van Linde-Sibenius Trip M, Jansen H, Erkelens DW: Different postprandial metabolism of olive oil and soybean oil: a possible mechanism of the high-density lipoprotein conserving effect of olive oil. $A m \mathrm{~J}$ Clin Nutr 1993, 58(4):477-483.

49. Higashi K, Ishikawa T, Shige H, Tomiyasu K, Yoshida H, Ito T, Nakajima K, Yonemura A, Sawada S, Nakamura H: Olive oil increases the magnitude of postprandial chylomicron remnants compared to milk fat and safflower oil. $J$ Am Coll Nutr 1997, 16(5):429-434.

50. Brouwer CB, de Bruin TW, Jansen H, Erkelens DW: Different clearance of intravenously administered olive oil and soybean-oil emulsions: role of hepatic lipase. Am J Clin Nutr 1993, 57(4):533-539.

51. Tierney AC, McMonagle J, Shaw DI, Gulseth HL, Helal O, Saris WH, Paniagua JA, Golabek-Leszczynska I, Defoort C, Williams CM et al: Effects of dietary fat modification on insulin sensitivity and on other risk factors of the metabolic syndrome-LIPGENE: a European randomized dietary intervention study. Int $J$ Obes (Lond) 2010. 


\section{CHAPTER 5}

\section{Impact of dietary fat quantity and quality on skeletal muscle fatty acid metabolism in subjects with the metabolic syndrome}

Anneke Jans, Anneke M.J. van Hees, Lauren M. Sparks, Ingrid M.F. Gjelstad, Audrey C. Tierney, Ulf Risérus, Christian A. Drevon, Helen M. Roche, Patrick Schrauwen and Ellen E. Blaak

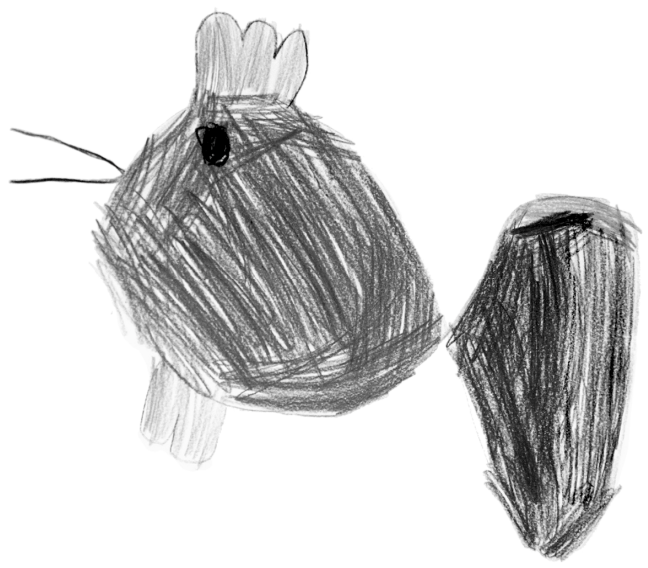




\section{Chapter 5}

ABStRACT

Introduction: Insulin resistance is characterized by disturbances in lipid metabolism in skeletal muscle. Our aim was to investigate whether gene expression and fatty acid (FA) profile of skeletal muscle lipids is affected by diets differing in fat quantity and quality in subjects with the metabolic syndrome (MetS) and varying degrees of insulin sensitivity.

Methods: 84 subjects (age $57.3 \pm 0.9 y$, BMI $30.9 \pm 0.4 \mathrm{~kg} / \mathrm{m}^{2}, 42 \mathrm{M} / 42 \mathrm{~F}$ ) were randomly assigned to one of four iso-energetic diets: high-SFA (HSFA); highMUFA (HMUFA) or two low-fat, high-complex carbohydrate diets, supplemented with $1.24 \mathrm{~g} /$ day of long-chain $n$-3 PUFA (LFHCC $n$-3) or control oil (LFHCC) for 12 weeks. In a subgroup of men $(n=26)$, muscle TAG, DAG, FFA and phospholipid contents were determined including their fractional synthetic rate (FSR) and FA composition at fasting and $4 \mathrm{~h}$ after consumption of a high-fat mixed-meal, both preand post-intervention.

Results: Genes involved in lipogenesis were downregulated after HMUFA (mean fold change -1.3) and after LFHCC $n-3$ (fold change -1.7) in insulin resistant subjects (< median of insulin sensitivity), whereas in insulin sensitive subjects (> median of insulin sensitivity) the opposite effect was shown (fold change +1.6 for both diets). HMUFA diet tended to decrease FSR in TAG $(p=0.055)$ and DAG $(p=0.066)$, whereas the LFHCC $n$-3 diet reduced TAG content $(p=0.032)$.

Conclusion: In conclusion, HMUFA and LFHCC $n-3$ diets reduced the expression of the lipogenic genes in skeletal muscle of insulin resistant subjects, whilst HMUFA reduced the fractional synthesis rate of DAG and TAG and LFHCC n-3 the TAG content. Our data indicate that these diets may reduce muscle fat accumulation by affecting the balance between FA synthesis, storage and oxidation. 


\section{INTRODUCTION}

The metabolic syndrome (MetS) is a cluster of factors enhancing the risk for development of type 2 diabetes and cardiovascular diseases [1]. Insulin resistance of skeletal muscle is fundamental to the metabolic dysregulation associated with obesity and physical inactivity, and contributes to the development of the MetS [2]. Potential mechanisms contributing to reduced insulin signaling and action in skeletal muscle include an increased supply of triacylglycerol (TAG) and free fatty acids (FFA) to 'nonadipose' tissues, such as skeletal muscle ('lipid overflow' hypothesis) [2], reduction in muscle mitochondrial oxidative capacity [3] and increased intramuscular lipid accumulation [4]. The accumulation of lipids, like diacylglycerol (DAG) and ceramides [4], may reduce insulin action in the skeletal muscle by interfering with insulin signalling and/or by inducing inflammatory pathways [4-6]. Also, changes in the FA composition of muscle lipids may play a role in the etiology of insulin resistance. It has been shown that endurance exercise training reduced total DAG content in skeletal muscle, as well as the saturation of the DAG fraction; these changes in intramuscular lipids were correlated with improved glucose tolerance [7]. Furthermore, the FA composition of membrane phospholipids may influence the action of insulin in the skeletal muscle and is correlated with insulin sensitivity [8-11]. Higher levels of polyunsaturated FA (PUFA) in cell membranes of cultured muscle cells increase membrane fluidity [8], the number of insulin receptors [12], the affinity of insulin to the insulin receptor [13] and glucose membrane transport [14]. Dietary intervention, aimed at reducing the intake of saturated fat, may improve lipid metabolism and insulin action in the MetS, possibly via effects on skeletal muscle FA handling [15]. It is unclear whether saturated fat should be replaced by carbohydrates or unsaturated fat, and little information is available on the relation between dietary fat quantity and quality and skeletal muscle FA handling in vivo. PUFA may chronically stimulate adipocyte differentiation [15, 16], thereby increasing lipid storage in adipose tissue and reducing lipid overflow towards muscle. A diet enriched with $n$-3 PUFA may increase long-chain (LC) $n$-3 PUFA in muscle cell membranes, thereby enhancing insulin sensitivity [11]. In addition, there are indications from human muscle cell lines, as well as rodents, that saturated FA (SFA) accumulate preferentially as $D A G$, thereby inhibiting insulin signalling; whereas unsaturated $F A$ are more readily converted into TAG $[17,18]$. Moreover, replacing SFA by unsaturated FA may favor fat oxidation above storage [17]. A 3-day high-carbohydrate diet has been shown to induce changes in partitioning of FA in healthy subjects, leading to increased fat deposition in liver and muscle, which might be related to lower 


\section{ChAPTER 5}

postprandial dietary FA oxidation and altered partitioning of FA to tissue esterification [19]. Regarding the possible differential mechanisms tuned by different $F A$, there are clearly defined intracellular pathways. PUFA may regulate gene transcription, acting as agonists of peroxisome proliferator-activated receptors (PPARs) (involved in FA catabolism) and downregulate sterol regulatory element-binding protein 1c (SREBP1c) (lipogenic pathways) expression [20]; whereas SFA and MUFA have little effect on these processes [21]. Furthermore, it has been proposed that lipid infusion and energy excess promote reduced expression of genes encoding key enzymes in oxidative metabolism and mitochondrial function (regulated by the transcription factor PPAR gamma coactivator $1 \alpha(P C G 1 \alpha)$ ) [22]. Recently, we validated an unique dual stable isotope tracer approach to study the contribution of dietary and endogenous FA to FA partitioning in detail. This technique makes it possible to study the contribution of dietary FA to skeletal muscle fat storage directly, which is very relevant since per os measurements will better reflect daily life conditions in humans than measurements under infusion conditions. The aim of the present study was to study the chronic effect (12 wk) of four isoenergetic diets differing in fat quality and quantity on skeletal muscle intracellular lipid partitioning and skeletal muscle lipid content and FA composition in subjects with the MetS.

\section{METHODS}

The LIPGENE human dietary intervention study was a randomized, controlled trial, carried out at 8 centres across Europe as part of the EU 6th Framework project LIPGENE (Contract no. FOOD-CT-2003-505944). In total, 486 volunteers with the MetS at the age of $35-70$ years and body mass index (BMI) $20-40 \mathrm{~kg} / \mathrm{m}^{2}$, were included and randomly assigned to receive one of four diets for a 12-week period $[23,24]$. The present study was performed in a sub-cohort of the LIPGENE intervention study. All subjects were informed about the study and written informed consent was attained before study participation. The study protocol was approved by the local research ethics committees at each intervention centre.

\section{Subjects and experimental design}

\section{Muscle gene expression}

In 4 out (Uppsala, Dublin, Oslo and Maastricht) of the 8 centres muscle biopsies were taken. A total of 84 muscle biopsies were available. The definition of the MetS was based on the NCEP ATP III report [25], with subjects meeting at least three 
out of five criteria as described previously [15]. In a subgroup of 26 men, skeletal muscle FA metabolism was studied in more detail by means of stable isotope tracers in one centre, at Maastricht University (see Figure 1).

480 men and women with the metabolic syndrome in 8 european centres

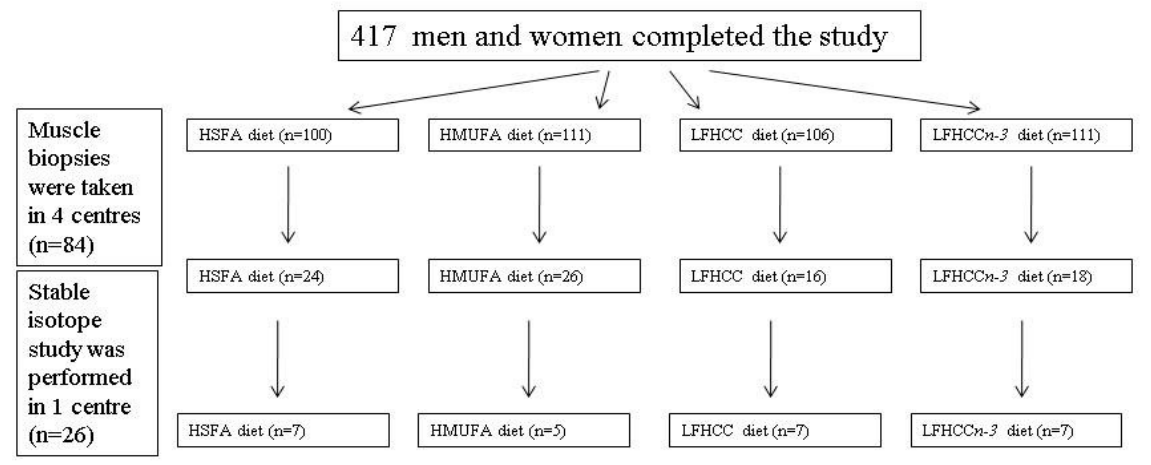

Figure 1. Flow chart of the study Subjects were randomized to 4 diets. The stable isotope study in Maastricht, was performed in only male subjects.

Pre- and post-intervention, subjects came to the centre after an overnight fast on two different occasions. On one day they completed anthropometric measurements, donated a fasting blood sample and completed an insulin-modified intravenous glucose tolerance test to measure insulin sensitivity as described previously [26, 27]. Insulin sensitivity was the primary end point of the LIPGENE human dietary intervention study. On a separate day, after an overnight fast, a biopsy was taken from the vastus lateralis muscle under local anesthesia of the skin and fascia using the Bergström method with suction [28]. Biopsies were cleaned from any visible fat and blood, immediately frozen in isopentane at its melting point or RNAlater, and stored at $-80^{\circ} \mathrm{C}$ until analysis.

\section{Muscle lipid metabolism}

In a sub-cohort of 26 men, a postprandial stable isotope study was performed preand post intervention in one centre (Maastricht University) [15]. At time point zero (Omin) subjects consumed a standardized high-fat mixed-meal containing $200 \mathrm{mg}$ [U- $\left.{ }^{13} \mathrm{C}\right]$-palmitate (98\% enrichment; Cambridge Isotope Laboratories). The high-fat mixed-meal meal was a liquid test meal providing $2.6 \mathrm{MJ}$, including $61 \%$ energy (E\%) fat $(35.5 \mathrm{E} \%$ SFA, $18.8 \mathrm{E} \%$ MUFA and $1.7 \mathrm{E} \%$ PUFA), 33E\% carbohydrates and $6.3 \mathrm{E} \%$ protein. 


\section{ChAPTER 5}

Biopsies from skeletal muscle were taken at fasting before the experiment and at the end of the postprandial measurement period (240min) to determine intramuscular TAG, DAG, FFA, and phospholipids (PL) content, their degree of saturation, as well as the fractional synthetic rate (FSR) of TAG, DAG, and PL (see skeletal muscle lipid analyses).

\section{Dietary intervention}

Subjects were randomly assigned to one of four iso-energetic intervention diets:

(1) High-fat (38E\%) SFA-rich diet (16E\% SFA, 12E\% monounsaturated fatty acids (MUFA), 6E\% PUFA) (HSFA)

(2) High-fat (38E\%) MUFA-rich diet (8E\% SFA, 20E\% MUFA, 6E\% PUFA) (HMUFA)

(3) Low-fat (28E\%), high-complex carbohydrate diet (8E\% SFA, 11E\% MUFA, 6E\% PUFA), with a control capsule (1g per day) (LFHCC)

(4) Low-fat (28E\%), high-complex carbohydrate diet (8E\% SFA, 11E\% MUFA, 6E\% PUFA), with a long-chain $n-3$ PUFA supplement $(1.24 \mathrm{~g}$ per day of eicosapentaenoic and docosahexaenoic acid, ratio 1.4:1) (LFHCC $n-3)$

The HSFA diet functioned as the control per reference diet, to reflect the fat content and composition of the Northern European diet. The intervention diets were specifically designed to reduced dietary SFA by replacement with MUFA or as part of an LFHCC diet, while keeping dietary energy and $n-6$ PUFA constant [29].

A range of fat-modified food products were provided to subjects with specific dietetic counseling, as described previously [15]. A food exchange model was developed, and carbohydrate-fat exchanges were used to ensure that all diets were isoenergetic. A detailed description of the food exchange model and assessment of compliance is published elsewhere [23]. Loders-Croklaan (Wormerveer, the Netherlands) supplied the study capsules used in diet LFHCC and LFHCCn-3. All subjects completed 3-day weighed food record at baseline, week 6 , and week 12 , and center-specific dietary analysis programs were used to analyze the food diaries. Subjects should remain weight stable within the range of $2 \mathrm{~kg}$ during the intervention period, and were asked to maintain their normal pattern of physical activity, alcohol consumption and smoking.

\section{Biochemical analyses}

Blood for lipid analyses was collected in potassium EDTA vacutainer tubes. Glucose samples were collected in fluoride oxalate vacutainers, and insulin samples in serum tubes. All plasma samples were centrifuged immediately (10min, 
$4^{\circ} \mathrm{C}, 1500 \mathrm{~g}$ ), whereas serum samples were allowed to clot for $30 \mathrm{~min}$ at room temperature before centrifugation. Samples were then aliquoted and stored $\left(-80^{\circ} \mathrm{C}\right)$ until further analysis. Serum insulin concentrations were determined by solid phase, two-side fluoro-immunometric assays (AutoDELFIA Insulin kit, Wallac Oy, Turku, Finland) using a 1235 AutoDELFIA automatic immunoassay system. Plasma TAG, glucose and HDL-cholesterol were determined with an ILab 600 clinical chemical analyzer (Instrumentation Laboratory, Warrington, UK) using enzymatic colorimetric kits. HDL-cholesterol was monitored by a HDL-cholesterol kit (Instrument Laboratory, Warrington, UK).

\section{Skeletal muscle lipid analyses}

Skeletal muscle biopsies were lyophilized and dissected free of extra-myocellular fat, blood, and connective tissue. Total lipids were extracted from 10-20mg muscle sample using chloroform-methanol $(2: 1 \mathrm{vol} / \mathrm{vol})$ and internal standards, and thereafter evaporated under nitrogen at $37^{\circ} \mathrm{C}$. The extracted lipids were separated into FFA, DAG, TAG, and PL by thin-layer chromatography and transferred into tubes for methylation. The TAG and DAG fractions were methylated by adding $1 \mathrm{ml}$ of toluene-methanol-(BF3-methanol 14\%) (20\%-55\%-25\% vol/vol) and incubated in capped tubes for $30 \mathrm{~min}$ at $100^{\circ} \mathrm{C}$. The PL fraction was methylated by adding $1 \mathrm{ml}$ of (BF3-methanol 14\%) and incubation in capped tubes for $90 \mathrm{~min}$ at $100^{\circ} \mathrm{C}$. The FFA fraction was methylated by adding $1 \mathrm{ml}$ of methanol-(BF3-methanol $14 \%)(50 \%$ $50 \% \mathrm{vol} / \mathrm{vol}$ ) and incubation in capped tubes at room temperature for $15 \mathrm{~min}$. After incubation, $2 \mathrm{ml}$ pentane was added to the samples, vortexed, and centrifuged $\left(1000 \mathrm{~g}, 5 \mathrm{~min}, 20^{\circ} \mathrm{C}\right.$ ), followed by isolation of the pentane extracts (upper phase) and evaporation under nitrogen at $30^{\circ} \mathrm{C}$. Finally, the residues were dissolved in isooctane and concentrations of FA in the fractions were determined using an analytical gas liquid chromatograph (GLC). Stable isotope enrichment of the lipid fractions was determined by measuring the ${ }^{13} \mathrm{C}$-to- ${ }^{12} \mathrm{C}$ ratio on a GLC-IRMS (Finnigan MAT-252).

\section{Skeletal muscle mRNA and DNA isolation}

RNA was isolated from approximately $25 \mathrm{mg}$ of muscle tissue. The tissues were homogenized in $1 \mathrm{ml}$ Trizol for RNA stabilization and subsequent RNA isolation according to a standardized protocol described by manufacturer. RNA was then purified using the RNeasy mini kit (Qiagen Benelux BV, Venlo, the Netherlands) followed by dissolving RNA in RNase and DNase free water. RNA was quantified and checked for purity on the NanoDrop 1000 (NanoDrop Technologies, Wilmington, DE, USA), and considered suitable for further processing at ratios 


\section{ChAPTER 5}

between $260 / 280$ and $260 / 230$ of $>1.7$. RNA integrity was evaluated using the BioAnalyzer (Agilent, Palo Alto, CA, USA) and considered to be intact with a RNA integrity number $>7.0$. Total DNA was isolated from $5 \mathrm{mg}$ of each muscle section using QIAqmp DNQ Micro Kit (Qiagen).

\section{Real-time $q R T$-PCR for RNA}

Both SYBR Green and Taqman were used for quantification of mRNA expression levels. For expression of the genes in the upper half of Table 1, isolated RNA was reversely transcribed using the iScript cDNA synthesis Kit. The qPCR reactions were performed in a volume of $25 \mu \mathrm{l}$ containing $12.5 \mathrm{ng}$ cDNA, 1x IQ SYBR Green Supermix and $400 \mathrm{nM}$ of gene-specific forward and reverse primers (Table 1). cDNA was amplified using a two-step program (40 cycles of $10 \mathrm{sec}$ at $95^{\circ} \mathrm{C}$ and $45 \mathrm{sec}$ at $60^{\circ} \mathrm{C}$ ) with a MyiQ system (Bio-Rad Laboratiories, Veenendaal, the Netherlands). Gene expression levels were expressed relative to geometric mean of two internal reference genes, i.e. ribosomal protein L13a (RPL13a) and $\beta-2-$ microglobulin. For expression of genes in the lower half of Table 1, all primers and probes were designed using Primer Express version 2.1 (Applied Biosystems, Roche, Branchburg, NJ). qRT-PCR reactions [30] were performed as one-step reactions in ABI PRISM 7900 (Applied Biosystems, Branchburg, NJ) using the following conditions: one cycle of $48^{\circ} \mathrm{C}$ for $30 \mathrm{~min}$, then $95^{\circ} \mathrm{C}$ for $10 \mathrm{~min}$, followed by 40 cycles at $95^{\circ} \mathrm{C}$ for $15 \mathrm{sec}$ and $60^{\circ} \mathrm{C}$ for $1 \mathrm{~min}$. For all assays performed using Taqman primers and probe, the ribosomal phosphoprotein large P0 gene (RPLP0) was used as internal control. Dividing the target genes by the internal control RPLPO gene normalized all expression data. The internal control gene was tested for inter-individual variability with a coefficient of variance to ensure precision in the measurements.

\section{Mitochondrial DNA content}

Quantification of mitochondrial content was performed as previously described using mtDNA copy number [31]. The sequences for the primer/probe sets used in the Taqman analysis of mtDNA content for NADH dehydrogenase subunit 1 (mitochondrial genome (ND1)) and of nuclear DNA for lipoprotein lipase (LPL), were designed using Primer express version 2.1 and can be e-mailed on request. 
Table 1. Gene-specific forward and reverse primers for RT- PCR

\begin{tabular}{|c|c|c|c|}
\hline Gene & Forward primer & Probe & Reverse primer \\
\hline$\beta 2 \mathrm{M}$ & GGACTTCGAGCAAGAGATGG & & AGCACTGTGTTGGCGTACAG \\
\hline RPL13a & CCTGGAGGAGAAGAGGAAAGAGA & & TTGAGGACCTCTGTGTATTTGTCAA \\
\hline LPL & САTCTCTTGGGATACAGCCTTG & & GGGCTTCTGCATACTCAAAGT \\
\hline PPAR & AAAAGCCTAAGGAAACCGTTCTG & & TATCGTCCGGGTGGTTGCT \\
\hline PGC1a & CCAGGTCAAGATCAAGGTCTCCAG & & TTCGGTGCGTGCGGTGTC \\
\hline ACC2 & GCAAGAACGTGTGGGGTTACT & & TCGTAGTGGGCTTGCTGAAAA \\
\hline mCPT1b & CGGGACAGGGGTAAGTTCTG & & TCTCGCAGGTCTGCTTTTGTG \\
\hline SREBP1C & ACACAGCAACCAGAAACTCAAGC & & GCCGACACCAGATCCTTCAGAG \\
\hline SREBP2 & GCACCACTCCGCAGACGAG & & TGGACTTGAGGCTCAAGGACTTG \\
\hline ChREBP & GCCTCAAGGTGAGCAAAGCTA & & GCTGGCACAGGTTAATGGC \\
\hline NDUFB5 & GCTGCTCCTGTTCGACACA & & CTGCTAGTTCAGCTTGACCAAT \\
\hline SDHB & CCACAGCTCCCCGTATCAAG & & TCGGAAGGTCAAAGTAGAGTCAA \\
\hline PPAR $\delta$ & СССTCACTGCTGGACCAAC & & GCGCTCACACTTCTCGTACT \\
\hline HSL & GCGGATCACACAGAACCTGGAC & & AGCAGGCGGCTTACCCTCAC \\
\hline ATGL & GTGTCAGACGGCGAGAATG & & TGGAGGGAGGGAGGGATG \\
\hline CD36 & AGTCACTGCGACATGATTAATGGT & CAGATGCAGCCTCATTTCCACCTTTTG & CTGCAATACCTGGCTTTTCTC \\
\hline FASN & TATGCTTCTTCGTGCAGCAGTT & AGCGCCTCCAGCACCCTGTTGT & GCTGCCACACGCTCCTCTAG \\
\hline SCD1 & TGGCATTCCAGAATGATGTCTATG & CGTGACCACCGTGCCCACCACA & GGAATTATGAGGATCAGCATGTGT \\
\hline DGAT1 & CGTGAGCTACCCGGACAATC & ACCTACCGCGATCTCTACTACTTCCTCTTCGC & AAAGTTGAGCTCGTAGCACAAGG \\
\hline CG158 & GGAGAGAGGTCAGGATGGCTAA & CTCCCCACATGGTGCCCTACGTCTATATC & AACATCTTCTCTTCAGCTTCTTTAAGG \\
\hline NRF1 & CGTTGCCCAAGTGAATTATTCTG & TTGTTCCACCTCTCCATCAGCCA & CCCTGTAACGTGGCCCAAT \\
\hline SIRT1 & AGAGCCTCACATGCAAGCTCTAG & ACTCCAAGGCCACGGATAGGTCCATATACTT & GCCAATCATAAGATGTTGCTGAAC \\
\hline RPLPO & CCATTCTATCATCAACGGGTACAA & TCTCCACAGACAAGGCCAGGACTCG & AGCAAGTGGGAAGGTGTAATCC \\
\hline
\end{tabular}

$\overline{\beta 2 M, ~ \beta-2-m i c r o g l o b u l i n ; ~ R P L 13 a, ~ r i b o s o m a l ~ p r o t e i n ~ L 13 a ; ~ L P L, ~ l i p o p r o t e i n ~ l i p a s e ; ~ P P A R ~} \alpha$, peroxisomep roliferator-activated receptor $\alpha$; PGC1 $\alpha$, peroxisome proliferators-activated receptor coactivator $1 \alpha$; ACC2, acetyl-CoA carboxylase 2; mCPT1b, muscle carnitine palmitoyltransferase 1b; SREBP1c, sterol regulatory element binding protein 1c; SREBP2, sterol regulatory element binding protein 2; ChREBP, carbohydrate responsive element binding protein; NDUFB5, NADH dehydrogenase (ubiquinone) $1 \beta$ subcomplex; SDHB, succinate dehydrogenase complex B; PPAR $\delta$, peroxisome proliferator-activated receptor反; HSL, hormone sensitive lipase; ATGL, adipose triglyceride lipase; CD36, cluster of differentiation 36; FASN, fatty acid synthase; SCD1, stearoyl-CoA desaturase 1; DGAT1, acyl CoA: diacylglycerol acyltransferase; CGI58, comparative gene identification 58; NRF1, nuclear respiratory factor 1; SIRT1, sirtuin 1; RPLP0, ribosomal protein, large, PO

\section{Calculations}

Insulin sensitivity was determined using the MINMOD Millennium program (version 6.02; R Bergman, Los Angeles, CA, USA) [27]. The homeostasis model assessment for insulin resistance ( $\left.\mathrm{HOMA}_{\mathrm{IR}}\right)$ was calculated according to Matthews et al [32]. The fractional synthetic rate (FSR) is expressed as the amount of dietary FA incorporated into the muscle lipid fractions per gram of dry muscle tissue per hour. The enrichment (determined by measuring the ${ }^{13} \mathrm{C}$-to- ${ }^{12} \mathrm{C}$ ratio) of the skeletal 


\section{Chapter 5}

muscle FFA pool at $4 \mathrm{~h}$ after meal consumption was used to represent the precursor pool from which the TAG, DAG and PL pool was synthesized.

$\operatorname{TAG~FSR~}(\% / \mathrm{h})=\frac{\underline{E}_{\text {TAG palm }}\left(\mathrm{t}_{1}\right)-\mathrm{E}_{\text {TAG palm }}\left(\mathrm{t}_{0}\right)}{\mathrm{E}_{\text {FFA palm }}\left(\mathrm{t}_{1}\right)} \underline{1}^{*} \underline{1}^{*} 100$

Where $E_{\text {TAG palm }}\left(t_{1}\right)$ is the enrichment of palmitate in the TAG pool after $4 \mathrm{~h}$ of ingestion and $E_{T A G}$ palm $\left(t_{0}\right)$ is the background enrichment in the muscle TAG pool. $\mathrm{E}_{\text {FFA palm }}\left(\mathrm{t}_{1}\right)$ is the enrichment of palmitate in the FFA pool after $4 \mathrm{~h}$ of ingestion. The content of individual FA in the TAG, DAG, FFA and PL pool extracted from the muscle was expressed as a percentage of the total $F A$ identified. Several indices (the sum of SFA, the sum of MUFA, the sum of PUFA ( $n-6$ and $n-3)$ ) were derived.

\section{Statistical methods}

Statistical analyses were performed using SPSS 16.0 for Macintosh (SPSS Inc., Chicago, IL, USA). All data are presented as means \pm standard error of the means (SEM). The data were normally distributed as tested the Kolmogorov-Smirnov test. One-way analysis of variance (ANOVA) was used to test for differences between dietary intervention groups pre-intervention. Repeated-measures ANOVA was applied to test for differences in changes between groups pre- and postintervention, with time as within-subjects factor and diet and center as betweensubjects factors. Corrections for gender, insulin sensitivity and baseline differences were performed in the repeated-measures ANOVA analysis. Post-hoc testing within diets was performed with paired sampled t-test. One-way ANOVA was used to test differences between in change in gene expression between insulin resistant and insulin sensitive subjects. Statistical significance was set at $p<0.05$.

\section{RESULTS}

In total, 84 subjects with the MetS completed pre- and post-intervention measurements (HSFA, $n=24$; HMUFA, $n=26$; LFHCC, $n=16$ and LFHCC $n-3, n=18$ ). Subject characteristics were comparable between all the groups pre-intervention, except for diastolic blood pressure, which was higher in the LFHCC group than in the HMUFA group (Table 2). By definition, subjects primarily had a large waist circumference, elevated blood pressure and low plasma HDL-cholesterol 


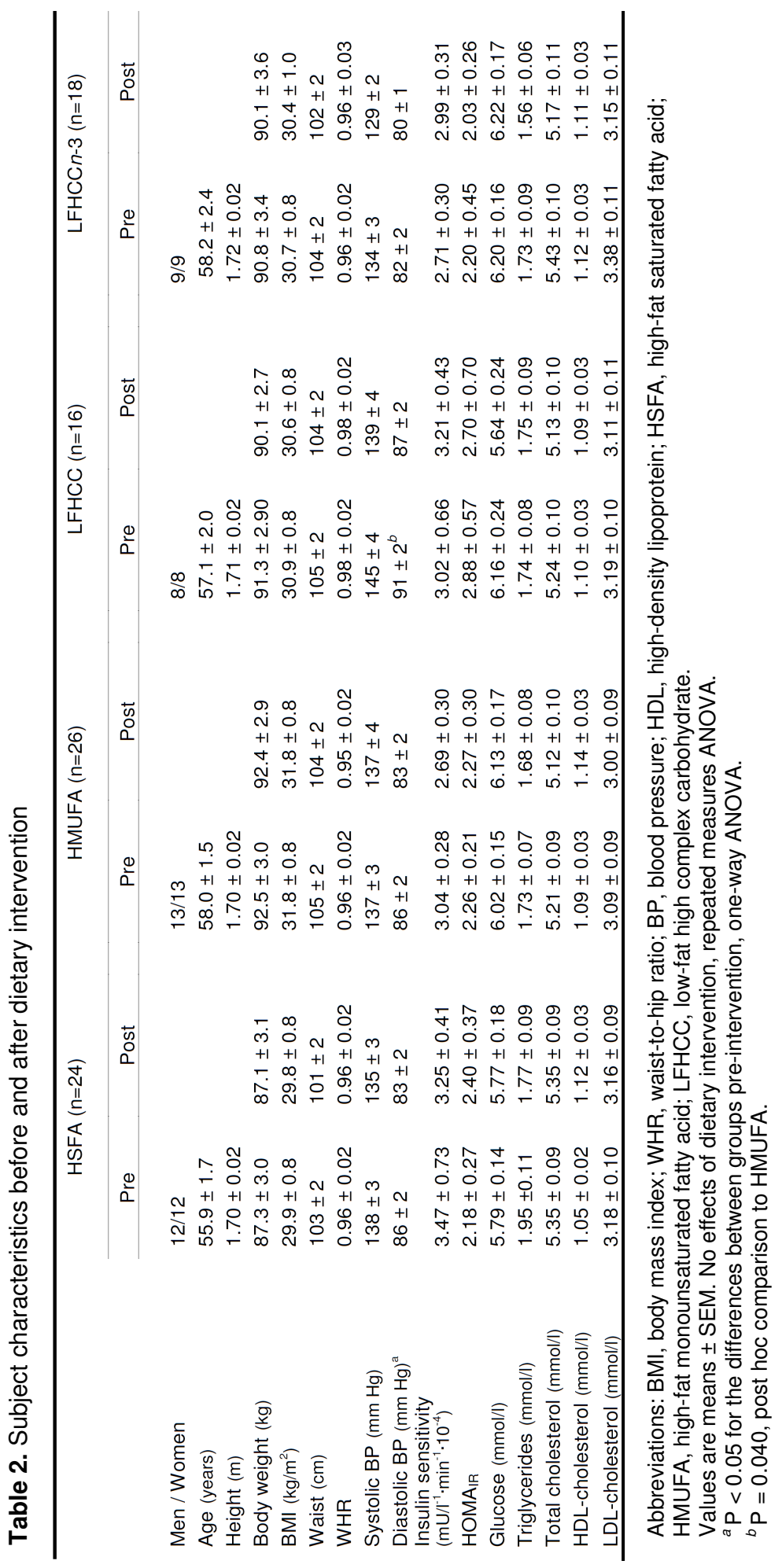




\section{ChAPTER 5}

concentrations, whereas mean fasting plasma glucose and TAG concentrations were only slightly elevated. The dietary intervention did not cause significant changes in the characteristics of the MetS and did not change insulin sensitivity and insulin resistance $\left(\mathrm{HOMA}_{\mathrm{IR}}\right)$ in our sub-cohort of the LIPGENE study (Table 2).

\section{Muscle gene expression}

\section{Changes after dietary intervention}

Skeletal muscle SREBP1C and ChREBP mRNA expression showed significant $\operatorname{diet}^{\star}$ time interactions $(p=0.048$ and $p=0.007)$, respectively (Figures $2 A$ and $B$ ). Post-hoc comparisons within the diets showed that SREBP1c mRNA only tended to increase after the HMUFA diet $(p=0.070$, Figure 2A), whereas the other diets did not induce any change. A sex-analysis showed that this increased SREBP-1C expression was only seen in men $(p=0.020$, Figure $2 C)$. Post-hoc testing revealed that the HSFA diet trended to increase the ChREBP mRNA expression $(p=0.14)$ in men and women. Gene expression of PGC1 $\alpha$, SREBP2, ACC2, mCPT1b, LPL, PPAR $\alpha$, PPAR $\delta$, NDUFB, SDHB, ATGL, CGI58, HSL, DGAT, CD36, SCD1, NRF, FAS and SIRT1 did not change after dietary intervention (data not shown), and there were no changes in mitochondrial DNA content as result of dietary intervention (data not shown).

The repeated measures ANOVA showed that there was a significant interaction between insulin sensitivity at baseline and diet-induced changes in gene expression for 7 out of 21 genes, which was independent of baseline expression levels. To illustrate these differential effects on gene expression, the total group was divided based on the median of insulin sensitivity $\left(2.69\left(\mathrm{mU} / /^{-1 *} \mathrm{~min}^{-1} * 10^{-4}\right)\right.$. At baseline, insulin resistant subjects (below median of insulin sensitivity, age $57.4 \pm 2.95 \mathrm{y}$ and BMI $31.3 \pm 1.0 \mathrm{~kg} / \mathrm{m}^{2}$ ) had higher SREBP1c and ACC2 mRNA expression levels in the fasting state than insulin sensitive subjects (above median of insulin sensitivity), age $56.7 \pm 2.6 y$ and $\left.B M I 30.5 \pm 1.6 \mathrm{~kg} / \mathrm{m}^{2}\right) \quad(p=0.001$ and $p=0.020$, respectively, data not shown). Insulin resistant and insulin sensitive subjects responded differently to the HMUFA and the LFHCC $n-3$ diet in mRNA levels of SREBP1c (diet*time*insulin sensitivity interaction $p<0.001$ ), SREBP2 $(p=0.055)$, ChREBP $(p=0.040)$, ACC2 $(p=0.088)$, NDUFB5 $(p=0.071), \quad$ SDHB $(p=0.032)$ and ATGL $(p=0.029)$ (Figure $3 \mathbf{A}, \mathbf{B}, \mathbf{C}, \mathbf{D}, \mathbf{E}, \mathbf{F}$ and $\mathbf{G}$, respectively). The HMUFA diet reduced the mRNA level of the lipogenic genes SREBP1c (oneway ANOVA $p=0.012$ ), SREBP2 (one-way ANOVA $p=0.002$ ), ChREBP (one-way ANOVA $p=0.008$ ) and ACC2 (one-way ANOVA $p=0.065$ ) and the lipolytic gene 
ATGL (one-way ANOVA $p=0.039$ ) among insulin resistant subjects, whereas the opposite effect was seen in insulin sensitive subjects. Moreover, insulin resistant subjects had lower mRNA levels of SREBP1c (one-way ANOVA $p=0.005$ ), SREBP2 (one-way ANOVA $p=0.002$ ) and ACC2 (one-way ANOVA $p=0.002$ ) after the LFHCC $n-3$ diet, whereas insulin sensitive subjects showed the opposite effect. The LFHCC $n-3$ diet enhanced expression of the OXPHOS genes NDUFB5 (oneway ANOVA $p=0.025$ ) and SDHB (one-way ANOVA $p=0.049$ ) among insulin sensitive subjects, but not in insulin resistant subjects

A
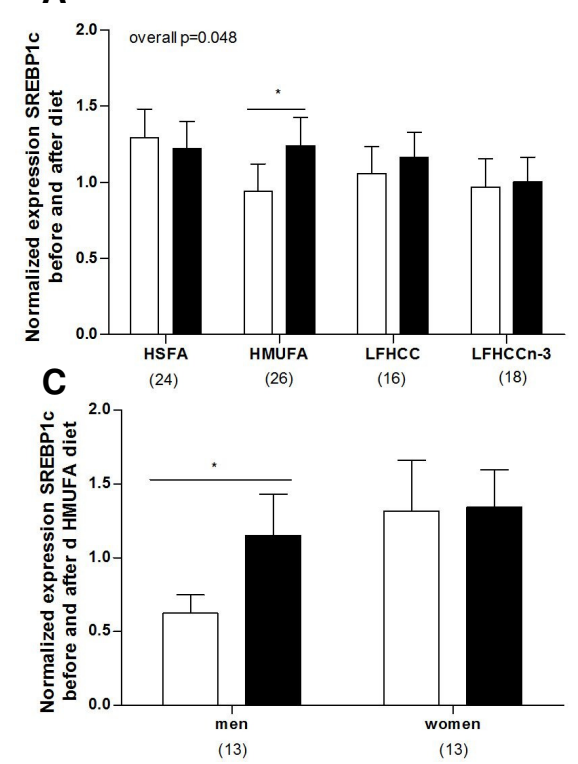

B

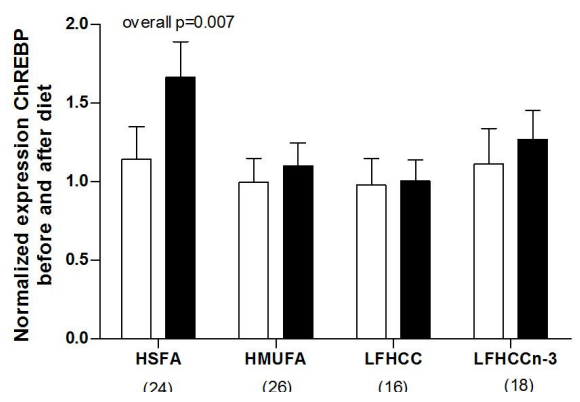

Figure 2. Normalized mRNA levels before and after dietary intervention (mean $\pm S E M$ ). SREBP1c (A), ChREBP (B) and SREBP1c after HMUFA diet for men $(n=13)$ and women $(n=13)(C)$. The overall difference for SREBP1c was $p=0.048$, with a post-hoc difference after the HMUFA diet $(p=0.070)$. For ChREBP the overall difference was $p=0.007$, with a tendency for increase after the HSFA diet. Paired t-test showed an increase for SREBP1c in men after the HMUFA diet $(p=0.020)$. Significant post-hoc differences within the diets are indicated with *. ${ }^{*} p<0.05$. White bars represent values before dietary intervention, black bars after dietary intervention.

\section{Muscle lipid metabolism}

\section{Fractional synthetic rate and content of the TAG, DAG, FFA and PL fractions}

A sub-cohort of 26 men at Maastricht University (HSFA, $n=7$; HMUFA, $n=5$; LFHCC, $n=7$ and LFHCC $n-3, n=7$ ) completed a postprandial stable isotope study. Subject characteristics were comparable at baseline, except for a slightly higher 


\section{Chapter 5}

body weight and BMI among subjects on the HMUFA diet than on the HSFA and LFHCC $n-3$ diets (Table 3). Total fasting plasma TAG concentration decreased significantly after the LFHCC $n$-3 diet (Post-hoc testing, $\mathrm{p}=0.032$, Table 3).

A

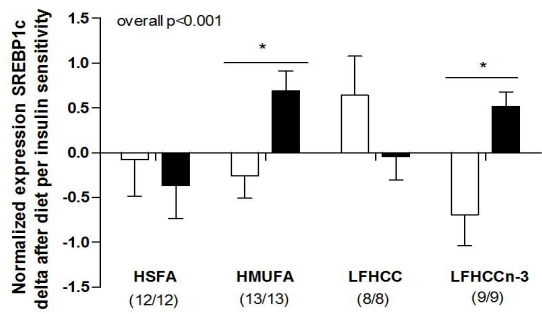

C

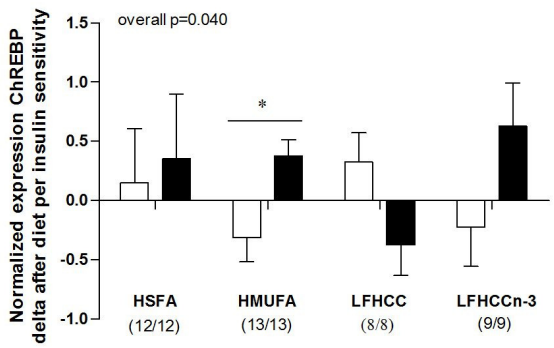

E

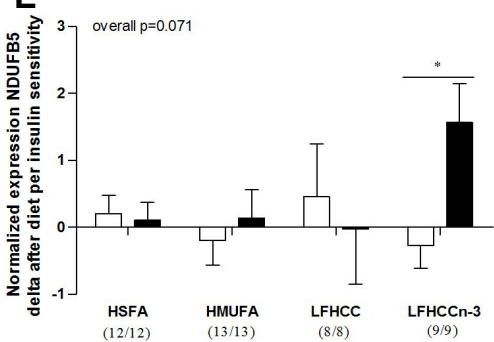

G

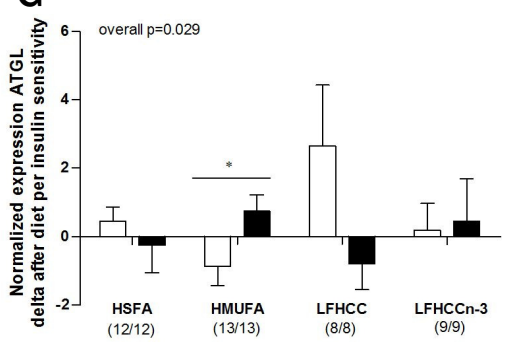

B
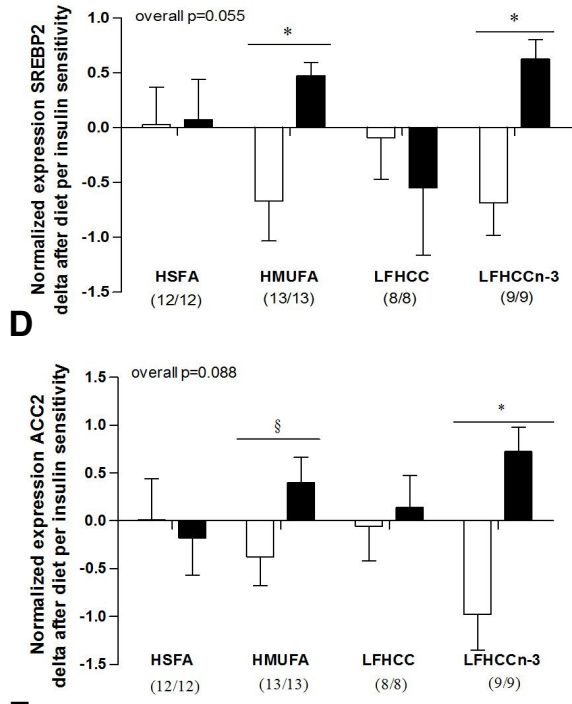

$\mathbf{F}$

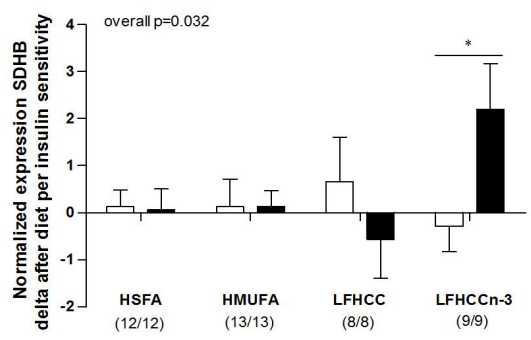

Figure 3. Change in normalized mRNA levels after dietary intervention (mean $\pm S E M$ ) among insulin resistant and insulin sensitive subjects as shown for SREBP1c (A), SREBP2 (B), ChREBP (C), ACC2 (D), NDUFB5 (E), SDHB (F) and ATGL (G). The change in gene expression was different between insulin resistant and insulin sensitive subjects after a HMUFA diet for SREBP1c (one-way ANOVA $p=0.012$ ), SREBP2 (one-way ANOVA $p=0.002$ ), ChREBP (one-way ANOVA $p=0.008$ ), ACC2 (one-way ANOVA $p=0.065$ ) and ATGL (one-way ANOVA $p=0.039$ ). * $p<0.05$. $\S$ indicates a trend. 


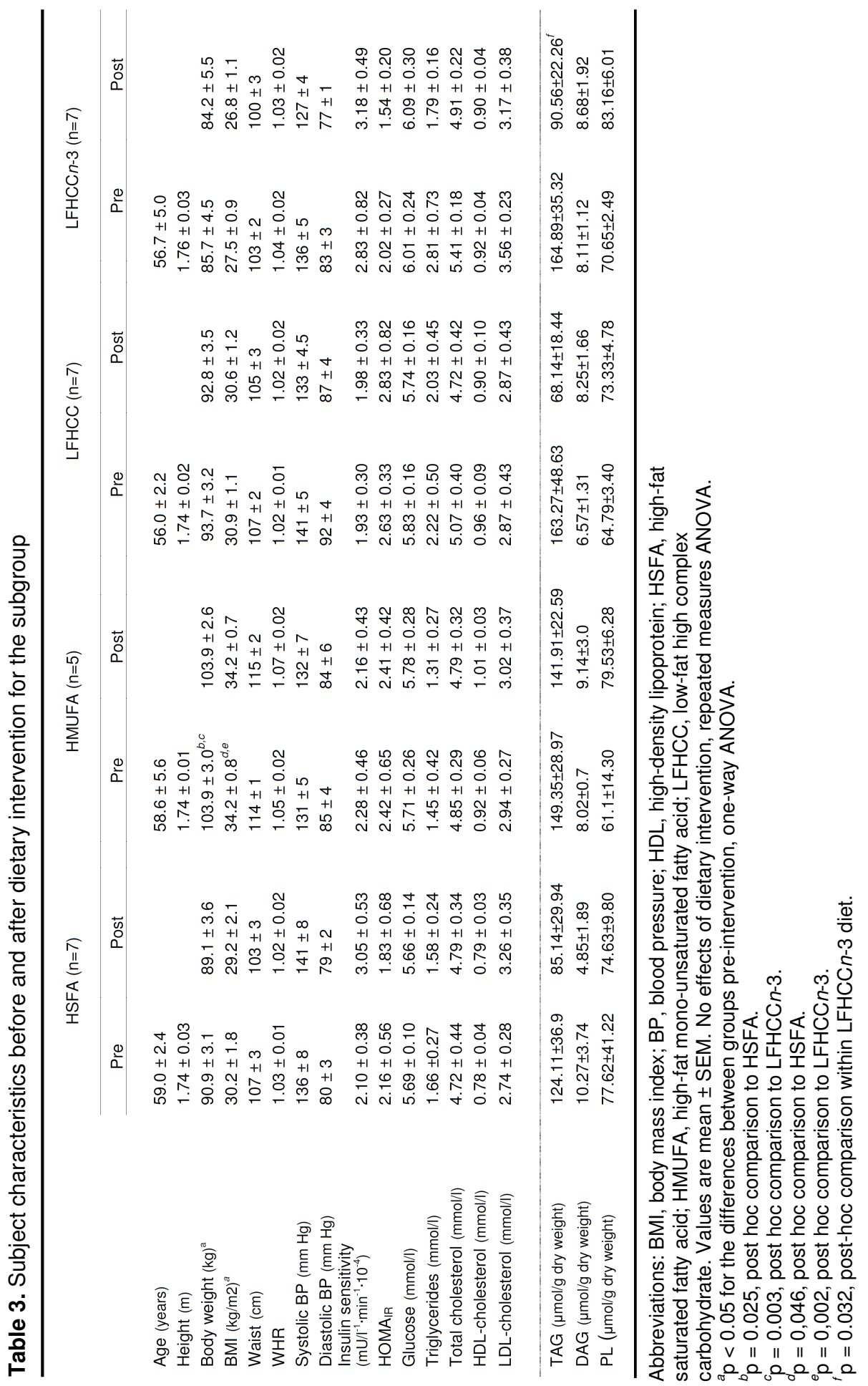




\section{ChAPTER 5}

The FSR of the TAG and DAG fraction (the incorporation of [U- $\left.{ }^{13} \mathrm{C}\right]$-palmitate from the high-fat mixed-meal) tended to change as result of dietary intervention as compared with baseline, but this did not reach statistical significance $(p=0.096$ and $p=0.126$, RM-ANOVA, Figure 4). The HMUFA diet seemed to reduce the postprandial FSR of the TAG fraction by $68 \%(p=0.054$, Figure $3 A)$ and of the DAG fraction by $56 \%(p=0.066$, Figure $4 B$ ). The four different diets did not induce any changes in FSR in the PL fraction (Figure $4 \mathrm{C}$ ).

A

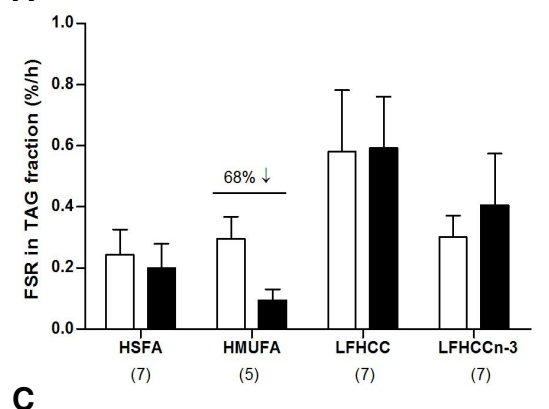

C

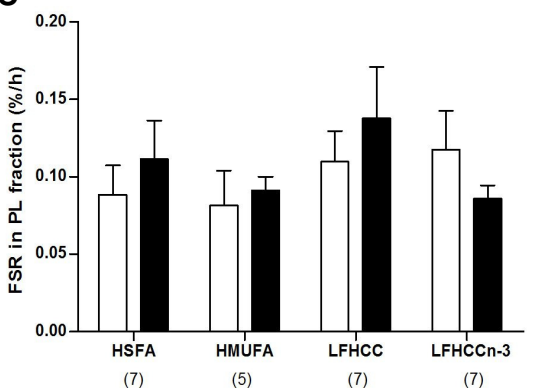

E

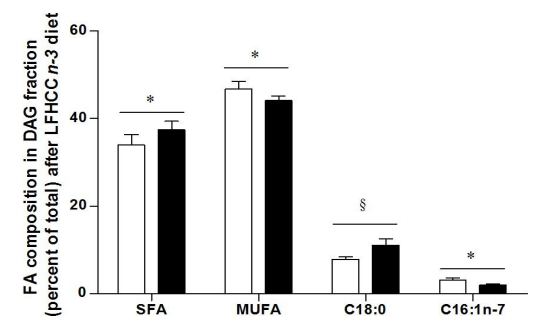

B

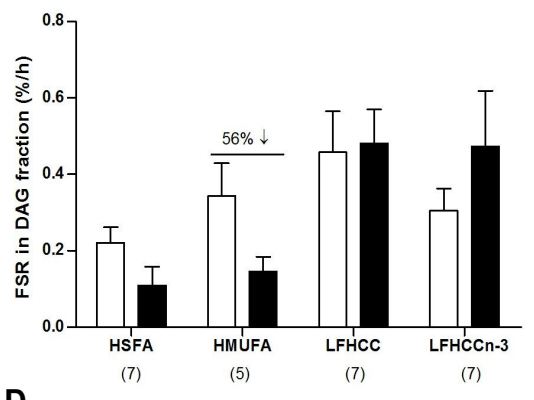

D
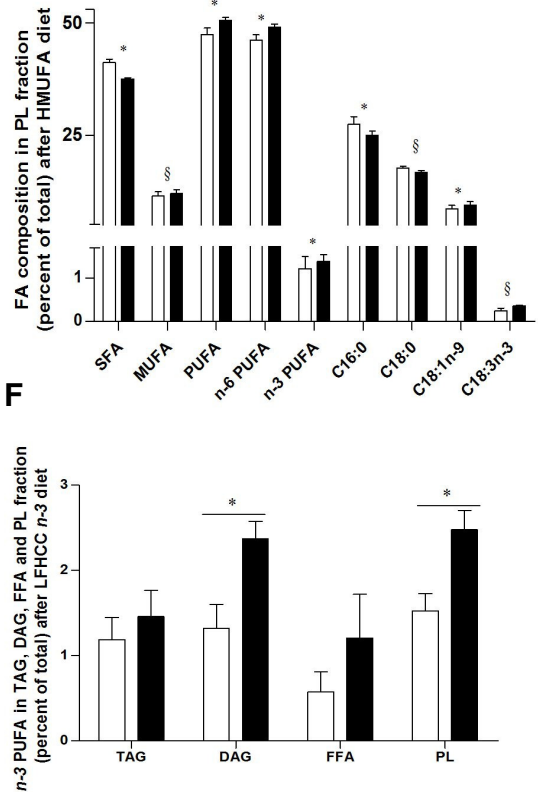

Figure 4. Incorporation of dietary FA in skeletal muscle as shown for TAG (A), DAG (B) and $\mathrm{PL}(\mathbf{C})$ and changes in skeletal muscle FA pattern after dietary intervention as shown for $\mathrm{PL}$ after the HMUFA diet (D), change in DAG after the LFHCCn-3 diet (E) and change in $\% n-3$ PUFA after the LFHCCn-3 diet $(\mathbf{F})$. The HMUFA diet seemed to reduce the postprandial FSR of the TAG fraction by $68 \%(p=0.054)$ and of the DAG fraction by $56 \%(p=0.066)$. * $p<0.05$. § indicates a trend. 


\section{Fatty acid composition of the TAG, DAG, FFA and PL fractions}

The HMUFA diet increased the \% PUFA $(p=0.020)$ significantly and trended to increase the \% MUFA ( $p=0.071)$ in the PL fraction as compared with baseline, concomitant with a reduction in the total degree of FA saturation. Specifically, the $\%$ C16:0 ( $p=0.024)$ and \% C18:0 ( $p=0.059)$ was reduced and the \% of C18:1 $n-9$ $(p=0.033)$ and $\mathrm{C} 18: 3 n-3(p=0.082)$ increased (Figure 4D). The LFHCC $n-3$ diet caused enhanced $\%$ SFA ( $p=0.042)$ and reduced $\%$ MUFA ( $p=0.023$ ) by increasing $\% \mathrm{C} 18: 0(\mathrm{p}=0.086)$ and reducing $\mathrm{C} 16: 1 n-7(\mathrm{p}=0.042)$ in the DAG fraction (Figure 4E). Furthermore, the LFHCC $n-3$ diet induced an increase in $\% n-3$ PUFA in the DAG $(p=0.007)$ and PL fraction $(p=0.036)$ (Figure 4F). The HSFA and LFHCC diets did not cause any differences in the FA composition of the different intramuscular lipid fractions.

\section{DISCUSSION}

This study examined the effect of diets differing in fat quantity and quality on skeletal muscle gene expression and intramuscular lipid partitioning in subjects with the MetS. There was a significant interaction between baseline insulin sensitivity and the diet-induced changes in gene expression. ATGL, SREBP1C and ACC2 mRNA expression decreased in insulin resistant subjects after the HMUFA whilst the LFHCC $n-3$ diets enhanced OXPHOS (NDUFB5 and SDHB) mRNA expression among insulin sensitive subjects. In line with this, the HMUFA diet tended to reduce incorporation of dietary palmitate in skeletal muscle TAG and DAG, whereas the LFHCC $n$-3 diet reduced the TAG content in skeletal muscle.

The HMUFA diet increased SREBP1c mRNA expression in men, but not in women. Interestingly, in the total cohort of the LIPGENE dietary intervention study, it was shown that increases in insulin sensitivity $\left(\mathrm{HOMA}_{\mathrm{IR}}\right)$ were more pronounced in women compared with men on the HMUFA diet [24]. Based on the gene expression data, it is tempting to speculate that this sexual dimorphism may be related to differences in skeletal muscle fat storage. This seems consistent with findings of an increased rate of FA oxidation during a high MUFA diet in women compared with men [33].

The insulin resistant and insulin sensitive subjects responded differently to the HMUFA and LFHCC $n-3$ diets with a more pronounced reduction of SREBP1C and ACC2 mRNA expression among insulin resistant subjects and an enhanced expression of the OXPHOS genes NDUFB5 and SDHB on the LFHCC $n-3$ diet 


\section{Chapter 5}

among insulin sensitive subjects. Although baseline expression levels of SREBP1c and ACC2 were higher in the insulin resistant group, the reduction of these lipogenic genes was independent of the baseline difference. In aggregate with the larger reduction of the lipogenic genes, the HMUFA diet seemed to reduce the incorporation of dietary FA (palmitate) in the DAG and TAG pool and the LFHCCn3 diet reduced the skeletal muscle TAG content in the subgroup of men. These data indicate a shift towards a lower accumulation of lipids in muscle on the diets high in MUFA or high in complex carbohydrates with $n$-3 supplement, which is dependent on the initial degree of insulin sensitivity (or insulin resistance). The primary mechanism for PUFA or MUFA to regulate SREBP1c mRNA may be related to the suppression of proteolytic processing, which in turn reduces mRNA transcription [34]. Low SREBP1c and ACC2 mRNA levels may lead to reduced malonyl-CoA concentration (via a reduction in ACC2 mRNA expression), and subsequently FA are directed towards oxidation instead of storage [35].

Previous studies have shown that diet may influence the FA composition of PL, which may influence the action of insulin within the skeletal muscle [8, 9]. A high level of PUFA in PL also may enhance membrane fluidity [8], the number of insulin receptors [12], the affinity of insulin to the insulin receptor [13] and glucose transport across the membrane [14]. In our present study we found a reduced saturation of the skeletal muscle PL fraction after a HMUFA diet (increased content oleic acid) and enhanced incorporation of $n-3$ PUFA in the DAG and PL pools on the LFHCC $n$-3 diet, illustrating dietary compliance to our intervention diets. Thus, it seems that the supplemented $n$-3 PUFA are incorporated into the DAG and PL fractions, in accordance with that the FA composition of skeletal muscle reflects the dietary fat composition in humans [36]. In a previous study, however, differences in the TAG fraction were also shown, whereas we only observed changes in the DAG and $\mathrm{PL}$ fractions. Increased $n-3$ in these fractions can contribute to a lower saturation level of these fractions.

As indicated above, we found tendencies towards effects of HMUFA and LFHCCn3 on lipogenic gene expression. Additionally, despite the fact that our one centrestudy on lipid metabolite composition and their FSR is hampered by a limited power, we found clear effects of the same diets on the FSR and lipid pool FA composition. Our present sub-study was not intended and powered to study the effect on insulin sensitivity. However, in the whole LIPGENE study no differential effects of diets on insulin sensitivity were found [24]. It is possible that the 12-week dietary period is too short or the changes in dietary composition and subsequent 
changes in skeletal muscle FA metabolism were too small to translate into significant differences in insulin sensitivity. It is also possible that $n-6$ PUFA, rather than MUFA or $n-3$ PUFA enhances insulin sensitivity in subjects with the MetS [37].

In summary, the 12-week HMUFA and LFHCC $n$-3 diets induced changes in gene expression and skeletal muscle FA partitioning, which may shift the balance from storage to oxidation in insulin resistant subjects, leading to less muscle lipid accumulation. Furthermore, these two diets affected skeletal muscle PL composition with a reduced saturation on the HMUFA diet and an enhanced content of $n-3$ PUFA on the LFHCC $n-3$ diet. These positive effects on lipid metabolism did not promote changes in insulin sensitivity. This might suggest that the range of dietary fat intake under condition of isoenergetic exchange was insufficient to affect insulin sensitivity or that lipid metabolism per se has no prominent role in the regulation of insulin sensitivity.

\section{ACKNOWLEDGEMENTS}

We thank the participants for so enthusiastically taking part in the present study. We are grateful to all of the staff at different centres whose help ensured the smooth running of this study. 


\section{REFERENCES}

1. Eckel RH, Grundy SM, Zimmet PZ: The metabolic syndrome. Lancet 2005, 365(9468):1415-1428.

2. Corpeleijn E, Saris WH, Blaak EE: Metabolic flexibility in the development of insulin resistance and type 2 diabetes: effects of lifestyle. Obes Rev 2009, 10(2):178-193.

3. Schrauwen P: High-fat diet, muscular lipotoxicity and insulin resistance. Proc Nutr Soc 2007, 66(1):33-41.

4. Itani SI, Ruderman NB, Schmieder F, Boden G: Lipid-induced insulin resistance in human muscle is associated with changes in diacylglycerol, protein kinase C, and IkappaB-alpha. Diabetes 2002, 51(7):2005-2011.

5. Schrauwen P, Hesselink MK: Oxidative capacity, lipotoxicity, and mitochondrial damage in type 2 diabetes. Diabetes 2004, 53(6):1412-1417.

6. Corcoran MP, Lamon-Fava S, Fielding RA: Skeletal muscle lipid deposition and insulin resistance: effect of dietary fatty acids and exercise. Am J Clin Nutr 2007, 85(3):662-677.

7. Bruce CR, Thrush AB, Mertz VA, Bezaire V, Chabowski A, Heigenhauser GJ, Dyck DJ: Endurance training in obese humans improves glucose tolerance and mitochondrial fatty acid oxidation and alters muscle lipid content. $A m \mathrm{~J}$ Physiol Endocrinol Metab 2006, 291(1):E99-E107.

8. Borkman M, Storlien LH, Pan DA, Jenkins AB, Chisholm DJ, Campbell LV: The relation between insulin sensitivity and the fatty-acid composition of skeletalmuscle phospholipids. N Engl J Med 1993, 328(4):238-244.

9. Helge JW, Dela F: Effect of training on muscle triacylglycerol and structural lipids: a relation to insulin sensitivity? Diabetes 2003, 52(8):1881-1887.

10. Pan DA, Lillioja S, Milner MR, Kriketos AD, Baur LA, Bogardus C, Storlien LH: Skeletal muscle membrane lipid composition is related to adiposity and insulin action. J Clin Invest 1995, 96(6):2802-2808.

11. Storlien LH, Jenkins AB, Chisholm DJ, Pascoe WS, Khouri S, Kraegen EW: Influence of dietary fat composition on development of insulin resistance in rats. Relationship to muscle triglyceride and omega-3 fatty acids in muscle phospholipid. Diabetes 1991, 40(2):280-289.

12. Ginsberg BH, Jabour J, Spector AA: Effect of alterations in membrane lipid unsaturation on the properties of the insulin receptor of Ehrlich ascites cells. Biochim Biophys Acta 1982, 690(2):157-164.

13. Grunfeld C, Baird KL, Kahn CR: Maintenance of 3T3-L1 cells in culture media containing saturated fatty acids decreases insulin binding and insulin action. Biochem Biophys Res Commun 1981, 103(1):219-226.

14. Field CJ, Ryan EA, Thomson AB, Clandinin MT: Diet fat composition alters membrane phospholipid composition, insulin binding, and glucose metabolism in adipocytes from control and diabetic animals. $\mathrm{J} \mathrm{BiOl} \mathrm{Chem}$ 1990, 265(19):11143-11150.

15. van Hees AM, Saris WH, Hul GB, Schaper NC, Timmerman BE, Lovegrove JA, Roche HM, Blaak EE: Effects of dietary fat modification on skeletal muscle fatty acid handling in the metabolic syndrome. Int $J$ Obes (Lond), 34(5):859870.

16. Madsen L, Petersen RK, Kristiansen K: Regulation of adipocyte differentiation and function by polyunsaturated fatty acids. Biochim Biophys Acta 2005, 1740(2):266-286.

17. Gaster M, Rustan AC, Beck-Nielsen H: Differential utilization of saturated palmitate and unsaturated oleate: evidence from cultured myotubes. Diabetes 2005, 54(3):648-656. 
18. Lee JS, Pinnamaneni SK, Eo SJ, Cho IH, Pyo JH, Kim CK, Sinclair AJ, Febbraio MA, Watt MJ: Saturated, but not $n-6$ polyunsaturated, fatty acids induce insulin resistance: role of intramuscular accumulation of lipid metabolites. $J$ Appl Physiol 2006, 100(5):1467-1474.

19. Roberts R, Bickerton AS, Fielding BA, Blaak EE, Wagenmakers AJ, Chong MF, Gilbert M, Karpe F, Frayn KN: Reduced oxidation of dietary fat after a short term high-carbohydrate diet. Am J Clin Nutr 2008, 87(4):824-831.

20. Roche HM: Fatty acids and the metabolic syndrome. Proc Nutr Soc 2005, 64(1):23-29.

21. Hannah VC, Ou J, Luong A, Goldstein JL, Brown MS: Unsaturated fatty acids down-regulate srebp isoforms 1a and 1c by two mechanisms in HEK-293 cells. J Biol Chem 2001, 276(6):4365-4372.

22. Patti ME, Kahn BB: Nutrient sensor links obesity with diabetes risk. Nat Med 2004, 10(10):1049-1050.

23. Shaw DI, Tierney AC, McCarthy S, Upritchard J, Vermunt S, Gulseth HL, Drevon CA, Blaak EE, Saris WH, Karlstrom B et al: LIPGENE food-exchange model for alteration of dietary fat quantity and quality in free-living participants from eight European countries. Br J Nutr 2009, 101(5):750-759.

24. Tierney AC, McMonagle J, Shaw DI, Gulseth HL, Helal O, Saris WH, Paniagua JA, Golabek-Leszczynska I, Defoort C, Williams CM et al: Effect of dietary fat modification on insulin sensitivity and other risk factors of the metabolic syndrome - LIPGENE: an European randomized dietary intervention study. International Journal Of Obesity 2010.

25. Cohen P, Miyazaki M, Socci ND, Hagge-Greenberg A, Liedtke W, Soukas AA, Sharma R, Hudgins LC, Ntambi JM, Friedman JM: Role for stearoyl-CoA desaturase-1 in leptin-mediated weight loss. Science 2002, 297(5579):240-243.

26. Finegood DT, Hramiak IM, Dupre J: A modified protocol for estimation of insulin sensitivity with the minimal model of glucose kinetics in patients with insulin-dependent diabetes. J Clin Endocrinol Metab 1990, 70(6):1538-1549.

27. Boston RC, Stefanovski D, Moate PJ, Sumner AE, Watanabe RM, Bergman RN: MINMOD Millennium: a computer program to calculate glucose effectiveness and insulin sensitivity from the frequently sampled intravenous glucose tolerance test. Diabetes Technol Ther 2003, 5(6):1003-1015.

28. Bergstrom J, Hermansen L, Hultman E, Saltin B: Diet, muscle glycogen and physical performance. Acta Physiol Scand 1967, 71(2):140-150.

29. Tierney AC, McMonagle J, Shaw DI, Gulseth HL, Helal O, Saris WH, Paniagua JA, Golabek-Leszczynska I, Defoort C, Williams CM et al: Effects of dietary fat modification on insulin sensitivity and on other risk factors of the metabolic syndrome-LIPGENE: a European randomized dietary intervention study. Int $J$ Obes (Lond).

30. Bustin SA: Absolute quantification of mRNA using real-time reverse transcription polymerase chain reaction assays. $J$ Mol Endocrinol 2000, 25(2):169-193.

31. Bogacka I, Xie H, Bray GA, Smith SR: Pioglitazone induces mitochondrial biogenesis in human subcutaneous adipose tissue in vivo. Diabetes 2005, 54(5):1392-1399.

32. Matthews DR, Hosker JP, Rudenski AS, Naylor BA, Treacher DF, Turner RC: Homeostasis model assessment: insulin resistance and beta-cell function from fasting plasma glucose and insulin concentrations in man. Diabetologia 1985, 28(7):412-419.

33. Kien CL, Bunn JY: Gender alters the effects of palmitate and oleate on fat oxidation and energy expenditure. Obesity (Silver Spring) 2008, 16(1):29-33. 


\section{Chapter 5}

34. Takeuchi Y, Yahagi N, Izumida Y, Nishi M, Kubota M, Teraoka Y, Yamamoto T, Matsuzaka T, Nakagawa Y, Sekiya M et al: Polyunsaturated fatty acids selectively suppress sterol regulatory element-binding protein-1 through proteolytic processing and autoloop regulatory circuit. J Biol Chem, 285(15):11681-11691.

35. Pender C, Trentadue AR, Pories WJ, Dohm GL, Houmard JA, Youngren JF: Expression of genes regulating malonyl-CoA in human skeletal muscle. $J$ Cell Biochem 2006, 99(3):860-867.

36. Andersson A, Nalsen C, Tengblad S, Vessby B: Fatty acid composition of skeletal muscle reflects dietary fat composition in humans. Am J Clin Nutr 2002, 76(6):1222-1229.

37. Summers LK, Fielding BA, Bradshaw HA, llic V, Beysen C, Clark ML, Moore NR, Frayn $\mathrm{KN}$ : Substituting dietary saturated fat with polyunsaturated fat changes abdominal fat distribution and improves insulin sensitivity. Diabetologia 2002, 45(3):369-377. 


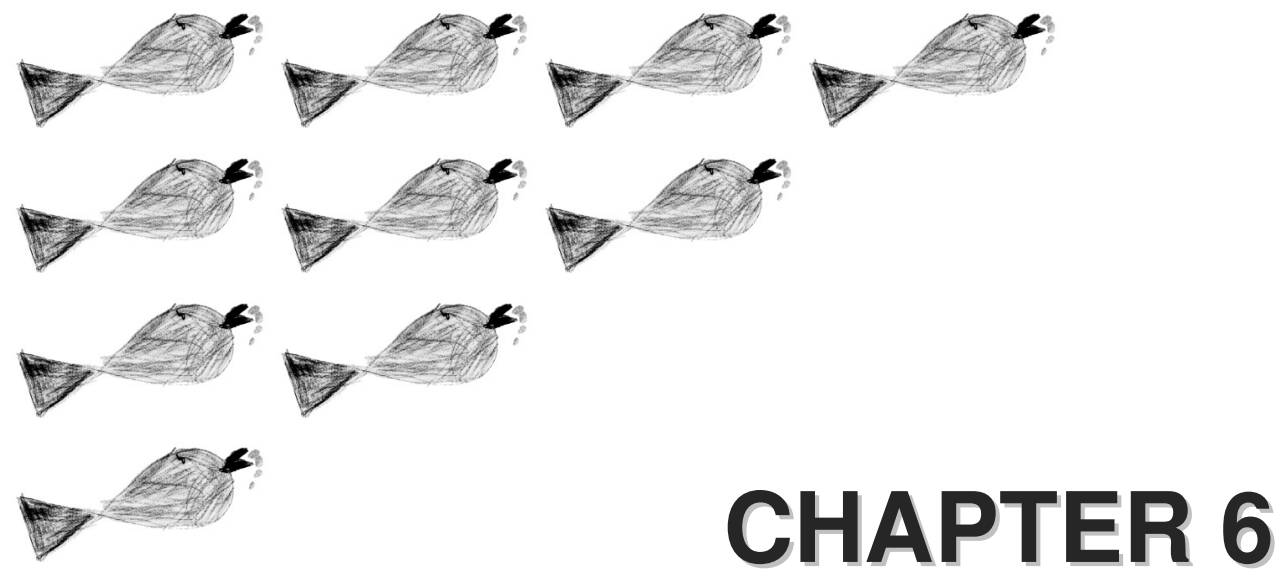

A human dietary intervention study to improve insulin sensitivity: effects on plasma FA profiles, estimated desaturase activities and steaoryl-CoA desaturase 1 (SCD1) in relation to insulin sensitivity

Anneke Jans, Herman E. Popeijus, Gijs H. Goossens, Audrey C. Tierney, Hanne L. Gulseth, Christine M Williams, Javier Delgado-Lista, Beata Kieć-Wilk, Małgorzata Malczewska-Malec, Jose Lopez-Miranda, Christian A. Drevon, Ulf Risérus, Brita Karlström, Julie A Lovegrove, Helen M. Roche and Ellen E. Blaak

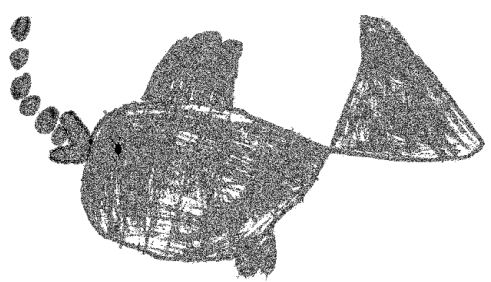




\section{Chapter 6}

\section{ABStRACt}

Introduction: The fatty acid (FA) composition of plasma may be related to insulin sensitivity. The aim of the present study was to investigate the effect of the quantity and quality of dietary FA on plasma FA profiles and the estimated enzyme activities of desaturases in relation to insulin sensitivity.

Methods: 417 subjects diagnosed with the metabolic syndrome (MetS) were randomly assigned to follow for 12 weeks one of four diets containing: high-fat saturated fat (HSFA), high-fat mono-unsaturated, low-fat high-complex carbohydrate (LFHCC) and LFHCC diet supplemented with $1.24 \mathrm{~g} / \mathrm{d}$ DHA/EPA LFHCC $n-3)$. The proportion of plasma FA was calculated and expressed as mole percent of the sum of the total plasma FA. Desaturase activity indices were estimated using product-to-precursor ratios. Steaoryl-CoA Desaturase 1 (SCD1) protein expression was determined in adipose tissue using Western blot analysis. Insulin sensitivity was determined by an insulin-modified intravenous glucose tolerance test.

Results: The changes in plasma FA composition after dietary intervention were determined by gender and habitual fat intake. ANCOVA analysis revealed no relationship between the change of plasma FA profile (individual FA as well as estimated desaturase activities) and insulin sensitivity. The HSFA diet increased adipose tissue SCD1 protein content $(p<0.05)$, whilst there was no change on the other diets. Furthermore, the change in SCD1 protein expression in adipose tissue was negatively related to insulin sensitivity.

Conclusion: Adipose tissue SCD1 expression increased after the HSFA diet, and this increase was negatively related to the change in insulin sensitivity. The latter may suggest that the increased SCD1 expression may be an early marker for the development of adipose tissue insulin resistance by promoting lipogenesis and adipose tissue expansion. 


\section{INTRODUCTION}

Overweight and obesity are steadily increasing worldwide and are linked to type 2 diabetes mellitus (T2DM) and cardiovascular disease [1]. These diseases may be preceded by insulin resistance, which is characterized by increased plasma concentrations of free fatty acid (FFA) and triacylglycerol (TAG). When dietary energy supply exceeds energy combustion for a long period of time, this may cause fat accumulation in non-adipose tissues (ectopic fat accumulation), which is strongly correlated with insulin resistance [2].

Lifestyle interventions aimed at improving dietary habits and increasing physical activity are known to be highly effective in the prevention of T2DM, although compliance can be a problem [3-5]. A change in dietary FA composition, as reflected by changes in plasma or serum FA profiles, has been shown to explain in part the positive lifestyle effects on insulin sensitivity [6]. A longitudinal study by Risérus et al. [7] showed that consumption of saturated fat (SFA) was inversely correlated with insulin sensitivity. In line, in the KANWU study, it was found that replacing SFA by monounsaturated FA (MUFA) improved insulin sensitivity under the restriction that the habitual dietary fat intake was less than 37E\% [8]. The FA composition of plasma lipids or tissues does not only mirror dietary FA intake during previous weeks but also reflects endogenous FA metabolism, including activities of enzymes responsible for synthesizing, desaturating and elongating FA $[9,10]$. The desaturases remodel FA by introduction of a double bound at the $\Delta^{5}$, $\Delta^{6}$ and $\Delta^{9}$ carbon of the FA chain [11] and have been linked to insulin resistance [12-14]. Stearoyl-CoA desaturase 1 (SCD1) or $\Delta^{9}$ desaturase is an endoplasmic reticulum-bound enzyme converting SFA to MUFA [11]. These MUFA are used as substrates for synthesis of TAG, cholesterol esters and phospholipids $[15,16]$. SCD1 is highly expressed in adipose tissue but also in liver and brain [11]. The $\Delta^{5}$ en $\Delta^{6}$ desaturases catalyze the synthesis of $n-6$ and $n-3$ poly-unsaturated FA (PUFA) [17]. Some studies suggest that an overexpression of SCD1 represents a protective mechanism against lipotoxicity by promoting TAG storage, reducing palmitate-induced apoptosis and reducing ceramide and diacylglycerol synthesis, thereby preventing insulin resistance [18-22]. On the other hand, mice deficient in SCD1 have increased energy expenditure, are lean, resistant to diet-induced obesity and insulin sensitive [16, 23-25]. SFA as well as MUFA have been identified as strong activators of SCD1 $[8,26]$, whereas PUFA are strong inhibitors $[26,27]$. In human studies, an increase in $\Delta^{6}$ desaturase activity and a decrease in $\Delta^{5}$ desaturase activity have been associated with insulin resistance and T2DM [10, 


\section{Chapter 6}

13, 28]. The LIPGENE human dietary intervention study investigated the effects of reduced SFA intake on insulin sensitivity by altering the composition or the quantity of dietary fat in a large European cohort of men and women with the metabolic syndrome (MetS). Overall, insulin sensitivity did not change after dietary fat modification under conditions of isocaloric exchange at group level [29]. However, the response to dietary fat quantity and quality may vary between subjects, among other factors depending on endogenous FA metabolism, habitual fat intake and gender. Thus, the aim of the current study was to investigate the relationship between diet-induced changes in plasma FA profiles, estimated desaturase activities in relation to insulin sensitivity, adjusting for relevant modulators. The activities of desaturases can be estimated using FA product-to-precursor ratios [3032]. As adipose tissue can be easily obtained from subjects compared with liver and brain tissue, and SCD1 has the highest expression and conducts it major functions in adipose tissue [11], we also explored the impact of dietary intervention on SCD1 at protein level in adipose tissue to unravel the metabolic responses following dietary intervention.

\section{METHODS}

Subjects and study design

The LIPGENE human dietary intervention study was a randomized, controlled trial, carried out at eight different centres across Europe as part of the EU Sixth Framework project LIPGENE (Contract no. FOOD-CT-2003-505944). In total, 480 volunteers with the MetS at the age of 35-70 years and body mass index (BMI) between 20 and $40 \mathrm{~kg} / \mathrm{m}^{2}$ were included in this study. Subjects were randomly assigned to receive one of four dietary interventions for a 12-week period (see 'dietary intervention) [29, 33]. The definition of the MetS was based on the NCEP ATP III report [34], with subjects fulfilling at least three out of five criteria as described previously [35]. A total of 417 volunteers completed the study. All subjects gave written informed consent before study participation. The study protocol was approved by the local research ethics committees at each of the eight intervention centres.

\section{Dietary intervention}

Subjects were randomly assigned to one of four isoenergetic intervention diets:

(1) High-fat (38\% energy (E\%)) SFA-rich diet (16E\% SFA, 12E\% MUFA, 6E\% PUFA) (HSFA) 
(2) High-fat (38E\%) MUFA-rich diet (8E\% SFA, 20E\% MUFA, 6E\% PUFA) (HMUFA)

(3) Isoenergetic low-fat (28E\%), high-complex carbohydrate diet (8E\% SFA, 11E\% MUFA, 6E\% PUFA), with a control high-oleic acid sunflower-seed oil capsule (1g per day) (LFHCC)

(4) Isoenergetic low-fat (28E\%), high-complex carbohydrate diet (8E\% SFA, 11E\% MUFA, 6E\% PUFA), with a long-chain (LC) $n$-3 PUFA supplement (1.24 g per day of eicosapentaenoic and docosahexaenoic acid, ratio 1.4:1) (LFHCC $n-3)$

A range of fat-modified food products were provided to the subjects with specific dietary counselling [35]. A food exchange model was developed, and carbohydrate-fat exchanges were used to ensure that all diets were isoenergetic. An extensive description of the food exchange model and assessment of compliance is published elsewhere [33]. Detailed dietary counselling was given to the volunteers and frequent monitoring and dietary reinforcement maximized volunteer compliance [29]. Loders-Croklaan (Wormerveer, the Netherlands) supplied the study capsules used in LFHCC and LFHCCn-3 diet. All subjects completed 3-day weighed food record at baseline, week 6, and week 12, and centre-specific dietary analysis computer programs were used to analyze the food diaries. Subjects had to remain weight stable within the range of $2 \mathrm{~kg}$ during the intervention period, and were asked to maintain their normal pattern of physical activity, alcohol consumption and smoking.

\section{Experimental design}

Pre-intervention and post-intervention, subjects came to the university after an overnight fast on two different occasions. On one day, anthropometric measurements were completed and fasting blood samples were taken to measure plasma lipid concentrations. On the other occasion, subjects completed an insulinmodified intravenous glucose tolerance test (IVGTT) to measure insulin sensitivity as described previously [36, 37]. Insulin sensitivity was the primary end point of the LIPGENE human dietary intervention study. In a subgroup $(n=41)$, a fasting abdominal subcutaneous adipose tissue biopsy $(\sim 1 \mathrm{~g})$ was collected $6-8 \mathrm{~cm}$ lateral from the umbilicus under local anesthesia ( $2 \%$ lidocaine) by needle biopsy to determine SCD1 protein level (see adipose tissue protein expression). Adipose tissue was washed with sterile saline and processed within $5 \mathrm{~min}$ at the bedside and was snap frozen in liquid nitrogen and stored at $-80^{\circ} \mathrm{C}$ until analysis. 


\section{ChAPTER 6}

SCD1 protein expression in adipose tissue

Western blotting was used to quantify the amount of SCD1 protein in lysates of

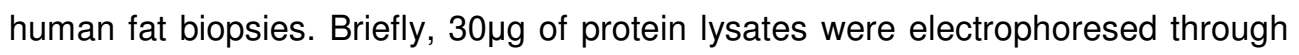
$10 \%$ SDS-PAGE gel. Electrophoresed proteins were transferred onto nitrocellulose membranes at $100 \mathrm{~mA}$ overnight at $4^{\circ} \mathrm{C}$ and visualized by Ponceau $S$ reagent. The blots were blocked with $5 \%$ non-fat dry milk/0.05\% TBS-Tween20 for $1 \mathrm{~h}$ at room temperature. Then blots were probed with mouse anti-SCD1 antibodies (1:1000) or rabbit anti beta actin antibodies $(1: 1000)$ overnight at $4^{\circ} \mathrm{C}$. The membranes were washed and incubated with swine anti-rabbit antibodies or anti-mouse antibodies conjugated to horseradish peroxidase $(1: 5000)$ for $1 \mathrm{~h}$ at room temperature. After further washing steps, visualization was performed using chemiluminiscence reagent (Pierce Biotechnology, Rockford, USA) and quantified by the ChemiDoc XRS+ system (Bio-Rad Laboratories, Hercules, CA).

\section{Biochemical analysis}

Blood for lipid and glucose analyses was collected in potassium EDTA, fluoride oxalate and plasma separator vacutainers. Samples, apart from plasma, were centrifuged immediately $(1500 \mathrm{~g})$, plasma was aliquoted and stored at $-80^{\circ} \mathrm{C}$. Standard methodologies were used to determine plasma insulin (AutoDELFIA Insulin and AutoDELFIA C-peptide kits; Wallac Oy, Turku, Finland). Plasma concentrations of total cholesterol, HDL-C, LDL-C, TAG, NEFA and glucose were analyzed (Instrumentation Laboratory, Warrington, UK; WAKO NEFA C kit, Alpha Laboratories, Hampshire, UK). HDL-C and LDL-C were precipitated (Randox CH1350 Laboratories Ltd, Co Antrim). Plasma FA were extracted and transmethylated with borontrifluoride in methanol; composition was determined by gas liquid chromatography using a Shimadzu GC2010 (Shimadzu, Japan).

\section{Statistical methods}

Statistical analyses were performed using SPSS 19.0 for Macintosh (SPSS Inc., Chicago, IL, USA). The data were checked for normal distribution and Intransformed to obtain normal distribution. One-way analysis of variance (ANOVA) was used to test for differences between the dietary intervention groups and to test for pre-intervention gender differences. Repeated-measures ANOVA was used to determine the effect of dietary intervention on metabolic parameters and plasma FA profiles, taking gender, habitual fat intake and body weight change into account. Post-hoc analyses were performed on significant interaction terms. Thereafter, insulin sensitivity (defined as $\mathrm{HOMA}_{\mathrm{IR}}$ or by IVGTT) was included as dependent variable in an analysis of covariance. In this analysis, plasma FA profile, 
habitual fat intake, gender, centre, body weight change (and mean level of $\mathrm{HOMA}_{\mathrm{IR}}$ or insulin sensitivity, IVGTT) and the interaction between these factors were entered. All data are presented as means \pm standard error of the means (SEM) and statistical significance was set at $p<0.05$.

\section{RESULTS}

Baseline characteristics according to dietary intervention groups are indicated in Table 1. The main outcome of the LIPGENE dietary intervention study has previously been described [29]. Overall, insulin sensitivity was unaltered after the intervention, whereas body weight was marginally but significantly reduced following both low-fat diets (LFHCC and LFHCC $n$-3 diet) [29].

\section{Plasma fatty acid profile and desaturase activities}

Dietary intervention resulted in minor effects on plasma FA profiles (Table 2). As previously reported [29], oleic acid (C18:1n-9) showed a significant diet*time interaction $(P=0.005)$, with a significant increase in oleic acid concentrations following the HMUFA diet $(p=0.033)$ (Table 2). Moreover, plasma oleic acid concentrations were significantly reduced following the HSFA $(P=0.005)$ and the LFHCC $n-3$ diet $(p=0.004)$. There was an increase in plasma EPA $(20: 5 n-3)$ and DHA (22:6n-3) concentration after the LFHCC $n-3$ diet $(p=0.005)$. There were neither direct changes in other individual plasma FA fractions nor for the estimated $\Delta^{9}\left(16: 1 / 16: 0\right.$, SCD1), the $\Delta^{5}$ (C20:4n-6/C20:3n-6) and $\Delta^{6}$ (C18: 3n-6/C18:2n-6) desaturase activity (Table 2). Several individual FA fractions and estimated $\Delta^{5}$ desaturase showed a significant diet $^{*}$ time ${ }^{*}$ gender $^{*}$ habitual fat intake interaction (C14:0 p<0.001, C16:0 p<0.001, C16:1n-7 p < 0.001, C18:0 p<0.001, C18:1n-9 p<0.001, $\mathrm{C} 18: 2 n-6 \mathrm{p}<0.001, \mathrm{C} 18: 4 n-3 p<0.001, \mathrm{c} 20: 3 \mathrm{p}<0.001, \mathrm{c} 20: 3 n-6 \mathrm{p}<0.001, \mathrm{C} 20: 4 n-3 \mathrm{p}=0.03$, $\mathrm{C} 20: 4 n-6 \mathrm{p}<0.001, \mathrm{C} 20: 5 n-3 \mathrm{p}<0.001, \mathrm{C} 22: 6 n-3 \mathrm{p}=0.029$ ). This interaction is shown for 16:0 in Figure 1A and 1B, although similar patterns were observed for the other FA (C16:0, C18:0 and 18:1). Following the LFHCC $n-3$ diet, in men with a habitual fat intake below $36 \mathrm{E} \%$, the average $\mathrm{C} 16: 0$ plasma concentration decreased $(p=0.029)$, whereas the average $C 16: 0$ plasma concentration increased $(p=0.007)$ in men with a habitual fat intake above $36 \mathrm{E} \%$. In women with a habitual fat intake above $36 \mathrm{E} \%$, the plasma concentration $\mathrm{C} 16: 0(p=0.074)$ tended to increase after the HMUFA diet. For the estimated $\Delta^{5}$ desaturase ratio a different pattern was found in men and women, with an increased ratio after the HSFA diet regardless the $\mathrm{E} \%$ fat intake in men (Figure $\mathbf{1 C}$ ). In women, the estimated $\Delta^{5}$ desaturase ratio increased after both LFHCC diets (Figure 1D). 


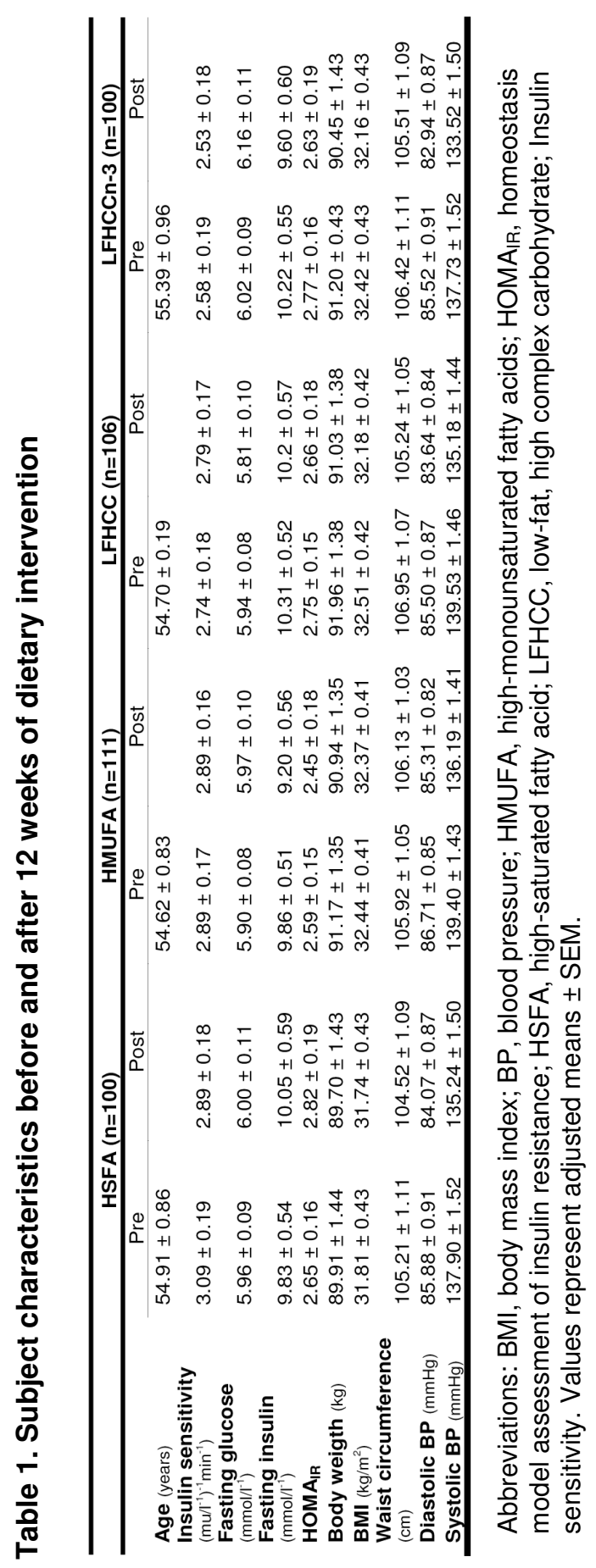




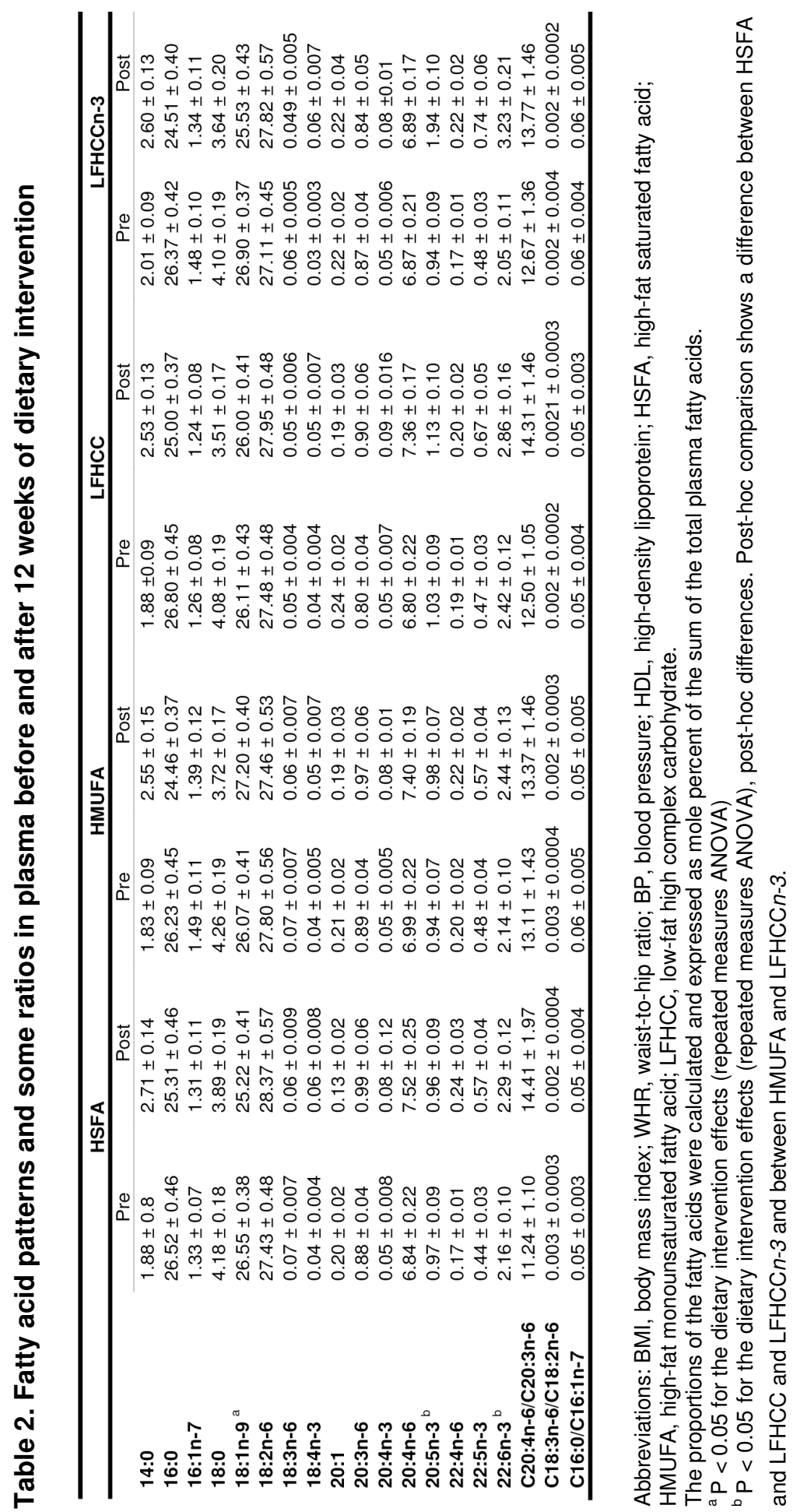




\section{ChAPTER 6}

\section{Relation with insulin sensitivity}

Analysis of covariance revealed no relationship between the change in plasma FA profile (both individual FA as well as estimated desaturase activities) and insulin sensitivity (as determined by IVGTT or HOMA $\mathrm{IR}_{\mathrm{R}}$ ), after adjustment for diet, habitual fat intake, gender, centre, body weight change and the interaction between these factors (data not shown).
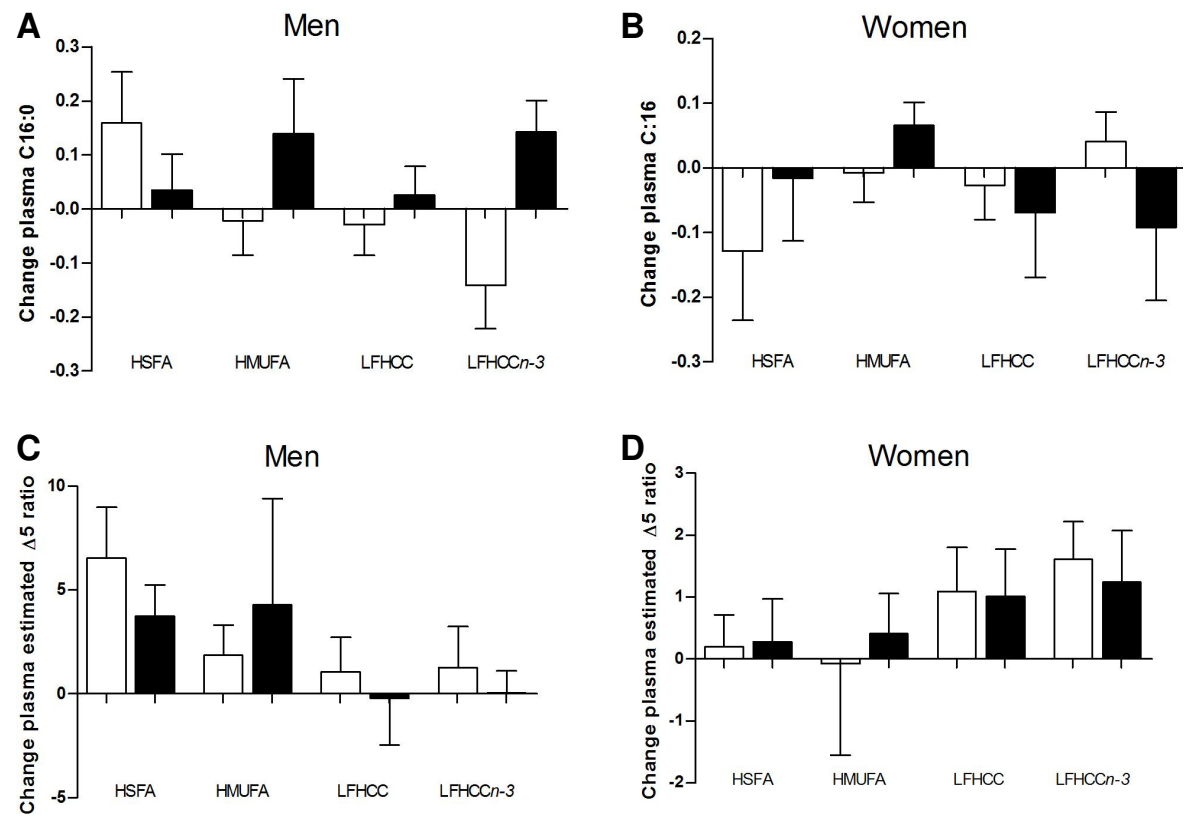

Figure 1. Change in estimated plasma desaturase ratios after dietary intervention. (A) Delta for percent C16:0 after the four diets for men between low $(<36 \mathrm{E} \%)$ and high $(>36 \mathrm{E} \%)$ habitual fat intake, (B) delta for percent C16:0 after the four diets between for women low $(<36 \mathrm{E} \%)$ and high $(>36 \mathrm{E} \%)$ habitual fat intake, (C) Delta for $\Delta^{5}$ desaturase after the four diets for men between low (<36E\%) and high ( $>36 \mathrm{E} \%)$ habitual fat intake and (D) delta for $\Delta^{5}$ desaturase after the four diets between for women low $(<36 \mathrm{E} \%)$ and high $(>36 \mathrm{E} \%)$ habitual fat intake. HSFA, high-fat saturated fatty acid; HMUFA, high-fat monounsaturated fatty acid; LFHCC, low-fat high complex carbohydrate. White bars represent $<36 \mathrm{E} \%$ and black bars $>36 \mathrm{E} \%$.

\section{Cross sectional analyses}

We investigated determinants of plasma FA profiles and the relationship between different plasma FA profiles and insulin sensitivity in the baseline data set (crosssectional analysis), adjusted for centre, diet, body weight, BMI, percentage of body fat and plasma TAG concentration. Analysis of covariance was performed with either $\mathrm{HOMA}_{\mathrm{IR}}$ or insulin sensitivity (as determined by IVGTT) as dependent variable and multiple determinants (centre, diet, baseline insulin sensitivity, body 
weight, BMI, percent body fat and plasma TAG concentration. At baseline, there was a positive relation between $\mathrm{C} 16: 0 \quad\left(r_{S}=0.150, p<0.001\right), C 18: 1 \quad\left(r_{S}=0.114\right.$, $p=0.006), C 18: 0 \quad\left(r_{S}=0.151, p=0,003\right)$ and $C 20: 3 n-6 \quad\left(r_{S}=0.134, p=0.003\right)$ and $\mathrm{HOMA}_{\mathrm{IR}}$. FA profiles and insulin sensitivity, as determined by IVGTT, were not correlated. Furthermore, a strong relationship was observed between body fat percentage and estimated SCD1 activity in plasma $\left(r_{S}=0.312, p<0.001\right.$ Figure 2A). However, estimated SCD1 activity in plasma did not relate to BMI, waist hip ratio and insulin sensitivity. Interestingly, women had higher baseline levels of estimated plasma SCD1 activity $(p<0.001$ Figure 2B) as well as higher expression of SCD1 protein in adipose tissue ( $p=0.013$ Figure $2 B$ ) compared with men.
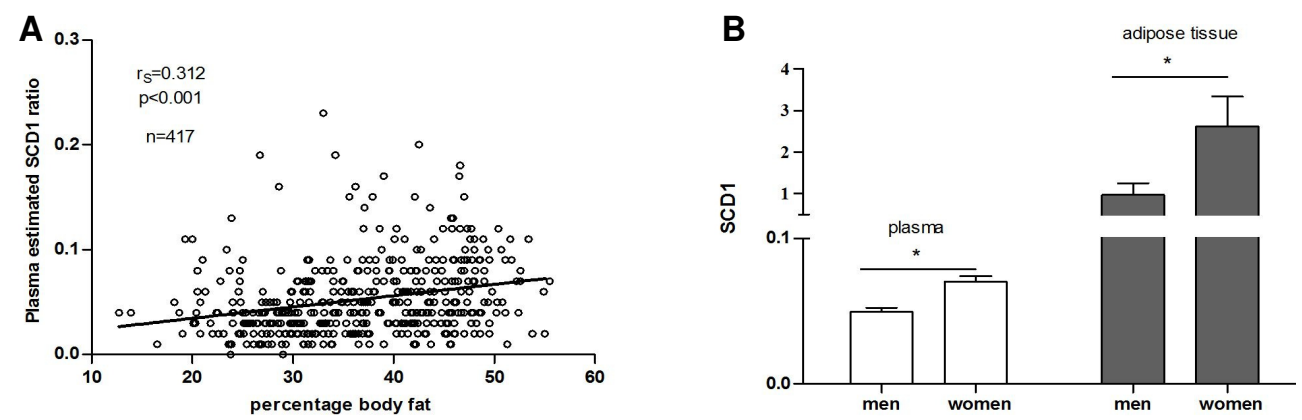

Figure 2. Cross sectional correlation between percentages of body fat and SCD1. (A) Correlation with estimated plasma SCD1 ratio and (B) gender differences in adipose tissue SCD1.

\section{Effect of dietary intervention on adipose tissue SCD1 protein expression}

The HSFA diet increased SCD1 protein expression in abdominal subcutaneous adipose tissue $(n=12$, paired $t$-test $p=0.039$ Figure $3 A$ ), whereas the levels remained unchanged following the other diets. Furthermore, SCD1 protein expression in adipose tissue was positively correlated with body fat percentage $\left(n=35, r_{s}=0.428, p=0.010\right.$ (Figure 3B), and inversely correlated with the change in insulin sensitivity $\left(n=34, r_{S}=-0.33, p=0.067\right.$ ) (Figure $3 C$ ), independent of diet. 


\section{Chapter 6}

A
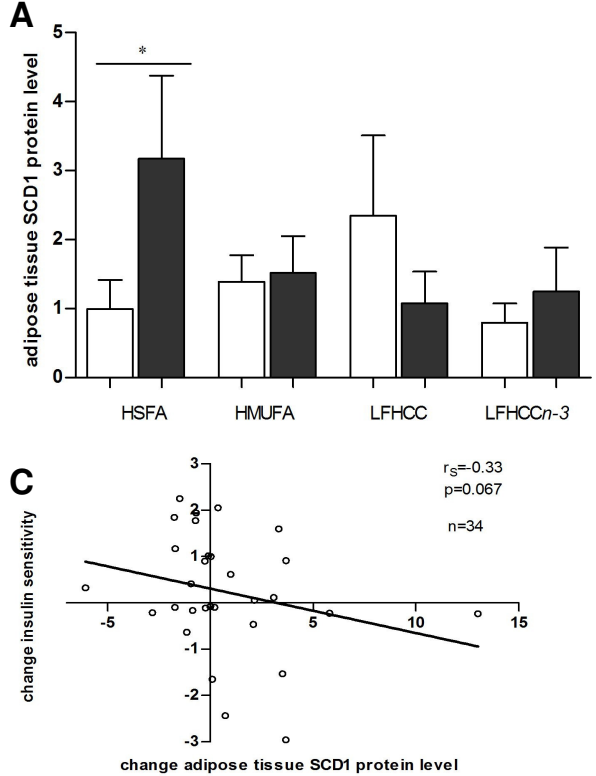

B

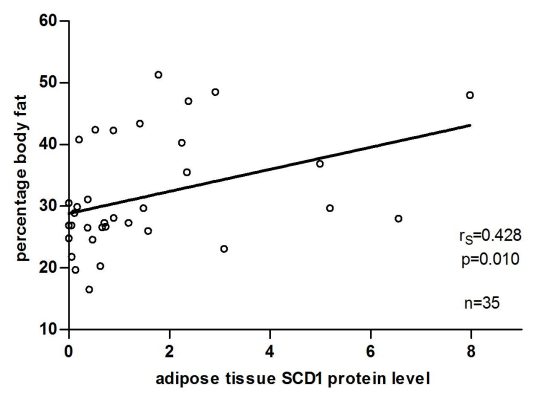

Figure 3. Change in adipose tissue SCD1 protein expression. (A) After the four diets, (B) correlation with SCD1 protein in adipose tissue and (C) correlation between the change in insulin sensitivity and the change in adipose tissue SCD1 protein expression. HSFA, high-fat saturated fatty acid; HMUFA, high-fat monounsaturated fatty acid; LFHCC, low-fat high complex carbohydrate. White bars represent before dietary intervention, black bars after dietary intervention.

\section{DISCUSSION}

In the present study, we investigated the effect of changes in dietary fat quality and quantity on plasma FA profiles and SCD1 protein levels in adipose tissue in relation to changes in insulin sensitivity. Interestingly, we observed an increase in SCD1 protein expression in adipose tissue after the HSFA diet, suggesting enhanced lipogenesis. Overall, a higher SCD1 expression in adipose tissue tended to correlate negatively with insulin sensitivity. The SCD1 protein level revealed no significant relation to the plasma FA profiles. Furthermore, diet, gender and habitual fat intake did significantly affect plasma FA profiles. There were no significant correlations between changes in FA profiles and insulin sensitivity (either by IVGTT or $\mathrm{HOMA}_{\mathrm{IR}}$ ), consistent with the previously reported nil effect on insulin sensitivity by either MUFA feeding or $n-3$ supplementation.

The median of the habitual dietary fat intake in our study was $36 \mathrm{E} \%$. Men and women seemed to respond differently to the LFHCC $n-3$ diet and the HMUFA diet with respect to plasma FA profiles. Men with a habitual fat intake below $36 \mathrm{E} \%$ decreased their plasma $\mathrm{C} 16: 0$ fraction, whereas an increased $\mathrm{C} 16: 0$ concentration 
was found in men with a habitual fat intake above $36 \mathrm{E} \%$. After the HMUFA diet, women, particularly those with a habitual fat intake above $36 \mathrm{E} \%$, showed an increased plasma $\mathrm{C} 16: 0$ fraction. For the estimated relative $\Delta^{5}$ desaturase activity we observed an increase in men after the HSFA diet, while women showed increase in the estimated relative $\Delta^{5}$ desaturase activity after both LFHCC diets. Thus, these data suggest that the metabolic profile of an individual has a significant impact on changes in plasma FA profiles and $\Delta^{5}$ desaturase activity after dietary intervention. Our observation that habitual dietary fat intake is an important factor in individual responsiveness to dietary intervention is in line with the findings from KANWU study [8]. Variation in plasma FA composition has been shown to be associated with insulin resistance in cross-sectional studies [38, 39] and proportional changes in the composition of FA in plasma are related to changes in insulin sensitivity in intervention studies independent of body weight [6]. Nevertheless, we could not confirm such relationship between changes in plasma FA composition and insulin sensitivity in our present study. This may be explained by the small effect on FA profile in the present intervention study. However, in specific subgroups we observed distinct differences in plasma FA profile but not in insulin sensitivity, suggesting that there may not be a causal relationship between FA profile and insulin sensitivity. Further research is required to elucidate this putative but controversial relationship.

Interestingly, we found a significant increase in SCD1 protein expression in adipose tissue after the HSFA diet. It has previously been shown that SFA may upregulate relative SCD1 activity as estimated from plasma FA [32, 40]. It can be postulated that the increase in SCD1 protein expression in adipose tissue after a SFA diet may stimulate lipogenesis, thereby contributing to expansion of adipose tissue mass and development of obesity [25]. Our data showed a tendency towards a negative correlation between SCD1 in adipose tissue and insulin sensitivity, which is in line previous published studies $[6,41]$. In the present study, the change in SCD1 protein expression in adipose tissue was unrelated to systemic changes in estimated relative SCD1 activity. This might be due to the fact that the liver plays a more important role than fat tissue in influencing plasma FA profile, which is in line with findings from Kotronen et al. [42], demonstrating that estimated SCD1 plasma ratios reflect the estimated activities of desaturases in the liver. However, the effect of desaturase activity, including SCD1 activity, might be too small to contribute detectable changes in plasma FA profile in contrast to the significant influence of habitual and dietary fat intake on the plasma FA profile.

As reported previously, in the total LIPGENE cohort no differences were found in whole-body insulin sensitivity following the different intervention diets under 


\section{ChAPTER 6}

conditions of isocaloric exchange. It may be that a chronic positive energy balance, mainly due to excessive saturated fat consumption, may exert more pronounced effects on adipose tissue SCD1 expression, which could then evoke differences in whole-body insulin sensitivity. A limitation of our study, like earlier studies [32, 43], may be the use of the ratio of individual FA to estimate activity of desaturases in the plasma. It is not possible, therefore, to draw definite conclusions about actual enzyme activities. Furthermore we used total plasma lipid fraction for assessing desaturase index, whilst the use of a single lipid fraction such as triglycerides or cholesteryl esters would have been preferable and especially in those subjects with elevated triglycerides [31, 44]. Finally, as previously also highlighted the plasma SCD1 index should thus be interpreted with caution as it might more reflect the activity of the liver or the FA consumed.

In the cross-sectional analysis, we observed a strong and positive association between body fat percentage and SCD1 in the plasma and adipose tissue. Other human studies found strong correlations between SCD1 and the occurrence of obesity [45-47]. Warensjö et al. [47] found relations between markers of obesity and estimated relative SCD1 plasma activity as measured by the substrate ratio and they suggested that desaturase ratios are associated with central adiposity and not to overweight in general. In our study, body fat percentage seemed to be a strong indicator for high levels of estimated SCD1 activity in the plasma and adipose tissue.

In conclusion, adipose tissue SCD1 protein expression increased after the HSFA diet. Although changes in adipose tissue SCD1 expression tended to correlate negatively with whole body insulin sensitivity there were no diet-induced changes in insulin sensitivity under conditions of isoenergetic exchange [29], nor any relationship between systemic plasma FA profiles and insulin sensitivity. From the present data it can be speculated that the increased SCD1 expression may be an early marker for the development of insulin resistance by promoting lipogenesis and adipose tissue expansion.

\section{ACKNOWLEDGEMENTS}

We thank all subjects for participation in the present study. We gratefully thank Jos Stegen, Wendy Sluijsmans, Hasibe Aydeniz, Yvonne Essers and Annemie Gijssen for their excellent analytical support. 


\section{REFERENCES}

1. Wyatt SB, Winters KP, Dubbert PM: Overweight and obesity: prevalence, consequences, and causes of a growing public health problem. Am J Med Sci 2006, 331(4):166-174.

2. Goossens $\mathrm{GH}$ : The role of adipose tissue dysfunction in the pathogenesis of obesity-related insulin resistance. Physiol Behav 2008, 94(2):206-218.

3. Lindstrom J, Louheranta A, Mannelin M, Rastas M, Salminen V, Eriksson J, Uusitupa M, Tuomilehto J: The Finnish Diabetes Prevention Study (DPS): Lifestyle intervention and 3-year results on diet and physical activity. Diabetes Care 2003, 26(12):3230-3236.

4. Knowler WC, Barrett-Connor E, Fowler SE, Hamman RF, Lachin JM, Walker EA, Nathan DM: Reduction in the incidence of type 2 diabetes with lifestyle intervention or metformin. N Engl J Med 2002, 346(6):393-403.

5. Roumen C, Corpeleijn E, Feskens EJ, Mensink M, Saris WH, Blaak EE: Impact of 3-year lifestyle intervention on postprandial glucose metabolism: the SLIM study. Diabet Med 2008, 25(5):597-605.

6. Corpeleijn E, Feskens EJ, Jansen EH, Mensink M, Saris WH, de Bruin TW, Blaak $\mathrm{EE}$ : Improvements in glucose tolerance and insulin sensitivity after lifestyle intervention are related to changes in serum fatty acid profile and desaturase activities: the SLIM study. Diabetologia 2006, 49(10):2392-2401.

7. Riserus U, Arnlov J, Berglund L: Long-term predictors of insulin resistance: role of lifestyle and metabolic factors in middle-aged men. Diabetes Care 2007, 30(11):2928-2933.

8. Vessby B, Uusitupa M, Hermansen K, Riccardi G, Rivellese AA, Tapsell LC, Nalsen C, Berglund L, Louheranta A, Rasmussen BM et al: Substituting dietary saturated for monounsaturated fat impairs insulin sensitivity in healthy men and women: The KANWU Study. Diabetologia 2001, 44(3):312-319.

9. Glatz JF, Soffers AE, Katan MB: Fatty acid composition of serum cholesteryl esters and erythrocyte membranes as indicators of linoleic acid intake in man. Am J Clin Nutr 1989, 49(2):269-276.

10. Vessby B, Gustafsson IB, Tengblad S, Boberg M, Andersson A: Desaturation and elongation of Fatty acids and insulin action. Ann N Y Acad Sci 2002, 967:183195.

11. Popeijus HE, Saris WH, Mensink RP: Role of stearoyl-CoA desaturases in obesity and the metabolic syndrome. Int J Obes (Lond) 2008, 32(7):1076-1082.

12. Dobrzyn A, Dobrzyn P, Lee SH, Miyazaki M, Cohen P, Asilmaz E, Hardie DG, Friedman JM, Ntambi JM: Stearoyl-CoA desaturase-1 deficiency reduces ceramide synthesis by downregulating serine palmitoyltransferase and increasing beta-oxidation in skeletal muscle. Am J Physiol Endocrinol Metab 2005, 288(3):E599-607.

13. Borkman M, Storlien LH, Pan DA, Jenkins AB, Chisholm DJ, Campbell LV: The relation between insulin sensitivity and the fatty-acid composition of skeletalmuscle phospholipids. N Engl J Med 1993, 328(4):238-244.

14. Hulver MW, Berggren JR, Carper MJ, Miyazaki M, Ntambi JM, Hoffman EP, Thyfault JP, Stevens R, Dohm GL, Houmard JA et al: Elevated stearoyl-CoA desaturase-1 expression in skeletal muscle contributes to abnormal fatty acid partitioning in obese humans. Cell Metab 2005, 2(4):251-261.

15. Miyazaki M, Gomez FE, Ntambi JM: Lack of stearoyl-CoA desaturase-1 function induces a palmitoyl-CoA Delta6 desaturase and represses the stearoyl-CoA desaturase-3 gene in the preputial glands of the mouse. J Lipid Res 2002, 43(12):2146-2154. 
16. Miyazaki M, Kim YC, Gray-Keller MP, Attie AD, Ntambi JM: The biosynthesis of hepatic cholesterol esters and triglycerides is impaired in mice with a disruption of the gene for stearoyl-CoA desaturase 1. J Biol Chem 2000, 275(39):30132-30138.

17. Nakamura MT, Nara TY: Structure, function, and dietary regulation of delta6, delta5, and delta9 desaturases. Annu Rev Nutr 2004, 24:345-376.

18. Pinnamaneni SK, Southgate RJ, Febbraio MA, Watt MJ: Stearoyl CoA desaturase 1 is elevated in obesity but protects against fatty acid-induced skeletal muscle insulin resistance in vitro. Diabetologia 2006, 49(12):30273037.

19. Peter A, Weigert C, Staiger H, Rittig K, Cegan A, Lutz P, Machicao F, Haring HU, Schleicher $\mathrm{E}$ : Induction of stearoyl-CoA desaturase protects human arterial endothelial cells against lipotoxicity. Am J Physiol Endocrinol Metab 2008, 295(2):E339-349.

20. Listenberger LL, Han X, Lewis SE, Cases S, Farese RV, Jr., Ory DS, Schaffer JE: Triglyceride accumulation protects against fatty acid-induced lipotoxicity. Proc Natl Acad Sci U S A 2003, 100(6):3077-3082.

21. Peter A, Weigert C, Staiger H, Machicao F, Schick F, Machann J, Stefan N, Thamer C, Haring HU, Schleicher E: Individual stearoyl-coa desaturase 1 expression modulates endoplasmic reticulum stress and inflammation in human myotubes and is associated with skeletal muscle lipid storage and insulin sensitivity in vivo. Diabetes 2009, 58(8):1757-1765.

22. Riserus U, Tan GD, Fielding BA, Neville MJ, Currie J, Savage DB, Chatterjee VK, Frayn KN, O'Rahilly S, Karpe F: Rosiglitazone increases indexes of stearoylCoA desaturase activity in humans: link to insulin sensitization and the role of dominant-negative mutation in peroxisome proliferator-activated receptorgamma. Diabetes 2005, 54(5):1379-1384.

23. Cohen P, Miyazaki M, Socci ND, Hagge-Greenberg A, Liedtke W, Soukas AA, Sharma R, Hudgins LC, Ntambi JM, Friedman JM: Role for stearoyl-CoA desaturase-1 in leptin-mediated weight loss. Science 2002, 297(5579):240-243.

24. Ntambi JM, Miyazaki M, Stoehr JP, Lan H, Kendziorski CM, Yandell BS, Song Y, Cohen P, Friedman JM, Attie AD: Loss of stearoyl-CoA desaturase-1 function protects mice against adiposity. Proc Natl Acad Sci U S A 2002, 99(17):1148211486.

25. Dobrzyn A, Ntambi JM: The role of stearoyl-CoA desaturase in body weight regulation. Trends Cardiovasc Med 2004, 14(2):77-81.

26. Mauvoisin D, Mounier C: Hormonal and nutritional regulation of SCD1 gene expression. Biochimie, 93(1):78-86.

27. Ntambi JM: Regulation of stearoyl-CoA desaturase by polyunsaturated fatty acids and cholesterol. J Lipid Res 1999, 40(9):1549-1558.

28. Kelley DE, Goodpaster BH, Storlien L: Muscle triglyceride and insulin resistance. Annu Rev Nutr 2002, 22:325-346.

29. Tierney AC, McMonagle J, Shaw DI, Gulseth HL, Helal O, Saris WH, Paniagua JA, Golabek-Leszczynska I, Defoort C, Williams CM et al: Effects of dietary fat modification on insulin sensitivity and on other risk factors of the metabolic syndrome-LIPGENE: a European randomized dietary intervention study. Int $J$ Obes (Lond).

30. Hodson L, Skeaff CM, Fielding BA: Fatty acid composition of adipose tissue and blood in humans and its use as a biomarker of dietary intake. Prog Lipid Res 2008, 47(5):348-380.

31. Karpe F, Hodson L: Caution on the interpretation of plasma fatty acid composition as a proxy marker for SCD1 activity: particular implications for using the 16:1/16:0 ratio in QTL studies involving hyperlipidemic patients. Arterioscler Thromb Vasc Biol 2008, 28(8):e152; author reply e153. 
32. Warensjo E, Riserus U, Gustafsson IB, Mohsen R, Cederholm T, Vessby B: Effects of saturated and unsaturated fatty acids on estimated desaturase activities during a controlled dietary intervention. Nutr Metab Cardiovasc Dis 2008, 18(10):683-690.

33. Shaw DI, Tierney AC, McCarthy S, Upritchard J, Vermunt S, Gulseth HL, Drevon CA, Blaak EE, Saris WH, Karlstrom B et al: LIPGENE food-exchange model for alteration of dietary fat quantity and quality in free-living participants from eight European countries. Br J Nutr 2009, 101(5):750-759.

34. Third Report of the National Cholesterol Education Program (NCEP) Expert Panel on Detection, Evaluation, and Treatment of High Blood Cholesterol in Adults (Adult Treatment Panel III) final report. Circulation 2002, 106(25):31433421.

35. van Hees AM, Saris WH, Hul GB, Schaper NC, Timmerman BE, Lovegrove JA, Roche HM, Blaak EE: Effects of dietary fat modification on skeletal muscle fatty acid handling in the metabolic syndrome. Int $J$ Obes (Lond), 34(5):859870.

36. Finegood DT, Hramiak IM, Dupre J: A modified protocol for estimation of insulin sensitivity with the minimal model of glucose kinetics in patients with insulin-dependent diabetes. J Clin Endocrinol Metab 1990, 70(6):1538-1549.

37. Boston RC, Stefanovski D, Moate PJ, Sumner AE, Watanabe RM, Bergman RN: MINMOD Millennium: a computer program to calculate glucose effectiveness and insulin sensitivity from the frequently sampled intravenous glucose tolerance test. Diabetes Technol Ther 2003, 5(6):1003-1015.

38. Fernandez-Real JM, Broch M, Vendrell J, Ricart W: Insulin resistance, inflammation, and serum fatty acid composition. Diabetes Care 2003, 26(5):1362-1368.

39. Vessby B, Tengblad S, Lithell $\mathrm{H}$ : Insulin sensitivity is related to the fatty acid composition of serum lipids and skeletal muscle phospholipids in 70-yearold men. Diabetologia 1994, 37(10):1044-1050.

40. Sampath H, Miyazaki M, Dobrzyn A, Ntambi JM: Stearoyl-CoA desaturase-1 mediates the pro-lipogenic effects of dietary saturated fat. J Biol Chem 2007, 282(4):2483-2493.

41. Van Woudenbergh GJ, Kuijsten A, Van der Kallen CJ, Van Greevenbroek MM, Stehouwer CD, Blaak EE, Feskens EJ: Comparison of fatty acid proportions in serum cholesteryl esters among people with different glucose tolerance status: The CoDAM study. Nutr Metab Cardiovasc Dis.

42. Kotronen A, Seppanen-Laakso T, Westerbacka J, Kiviluoto T, Arola J, Ruskeepaa $\mathrm{AL}$, Yki-Jarvinen $\mathrm{H}$, Oresic M: Comparison of lipid and fatty acid composition of the liver, subcutaneous and intra-abdominal adipose tissue, and serum. Obesity (Silver Spring), 18(5):937-944.

43. Woudenberg van G.J. KA, Kallen Van der C.J., Greevenbroek Van M.M., Stehouwer C.D., Blaak E.E., Feskens E.J.M.: Comparisons of fatty acid proportions in serum cholesteryl esters among people with different glucose tolerance status: The CoDAM study. Nutrition, Metabolism \& Cardiovascular Diseases 2010:1-8.

44. Bjermo H, Riserus U: Role of hepatic desaturases in obesity-related metabolic disorders. Curr Opin Clin Nutr Metab Care 2010, 13(6):703-708.

45. Francois P: Plasma palmitoleic acid, a product of stearoyl-CoA desaturase activity, is an independent marker of triglycerimia and abdominal adiposity. Nutrition, Metabolism and Cardiovascular Diseases 2007.

46. Gong J, Campos H, McGarvey S, Wu Z, Goldberg R, Baylin A: Adipose tissue palmitoleic acid and obesity in humans: does it behave as a lipokine? $A m \mathrm{~J}$ Clin Nutr, 93(1):186-191. 


\section{Chapter 6}

47. Warensjo E, Ohrvall M, Vessby B: Fatty acid composition and estimated desaturase activities are associated with obesity and lifestyle variables in men and women. Nutr Metab Cardiovasc Dis 2006, 16(2):128-136. 


\section{CHAPTER 7}

General discussion
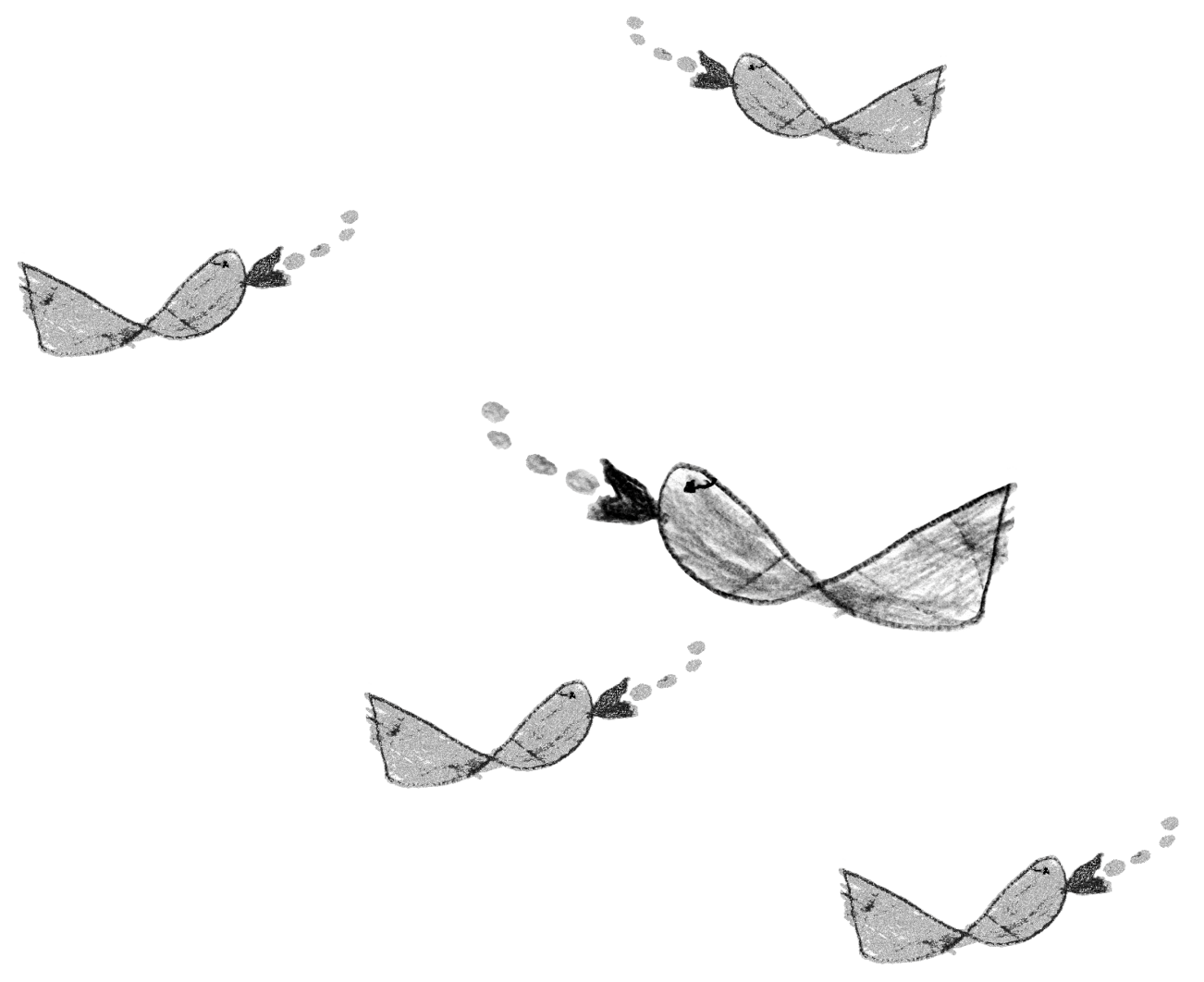


\section{ChAPTER 7}

The metabolic syndrome (MetS) is a cluster of metabolic abnormalities including obesity and insulin resistance which are associated with an increased risk for the development type 2 diabetes mellitus (T2DM) and cardiovascular diseases (CVD) [1-4]. The MetS is a complex disorder and different tissues including adipose tissue, liver, gut and skeletal muscle are involved in its pathophysiology. Skeletal muscle has a crucial role in maintaining normal glucose homeostasis, and insulin resistance of the skeletal muscle proceeds to the development of T2DM [5]. This thesis focuses on skeletal muscle fatty acid (FA) handling in relation to insulin resistance.

General approaches for prevention of the MetS are pharmacological interventions aimed at specific risk factors of the MetS and lifestyle interventions aimed at diet and physical activity. With respect to the latter not only energy restriction is of importance, but also diet composition may affect insulin resistance and the risk factors of the MetS. To enlarge our understanding on how diet interacts with insulin resistance, the present thesis focuses on how specific dietary FA affect insulin sensitivity and on the mechanisms underlying these effects. This final chapter will give a comprehensive overview of the main findings described in this thesis, which will be discussed in light of recent research in the field. Research described in this thesis was largely performed as part of the European LIPGENE dietary intervention study, a pan-European multi-centre study designed to investigate the effects of dietary fat modification on insulin sensitivity and various risk factors of the MetS in subjects with the MetS.

\section{Disturbances in skeletal muscle fatty acid handling in insulin resistance}

Disturbances in skeletal muscle lipid metabolism may play a central role in the development of insulin resistance, the MetS and T2DM [6-8]. Skeletal muscle insulin resistance is strongly associated with the intramuscular accumulation of lipid metabolites like DAG and ceramides [9-11]. Both intrinsic disturbances in skeletal muscle FA handling and the lipid overflow contribute to the intramyocellular lipid accumulation. So far, little is known of the contribution of dietary fat (chylomicrontriacylglycerol (TAG)) and endogenous fat (very low-density lipoprotein (VLDL)TAG) to the lipid overflow and to the intramuscular lipid accumulation. 


\subsection{Fatty acid supply and uptake}

The obese insulin resistant state is characterized by increased circulating TAG and FFA levels (i.e. lipid overflow), resulting in an elevated FA supply to peripheral tissues like skeletal muscle and the liver [12]. Contrary to this general concept, there are also studies that show that plasma FFA concentrations are only slightly increased or not increased at all in the obese insulin resistant state, but that rather TAG concentrations are increased [13-15]. An increased supply of endogenous FFA to the liver increases the VLDL-TAG output, and this may contribute to the rise in plasma TAG concentrations in insulin resistance. Furthermore, dietary FA intake increases the circulating chylomicron-TAG postprandially but the dietary FA can also make a substantial contribution to VLDL-TAG, already in the early postprandial phase $[16,17]$. In chapter 2 , we investigated the contribution of dietary versus endogenous FA to lipid overflow and to skeletal muscle FA uptake and storage in insulin resistant versus control subjects. To study the metabolic fate of dietary versus endogenous FA, a dual stable isotope technique was applied. [U${ }^{13} \mathrm{C}$-palmitate was added to a high-fat mixed-meal to label chylomicron-TAG (dietary TAG) in the circulation and $\left[{ }^{2} \mathrm{H}_{2}\right]$-palmitate was infused intravenously to label the endogenous pool of $F A$. As $\left[{ }^{2} \mathrm{H}_{2}\right]$-palmitate can be incorporated into TAG in the liver, $\left[{ }^{2} \mathrm{H}_{2}\right.$ ]-labelled TAG reflects VLDL-TAG (endogenous TAG) in the circulation. Moreover, this stable isotope technique was combined with measurements of arterio-venous concentration differences across the forearm muscle to investigate skeletal muscle FA handling and the specific contribution of the different fat sources to skeletal muscle FA handling. In chapter 2 arterial FFA concentration were slightly higher in the insulin resistant group versus the control group with comparable body composition. There was no difference in fasting whole body rate of appearance of FFA ( $\left(\mathrm{Ra}_{\mathrm{FFA}}\right)$ and in the degree of suppression of $\mathrm{Ra}_{\mathrm{FFA}}$ after the consumption of a high-fat mixed-meal between insulin resistant men and controls. This is consistent with some previous studies in obese and/or insulin resistant subjects [14, 18-20]. These data suggest that there are no pronounced impairments in the postprandial regulation of lipolysis in the insulin resistant state that result in lipid overflow in the circulation. Furthermore, there were also no differences in the arterial chylomicron and VLDL-TAG concentrations between both groups, indicating that both chylomicron-TAG and VLDL-TAG are equally produced and/or cleared from the circulation. This is not entirely consistent with literature where elevated TAG concentration are described in the obese insulin resistant state [12]. The lack of difference in circulating concentrations of chylomicron-TAG, VLDL-TAG and total TAG between insulin resistant men and controls in the present 


\section{ChAPTER 7}

study may be explained by the subjects characteristics of the two groups: all subjects had the MetS and were divided in two groups based on the median of insulin sensitivity. We accomplished a good separation with respect to insulin sensitivity (the mean values of insulin sensitivity were in line with those reported in literature for healthy subjects and subjects with T2DM), whereas groups were comparable with respect to BMI, body fat and other risk factors of the MetS, indicating that we studied metabolic disturbances related to insulin sensitivity per se. We hypothesize that it is possible that obesity has larger impact on increased plasma lipids than insulin resistance per se, as also indicated in a recent review by Boden et al. [21].

Despite the comparable supply of TAG to skeletal muscle, we observed that insulin resistant men had a higher net extraction of VLDL-TAG across forearm muscle compared with a control group during the first $2 \mathrm{~h}$ after ingestion of a mixed meal high in SFA. This finding may possibly extend to chylomicron-TAG as also the uptake of these particles tended to increase more in the insulin resistant men at the end of the $4 \mathrm{~h}$ postprandial period. It is difficult to study the contribution of chylomicron-TAG and VLDL-TAG to postprandial TAG metabolism due to rapid recycling of dietary FA into VLDL particles. Chylomicron-TAG labelled with $\left[\mathrm{U}-{ }^{13} \mathrm{C}\right]-$ palmitate can be cleared by the liver and the $\left[\mathrm{U}-{ }^{13} \mathrm{C}\right]$-palmitate can be incorporated in VLDL-TAG and released in the circulation within 2-3h after a meal [16, 22]. The majority of the $\left[\mathrm{U}-{ }^{13} \mathrm{C}\right]$-labelled TAG in the circulation represents chylomicron-TAG in the first $3 \mathrm{~h}$ postprandially, whilst approximately $20 \%$ of dietary FA, and thus [U$\left.{ }^{13} \mathrm{C}\right]$-palmitate, is incorporated in VLDL-TAG after 6h [16, 23, 24]. Nevertheless, the fact that we found an increased extraction of VLDL-TAG in the early postprandial phase suggest an increased postprandial removal (VLDL)-TAG removal across skeletal muscle in the insulin resistant state.

The expression and the activity of lipoprotein lipase (LPL) plays a major role in skeletal muscle TAG extraction and in insulin resistance. Inhibitory effects of insulin on skeletal muscle LPL activity may be impaired in the insulin resistant state, resulting in an increased postprandial skeletal muscle TAG extraction. Indeed, it was shown in mice that LPL deletion in skeletal muscle reduces lipid storage and increases insulin signalling in skeletal muscle [25] and that muscle-specific overexpression of LPL causes muscle-specific insulin resistance by causing defects in muscle insulin signalling and action [26], whereas skeletal muscle LPL knockout mice show the opposite effects. As shown in chapter 2, fasting and postprandial skeletal muscle LPL mRNA were not different after ingestion of a high- 
fat mixed-meal between groups, but a role of LPL cannot be excluded since it has been shown that LPL activity is mainly regulated at posttranscriptional and posttranslational levels [27-29]. Furthermore, in chapter 3, we studied skeletal muscle FA handling at the transcriptional level in 122 male and female subjects with the MetS with a wide range of insulin sensitivity and found that in more severe insulin resistance (lower quartile of insulin resistance) fasting muscle LPL mRNA was not increased but rather reduced. These data do not support an increased LPL activity as putative mechanism for the increased VLDL-extraction in insulin resistance (as reported in chapter 2 ). Also, these data seem, in the first instance, in contrast to mice studies showing that muscle specific LPL knock-out improves skeletal muscle insulin sensitivity. Nevertheless, lack of muscle LPL activity may result in insulin resistance in other key metabolic tissues in the long(er) term since the reduction of LPL-dependent lipid processing in skeletal muscle must result in the partitioning of TAG-rich lipoproteins to other tissues, and ultimately leads to obesity and systemic insulin resistance $[25,26]$.

Thus, although the exact underlying mechanisms remain to be elucidated, the present study stresses the importance of TAG metabolism in insulin resistance, which extends results from a previous study investigating FA metabolism using the same dual stable isotope methodology [14], in which the insulin resistant state was closely related to disturbances in TAG metabolism and not to FFA metabolism.

\subsection{Intramyocellular lipid partitioning}

Apart from the observed differences in lipid uptake, also the partitioning of FA within skeletal muscle has previously been shown to be more directed towards storage than oxidation in the insulin resistant state [6]. The human insulin resistant muscle is characterized by a reduced capacity to increase intramuscular fat oxidation during conditions of increased FA supply such as exercise and fasting, whereas postprandial suppression of muscle fat oxidation has shown to be impaired in obesity and T2DM (defined as metabolic inflexibility) [6, 30, 31]. A reduced FA transport across the mitochondrial membrane and a reduced mitochondrial function and content are putative mechanisms for a reduced FA oxidation in insulin resistance and T2DM [7, 32-34]. Lipid infusion studies, with an acute increase in plasma FFA, show a decrease in the expression of mitochondrial genes in the skeletal muscle of healthy subjects [35, 36]. Also, a decreased expression of genes of the mitochondrial respiratory chain is found in the skeletal muscle of patients with T2DM [37-40]. A decreased expression of PGC1 $\alpha$ has 


\section{ChAPTER 7}

been implicated in the development of muscular insulin resistance [40, 41] and the development of T2DM [39, 42]. PGC1 $\alpha$ is involved in the mitochondrial biogenesis by regulating the transcriptional activity of genes involved in the oxidative metabolism (OXPHOS genes) [42-44], and activation of the transcription factors necessary for mitochondrial DNA (mtDNA) replication. These data show us that the underlying genetics of T2DM are very complex and it is clear that several genes play a role in this disease.

Although TAG accumulation has been shown to be associated with insulin resistance, it is now evident that bioactive lipid metabolites like diacylglycerol, (DAG), long chain fatty acyl-CoA and ceramides are particularly associated with insulin resistance by interfering with insulin signalling and/or by inducing inflammatory pathways [45-47]. In chapter 2, there were no differences in intramyocellular DAG, FFA and phospholipid content between obese insulin resistant men and controls, whereas muscle TAG content tended to be increased in the insulin resistant state. In addition to intramuscular lipid content and synthesis rate, FA composition of these lipids also may influence insulin sensitivity [48, 49]. There are accumulating data suggesting that intramuscular DAG saturation may relate to insulin sensitivity [50-52]. Our data support this concept showing that not DAG content but rather DAG saturation was significantly higher in insulin resistant men compared with controls at baseline. It is still unclear how the saturation of DAG influences PKC activity [53], which is proposed to be the leading mechanism explaining DAG-induced insulin resistance [47]. It is important to mention that total DAG content as measured by others and us, might not reflect the DAG component that may interfere with insulin signalling and contribute to the development of insulin resistance [52, 54, 55]. Other studies, on the other hand, show no differences with respect to total DAG content as well as degree of saturation in obese versus lean [56] or insulin resistant versus insulin sensitive obese individuals [57] or observed increased DAG content in obese and obese subjects with T2DM [47]. Different DAG species and degree of saturation, cellular localisation of DAG and muscle fibre type may determine the effect of intramyocellular DAG on insulin sensitivity and should be considered in future studies.

An increased TAG fractional synthetic rate (FSR) may protect the muscle from excess FFA concentrations and subsequent accumulation of lipid metabolites that may interfere with insulin signalling. The FSR was measured by the incorporation $\left[\mathrm{U}-{ }^{13} \mathrm{C}\right]$-labelled palmitate from the muscle FFA pool into the different lipid fractions. 
In chapter 2, we did not observe a difference in FSR (after a saturated high-fat mixed-meal) of intramuscular DAG, TAG and phospholipids between insulin resistant men and controls. Also, analyses of mRNA expression levels of several key genes important in skeletal muscle FA uptake, mitochondrial FA transport, oxidation and synthesis showed no significant differences between insulin resistant men and controls. Although one should keep in mind that mRNA expression levels are not fully representative of protein expression levels and activity, these data imply that intramyocellular lipid partitioning was comparable between insulin resistant men and controls in our study. This is in line with findings from a recent study of intramuscular lipid synthesis in smokers and non-smokers with clear differences in insulin sensitivity [52]. In contract, Perreault et al. [58] showed a higher FSR of the TAG and a reduced suppression of FSR during exercise in obese insulin resistant subjects versus the obese insulin sensitive control subjects, whereas Saccheti et al. [59] reported a complete suppression of the FSR during exercise in a group of healthy, young and lean subjects [58]. The reason for these inconsistent findings is not entirely clear but may relate to differences in subject characteristics.

It must be emphasised that differences in intramyocellular lipid partitioning could be rather small and that several previous studies addressed similar issues with inconsistent results, which may be due to a large heterogeneity in subjects characteristics and a relatively low number of subjects per group. For this reason, the intramyocellular lipid partitioning was investigated at a transcriptional level in large group of subjects $(n=122)$ with a wide range of insulin resistance in chapter 3. The size of our study in combination with a detailed phenotype and a wide range of insulin sensitivity provides an unique possibility to study the impact of degree of insulin resistance, independent of body weight and BMI. We showed in chapter 3 that for several genes, it is important to define more specific groups with different degrees of insulin sensitivity. We demonstrated that the most insulin resistant group (lowest quartile of insulin sensitivity) had a reduced expression of PGC1 $\alpha$, PPAR $\alpha$ and mCTP1b. Lower expression of these genes important in FA oxidation and mitochondrial FA transport would imply lower mitochondrial FA transport and oxidation. Hence, the lower expression of these genes was also found in the most insulin sensitive group (highest quartile of insulin sensitivity). This implies that these levels in insulin sensitive group are sufficient for normal FA oxidation and for maintaining normal insulin sensitivity. The middle groups may increase their basal FA oxidation, via upregulation of PGC1 $\alpha$, PPAR and mCPT1b and would then be able to maintain a certain degree of insulin sensitivity. This would fit with the 


\section{ChAPTER 7}

concept postulated by Perseghin et al. [60] showing that higher lipid oxidation rates might counteract lipid accumulation in skeletal muscle and thereby avoid FAinduced insulin resistance in overweight individuals. The insulin resistant group in chapter 2 was not as insulin resistant as the most insulin resistant group used in chapter 3 which could explain the discrepancy between both chapters.

The results described in chapter 2 indicate no marked differences in lipid overflow from either endogenous (FFA or VLDL-) or dietary (chylomicron)-TAG in insulin resistant men compared to controls. Even with the similar supply of TAG in insulin resistant men and controls, we demonstrated that insulin resistance is associated with increased postprandial TAG extraction across the forearm muscle, an increased saturation of DAG and with minor differences in intramyocellular lipid partitioning at a transcriptional level (chapter 3). It is important to emphasize that small differences in lipid partitioning at transcriptional level could be detected in subjects within the lowest and highest quartile of insulin sensitivity, thus in the more extreme subgroups.

\section{Effect of dietary fat quality and quantity on fatty acid metabolism and insulin sensitivity}

Lifestyle intervention can improve FA handling of skeletal muscle, which refers to the ability of the muscle to increase fat oxidation upon increased FA availability and to switch between fat and carbohydrate oxidation under different conditions, such as the fasting-to-fed state $[30,61]$. These lifestyle interventions were mainly aimed at weight loss and/or increasing physical activity, and little information is available on the effects of dietary fat composition on in vivo skeletal muscle FA handling.

An important aim of this thesis was to see how insulin sensitivity can be influenced by dietary fat modification. There is general consensus that the saturated fat content of the diet has to be reduced in the prevention of T2DM and the MetS. The key question is whether this saturated fat should be replaced by carbohydrates or by unsaturated FA. In chapter 4, the effect of 3 high-fat mixed-meals (high in SFA (35.5E\% SFA) versus MUFA (42.2E\% MUFA) versus PUFA (34.8E\% PUFA)) on postprandial insulin sensitivity was investigated in obese insulin resistant men. It was found that a PUFA meal increased postprandial insulin sensitivity as compared with a SFA meal. Our data are in line with previous studies, showing that a PUFA meal improved insulin sensitivity as compared with a SFA meal [62,63], The effect 
of MUFA was intermediate between the SFA meal and the PUFA meal, which is partially in agreement with studies that have shown beneficial effects of MUFA on insulin sensitivity as compared with SFA [63-66]. With the dual FA stable isotope technique (as described above) and muscle gene expression analysis (microarrays) several possible underlying mechanism that could be affected by dietary fat composition were investigated. We detected a reduced muscle TAG-derived FA uptake in insulin resistant men after ingestion of a meal high in PUFA as compared with a meal high in SFA or MUFA. Beside the reduced uptake of TAG-derived FA, there was a tendency towards a higher FSR (incorporation $\left[\mathrm{U}-{ }^{13} \mathrm{C}\right]$-labelled palmitate from the muscle FFA pool into the different lipid fractions) of the PL pool after the PUFA meal and TAG, DAG and PL pool after the MUFA meal compared with the SFA meal. Additionally, micro-array analysis showed that there was a reduced downregulation of oxidative pathways after the PUFA compared with the SFA or MUFA meal. Together these data indicate that beside a reduced TAGderived FA uptake, overall muscle lipid turnover may be higher after the PUFA compared with the SFA meal. It remains to be established if improvement in insulin sensitivity after the PUFA meal due to lower lipid uptake (and possible less accumulation of fat in the muscle) is directly related to the higher postprandial insulin sensitivity. In fact, the increase in insulin sensitivity after the PUFA meal may also be explained by other mechanisms beside lower lipid uptake. For example, differences in the secretion of gut hormones (glucagon-like peptide 1 and cholecystokinin) could potentiate differential insulin secretion and insulin sensitivity according to FA composition of the meals $[65,67]$. Thus, although our results point towards an important role of muscle FA uptake and lipid turnover in the higher postprandial insulin sensitivity with PUFA, this should be elucidated in more detail in future studies. Furthermore, it remains to be established whether these acute effects may contribute to findings after long-term dietary intervention.

Therefore, besides the acute effect of dietary fat on skeletal muscle FA handling, also the chronic effect of dietary modification on muscle FA handling was studied. The chronic effects were studied as a part of the human dietary intervention study LIPGENE. A specific objective of the LIPGENE study was to study the effect of isoenergetic modification of dietary fat quality and quantity on insulin sensitivity and risk factor for the MetS. Men and women with the MetS were randomised to four isoenergetic dietary treatments for 12 weeks (high-SFA (HSFA); high-MUFA (HMUFA) or two low-fat, high-complex carbohydrate diets, supplemented with capsules containing $1.24 \mathrm{~g} /$ day of long-chain $n-3$ PUFA (LFHCC $n-3$ ) or control capsules containing oil (LFHCC)). As reported previously [68], In the whole LIPGENE study, no differential effects of diets on insulin sensitivity were found. 


\section{ChAPTER 7}

Nevertheless, the consumption of a low-fat high-carbohydrate (LFHCC) supplemented with $n-3$ diet ( $1.24 \mathrm{~g} /$ day) reduced the risk of MetS as compared with iso-energetic high-fat (HSFA and HMUFA) and LFHCC diets [69]. The prevalence of MetS fell by $20.5 \%$ after LFHCC $n-3$ diet compared with the HSFA $(10.6 \%)$, HMUFA (12\%) diet or LFHCC (10.4\%) diets [69]. In line, our group [70] recently published that the isoenergetic modulation of dietary fat quality and quantity did not affect postprandial skeletal muscle FA uptake in men with the MetS of the LIPGENE cohort, but reduced post-prandial chylomicron-TAG concentration on the LFHCC $n-3$ diet. This could possibly contribute to less muscle lipid accumulation in the longer term and could explain the lower prevalence of the MetS. In chapter $\mathbf{5}$, the effect of the diets differing in fat quantity and quality on intramuscular lipid partitioning and lipid turnover was examined in the same subjects with the MetS, as studied before [71]. There was a significant interaction between baseline insulin sensitivity and the diet-induced changes in gene expression. The insulin resistant and insulin sensitive subjects responded differently to the HMUFA and LFHCC $n-3$ diets with a more pronounced reduction in the mRNA expression of the lipogenic genes SREBP1C and ACC2 among insulin resistant subjects after the HMUFA diet and an enhanced expression of the oxidative genes OXPHOS, NDUFB5 and SDHB on the LFHCCn-3 diet among insulin sensitive subjects. In line with the larger reduction of the lipogenic genes, the HMUFA diet seemed to reduce the FSR of the DAG and TAG pool and the LFHCCn-3 diet reduced the skeletal muscle TAG content. These data indicate a shift towards a lower accumulation of lipids in muscle on the diets high in MUFA or LFHCC diets with $n-3$ supplementation, which is most pronounced in subjects with insulin resistance at baseline.

In conclusion, in both the acute (chapter 4) and chronic study (chapter 5), a meal/diet enriched with PUFA induced a shift towards a reduced muscle lipid uptake and/or fat storage. In the acute study in chapter 4 the PUFA meal consisted of a $1: 1$ mixture of $n-3$ and $n-6$ PUFA and in the 12 week study in chapter 5 only $n-3$ was supplemented to a low fat, high complex carbohydrate diet. It is therefore also possible that $n-6$ PUFA, rather than MUFA or $n-3$ PUFA affects lipid handling in subjects with the MetS [72]. This differential lipid handling may have contributed to the reduced the risk of MetS [69] on a LFHCCn-3 diet as compared with iso-energetic HSFA, HMUFA and LFHCC diets.

From the results in chapter $\mathbf{4}$ and $\mathbf{5}$ we can conclude that the effect of dietary FA are complex and that effect can diverge in subjects with different phenotypes and metabolic profiles. Insulin resistance is associated with specific plasma and serum FA profiles, reflecting dietary FA intake and/or endogenous FA metabolism [73-75], 
including the activities of enzymes responsible for synthesizing, desaturating and elongating FA [76, 77]. There is growing evidence that in rodents and humans that desaturase enzymes are related to insulin sensitivity [78-80]. In human studies, an increase in $\Delta^{6}$ desaturase (C18: $\left.3 n-6 / C 18: 2 n-6\right)$ activity and a decrease in $\Delta^{5}$ desaturase (C20:4n-6/C20:3n-6) activity have been associated with insulin resistance and T2DM [77, 79, 81]. It is noteworthy that overexpression of $\Delta^{9}$ desaturase (C16:1n-7/C16:0) or stearoyl CoA desaturase 1 (SCD1) results in TAG esterification, and attenuates ceramide and DAG accumulation and protects against FA-induces insulin resistance [82]. In chapter $\mathbf{6}$, the effect of 12 week LIPGENE dietary intervention of dietary fat content and quality on plasma FA profiles and the estimated desaturase activities as well adipose tissue $\Delta^{9}$ desaturase (SCD1) expression was studied in relation to changes in insulin sensitivity. The results of chapter 6 show that the effect of dietary intervention on plasma FA profile was dependent on gender and habitual fat intake and that men and women have a differential FA profile in response to a HMUFA and the LFHCC $n-3$ diet. However, there was no association between plasma FA profiles and change in insulin sensitivity. Interestingly, the HSFA diet increased the SCD1 protein expression in adipose tissue and this increase was negatively related to the change in insulin sensitivity. SCD1 may enhance TAG storage by providing the preferential FA for storage (C16:1n-7 and $\mathrm{C} 18: 1 n-9)$ Indeed, it was found in previous studies that cultured myocytes from obese subjects had a reduced fat oxidation, an increased protein expression of SCD1 and increased FA esterification. [83]. In contrast, mice deficient in SCD1 have an increased energy expenditure, are lean, resistant to diet-induced obesity and insulin sensitive [8487]. These data indicate that the tendency towards a negative relation between SCD1 and insulin sensitivity on the HSFA may possibly be explained by an lipogenesis-promoting effect. However, this does not translate in changes in body composition and insulin sensitivity at group level, suggesting that the change in SCD1 may be an early marker of this sequence of events.

\section{Concluding remarks and suggestions for further research}

This thesis provides a better understanding of the impairments in fat metabolism in insulin resistance and the impact of dietary fat quantity and quality intervention. More insight could certainly lead to more appropriate nutritional guidelines how to prevent human disorders in which muscle lipotoxicity contributes to the pathogenesis of obesity, T2DM and the MetS. The main outcomes of this thesis as 


\section{ChAPTER 7}

well as concluding remarks and suggestions for future research are summarized in this section.

1. Disturbances in TAG metabolism are more pronounced in insulin resistance than disturbances in FFA metabolism. Insulin resistance is accompanied by an increased muscle (VLDL) TAG extraction and slight differences in intramyocellular partitioning in the postprandial state, despite comparable FA supply (from FFA and TAG) (chapter 2). Although the differences are small, in the long term this may be one of the mechanisms leading to intramyocellular lipid accumulation and the development of T2DM. These data challenge the role of lipid overflow in the development of skeletal muscle insulin resistance. We studied metabolic disturbances related to insulin resistance per se, independent of obesity and other characteristics of the MetS. Future research should be performed to test the lipid overflow theory in obesity and/or insulin resistance versus a healthy population.

2. There are no differences in intramyocellular TAG, DAG, FFA and PL content as well as their FSR between insulin resistant men and controls, but the saturation of DAG is increased in the insulin resistant state (chapter 2). This implicates that the composition of the lipid fractions could be more important that their content in insulin resistance. It would be interesting to further evaluate the role of the FSR, intramyocellular lipid fraction content and composition in relation to insulin resistance.

3. There were specific gene expression patterns associated with the condition of insulin resistance (chapter 3). The results presented here, emphasise that it is important to study larger groups with a detailed phenotype or select more homogenous groups, since we found subgroups with comparable levels of gene expression (i.e. PGC1a) but in the upper and lower extreme quartile of insulin sensitivity. This suggest that the same expression levels may reflect different metabolic profiles. Future research should be performed to further elucidate the role of specific gene expression patterns in relation to metabolic profile and insulin sensitivity.

4. In this thesis, an acute change in insulin sensitivity was found by replacing SFA in the meal with PUFA. However, it seems that long-term effects on insulin sensitivity are more complex (chapter 3 and 4). Nevertheless, insulin resistant subjects had a more pronounced shift towards a lower accumulation of lipids in muscle on the diets high in MUFA or LFHCC diets with $n-3$ supplementation as compared with insulin sensitive subjects 
(chapter 5). Furthermore, there was no effect on insulin sensitivity in the LIPGENE study, but when considering gender differences, a MUFA rich diet improved insulin sensitivity $\left(\mathrm{HOMA}_{\mathrm{IR}}\right)$ in women that a dietary fat intake lower than $36 \mathrm{E} \%$ [88]. Overall, the type of FA may be of importance but it is indispensable to look at specific subgroups (chapter 5 en 6), because the effects can be levelled out in a large group with a more heterogeneous phenotype. We have to consider that perhaps a more personalized dietary approach is necessary.

5. Both an acute increase in PUFA in a meal ( $n-3$ and $n-6$, in $1: 1$ ratio) as well as a chronic increase in PUFA ( $n-3$ FA) by adding this to a low fat, high complex $\mathrm{CHO}$ diet tended to direct skeletal muscle lipid handling towards a reduced lipid storage (chapter 3 and chapter 5). This altered muscle FA handling may be one of the underlying mechanisms for the acute PUFAinduced increase in postprandial insulin sensitivity or the reduced prevalence of the MetS after the 12week LFHCCn-3 diet. It would be interesting to further elucidate the role of combining $n-3$ FA with a relatively high fat diet with respect to effect on muscle FA handling and insulin sensitivity.

Overall this thesis provides suggestive evidence that changing dietary fat quantity and quality could contribute to an improvement in muscle FA handling and an improvement in insulin sensitivity but the data suggest that changes in the diet must be fine tuned based on the genetic and metabolic profile of groups of the subjects. Therefore, research has to be directed towards responders and nonresponders to manipulation of dietary fat quantity and quality in order to increase the effectiveness of lifestyle intervention. 


\section{REFERENCES}

1. Glatz JF, Luiken JJ, Bonen A: Membrane fatty acid transporters as regulators of lipid metabolism: implications for metabolic disease. Physiol Rev 2010, 90(1):367-417.

2. Goodpaster BH, He J, Watkins S, Kelley DE: Skeletal muscle lipid content and insulin resistance: evidence for a paradox in endurance-trained athletes. $J$ Clin Endocrinol Metab 2001, 86(12):5755-5761.

3. Zimmet $P$, Alberti KG, Shaw J: Global and societal implications of the diabetes epidemic. Nature 2001, 414(6865):782-787.

4. $\quad$ Grundy SM, Brewer HB, Jr., Cleeman JI, Smith SC, Jr., Lenfant C: Definition of metabolic syndrome: Report of the National Heart, Lung, and Blood Institute/American Heart Association conference on scientific issues related to definition. Circulation 2004, 109(3):433-438.

5. Montell E, Turini M, Marotta M, Roberts M, Noe V, Ciudad CJ, Mace K, GomezFoix AM: DAG accumulation from saturated fatty acids desensitizes insulin stimulation of glucose uptake in muscle cells. Am J Physiol Endocrinol Metab 2001, 280(2):E229-237.

6. Blaak EE: Basic disturbances in skeletal muscle fatty acid metabolism in obesity and type 2 diabetes mellitus. Proc Nutr Soc 2004, 63(2):323-330.

7. Savage DB, Petersen KF, Shulman GI: Disordered lipid metabolism and the pathogenesis of insulin resistance. Physiol Rev 2007, 87(2):507-520.

8. Petersen KF, Dufour S, Savage DB, Bilz S, Solomon G, Yonemitsu S, Cline GW, Befroy D, Zemany L, Kahn BB et al: The role of skeletal muscle insulin resistance in the pathogenesis of the metabolic syndrome. Proc Natl Acad Sci U S A 2007, 104(31):12587-12594.

9. Pan DA, Lillioja S, Kriketos AD, Milner MR, Baur LA, Bogardus C, Jenkins AB, Storlien LH: Skeletal muscle triglyceride levels are inversely related to insulin action. Diabetes 1997, 46(6):983-988.

10. Krssak M, Falk Petersen K, Dresner A, DiPietro L, Vogel SM, Rothman DL, Roden $\mathrm{M}$, Shulman Gl: Intramyocellular lipid concentrations are correlated with insulin sensitivity in humans: a 1H NMR spectroscopy study. Diabetologia 1999, 42(1):113-116.

11. Perseghin G, Scifo P, De Cobelli F, Pagliato E, Battezzati A, Arcelloni C, Vanzulli A, Testolin G, Pozza G, Del Maschio A et al: Intramyocellular triglyceride content is a determinant of in vivo insulin resistance in humans: a $1 \mathrm{H}-13 \mathrm{C}$ nuclear magnetic resonance spectroscopy assessment in offspring of type 2 diabetic parents. Diabetes 1999, 48(8):1600-1606.

12. Blaak EE: Fatty acid metabolism in obesity and type 2 diabetes mellitus. Proc Nutr Soc 2003, 62(3):753-760.

13. Jocken JW, Goossens GH, van Hees AM, Frayn KN, van Baak M, Stegen J, Pakbiers MT, Saris WH, Blaak EE: Effect of beta-adrenergic stimulation on whole-body and abdominal subcutaneous adipose tissue lipolysis in lean and obese men. Diabetologia 2008, 51(2):320-327.

14. Bickerton AS, Roberts R, Fielding BA, Tornqvist $H$, Blaak EE, Wagenmakers AJ, Gilbert M, Humphreys SM, Karpe F, Frayn KN: Adipose tissue fatty acid metabolism in insulin-resistant men. Diabetologia 2008, 51(8):1466-1474.

15. McQuaid SE, Hodson L, Neville MJ, Dennis AL, Cheeseman J, Humphreys SM, Ruge T, Gilbert M, Fielding BA, Frayn KN et al: Downregulation of adipose tissue fatty acid trafficking in obesity: a driver for ectopic fat deposition? Diabetes 2011, 60(1):47-55. 
16. Heath RB, Karpe F, Milne RW, Burdge GC, Wootton SA, Frayn KN: Selective partitioning of dietary fatty acids into the VLDL TG pool in the early postprandial period. J Lipid Res 2003, 44(11):2065-2072.

17. Heath RB, Karpe F, Milne RW, Burdge GC, Wootton SA, Frayn KN: Dietary fatty acids make a rapid and substantial contribution to VLDL-triacylglycerol in the fed state. Am J Physiol Endocrinol Metab 2007, 292(3):E732-739.

18. Mittendorfer B, Fields DA, Klein S: Excess body fat in men decreases plasma fatty acid availability and oxidation during endurance exercise. Am J Physiol Endocrinol Metab 2004, 286(3):E354-362.

19. Hickner RC, Racette SB, Binder EF, Fisher JS, Kohrt WM: Suppression of whole body and regional lipolysis by insulin: effects of obesity and exercise. J Clin Endocrinol Metab 1999, 84(11):3886-3895.

20. Hodson L, Bickerton AS, McQuaid SE, Roberts R, Karpe F, Frayn KN, Fielding BA: The contribution of splanchnic fat to VLDL triglyceride is greater in insulinresistant than insulin-sensitive men and women: studies in the postprandial state. Diabetes 2007, 56(10):2433-2441.

21. Boden G: Obesity, insulin resistance and free fatty acids. Curr Opin Endocrinol Diabetes Obes 2011, 18(2):139-143.

22. Bickerton AS, Roberts R, Fielding BA, Hodson L, Blaak EE, Wagenmakers AJ, Gilbert M, Karpe F, Frayn KN: Preferential uptake of dietary Fatty acids in adipose tissue and muscle in the postprandial period. Diabetes 2007, 56(1):168-176.

23. Barrows BR, Parks EJ: Contributions of different fatty acid sources to very low-density lipoprotein-triacylglycerol in the fasted and fed states. J Clin Endocrinol Metab 2006, 91(4):1446-1452.

24. Cohn JS, Johnson EJ, Millar JS, Cohn SD, Milne RW, Marcel YL, Russell RM, Schaefer EJ: Contribution of apoB-48 and apoB-100 triglyceride-rich lipoproteins (TRL) to postprandial increases in the plasma concentration of TRL triglycerides and retinyl esters. J Lipid Res 1993, 34(12):2033-2040.

25. Wang H, Knaub LA, Jensen DR, Young Jung D, Hong EG, Ko HJ, Coates AM, Goldberg IJ, de la Houssaye BA, Janssen RC et al: Skeletal muscle-specific deletion of lipoprotein lipase enhances insulin signaling in skeletal muscle but causes insulin resistance in liver and other tissues. Diabetes 2009, 58(1):116-124.

26. Kim JK, Fillmore JJ, Chen Y, Yu C, Moore IK, Pypaert M, Lutz EP, Kako Y, VelezCarrasco W, Goldberg IJ et al: Tissue-specific overexpression of lipoprotein lipase causes tissue-specific insulin resistance. Proc Natl Acad Sci U S A 2001, 98(13):7522-7527.

27. Semenkovich CF, Wims M, Noe L, Etienne J, Chan L: Insulin regulation of lipoprotein lipase activity in 3T3-L1 adipocytes is mediated at posttranscriptional and posttranslational levels. J Biol Chem 1989 264(15):9030-9038.

28. Doolittle MH, Ben-Zeev O, Elovson J, Martin D, Kirchgessner TG: The response of lipoprotein lipase to feeding and fasting. Evidence for posttranslational regulation. J Biol Chem 1990, 265(8):4570-4577.

29. Wang $\mathrm{H}$, Eckel $\mathrm{RH}$ : Lipoprotein lipase: from gene to obesity. Am J Physiol Endocrinol Metab 2009, 297(2):E271-288.

30. Corpeleijn E, Saris WH, Blaak EE: Metabolic flexibility in the development of insulin resistance and type 2 diabetes: effects of lifestyle. Obes Rev 2009, 10(2):178-193.

31. Stump CS, Henriksen EJ, Wei Y, Sowers JR: The metabolic syndrome: role of skeletal muscle metabolism. Ann Med 2006, 38(6):389-402.

32. Lowell BB, Shulman GI: Mitochondrial dysfunction and type 2 diabetes. Science 2005, 307(5708):384-387. 
33. Phielix E, Schrauwen-Hinderling VB, Mensink M, Lenaers E, Meex R, Hoeks J, Kooi ME, Moonen-Kornips E, Sels JP, Hesselink MK et al: Lower intrinsic ADP. stimulated mitochondrial respiration underlies in vivo mitochondrial dysfunction in muscle of male type 2 diabetic patients. Diabetes 2008, 57(11):2943-2949.

34. Schrauwen-Hinderling VB, Kooi ME, Hesselink MK, Jeneson JA, Backes WH, van Echteld CJ, van Engelshoven JM, Mensink M, Schrauwen P: Impaired in vivo mitochondrial function but similar intramyocellular lipid content in patients with type 2 diabetes mellitus and BMI-matched control subjects. Diabetologia 2007, 50(1):113-120.

35. Richardson DK, Kashyap S, Bajaj M, Cusi K, Mandarino SJ, Finlayson J, DeFronzo $\mathrm{RA}$, Jenkinson CP, Mandarino LJ: Lipid infusion decreases the expression of nuclear encoded mitochondrial genes and increases the expression of extracellular matrix genes in human skeletal muscle. J Biol Chem 2005, 280(11):10290-10297.

36. Hoeks J, Hesselink MK, Russell AP, Mensink M, Saris WH, Mensink RP, Schrauwen P: Peroxisome proliferator-activated receptor-gamma coactivator1 and insulin resistance: acute effect of fatty acids. Diabetologia 2006, 49(10):2419-2426.

37. Mootha VK, Lindgren CM, Eriksson KF, Subramanian A, Sihag S, Lehar J, Puigserver P, Carlsson E, Ridderstrale M, Laurila E et al: PGC-1alpha-responsive genes involved in oxidative phosphorylation are coordinately downregulated in human diabetes. Nat Genet 2003, 34(3):267-273.

38. Boushel R, Gnaiger E, Schjerling P, Skovbro M, Kraunsoe R, Dela F: Patients with type 2 diabetes have normal mitochondrial function in skeletal muscle.

Diabetologia 2007, 50(4):790-796.

39. Kelley DE, He J, Menshikova EV, Ritov VB: Dysfunction of mitochondria in human skeletal muscle in type 2 diabetes. Diabetes 2002, 51(10):2944-2950.

40. Patti ME, Butte AJ, Crunkhorn S, Cusi K, Berria R, Kashyap S, Miyazaki Y, Kohane I, Costello M, Saccone R et al: Coordinated reduction of genes of oxidative metabolism in humans with insulin resistance and diabetes: Potential role of PGC1 and NRF1. Proc Natl Acad Sci U S A 2003, 100(14):8466-8471.

41. Scarpulla RC: Nuclear activators and coactivators in mammalian mitochondrial biogenesis. Biochim Biophys Acta 2002, 1576(1-2):1-14.

42. Petersen KF, Befroy D, Dufour S, Dziura J, Ariyan C, Rothman DL, DiPietro L, Cline GW, Shulman GI: Mitochondrial dysfunction in the elderly: possible role in insulin resistance. Science 2003, 300(5622):1140-1142.

43. Baruffi R, Mauri AL, Petersen CG, Felipe V, Franco JG, Jr.: Effects of vaginal progesterone administration starting on the day of oocyte retrieval on pregnancy rates. J Assist Reprod Genet 2003, 20(12):517-520.

44. Spiegelman BM, Puigserver P, Wu Z: Regulation of adipogenesis and energy balance by PPARgamma and PGC-1. Int J Obes Relat Metab Disord 2000, 24 Suppl 4:S8-10.

45. Schrauwen P, Hesselink MK: Oxidative capacity, lipotoxicity, and mitochondrial damage in type 2 diabetes. Diabetes 2004, 53(6):1412-1417.

46. Corcoran MP, Lamon-Fava S, Fielding RA: Skeletal muscle lipid deposition and insulin resistance: effect of dietary fatty acids and exercise. Am J Clin Nutr 2007, 85(3):662-677.

47. Itani SI, Ruderman NB, Schmieder F, Boden G: Lipid-induced insulin resistance in human muscle is associated with changes in diacylglycerol, protein kinase C, and IkappaB-alpha. Diabetes 2002, 51(7):2005-2011.

48. Kris-Etherton PM, Harris WS, Appel LJ: Fish consumption, fish oil, omega-3 fatty acids, and cardiovascular disease. Circulation 2002, 106(21):2747-2757. 
49. Matsuzaka T, Shimano H, Yahagi N, Kato T, Atsumi A, Yamamoto T, Inoue N, Ishikawa M, Okada S, Ishigaki $\mathrm{N}$ et al: Crucial role of a long-chain fatty acid elongase, Elovl6, in obesity-induced insulin resistance. Nat Med 2007, 13(10):1193-1202.

50. Perreault L, Bergman BC, Hunerdosse DM, Eckel RH: Altered intramuscular lipid metabolism relates to diminished insulin action in men, but not women, in progression to diabetes. Obesity (Silver Spring) 2010, 18(11):2093-2100.

51. Bruce CR, Thrush AB, Mertz VA, Bezaire V, Chabowski A, Heigenhauser GJ, Dyck DJ: Endurance training in obese humans improves glucose tolerance and mitochondrial fatty acid oxidation and alters muscle lipid content. $A m \mathrm{~J}$ Physiol Endocrinol Metab 2006, 291(1):E99-E107.

52. Bergman BC, Perreault L, Hunerdosse DM, Koehler MC, Samek AM, Eckel RH: Intramuscular lipid metabolism in the insulin resistance of smoking. Diabetes 2009, 58(10):2220-2227.

53. Bergman BC, Perreault L, Hunerdosse DM, Koehler MC, Samek AM, Eckel RH: Increased intramuscular lipid synthesis and low saturation relate to insulin sensitivity in endurance-trained athletes. J Appl Physiol 2010, 108(5):11341141.

54. Chavez JA, Summers SA: Characterizing the effects of saturated fatty acids on insulin signaling and ceramide and diacylglycerol accumulation in 3T3-L1 adipocytes and C2C12 myotubes. Arch Biochem Biophys 2003, 419(2):101-109.

55. Amati F, Dube JJ, Carnero EA, Edreira MM, Chomentowski P, Coen PM, Switzer GE, Bickel PE, Stefanovic-Racic M, Toledo FG et al: Skeletal-Muscle

Triglycerides, Diacylglycerols, and Ceramides in Insulin Resistance: Another Paradox in Endurance-Trained Athletes? Diabetes 2011.

56. Jocken JW, Moro C, Goossens GH, Hansen D, Mairal A, Hesselink MK, Langin D, van Loon LJ, Blaak EE: Skeletal muscle lipase content and activity in obesity and type 2 diabetes. J Clin Endocrinol Metab 2010, 95(12):5449-5453.

57. Coen PM, Dube JJ, Amati F, Stefanovic-Racic M, Ferrell RE, Toledo FG, Goodpaster $\mathrm{BH}$ : Insulin resistance is associated with higher intramyocellular triglycerides in type I but not type II myocytes concomitant with higher ceramide content. Diabetes 2010, 59(1):80-88.

58. Perreault L, Bergman BC, Hunerdosse DM, Playdon MC, Eckel RH: Inflexibility in intramuscular triglyceride fractional synthesis distinguishes prediabetes from obesity in humans. Obesity (Silver Spring) 2010, 18(8):1524-1531.

59. Sacchetti M, Saltin B, Osada T, van Hall G: Intramuscular fatty acid metabolism in contracting and non-contracting human skeletal muscle. J Physiol 2002, 540(Pt 1):387-395.

60. Perseghin G, Scifo P, Danna M, Battezzati A, Benedini S, Meneghini E, Del Maschio A, Luzi L: Normal insulin sensitivity and IMCL content in overweight humans are associated with higher fasting lipid oxidation. American journal of physiology 2002, 283(3):E556-564.

61. Corpeleijn E, Mensink M, Kooi ME, Roekaerts PM, Saris WH, Blaak EE: Impaired skeletal muscle substrate oxidation in glucose-intolerant men improves after weight loss. Obesity (Silver Spring) 2008, 16(5):1025-1032.

62. Xiao C, Giacca A, Carpentier A, Lewis GF: Differential effects of monounsaturated, polyunsaturated and saturated fat ingestion on glucosestimulated insulin secretion, sensitivity and clearance in overweight and obese, non-diabetic humans. Diabetologia 2006, 49(6):1371-1379.

63. Lopez S, Bermudez B, Pacheco YM, Villar J, Abia R, Muriana FJ: Distinctive postprandial modulation of beta cell function and insulin sensitivity by dietary fats: monounsaturated compared with saturated fatty acids. Am J Clin Nutr 2008, 88(3):638-644. 
64. Lopez S, Bermudez B, Ortega A, Varela LM, Pacheco YM, Villar J, Abia R, Muriana $\mathrm{FJ}$ : Effects of meals rich in either monounsaturated or saturated fat on lipid concentrations and on insulin secretion and action in subjects with high fasting triglyceride concentrations. Am J Clin Nutr 2011, 93(3):494-499.

65. Robertson MD, Jackson KG, Fielding BA, Williams CM, Frayn KN: Acute effects of meal fatty acid composition on insulin sensitivity in healthy post-menopausal women. Br J Nutr 2002, 88(6):635-640.

66. Paniagua JA, de la Sacristana AG, Sanchez E, Romero I, Vidal-Puig A, Berral FJ, Escribano A, Moyano MJ, Perez-Martinez P, Lopez-Miranda J et al: A MUFA-rich diet improves posprandial glucose, lipid and GLP-1 responses in insulinresistant subjects. J Am Coll Nutr 2007, 26(5):434-444.

67. Zampelas A, Peel AS, Gould BJ, Wright J, Williams CM: Polyunsaturated fatty acids of the $n-6$ and $n-3$ series: effects on postprandial lipid and apolipoprotein levels in healthy men. Eur J Clin Nutr 1994, 48(12):842-848.

68. Tierney AC, McMonagle J, Shaw DI, Gulseth HL, Helal O, Saris WH, Paniagua JA, Golabek-Leszczynska I, Defoort C, Williams CM et al: Effect of dietary fat modification on insulin sensitivity and other risk factors of the metabolic syndrome - LIPGENE: an European randomized dietary intervention study. International Journal Of Obesity 2010.

69. Paniagua JA, Perez-Martinez P, Gjelstad IM, Tierney AC, Delgado-Lista J, Defoort C, Blaak EE, Riserus U, Drevon CA, Kiec-Wilk B et al: A low-fat highcarbohydrate diet supplemented with long-chain n-3 PUFA reduces the risk of the metabolic syndrome. Atherosclerosis 2011.

70. van Hees AM, Saris WH, Hul GB, Schaper NC, Timmerman BE, Lovegrove JA, Roche HM, Blaak EE: Effects of dietary fat modification on skeletal muscle fatty acid handling in the metabolic syndrome. Int J Obes (Lond) 2010, 34(5):859-870.

71. van Hees AM, Jans A, Hul GB, Roche HM, Saris WH, Blaak EE: Skeletal Muscle Fatty Acid Handling in Insulin Resistant Men. Obesity (Silver Spring) 2011.

72. Summers LK, Fielding BA, Bradshaw HA, llic V, Beysen C, Clark ML, Moore NR, Frayn KN: Substituting dietary saturated fat with polyunsaturated fat changes abdominal fat distribution and improves insulin sensitivity. Diabetologia 2002, 45(3):369-377.

73. Salmeron J, Hu FB, Manson JE, Stampfer MJ, Colditz GA, Rimm EB, Willett WC: Dietary fat intake and risk of type 2 diabetes in women. Am J Clin Nutr 2001, 73(6):1019-1026.

74. Hu FB, van Dam RM, Liu S: Diet and risk of Type II diabetes: the role of types of fat and carbohydrate. Diabetologia 2001, 44(7):805-817.

75. Wang L, Folsom AR, Zheng ZJ, Pankow JS, Eckfeldt JH: Plasma fatty acid composition and incidence of diabetes in middle-aged adults: the Atherosclerosis Risk in Communities (ARIC) Study. Am J Clin Nutr 2003, 78(1):91-98.

76. Glatz JF, Soffers AE, Katan MB: Fatty acid composition of serum cholesteryl esters and erythrocyte membranes as indicators of linoleic acid intake in man. Am J Clin Nutr 1989, 49(2):269-276.

77. Vessby B, Gustafsson IB, Tengblad S, Boberg M, Andersson A: Desaturation and elongation of Fatty acids and insulin action. Ann N Y Acad Sci 2002, 967:183195.

78. Dobrzyn A, Dobrzyn P, Lee SH, Miyazaki M, Cohen P, Asilmaz E, Hardie DG, Friedman JM, Ntambi JM: Stearoyl-CoA desaturase-1 deficiency reduces ceramide synthesis by downregulating serine palmitoyltransferase and increasing beta-oxidation in skeletal muscle. Am J Physiol Endocrinol Metab 2005, 288(3):E599-607. 
79. Borkman M, Storlien LH, Pan DA, Jenkins AB, Chisholm DJ, Campbell LV: The relation between insulin sensitivity and the fatty-acid composition of skeletalmuscle phospholipids. N Engl J Med 1993, 328(4):238-244.

80. Hulver MW, Berggren JR, Carper MJ, Miyazaki M, Ntambi JM, Hoffman EP, Thyfault JP, Stevens R, Dohm GL, Houmard JA et al: Elevated stearoyl-CoA desaturase-1 expression in skeletal muscle contributes to abnormal fatty acid partitioning in obese humans. Cell Metab 2005, 2(4):251-261.

81. Kelley DE, Goodpaster BH, Storlien L: Muscle triglyceride and insulin resistance. Annu Rev Nutr 2002, 22:325-346.

82. Pinnamaneni SK, Southgate RJ, Febbraio MA, Watt MJ: Stearoyl CoA desaturase 1 is elevated in obesity but protects against fatty acid-induced skeletal muscle insulin resistance in vitro. Diabetologia 2006, 49(12):3027-3037.

83. Nakamura MT, Nara TY: Structure, function, and dietary regulation of delta6, delta5, and delta9 desaturases. Annu Rev Nutr 2004, 24:345-376.

84. Miyazaki M, Kim YC, Gray-Keller MP, Attie AD, Ntambi JM: The biosynthesis of hepatic cholesterol esters and triglycerides is impaired in mice with a disruption of the gene for stearoyl-CoA desaturase 1. J Biol Chem 2000, 275(39):30132-30138.

85. Cohen P, Miyazaki M, Socci ND, Hagge-Greenberg A, Liedtke W, Soukas AA, Sharma R, Hudgins LC, Ntambi JM, Friedman JM: Role for stearoyl-CoA desaturase-1 in leptin-mediated weight loss. Science 2002, 297(5579):240-243.

86. Ntambi JM, Miyazaki M, Stoehr JP, Lan H, Kendziorski CM, Yandell BS, Song Y, Cohen P, Friedman JM, Attie AD: Loss of stearoyl-CoA desaturase-1 function protects mice against adiposity. Proc Natl Acad Sci U S A 2002, 99(17):1148211486.

87. Dobrzyn A, Ntambi JM: The role of stearoyl-CoA desaturase in body weight regulation. Trends Cardiovasc Med 2004, 14(2):77-81.

88. Tierney AC, McMonagle J, Shaw DI, Gulseth HL, Helal O, Saris WH, Paniagua JA, Golabek-Leszczynska I, Defoort C, Williams CM et al: Effects of dietary fat modification on insulin sensitivity and on other risk factors of the metabolic syndrome-LIPGENE: a European randomized dietary intervention study. Int $J$ Obes (Lond) 2010. 



\section{Summary}
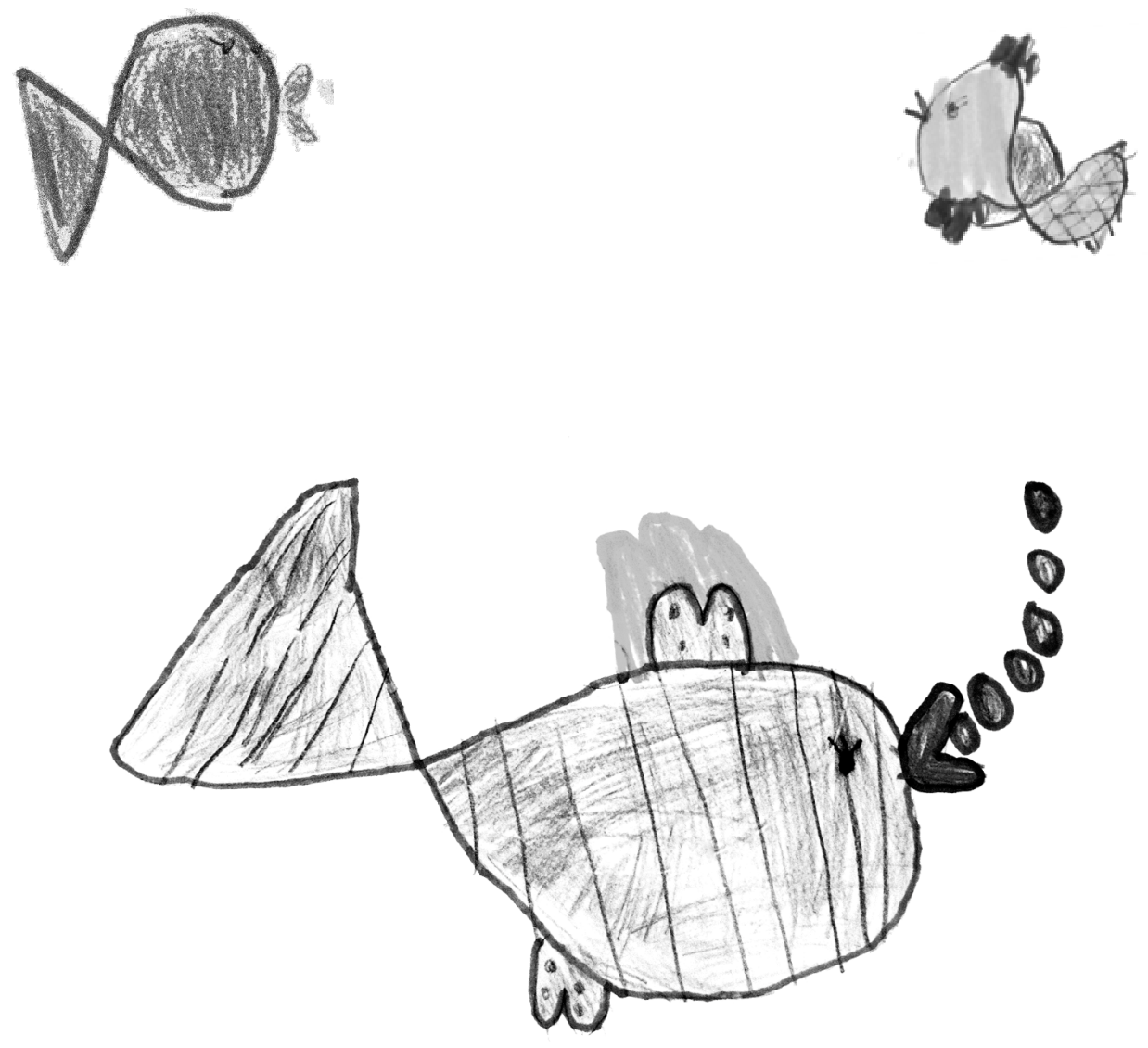


\section{ChAPTER 7}

The metabolic syndrome (MetS) represents a clustering of risk factors for the development of type 2 diabetes mellitus (T2DM) and cardiovascular disease (CVD), like high blood pressure, dyslipidemia, insulin resistance and abdominal obesity. During the last two decades the number of people with the MetS worldwide has increased rapidly together with the global epidemic of obesity and T2DM. Insulin resistance and central obesity have each been considered to be the primary factors underlying the MetS, although the underlying biological mechanisms are complex and not fully understood. There is evidence that dietary fat quality may modulate muscle fatty acid (FA) partitioning and lipid accumulation, resulting in a subsequent change in insulin sensitivity. The focus of this thesis is on skeletal muscle FA handling in relation to insulin sensitivity and the effect of dietary fat quantity and quality on skeletal muscle FA handling.

In chapter 2, we studied the contribution of dietary (chylomicron-TAG) and endogenous FA (VLDL-TAG and FFA) to skeletal muscle FA uptake and storage in insulin resistant men and a control group. FA partitioning was studied using an unique recently developed dual stable isotope tracer technique in combination with arterio-venous concentration measurements across the forearm muscle. Insulin resistance was associated with increased postprandial (VLDL)-TAG extraction across the forearm muscle in the early postprandial state, despite similar circulating TAG concentrations. Intramyocellular TAG, DAG, FFA and phospholipid content, and their fractional synthetic rates, were not different between the two groups. However, the saturation of intramyocellular DAG was increased in the insulin resistant state. These data suggest that an increased VLDL-TAG extraction and increased saturation of intramuscular DAG are associated with insulin resistance.

In chapter 3, the insulin resistant phenotype was further characterized at the transcriptional level in skeletal muscle. The muscle gene expression profiles of a relatively large group of subjects with a wide range of insulin sensitivity were studied. The expression of sterol regulatory element binding protein 1c (SREBP1C), acetyl-CoA carboxylase 2 (ACC2), diacylglycerol acyltransferase (DGAT1), and nuclear respiration factor (NRF) was higher in the lowest two quartiles of insulin sensitivity compared with the highest two quartiles of insulin sensitivity. 


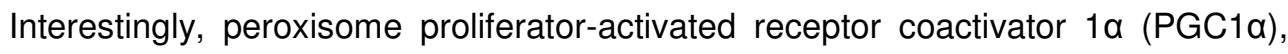
peroxisome proliferator-activated receptor a (PPARa), and muscle carnitine palmitoyl transferase $1 \mathrm{~b}$ (mCPT1), important for oxidative metabolism, showed a complex mRNA expression profile; levels were lower in both the most 'insulin sensitive' as well as the most 'insulin resistant' individuals. Lipoprotein lipase (LPL) mRNA was reduced in the lowest quartile of insulin sensitivity. Enhanced gene expression of SREBP1C, ACC2 and DGAT1 in the insulin resistant state suggests a tendency towards FA storage rather than oxidation. From the lower expression of PGC1a, PPARa, and mCPT1 in both the most 'insulin sensitive' as well as the most 'insulin resistant' individuals, it may be speculated that 'insulin sensitive' subjects do not need to upregulate these genes to have a normal FA oxidation, whereas the most 'insulin resistant' individuals are inflexible in upregulating these genes. This suggest that the same expression levels may reflect different metabolic profiles. The results presented here, emphasise that it is important to study larger groups with a detailed phenotype or select more homogenous groups.

Dietary fat quality may affect skeletal muscle FA handling thereby possibly improving insulin sensitivity. In chapter $\mathbf{4}$, the acute effect of meals different in fat quality on skeletal muscle FA handling and postprandial insulin sensitivity was studied in obese insulin resistant men. The results of this study showed that PUFA reduced TAG-derived skeletal muscle FA uptake as compared to a high SFA meal, which was accompanied by higher postprandial insulin sensitivity, a more transcriptional oxidative phenotype and altered intramyocellular lipid partitioning The reduced TAG extraction and increased muscle lipid turnover may be one of the underlying mechanisms for an improved insulin sensitivity

Subsequently, we studied the chronic effects of $12 \mathrm{wk}$ isocaloric manipulation of dietary fat quantity and quality on muscle FA partitioning within the framework of the European multi-centre dietary intervention study, LIPGENE (chapter 5), in eight European countries. Men and women with the MetS were included and randomized to four isoenergetic dietary treatments: a control high-fat diet rich in saturated fat (HSFA), a high-fat diet rich in monounsaturated fat (HMUFA) and two low-fat high-complex carbohydrate diets (LFHCC), one supplemented with $1.24 \mathrm{~g} / \mathrm{d}$ 


\section{Chapter 7}

long-chain $n-3$ polyunsatured FA ( $\mathrm{LFHCC} n-3)$. The data indicate a shift towards a lower accumulation of lipids in muscle on the diets high in MUFA or LFHCC diets with $n-3$ supplementation, which is most pronounced in subjects with insulin resistance at baseline.

Finally, we investigated, the relationship between dietary fat quality and quantityinduced changes in plasma FA profiles (and estimated desaturase activities) and insulin sensitivity within the framework of the LIPGENE study. The activity of $\Delta^{9}$ desaturase (SCD1) was studied in more detail in abdominal subcutaneous adipose tissue. The results of chapter 6 show that there was no association between plasma FA profiles and change in insulin sensitivity. Interestingly, the HSFA diet increased the adipose tissue SCD1 protein expression and this increase was negatively related to the change in insulin sensitivity. This tendency may possibly be explained by a lipogenesis-promoting effect on the HSFA diet.

Replacing SFA in the meal with PUFA acutely changed insulin sensitivity and in the longer term insulin resistant subjects had a more pronounced shift towards a lower accumulation of lipids in muscle on the diets high in MUFA or LFHCC diets with $n-3$ supplementation as compared with insulin sensitive subjects. Overall this thesis provides suggestive evidence that changing dietary fat quantity and quality could contribute to an improvement in muscle FA handling and an improvement in insulin sensitivity but the data suggest that changes in the diet must be fine tuned based on the genetic and metabolic profile of groups of the subjects. Therefore, research has to be directed towards responders and non-responders to manipulation of dietary fat quantity and quality in order to increase the effectiveness of lifestyle intervention. 


\section{Samenvatting}
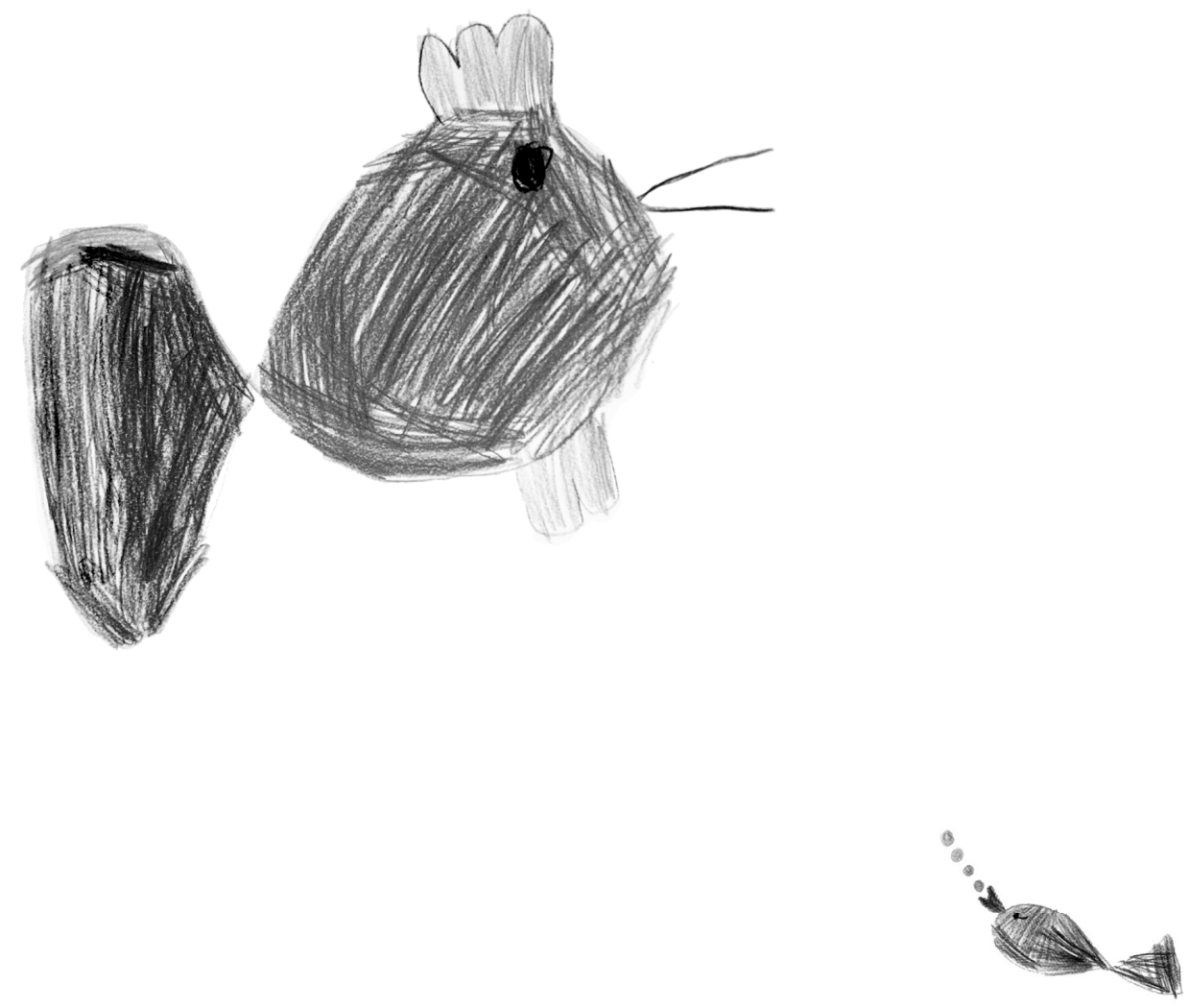


\section{SAMENVATTING}

Het metabool syndroom (MetS) is een cluster van risicofactoren voor het ontwikkelen van type 2 diabetes (T2D) en hart- en vaatziekten, zoals hoge bloeddruk, een verstoorde lipidenbalans, insuline resistentie en obesitas (zwaarlijvigheid). Tijdens de laatste twee decennia is het aantal mensen met het MetS wereldwijd toegenomen, dit samen met een wereldwijde epidemie van zwaarlijvigheid en T2D. Insuline resistentie en centrale obesitas worden elk beschouwd als belangrijke factoren die ten grondslag liggen aan het MetS, hoewel de onderliggende biologische mechanismen complex zijn en nog niet volledig zijn. $\mathrm{Er}$ is bewijs dat het type vet in de voeding de insuline gevoeligheid van de spier kan veranderen door de opslag en oxidatie van vetten in de spier te beïnvloeden. Dit proefschrift richt zich op de vetstofwisseling van de skeletspier in relatie tot insuline gevoeligheid en bestudeert het effect van de hoeveelheid en het type vet hierop.

In hoofdstuk 2 hebben we gekeken naar de bijdrage van vetten uit de voeding (chylomicronen) of vetten reeds aanwezig in het lichaam (endogene vetten; vrije vetzuren en vetten in de vorm van VLDL deeltjes) aan de verhoogde concentratie van vetten in de circulatie en de ophoping van vet in de spier. Hiertoe gebruikten we twee verschillende stabiele isotopen van het vetzuur palmitaat, in combinatie met metingen van arterio-veneuze concentratie-verschillen over de onderarmspier. Insuline resistentie was geassocieerd met een verhoogde extractie van (VLDL-)TAG door de skeletspier na de maaltijd, terwijl circulerende TAG concentraties vergelijkbaar waren. De hoeveelheid van verschillende spierlipidenfracties (TAG, diacylglycerol (DAG), FFA en fosfolipiden) waren vergelijkbaar bij de insuline resistente groep en de controle groep. Er was echter wel een verhoogde verzadiging van DAG in de spier bij de insuline resistente mannen. Deze resultaten suggereren dat een verhoogde extractie van VLDL-TAG door de spier en de verhoogde verzadiging van DAG in de spier geassocieerd zijn met insuline resistentie.

In hoofdstuk 3, werd het insuline resistente fenotype verder onderzocht op transcriptioneel niveau in de skeletspier. De expressie SREBP1c, ACC2, DGAT1 (belangrijk bij de vetvorming) en NRF was hoger bij mensen in de laagste twee kwartielen van insuline gevoeligheid ten opzichte van degenen in de twee hoogste kwartielen van insuline gevoeligheid. PGC1a, PPARa, en mCPT1, allen belangrijk voor het oxidatieve metabolisme in de spier, toonden een complex mRNA expressie profiel. Er was een lage expressie in zowel de meest 'insuline gevoelige' als de meest 'insuline resistente' individuen. De verhoogde genexpressie van 
SREBP1c en ACC2 en DGAT1 in de insuline resistente toestand wijst op een tendens naar vetopslag in plaats van vetverbranding. Uit de lagere expressie van PGC1a, PPARa, en mCPT1 in zowel de meest 'insuline gevoelige' als de meest 'insuline resistentie' individuen, kan geconcludeerd worden dat 'insuline gevoelige' individuen deze genen niet hoeven op te reguleren voor een normale vetverbranding en dat de meest 'insuline resistentie' individuen niet meer in staat zijn deze genen op te reguleren.

Het type voedingsvet kan het vetmetabolisme van de skeletspier beïnvloeden en zo de insuline gevoeligheid van de spier beïnvloeden. In hoofdstuk 4, werd het acute effect van maaltijden met verschillende type vetten op het vetmetabolisme van de spier en de insuline gevoeligheid bestudeerd in obese insuline resistente mannen. De resultaten van deze studie toonden aan dat een maaltijd hoog in meervoudig onverzadigde vetzuren (PUFA) de extractie van VLDL-TAG in de skeletspieren vermindert in vergelijking met een maaltijd hoog in verzadigd vet (SFA). Deze verminderde opname ging gepaard met een verhoogde insuline gevoeligheid en een meer oxidatief transcriptioneel fenotype. Deze veranderingen van het vetmetabolisme kunnen mogelijk een rol spelen bij de verbeterde insuline gevoeligheid.

Vervolgens bestudeerden we het lange termijn effect (12 weken) van iso-calorische manipulatie van de kwaliteit en de hoeveelheid van vetten in de voeding op de spiervetstofwisseling. Dit werd gedaan in het kader van de Europese multicenter dieet interventiestudie, LIPGENE (hoofdstuk 5). Mannen en vrouwen met het MetS werden ad random opgenomen in vier iso-energetische dieetgroepen: een controle hoog vet dieet, rijk aan verzadigde vetten (HSFA), een hoog vet dieet, rijk aan enkelvoudig onverzadigde vetten (HMUFA) en twee laag-vet hoog complexe koolhydraat diëten (LFHCC), aangevuld met een 1,24g/d lange-keten $n-3$ meervoudig onverzadigde vetzuren (LFHCC $n-3$ ) of placebo. De resultaten wijzen op een verschuiving naar een verlaagde vetopstapeling in spier na het dieet hoog in MUFA of het LFHCC met $n$-3 supplementatie dieet.

Tot slot onderzochten we de relatie tussen de hoeveelheid en het type vet in de voeding en vetzuurprofielen in het plasma en de insuline gevoeligheid in het kader van de LIPGENE studie. We hebben de activiteit van $\Delta^{9}$ desaturase (SCD1), betrokken bij de omzetting van verzadigde naar enkelvoudig onverzadigde vetzuren in meer detail bekeken op vetweefselniveau. De resultaten van hoofdstuk 6 laten zien dat er geen verband was tussen vetzuurprofielen in het 


\section{SAMENVATTING}

plasma en verandering in insuline gevoeligheid. Interessant is dat het HSFA dieet zorgt voor een verhoogde SCD1 eiwit expressie in vetweefsel en dat deze stijging negatief gerelateerd was aan de verandering in insuline gevoeligheid. Deze gegevens wijzen erop dat er een lipogenese-bevorderend effect is na een maaltijd hoog in SFA.

Het vervangen van SFA in de maaltijd met PUFA zorgt voor een acute verandering in de gevoeligheid voor insuline. Op de lange termijn lijken de insuline resistente mensen een verschuiving te hebben naar een lagere stapeling van vetten in spier na een maaltijd met MUFA of LFHCC met $n-3$ in vergelijking met mensen die wel gevoelig zijn voor insuline. In het algemeen geeft dit proefschrift bewijs dat verandering van de kwaliteit en de kwantiteit van vet in de voeding kan leiden tot een verbetering van de manier waarop de spier omgaat met vetten en dus een verbetering van insuline gevoeligheid. Maar de resultaten tonen aan dat veranderingen in het dieet goed moeten worden afgestemd op het genetisch en metabool profiel van groepen van mensen. Onderzoek zou daarom gericht moeten worden op 'responders' en 'non-responders' op een manipulatie van de kwaliteit en de hoeveelheid van vet in de voeding om de effectiviteit van leefstijlinterventie te verhogen. 


\section{Acknowledgements}

Dankwoord
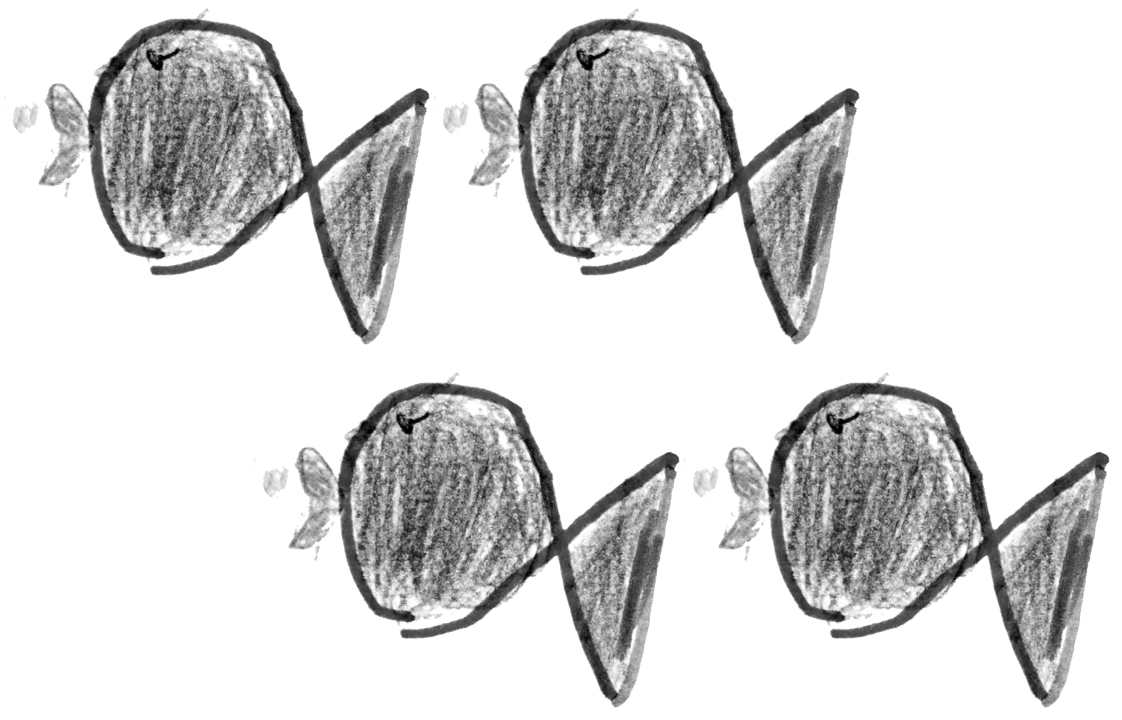
ACKNOWLEDGEMETNS - DANKWOORD

De mensen zijn als muzieknoten.... Slechts in samenwerking met anderen betekenen ze iets!

En dan nu het laatste stukje van mijn boekje, mijn dankwoord! Volgens mij het leukste deel om te schrijven. Eindelijk iedereen een keertje kunnen bedanken die op welke wijze dan ook heeft bijgedragen aan het tot stand komen van dit proefschrift. Bij deze wil ik me verontschuldigen als ik iemands naam moest vergeten zijn.

Allereerst wil ik mijn promotor Prof. dr. Ir. E.E. Blaak. Beste Ellen, bedankt om me 4 jaar geleden deze kans te geven om als aio bij jou te beginnen. Weer een extra Belg op de afdeling. Nederland en België, 2 buurlanden, zogezegd dezelfde taal en toch heel erg verschillend. Bedankt voor de steun, de begeleiding en het kritische bekijken van mijn abstracts, posters, presentaties en artikels! Ook wil ik je bedanken voor alle congressen die ik heb mogen bezoeken, welke leerzaam en fijn waren.

De beoordelingscommissie, bestaande uit Prof. dr. ir. R.P. Mensink, Prof. dr. L.J.C. van Loon, Prof. dr. H.P. Sauerwein, Prof. dr. J.F.C. Glatz en Prof. dr. M. Diamant, wil ik bedanken voor het kritisch lezen en beoordelen van mijn proefschrift.

Een humane studie zou niet kunnen afgerond worden zonder vrijwilligers. Daarom wil ik alle 'proefpersonen' bedanken voor hun zeer essentiële bijdrage aan mijn onderzoeken! Om een goede humane studie af te ronden moet je veel dingen leren. Chantalle, bedankt om me de kneepjes van het SI-testen en het clampen te leren (en het schrijven van 1000-den cupjes). Je leerde me alle vaardigheden zodat Ellen K. en ik onze humane studie goed konden afronden!

Eefje, mijn eerste kamergenootje, wat hadden we het leuk gevonden moest jij me ook begeleid hebben, maar eigenlijk heb je dit gedaan. Met vele vragen kon ik bij je terecht en het enige wat ik kon doen was je het Belgisch aanleren. We hebben veel gelachen met ons golfje met onze tirette en onze sjakose op de chauffage, ons eten in de frigo of de soep in de microgolfoven. Je bent naar Groningen vertrokken om daar verder onderzoek te doen. Het gaat je goed daar samen met 
Michael en kleine Joppe (ondertussen al bijna ander halfjaar! Jeetje de tijd gaat snel). Mati en ik gaan echt nog eens langskomen, dat is echt beloofd!

Bedankt aan alle vetstoffers: Annemieke, Ellen K., Chantalle, Gijs, Johan, Anneke vH., Judith, Yvonne, Eefje, Hanneke, Marleen, Ellen B., Kariana, Janneke, Dorit en Jasper. Bedankt voor de collegialiteit, de gezellige lunches, gesprekken over werk en andere zaken en de leuke activiteiten buiten het werk om. Ook wil ik alle andere collega's van HB bedanken, inclusief de dames van het secretariaat en natuurlijk Laurens, Loek en Paul. Tijdens mijn vier jaar in Maastricht heb ik er drie computers doorgejaagd en twee klaviers! Bedankt dat jullie de computerproblemen steeds hebben proberen op te lossen. Sorry, maar MAC is gewoon niet mijn ding... Herman, ik denk dat je toch ongeveer drie jaar mijn buurman geweest bent! Bedankt voor je kritische en gevatte opmerkingen en voor je bezoekjes aan onze kamer. Natuurlijk moet ik jou samen met Janneke de Wilde bedanken voor jullie goede uitleg over het RNA isoleren, RIN waarden, het PCR-en enzovoorts.

Edwin, bedankt voor de rust en humor en de moed die je mij en Ellen K. kwam inspreken. Uiteindelijk hebben we van onze studie toch een mooi verhaal kunnen schrijven. Johan, mijn voorbeeld van een goede wetenschapper! Bedankt voor jouw adviezen en natuurlijk bedankt voor je geweldig gezelschap op mijn laatste congres naar San Diego. Samen met jou waren de lange vluchten toch wel heel aangenaam. Anneke van Hees, door jouw studie had ik al direct werk klaarliggen waar ik mee kon beginnen. Bedankt voor alle ondersteuning en de toffe momenten op de LIPGENE bijeenkomsten. Zonder jou was het verwerken van alle stabiele isotopen data zeker nooit gelukt... En natuurlijk bedankt voor alle praktische informatie omtrent het promoveren.

Wetenschap is een teamsport en als zodanig onmogelijk zonder de input van de coauteurs. Ingrid Gjelstad, Lauren Sparks, Anneke van Hees, Audrey Thierney, Herman Popeijus, Freek Bouwman, Gijs Goossens, Mark Van Boekschoten, Lydia Afman, Michael Müller, Hanne Gulseth, Christine Williams, Javier Delgado-Lista, Małgorzata Malczewska-Malec, Beata Kieć-Wilk, Jose Lopez-Miranda, Julie Lovegrove, Ulf Risérus, Christian Drevon, Helen Roche, Patrick Schrauwen, Edwin Mariman en Ellen Blaak, thank you for your collaboration and contribution to the different chapters of this thesis.

Wat ben je in een humane studie zonder analisten. Jos, Wendy, Hasibe, Annemie en Yvonne, jullie wil ik hartelijk danken voor het uitvoeren van alle analyses in het 


\section{ACKNOWLEDGEMENTS - DANKWOORD}

labo en voor de ontspannende werksfeer. Naast de verschillende analyses hebben jullie me ook jullie expertise in het bepalen van verschillende vetzuurfracties toevertrouwd. Een protocol van ongeveer een 4-tal dagen voor slechts 20 samples en ik had er ongeveer 600 te doen. Ik ben blij dat ik zelf aan deze opwerking heb kunnen werken, het gaf me zelf ook de kans om meer inzicht te krijgen in de processen waardoor de interpretatie van de data toch iets makkelijker werd. Jos, niet alleen een woordje van dank voor al je nauwkeurig werk, maar vooral ook voor je vaak kritische en gevatte opmerkingen. Ook hartelijk dank aan de mensen met wie ik jaren op het labo heb gewerkt. Freek, Anja, Anke, Jonathan, Antoine, Montserrat en Johan Senden bedankt voor de leuke samenwerking en toffe momenten in het labo.

Ellen en Annemieke, jullie waren lange tijd mijn kamergenoten en dus mijn keuze voor jullie als mijn paranimfen is dus eigenlijk een logische keuze. Bedankt dat jullie me willen bijstaan bij het verdedigen van dit proefschrift.

Ellen K. waar begin ik met jou te bedanken? Bedankt voor de fantastische samenwerking en zoveel meer! We hebben onze studie geweldig goed afgerond, we werkten enorm goed samen. Ook moet ik je bedanken voor de fijne carpoolmomenten. We hebben samen heel wat kilometers afgelegd. Een ruwe schatting brengt me op $30000 \mathrm{~km}$ dat we naast elkaar hebben doorgebracht op wegen van Hasselt naar Maastricht. Echt leuk als je eens na een dagje werken niet zelf hoeft te rijden en zelfs een oogje kan dicht doen. Maar ook aan onze gesprekken in de auto heb ik veel gehad. Hoeveel hebben we niet met elkaar gedeeld, als soms sommige dingen niet verlopen waren zoals het hoorde .....

Annemieke, ook jou wil ik heel erg bedanken. Zeker de laatste maanden heb je heel erg veel werk gehad door mij. Maar mijn kaft en de uitnodigingen mogen vast en zeker gezien worden! Bedankt voor de voorbije jaren, bedankt voor al de fotomomenten (vooral dan op de rollercoaster). Bedankt ook om Ellen en mij steeds bij te staan met de soms wat 'moeilijkere' momenten. Jij was er steeds om ons te zeggen dat we moesten volhouden en kritisch moesten blijven. Trouwens ook bedankt voor al je goede raad over de statistiek.

Isabelle, Anneleen en Ellen, bedankt voor de lunches! Toch leuk om verhalen van andere afdelingen te horen en dan toch door te hebben dat overal vergelijkbare dingen gebeuren. Op de hoogte blijven van de laatste roddels... 
Ondertussen heb ik ook al weer nieuwe collega's in het Imelda Ziekenhuis! Mevr. Mertens-Doms, beste Magda, bedankt voor je vertrouwen in mij! Al voor september kreeg ik het gevoel dat ik zeer welkom was in jullie team. Bedankt voor de open ontvangst en je belangstelling in mijn proefschrift. Ondertussen zijn we al enkele maanden verder en stilaan begin ik de regels rond MKG, MVG en het BFM onder de knie te krijgen en begin ik ook de scanner op het archief te kennen. Ook wil ik heel erg graag mijn medewerkers bedanken van de medische registratie en het archief: Sabine, Thierry, Ilse, Veerle, Ellen, Annemieke, Suzanne, Christel P., Mieke, Christel VG., Gerda, Laure, Kim, Marina, Ines, Annelies, Sara, Ingrid, Marita, Harry, Yves, Carine en Anneke. We zijn een grote ploeg, maar ik heb er alle vertrouwen in dat we samen een goed team vormen. Daarnaast wil ik natuurlijk ook alle andere medewerkers van het Imelda Ziekenhuis bedanken voor de aangename samenwerking.

Familie en vrienden wil ik bedanken voor hun interesse in mijn werk en hun geduld. Vragen als 'Wat doe je nu eigenlijk?' en 'Wanneer ben je klaar?, heb ik vaak gehoord en eigenlijk nooit goed kunnen beantwoorden. Hopelijk is het na mijn verdediging allemaal een beetje duidelijker. Een woordje van dank aan mijn Belgische vriendinnen. Eerst ons viertallig clubje: dr. Nele, bijna dr. Hanne en fiere mama Els! Nele en Hanne jullie begrijpen maar al te goed wat ik in Maastricht gedaan heb! Nele vorig jaar was ik zo trots op jou toen jij daar je eindwerk stond de verdedigen, ik kan alleen maar hopen dat ik het half zo goed ga doen als jij. Hanne, de volgende ben jij! We kijken er naar uit. Els, de trotse mama van Anna Sophie, wat is ze toch een prachtige dochter! Nele D. al van de kleuterklas zijn we vriendinnen en ik ben er zeker van dat we dat nog lang gaan blijven. Lieselotte en Machteld mijn beste koormaatjes! Ik hoop (ondanks onze drukke agenda's) dat we in de toekomst nog vaak kunnen blijven afspreken.

Ook een welgemeend woordje van dank aan mijn schoonouders Riet en Guido en mijn schoonbroer Tim. Bedankt voor de steun en interesse de afgelopen jaren.

Lieve zus, Heidi, mijn grote zus! Naar jou kijk ik echt wel op. Bedankt voor al je steun en interesse. Op een afstand heb je toegekeken hoe ik dit allemaal heb klaargespeeld. Bij jou kon ik zeker terecht voor de nodige ontspanning. Ik zou je nog voor zoveel willen bedanken, het is fijn om te weten dat ik bij jou terecht kan. Ook dank aan Davy voor toch wel de nodige ontspanning, samen met Mati zijn jullie soms echt niet te doen. 


\section{ACKNOWLEDGEMENTS - DANKWOORD}

Yara en Larz, jullie zijn waarschijnlijk nog te jong om te beseffen wat meteke/tantie hier heeft neer geschreven. Jullie zijn 2 schatten van kinderen, die zeker hebben geholpen om mij te ontspannen als ik met jullie speelde. Al was het nu voor een tent te maken, onder de tafel kruipen, met het toverhuis spelen, met de treinen spelen, tekenen of schilderen altijd was het leuk! Yara jouw mooie tekeningen hebben ervoor gezorgd dat ik een prachtige kaft heb! Jullie worden snel groot, maar eens dit allemaal afgerond is, dan zullen meteke/tantie en nonkel Mati zorgen voor leuke neefjes en/of nichtjes om mee te spelen.

Beste mama en papa, hoe kan ik jullie bedanken? Wat ik hier kan opschrijven, kan niet eens voor de helft beschrijven hoe dankbaar ik jullie ben. Wat zou ik toch zijn zonder jullie? Jullie zijn er steeds en altijd voor mij en voor alles kan ik bij jullie terecht. Talloze presentaties heb ik voor jullie geoefend en ook al begrepen jullie misschien niet altijd de inhoud, toch bleven jullie je best doen om naar mij te luisteren. En ja mama, als een project over de spier gaat, dan kan het gebeuren dat ik vaak het woord muscle gebuikt in mijn presentatie ;-). Ik weet dat jullie trots op mij zijn, maar weet ook dat ik trots op jullie ben! Bedankt voor alles.

Mijn allerliefste koekie, mijn schatteke. Mati, de laatste in de lange rij, maar ook de belangrijkste factor in mijn leven. Ik leerde je kennen vlak voor ik aan dit avontuur begon, je hebt het dus helemaal meegemaakt. De ups en downs... Bedankt voor je kritische commentaren, zelfs op mijn dankwoord aan jou!! Tijdens deze periode zijn we ook getrouwd en nu staan we klaar voor ons volgend avontuur. Rustige tijden gaan nu zeker niet aanbreken, maar genieten zullen we zeker...

\section{BEDANKT!!!}




\section{List of publications}

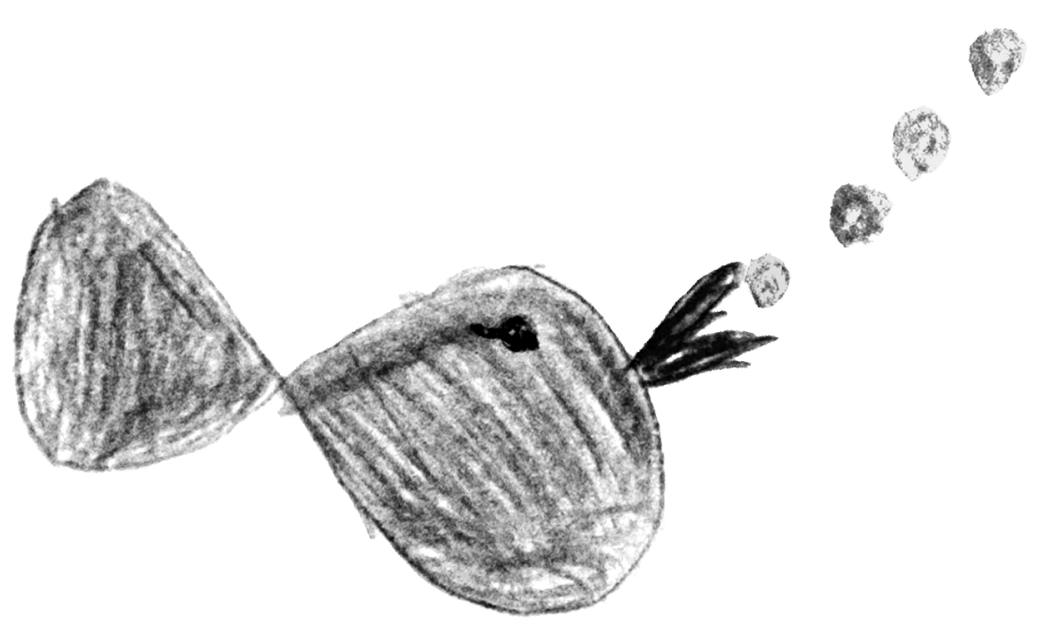




\section{FULL PAPERS}

Skeletal muscle fatty acid handling in insulin resistant men. Anneke M.J. van Hees, Anneke Jans, Gabby B. Hul, Helen M. Roche, Wim H.M. Saris and Ellen E. Blaak. Obesity, $201111 \mathrm{Jul} ; 19(7): 1350-9$.

Transcriptional metabolic inflexibility in skeletal muscle among individuals with increasing insulin resistance. Anneke Jans, L.M. Sparks, A.M.J van Hees, I.M.F. Gjelstad, A.C. Tierney, U. Risérus, C.A. Drevon, H.M. Roche, P. Schrauwen and E.E. Blaak. Obesity (Silver Spring). 2011 Nov;19(11):2158-66. doi: 10.1038/oby. 2011.149. 2011 Jun 23.

Expression of perilipins in human skeletal muscle in vitro and in vivo in relation to diet, exercise and energy balance. Gjelstad IM, Haugen F, Gulseth HL, Norheim F, Jans Anneke, Bakke SS, Raastad T, Tjønna AE, Wisløff U, Blaak EE, Risérus U, Gaster M, Roche HM, Birkeland KI, Drevon CA. Arch Physiol Biochem. 2011 Nov 25.

Polyunsaturated fatty acids acutely affect triacylglycerol-derived skeletal muscle fatty acid uptake and increases postprandial insulin sensitivity. Anneke Jans $^{*}$, Ellen Konings ${ }^{*}$, Freek G. Bouwman, Chantalle C. Moors, Gijs H. Goossens, Mark V. Boekschoten, Lydia A. Afman, Michael Müller, Edwin C. Mariman and Ellen E. Blaak. In press in the American Journal of Clinical Nutrition.

* Both authors contributed equally

Impact of dietary fat quantity and quality on skeletal muscle fatty acid metabolism in subjects with the metabolic syndrome. Anneke Jans, A.M.J. van Hees, I.M.F. Gjelstad, L. Sparks, A.C. Tierney, U. Risérus, C.A. Drevon, P.Schrauwen, H.M. Roche and E.E. Blaak.

A human dietary intervention study to improve insulin sensitivity: effects on plasma fatty acid profiles, estimated desaturase activities and stearoly-CoA desaturase 1 (SCD1) in relation to insulin sensitivity. Anneke Jans, Herman E. Popeijus, Gijs H. Goossens, Audrey C. Tierney, Hanne L. Gulseth, Christine M Williams, Javier Delgado-Lista, Beata Kieć-Wilk, Małgorzata Malczewska-Malec, Jose Lopez-Miranda, Christian A. Drevon, Ulf Risérus, Brita Karlström, Julie A Lovegrove, Helen M. Roche and Ellen E. Blaak. 
Different skeletal muscle fatty acid handling in subjects with impaired fasting glucose and impaired glucose tolerance. Chantalle C.M. Moors, Gijs H. Goossens, Nynke J. van der Zijl, Anneke Jans, E. Konings, Michaela Diamant, Ellen E. Blaak

\section{ABStRACTS SELECTED FOR ORAL PRESENTATIONS}

Effect of dietary fat quantity and quality on skeletal muscle gene expression in the Metabolic Syndrome. Anneke Jans, A.M.J. van Hees, I.M.F. Gjelstad, L. Sparks,

A.C. Tierney, U. Risérus, C.A. Drevon, P. Schrauwen, H.M. Roche and E.E. Blaak. 2008, NVDO/NASO (Nederlandse vereniging voor Diabetes onderzoek/ Nederlandse Associatie voor de Studie van Obesitas), Doorwerth

Best meeting abstract

Expression of genes involved in lipid metabolism in relation to insulin sensitivity. Anneke Jans, A.M.J. van Hees, I.M.F. Gjelstad, L. Sparks, A.C. Tierney, U.

Risérus, C.A. Drevon, P. Schrauwen, H.M. Roche and E.E. Blaak. 2009, NVDO/NASO, Bilthoven

Effect of dietary fat quantity and quality on skeletal muscle gene expression in the Metabolic Syndrome. Anneke Jans, A.M.J. van Hees, I.M.F. Gjelstad, L. Sparks,

A.C. Tierney, U.Risérus, C.A. Drevon, P. Schrauwen, H.M. Roche and E.E. Blaak. 2009, NASO voorjaarsymposium

Impact of different dietary fat quantity and quality on skeletal muscle fatty acid handling in subjects with the metabolic syndrome. Anneke Jans, A.M.J. van Hees, I.M.F. Gjelstad, L. Sparks, A.C. Tierney, U.Risérus, C.A. Drevon, P. Schrauwen, H.M. Roche and E.E. Blaak. 2010, NVDO/NASO, Bilthoven

Impact of different dietary fat quantity and quality on skeletal muscle fatty acid handling in subjects with the metabolic syndrome. Anneke Jans, A.M.J. van Hees, I.M.F. Gjelstad, L. Sparks, A.C. Tierney, U. Risérus, C.A. Drevon, P. Schrauwen, H.M. Roche and E.E. Blaak. 2010, EASD (European Association for the Study on Diabetes), Stockholm 
Impact of different dietary fat quantity and quality on skeletal muscle fatty acid handling in subjects with the metabolic syndrome. Anneke Jans, A.M.J. van Hees, I.M.F. Gjelstad, L. Sparks, A.C. Tierney, U. Risérus, C.A. Drevon, P. Schrauwen, H.M. Roche and E.E. Blaak. 2010, ISSFAL (International Society for the Study of Fatty Acids and Lipids), Maastricht

Skeletal muscle fatty acid handling in relation to insulin sensitivity. Anneke Jans, 2010, Diabetesmeeting, Maastricht

Impact of different dietary fat quantity and quality on skeletal muscle fatty acid handling in subjects with the metabolic syndrome. Anneke Jans, A.M.J. van Hees, I.M.F. Gjelstad, L. Sparks, A.C. Tierney, U. Risérus, C.A. Drevon, P. Schrauwen, H.M. Roche and E.E. Blaak. 2010, NASO voorjaarsymposium,

Utrecht

The acute effect of dietary fatty acids on skeletal muscle fatty acid handling. Anneke Jans, Ellen Konings, Freek G. Bouwman, Chantalle C. Moors, Gijs H. Goossens, Mark V. Boekschoten, Lydia A. Afman, Michael Müller, Edwin C. Mariman and Ellen E. Blaak. 2011, NASO voorjaarsymposium, Zwolle

\section{ABSTRACTS SELECTED FOR POSTER PRESENTATIONS}

Effect of dietary fat quantity and quality on skeletal muscle gene expression in people with MetS. Anneke Jans, A.M.J. van Hees, I.M.F. Gjelstad, L. Sparks, A.C. Tierney, U. Risérus, C.A. Drevon, P. Schrauwen, H.M. Roche and E.E. Blaak. 2008, Lipgene Meeting, Dublin

Effect of dietary fat quantity and quality on skeletal muscle gene expression in people with MetS. Anneke Jans, A.M.J. van Hees, I.M.F. Gjelstad, L. Sparks, A.C. Tierney, U. Risérus, C.A. Drevon, P. Schrauwen, H.M. Roche and E.E. Blaak. 2008, Nutrimdag, Maastricht

Effect of dietary fat quantity and quality on skeletal muscle gene expression in the Metabolic Syndrome Anneke Jans, A.M.J. van Hees, I.M.F. Gjelstad, L. Sparks, A.C. Tierney, U. Risérus, C.A. Drevon, P. Schrauwen, H.M. Roche and E.E. Blaak. 2009, ECO (European Congress on Obesity), Amsterdam 
Expression of genes involved in lipid metabolism in relation to insulin sensitivity. Anneke Jans, A.M.J. van Hees, I.M.F. Gjelstad, L. Sparks, A.C. Tierney, U. Risérus, C.A. Drevon, P. Schrauwen, H.M. Roche and E.E. Blaak. 2009, Nutrimdag, Maastricht

Association between alterations in estimated plasma Stearoyl-CoA Desaturase 1 (SCD1) activity and insulin sensitivity after dietary intervention. Anneke Jans, Herman E. Popeijus, Gijs H. Goossens, Audrey C. Tierney, Hanne L. Gulseth, Christine M Williams, Javier Delgado-Lista, Beata Kieć-Wilk, Małgorzata Malczewska-Malec, Jose Lopez-Miranda, Christian A. Drevon, Ulf Risérus, Brita Karlström, Julie A Lovegrove, Helen M. Roche and Ellen E. Blaak. 2010, Nutrimdag, Maastricht

PUFA acutely decreases muscle triacylglycerol-derived fatty acid uptake and increases postprandial insulin sensitivity. Anneke Jans, Ellen Konings, Freek G. Bouwman, Chantalle C. Moors, Gijs H. Goossens, Mark V. Boekschoten, Lydia A. Afman, Michael Müller, Edwin C. Mariman and Ellen E. Blaak. 2011, ADA (American Diabetes Association), San Diego 



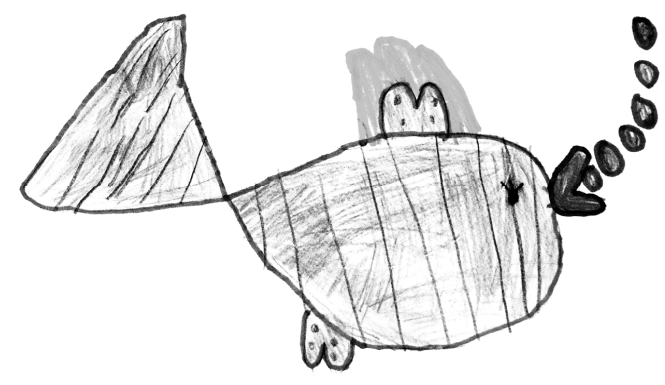

\section{Curriculum vitae}

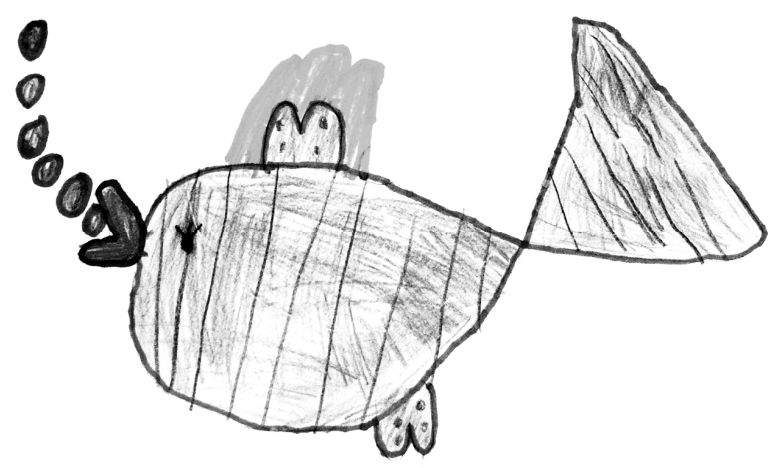




\section{CuRriculum VITAE}

Anneke Jans was born on January $26^{\text {th }} 1984$ in Hasselt, Belgium. In 2002 she completed secondary school at the 'Sint-Ursula Instituut' in Herk-de-Stad, Belgium. In the same year, she started her study Biomedical Sciences at the University of Hasselt, where she graduated (cum laude) in 2007 as Master in Clinical Molecular Life Sciences.

In September 2007 she started her PhD at the Department of Human Biology (NUTRIM), Maastricht University, under supervision of Prof. dr. Ellen Blaak. During her $\mathrm{PhD}$ project Anneke presented several abstracts at international conferences. She was awarded with the Best meeting abstract in 2008 at the annual meeting of the Dutch Diabetes Research Foundation.

In September 2011 she started working as a head of the Department Medical Registration and the Archive at the Imelda Hospital, Bonheiden (Belgium). 